\title{
A MOUNTAIN FEELING: \\ THE NARRATIVE CONSTRUCTION OF MEANING AND SELF THROUGH A COMMITMENT TO MOUNTAINEERING IN AOTEAROA/NEW ZEALAND
}

\author{
By \\ Lee Davidson \\ BA Hons (Otago), MA (Victoria University of Wellington)
}

\author{
A thesis \\ submitted in fulfilment \\ of the requirements for the degree of \\ Doctor of Philosophy
}

Department of Management

Monash University

2006 



\section{Table of contents}

$\begin{array}{ll}\text { TABLE OF FIGURES VI } & \text { VIS }\end{array}$

$\begin{array}{lll}\text { ABSTRACT VII } & \text { VIT }\end{array}$

STATEMENT OF AUTHORSHIP IX IX

ACKNOWLEDGEMENTS XI

CHAPTER 1. INTRODUCTION AND BACKGROUND TO THE STUDY 1

$\begin{array}{ll}\text { Introduction } & 1\end{array}$

Historical, social and cultural context of mountaineering 5

A brief history of mountaineering $\quad 6$

Contemporary context $\quad 8$

Review of relevant research on adventurous leisure $\quad 9$

$\begin{array}{lr}\text { Personality theories } & 10\end{array}$

Identifying motivations $\quad 11$

$\begin{array}{ll}\text { Dimensions of adventurous activity and experience } & 13\end{array}$

$\begin{array}{lr}\text { Voluntary risk taking and the search for authenticity in rationalised society } & 15\end{array}$

$\begin{array}{ll}\text { Mountaineering-specific research and theory } & 17\end{array}$

Discussion of research aims $\quad 25$

Further relevant theory $\quad 30$

The human need for meaning $\quad 30$

Problems of self and identity 36

The narrative construction of meaning and self 38

$\begin{array}{ll}\text { Summary } & 41\end{array}$

CHAPTER 2. THE RESEARCH PROCESS: APPROACH, METHODS AND INTERPRETATION 43

Introduction $\quad 43$

The biographical narrative approach $\quad 44$

$\begin{array}{ll}\text { Research population } & 47\end{array}$

The interviews $\quad 49$

Selection of interviewees $\quad 49$

Sample size $\quad 52$

Characteristics of the interviewees

Structure of the interviews $\quad 54$

Contextual material $\quad 57$

Additional personal records $\quad 57$

Supporting literature and other media $\quad 57$

Key informants $\quad 59$

Autobiographical experience or 'prior ethnography' $\quad 59$ 
Interpretation of empirical material $\quad 62$ $\begin{array}{lr}\text { Interactional issues } & 66\end{array}$

\begin{tabular}{lr} 
Ethical issues & 67 \\
\hline Profiles of & 69
\end{tabular}

$\begin{array}{lr}\text { Profiles of interviewees } & 69\end{array}$

$\begin{array}{lr}\text { Summary } & 77\end{array}$

CHAPTER 3. THE NARRATIVE CONSTRUCTION OF MOUNTAINEERING SELVES

$\begin{array}{lr}\text { Introduction } & 79\end{array}$

$\begin{array}{lr}\text { Emerging identities: becoming and being a mountaineer } & \mathbf{8 0}\end{array}$

Getting a "mountain feeling” $\quad 81$

Entering the social world of mountaineering $\quad 85$

$\begin{array}{lr}\text { Making choices } & 89 \\ \text { Summary } & 93\end{array}$

$\begin{array}{lr}\text { Summary } & 93\end{array}$

\begin{tabular}{l} 
The durability of mountaineering selves \\
\hline
\end{tabular}

$\begin{array}{lr}\text { Introduction: Dave's story } & 94\end{array}$

$\begin{array}{lr}\text { Discovering self } & 98\end{array}$

$\begin{array}{ll}\text { Expanding self } & 105\end{array}$

Expressing self $\quad 114$

Summary $\quad 116$

CHAPTER 4. THE 'TRUE' MOUNTAINEER: COMMUNAL NARRATIVES OF IDENTITY AND MOUNTAINEERING AS MORAL SOURCE

$\begin{array}{ll}\text { Introduction } & 121\end{array}$

$\begin{array}{lr}\text { Mountaineering as a 'living tradition' } & 124\end{array}$

Community, identity and shared values $\quad 125$

Tradition and innovation in New Zealand mountaineering $\quad 128$

The 'true' mountaineer and the mountaineering virtues 131

Enduring commitment $r$

Humility 136

$\begin{array}{lr}\text { Non-materialism } & 139\end{array}$

$\begin{array}{lr}\text { Responsibility } & 140\end{array}$

Being a mountaineer in an inhospitable world $r$

Divided commitments $r$

$\begin{array}{lr}\text { Desire for recognition } & 148\end{array}$

“False values” of the outside world $r$

Solidity, liquidity and the world of mountaineering 155

A world of "clarity" and a "sense of control”" 156

Direction and life-focus $r$

Perspective: Determining the "real” from the "trivial” 162

$\begin{array}{lr}\text { Summary } & 164\end{array}$ 
CHAPTER 5. THE CALCULABLE AND THE INCALCULABLE: NARRATIVES

OF SAFETY, DANGER AND DEATH

Introduction

Theories of risk and danger

Survival strategies: staying safe in the mountains

Gaining experience and surviving a youthful sense of invincibility

Developing judgment and other techniques for survival

Making sense of accidents: calculable and incalculable dangers Human error and the causes of accidents 184 $\begin{array}{lr}\text { Luck, chance and uncertainty } & 188\end{array}$

$\begin{array}{lr}\text { Dealing with danger } & 194\end{array}$

Mountaineering, mortality and death $\quad 203$

$\begin{array}{lr}\text { Accepting death, confronting mortality and finding meaning } & 205\end{array}$

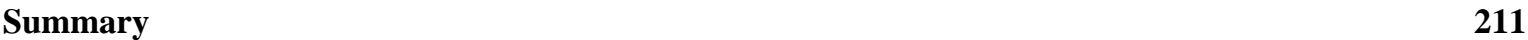

CHAPTER 6. CONCLUSIONS 213

$\begin{array}{ll}\text { BIBLIOGRAPHY } & 231\end{array}$

APPENDIX A. NEW ZEALAND ALPINE CLUB MEMBERSHIP DATA 247

APPENDIX B. INTERVIEW GUIDE $\quad 249$

APPENDIX C. INTERACTIONAL ISSUES BY INTERVIEWEE 251

APPENDIX D. EXAMPLE OF A ‘CONDENSED’ NARRATIVE 257

$\begin{array}{ll}\text { APPENDIX E. } & 265\end{array}$

$\begin{array}{ll}\text { APPENDIX F. } & 269\end{array}$

$\begin{array}{ll}\text { APPENDIX G. } & 275\end{array}$

APPENDIX H. A BRIEF HISTORY OF A CULTURE OF SAFETY IN THE NEW ZEALAND ALPINE CLUB, 1950-1970 


\section{Table of figures}

FIGURE 1: MAP OF NEW ZEALAND SHOWING RESEARCH LOCATIONS 


\begin{abstract}
Mountaineering is commonly associated with feats of daring in a landscape of extreme danger. Past theories of mountain climbing, and other adventurous leisure activities, have predominantly focused on uncovering the motives for participation; and risk has been posited as a primary attraction. A number of studies have concluded that identity and meaning are factors related to participation. However, none to date have examined the dynamics by which these factors are constructed and maintained in the lives of participants. This thesis places meaning and self or identity at the centre of its enquiry into how New Zealand mountaineers sustain their commitment to an adventurous leisure activity. Thus, it seeks to address the current lack of knowledge regarding the way in which activities such as mountain climbing can contribute to participants' sense of who they are and what their lives are about.
\end{abstract}

A biographical narrative approach was adopted to achieve this central aim as, it is argued, self and meaning are constructed through the stories told about life experiences. Narrative interviews were conducted with twenty-two committed New Zealand mountaineers; and supporting materials were collected from publications and other relevant sources. The interpretation of the research material was facilitated by theories of the interrelationship between narrative, meaning and self, and the implications of current social conditions for their construction. By applying a narrative approach to the study of mountaineers for the first time, this thesis sheds new light on our understanding of mountaineering. It demonstrates the way in which mountaineers weave together the biographical particulars of their lives with a 'folk psychology' of mountaineering to produce a strong sense of self. In addition, it shows how these 'mountaineering selves' are influenced by a communal narrative, or shared discourse, about what it means to be a mountaineer in New Zealand. The research also reveals the complexities in approaches to the dangers of mountain climbing, and offers an alternative conceptualisation of this issue which does not characterise mountaineers as principally risk seeking individuals.

These findings provide an empirical basis by which to consider theories relating to the impact of socio-historical conditions upon individual experience, and the efficacy of certain strategies for addressing dilemmas of meaning and self. Finally, although the study is situated within a specific social and historical context, it contributes - in the spirit of interpretive hermeneutics - to an on-going exchange of meanings about mountaineering and leisure in contemporary society. 



\section{Statement of authorship}

Except where specific reference is made in the main text of the thesis, this thesis contains no material extracted in whole or part from a thesis, dissertation, or research paper presented by me for another degree or diploma.

No other person's work (published or unpublished) has been used without due acknowledgment in the main text of the thesis.

This thesis has not been submitted for the award of any other degree or diploma in any other tertiary institution. 



\section{Acknowledgements}

There are many people whose support, guidance and encouragement have helped me to complete this thesis.

I have been extremely fortunate to have received supervision for this project from Professor Betty Weiler and Emeritus Professor Elery Hamilton-Smith. Both were warm and enthusiastic from the first point of contact. They gave generously of their time and experience throughout my candidature, and have been impressive role models, complementing each other with their individual strengths and styles. I particularly want to thank Betty, my official supervisor at Monash University, for making me feel part of the Tourism Research Unit, in spite of my being on campus only once or twice a year. She always ensured that I had the support I required to undertake my research. My special thanks to Elery for the long talks in his wonderful library; and for being the kind of mentor who inspired by example, and gave me the confidence to feel that I could accomplish what I had set out to.

I am also deeply grateful to Dr Aat Vervoorn of Australia National University, who advised me at crucial stages during the research, as both a philosopher and a mountaineer. Aat's insight and support for the research has been invaluable. Allan Laidler read my final draft with remarkable thoroughness. I thank him for being the curious and enthusiastic reader, and the 'nit-picker', and for reminding me of Ozymandias. I was also very fortunate to have met Professor Bob Stebbins, from the University of Calgary, during the early stages of this research. Bob's encouragement since that chance meeting has been greatly appreciated. Associate Professor Jenny Neale provided coffee, chocolate and mentoring at Victoria University of Wellington where I work. In addition, the generous assistance of my colleague, Dr Conal McCarthy, has helped me manage the conflicting demands of work and study, particularly during the past 18 months.

My friend, climbing companion and fellow doctoral student, Jen Purdie, and her husband, Sam Bosshard, provided the perfect place for me to stay while I conducted my interviews for six weeks in Wanaka, in the Southern Alps of New Zealand. They assisted me in finding potential interviewees, shared their own ideas and organised climbing trips. My friends in Melbourne, Bernadette Wood and Michelle Goldingay, were also exceptionally hospitable; housing and entertaining the 'kiwi' who showed up on their doorstep at irregular intervals. Friends in Wellington provided support in many different ways. In 
particular I want to thank my proof readers: Jillian Grant, Lynley Povey, Judy Reid and Anja Stoldt. Additional thanks to Jillian for her map making skills.

To my family, thank you for buoying me along and providing much needed opportunities for rest and recreation. Special thanks to my grandmother, Lucy Davidson, who always supported and encouraged me, but made me promise that this would be my last degree. In her $94^{\text {th }}$ year, she is an inspiration to me for how to live a long and meaningful life.

Finally, this thesis would not have been possible without the mountaineers who so generously shared their stories with me. This thesis is my tribute to them, and to all who have shared time with me in the mountains and become part of my own story. 


\section{Chapter 1}

\section{Introduction and background to the study}

\section{Introduction}

This thesis explores the construction of a sense of meaning and self by mountaineers in Aotearoa/New Zealand, ${ }^{1}$ through their narratives about mountaineering. It is concerned with people who have a high level of commitment to a life centred on an adventurous leisure pursuit, and with understanding the foundations of this commitment and the means by which it is sustained. In pursuing this central aim, the research builds on the work of Simmel (1959) and the principles underpinning narratology (Wengraf, 2001), by examining mountaineering as an activity that is instilled with biographical, social and cultural meanings through the stories or narratives that are told about it. These narratives are connected to and contribute to the self or identity, and the life-meaning of the mountaineer.

The focus on one specific form of adventurous leisure (mountaineering) and one specific geographical region (New Zealand), reflects and builds upon my own autobiographical experiences of mountain climbing, and my previous research on the history of mountaineering in New Zealand (Davidson, 2002). This background gives me the advantage of being an 'informed reader' (Denzin, 2001a) - of understanding the language used, and of having had similar experiences. In spite of its specific focus, this study contributes to a broader narrative concerning the contemporary phenomenon of adventurous leisure and its social, cultural and historical context. Through an analysis of life-meanings and self-identities centred on climbing mountains, it expands the current understanding of the pursuit of adventure. In the past, the study of adventure has primarily been concerned with motivations and, in particular, risk taking as the central motive for, and the meaning of, participation. By adopting biographical narrative interviewing as the primary source of empirical material, this study also departs from previous studies in its methodological approach.

In addition, the research seeks to provide insight into a population that has sustained a commitment to a demanding activity, voluntarily chosen and unremunerated, at a time

\footnotetext{
1 'Aotearoa' is the Māori name for New Zealand. The common translation is 'land of the long white cloud' ("Nationhood and identity," 2006). Since 1987, when Māori became an official language of New Zealand, usage of 'Aotearoa' has increased (Morin, Longhurst, \& Johnston, 2001). To acknowledge this, I have included Aotearoa in the title of this thesis. Hereafter, I refer simply to New Zealand.
} 
when commitment and continuity in leisure and in life are thought to be the exception, rather than the rule (Bauman, 2001; Rojek, 1993). In relation to leisure theory, this aspect of the study places mountaineering within the realm of activities identified by Stebbins $(1992: 3 ; 2001)$ as serious leisure; that is, 'the systematic pursuit of an amateur, hobbyist, or volunteer activity that participants find so substantial and interesting that, in the typical case, they launch themselves on a career centred on acquiring and expressing its special skills, knowledge, and experience'. Indeed, Stebbins' (2005) most recent study in this area examines what he terms 'nature-challenge' hobbies, including mountaineering. Naturechallenge hobbies, like all serious leisure, according to Stebbins, can be considered 'central life interests' in the sense intended by Dubin (1979).

A central life interest 'is that portion of an individual's life space in which [a major] affective investment has been made' (Dubin, 1979:419). Through aspects of lifestyle, the extent of one's investment in a serious leisure pursuit may be identified. Stebbins (2005:24) labels as 'devotees' those hobbyists who demonstrate a high level of dedication to their chosen activity, and differentiates these from "the more ordinary "participant", who invests less significantly and commits less time to their hobby. The mountaineers in this study are 'devotees', in that they have made substantial investments of time and affect in mountaineering; they have chosen lifestyles that allow them to participate as much as possible in the core activity and associated activities (for example, training, staying fit, reading about and socialising with other mountaineers); and it is central to their sense of who they are. Importantly, also, they have sustained this level of investment over a long period of time. Because I have included in this study mountaineers from a range of age groups, this 'period of time' varies from five years to more than fifty years. Nevertheless, they all expressed an intention to continue mountaineering in some capacity for the duration of their life time, and all had made important life choices in order to facilitate this. This is what I understand as commitment for the purposes of this study.

In keeping with a leisure perspective, the mountaineers in this study were selected on the basis that they do not, for the most part, earn a living from their hobby. Neither do they climb primarily as the clients of professional guides. Comparisons between recreational mountaineers and 'mountaineering adventure tourists' have been made elsewhere (Beedie, 2003; Beedie \& Hudson, 2003; Pomfret, 2006), and the problematic nature of commercialised adventure has been explored by a number of researchers and other commentators (Elmes \& Barry, 1999; Holyfield, 1999; Jenkins, 1994; Johnston \& Edwards, 1994; Palmer, 2002, 2004; Vause, 2000). But commodification processes and 
the position of mountaineering within the tourism industry are not the focus of the current study.

In this chapter I provide background to the study, by briefly outlining the historical, social and cultural context within which New Zealand mountaineers are situated, and which inevitably colours both popular and academic approaches to understanding the phenomenon. I then give an overview of the growing body of research and theory surrounding adventurous leisure pursuits, which includes mountain climbing alongside a variety of other activities, before taking a closer look at the main themes of the research that pertain specifically to climbing and mountaineering.

This overview is followed by a discussion of my research aims in relation to previous research, and the reasons for my central interest in the narrative construction of meaning and self by mountaineers. I also discuss here the relevance of Simmel's (1959) theory of adventure as a form of experiencing, which points to the potential for a study of adventurers such as mountaineers to further our understanding of the nature of human experience more broadly. Due to Simmel's primary focus on forms of human experience, and my desire to move away from the preoccupations of other theories of adventure, Simmel's conceptualisation of the adventurer is an appropriate starting point for this study.

The final section of this chapter provides an introduction to additional theory that has been instrumental in the framing of my research around questions of meaning and self, particularly the work of Frankl (1992; 2000), Fromm (1956b; 1994; 1999), and Antonovsky (1987), relating to the human need for meaning and its expression in contemporary society. In addition, this section includes an overview of theories on the relationship between meaning and self or identity, in particular the work of Bauman (2001), Bruner (1990; 2002) and Taylor (1989), which have been influential both in my choice of a biographical narrative approach, and in my interpretation of the research material. Theories about the problems of self or identity under current social conditions are also relevant to my interest in people with a high level of commitment to leisure pursuits such as mountaineering.

The literature presented in this chapter is intended as an introduction, providing important background to the framing and context of this study. Further literature, however, has been embedded at pertinent points within later chapters. Clandinin and Connelly (2000:41) see the weaving of literature into a text, so as to provide the sense of a 'seamless link between 
the theory and practice embodied in the inquiry', as being appropriate for narrative research. The unfolding of the literature in this way mirrors, to a large degree, the way in which my thinking around mountaineering, meaning and self has evolved, as themes that emerged during the collection and interpretation of the biographical narratives sent me in search of further reading in order to illuminate what I was finding. This also demonstrates the essentially inductive nature of the research, for although it was initially influenced by research and theories outlined in this chapter, I have endeavoured, as much as possible, to allow the themes of self and meaning to emerge from the narratives. This process involved using various theories as tools of understanding, rather than imposing any particular existing theory as the structure within which the mountaineers' voices would be heard.

Another characteristic of this approach has been the cross-disciplinary nature of the literature referred to in this thesis, as my search for relevant theory took me beyond the scope of leisure studies, into sociology, psychology, philosophy and occasionally elsewhere. The guiding thread has been the construction of meaning and self through narrative, and the potential weakness of not being decisively rooted in the theoretical structure of one particular discipline has, I believe, been countered by the understandings made possible by bringing a number of perspectives to bear upon one inevitably complex social phenomenon.

My approach to this research has also been informed by an interpretive hermeneutic framework, which stands at an intersection between philosophy and social science (Rabinow \& Sullivan, 1987). In adopting this position I have been influenced by my own background as an historian, by its use within leisure studies by Tony Blackshaw (2003), and by a number of theorists including the sociologist, Zygmunt Bauman (1978) and the philosophers, Charles Taylor (1987) and Paul Ricoeur (1992). The hermeneutic tradition acknowledges the 'endemic fluidity of meaning' (Bauman, 1978:229), and sees interpretation as 'always something begun, but never completed' (Kearney, 2004:4). In his discussion of Ricoeur's work, Kearney (2004:5) describes the attempt to interpret meaning as arriving 'in the middle of an exchange which has already begun and in which we seek to orient ourselves in order to make new sense of it'. But hermeneutics is not just about better understanding 'alien meanings'; it is also a process that leads us to better understand ourselves. And so I have arrived in the middle of the historically situated phenomenon of mountaineering in the socio-cultural context of New Zealand and I have sought to make some 'new' sense of it. It is my intention that this sense - which has by its hermeneutic nature both been informed by and transformed my own 'inner meaning' - will contribute 
to the on-going exchange of meanings about mountaineering and about leisure in contemporary society. That said, there is always, as Blackshaw (2003) reminds us, 'something more to be said'.

\section{Historical, social and cultural context of mountaineering}

Climbing, as a broad term, includes a number of forms such as mountaineering, iceclimbing and rock climbing, the last of which can be differentiated as traditional (or adventure) climbing, sport climbing and bouldering. Some past studies have failed to differentiate between forms of climbing, and thus to appreciate the significance of the differences. ${ }^{2}$ My own research is concerned with climbers whose primary focus is on climbing in wilderness or alpine settings and who are generally referred to as mountaineers, although the terms 'climber' and 'mountaineer' are often used interchangeably. For some of these mountaineers, rock routes on mountains are their preferred medium, as opposed to ice or snow with which mountaineering is most often associated. However, those who climb alpine rock can be distinguished from the sport climber or boulderer, whose activities are often undertaken in more urban and indoor settings, and are primarily concerned with athletic achievement and competition.

Mountaineers have more in common with traditional or adventure rock climbers, as both groups rely for their safety on temporary devices they have placed in order to protect them in the event of a fall. In New Zealand, mountaineers whose predominant interest is in climbing in mountain areas frequently also participate in bouldering and sport climbing, although this is usually for the purposes of training and fitness, rather than as an end in itself.

This section situates mountaineering within its historical, social and cultural context. First, I give an overview of the historical development of mountaineering, from its appearance in Europe in the nineteenth century and its cultural significance in the context of British imperialism and post-colonialism, to its introduction and growth as a leisure pursuit in New Zealand. Following this, I provide a short introduction to the contemporary context of mountaineering.

\footnotetext{
${ }^{2}$ Kiewa (2002) and Lewis $(2000 ; 2004)$ are examples of researchers who have been explicit in recognising the importance of distinguishing between different forms of climbing. Notably, both of these researchers are themselves climbers.
} 


\section{A brief history of mountaineering}

Histories of mountaineering are generally highly ethnocentric, beginning with Europe in the past few hundred years. Indeed, we seem to know very little about other cultural histories and their versions of the mountaineer, and have assumed it to be a recent, and unprecedented, Western invention. One example which suggests this conclusion is unfounded is that of Hua Shan, the Holy Peak of the West, in China. As far back as the sixth century, when the first guide to climbing the peak was written, pilgrims, scholars and poets had been climbing Hua Shan for a variety of purposes which appear no more or less 'leisurely' than those of present day mountaineers (Vervoorn, 1990-91). While today the ascent route on Hua Shan has been sufficiently altered to make it reasonably straightforward for the relatively inexperienced, in times past its sheer granite walls 'posed a serious mountaineering problem' which took some skill and tenacity to overcome (Vervoorn, 1990-91:15).

More typically, histories of mountaineering as a leisure pursuit have focused on the English Victorians, who founded the first mountaineering club, the Alpine Club, in 1857 (Lunn, 1957). An interest in climbing mountains for essentially recreational purposes was awakened in European minds over the preceding centuries by the Scientific Revolution and rise of the Romantic tradition which, according to MacFarlane (2004), allowed the mountains to be 'imagined' differently from before: as geological formations and places in which to encounter the sublime, rather than the lairs of dragons and the haunts of devils. During the eighteenth century, a small number of individuals were climbing in the European Alps and, by 1850, a few major ascents had been made by continental mountaineers.

In the latter half of the nineteenth century, the English came to the forefront of mountaineering in Europe. The new 'sport' of mountaineering had a particular appeal for the urban middle class culture in mid-Victorian Britain, who lauded mountaineering for its combination of effort and beauty. To the Victorian mind, patriotism, athleticism and romanticism were served by climbing mountains, and character was forged through struggle, challenge, hardship, cooperative effort and the conquering of adversity (Donnelly, 1981a). British mountaineering literature of the nineteenth century centred on a discourse of reward for hard and resolute effort, manliness, physical and moral fitness, competition and mastery over nature. It was more than just a sport; its significance was deeper, almost mystical (Robbins, 1987). 
According to Hansen (1995), part of the appeal was that the Victorian middle classes were beset with new leisure patterns and in search of new status symbols. At the same time, he argues, an assertive masculinity was actively being constructed to uphold an imagined sense of British imperial power. The founders of the Alpine Club in Britain adopted the language of exploration and adventure from imperial explorers in Africa and the Arctic, and recast mountains and mountaineering in relation to masculinity and British power. Club members set about climbing all the major alpine peaks in Europe, and their accomplishments became cultural symbols. ${ }^{3}$

By 1880, having climbed all the major peaks in the Alps, the English and their continental guides took their techniques and experience and launched expeditions to mountain ranges in other parts of the world (Temple, 1969). In 1882, the Reverend William Spotswood Green, a member of the English Alpine Club, came to New Zealand to make the first attempt to climb Aoraki/Mount Cook, ${ }^{4}$ the highest mountain (Green, 1883). Green's record of sublime experiences and imperialist sentiments, inspired young New Zealanders to attempt to climb their own mountains, and thus early mountaineering in the young colony was strongly influenced by the English traditions (Ross, 1914).

I have described elsewhere (Davidson, 2002) the way in which mountaineering in New Zealand began with this Victorian influence, but soon developed a flavour of its own inspired by a colonial pioneering spirit. Yet it was not until the inter-war period in the twentieth century that climbing mountains for recreation really caught on, and young people pursued the activity in significant numbers. While this was in part due to increased mobility and an interest by the government in promoting recreation in the $1930 \mathrm{~s}$, I have argued that it was also a reflection of a growing search for a sense of national identity which was manifesting itself in art and literature at the time, but expressed itself simultaneously as a desire for familiarity with and attachment to the physical landscape. As this period was one of dislocation and disillusionment, as well as expanding bureaucracies and rationalisation (Olssen, 1981), the growing enthusiasm for mountain recreation between the wars can also be read as a desire to inhabit, however temporarily,

\footnotetext{
${ }^{3}$ Later, British success in mounting the first successful expedition to climb Mount Everest was also viewed as a 'symbolic event', reinforcing Britian's identity as a world power (Stewart, 1995). The way in which Everest became a site for the expression of paramouncy for the British in the mid-twentieth century, and has since remained a point of nationalist striving, particularly in the context of postcolonialism, has also been explored by Slemon (1998).

${ }^{4}$ New Zealand's highest peak has two official names. 'Aoraki', or the regional variation 'Aorangi', is the Māori name. Aoraki was given the name Mount Cook by Europeans to commemorate the achievements of the English explorer James Cook. Climbers typically use only the European name, however, I have used both official names throughout the thesis.
} 
landscapes in which the values nurtured in the young colony could be maintained. These values were encapsulated in a simple and informal environment where what mattered most was character, companionship, 'kiwi ingenuity' and physical endurance (Davidson, 2002).

New Zealand mountaineering perhaps felt it had come of age when Edmund Hillary made the first ascent of Mount Everest with Tenzing Norgay in 1953, as members of a British expedition (Morin et al., 2001). In the half century since this achievement, the popularity of mountaineering in New Zealand has continued to grow ${ }^{5}$ and, in doing so, to reflect international developments, as well as its own distinctiveness. While these developments and the distinguishing features of New Zealand mountaineering are not the central focus of this study, they are part of the background and context of the research and I refer to them at times throughout the thesis where I feel that they are particularly pertinent. The most important consideration here is that, while this is not an historical study, it is situated historically in the period from post-World War Two until present day in the early twentyfirst century. In addition, the study is firmly culturally situated within a New Zealand context and does not aspire to depict all mountaineers, everywhere. Such a task would be impossible, not least because generalisation would conceal significant cultural differences already identified by other researchers (see, for example, Frohlick, 2003; Ortner, 1999).

\section{Contemporary context}

In recent years, there has been a growing interest in mountain climbing and other adventurous leisure pursuits, in terms of both participation and spectatorship (through its consumption in the mass media), with each apparently fuelling the other. Two themes that dominate the popular literature are a grappling with what motivates such pursuits and a perhaps morbid interest in the details of disaster. For example, in 1996 when eight climbers died on Everest during one storm, both the event and the aftermath were presented in the media with a commentary of triumph and tragedy: instantaneously through photos, films and radio dispatches filed on the World Wide Web; and in retrospect in numerous newspaper and magazine articles, books, documentaries and films (Gillman, 1997). News of the disaster intensified public interest in climbing the mountain (Breashears, 1997; Heath, 1997; Nordland, 1997) and consolidated the position of 'adventure disaster' as a 'hot genre' in the mainstream media (Buchanan, 1998).

Industry observers tend to agree that the media has played a role in creating more public awareness of adventure pursuits (Allen, 1987; Heath, 1997). Advertising has provided a

\footnotetext{
${ }^{5}$ See Figure 2: New Zealand Alpine Club Membership 1938-2006, Appendix A. 
large degree of exposure, while the marketing value of 'risky' sport illustrates its appeal to a youth-oriented popular culture (Johnston \& Edwards, 1994; Shoham, Rose, \& Kahle, 1998). As Celsi, Rose and Leigh (1993) point out, 'high-risk sports have become a badge of our times. We are all admonished to "just do it," and "play hard," for "life is short".' It is also argued that 'high-risk' activities are dramatic in form, and are to an extent motivated by a dramatic worldview which is both reflected in and reinforced by the mass media, literature and film (Celsi et al., 1993; Shoham et al., 1998).

One of the down-sides of the growing popularity of outdoor adventure pursuits has been crowding in fragile and remote locales and resulting environmental damage (Fluker \& Turner, 2000; Woodbury, 1999). In addition, the growing commercialisation of adventure pursuits, in particular the extent to which climbing Mount Everest has become imbued with commercial interests, has attracted much criticism and regret. Both before and after the 1996 tragedy, which involved two commercially-guided expeditions (one of which was run by a New Zealand company), commentators lamented that Mount Everest had become a playground for the rich to massage their egos; that the Nepalese government regarded Everest as a 'cash cow', and that a 'circus atmosphere' had prevailed as people tried to set ever more improbable world records ("Mountains of money," 1995; "No room at the top; Climbing Everest; Too many climbers on Mount Everest," 2001). The end result, according to some, is the desacralisation and defiling of one of the world's most revered symbols of adventure (Crumley, 1996; Roberts, 1994).

Thus, the powerful influence of the media, growing commercial forces and public interest in the exploits of outdoor adventurers, provide a context within which New Zealand mountaineers seek their leisure through climbing mountains. They also provide the background for increasing academic interest, to which I refer below.

\section{Review of relevant research on adventurous leisure}

Accompanying the growth in participation and popular interest in adventure pursuits has been an increase in research and theory in this area. Within this body of literature, mountaineering and/or climbing is included among a group of activities variously termed outdoor adventure recreation/pursuits (Ewert, 1987a, 1987b, 1989), risk recreation (Allen, 1987; Robinson, 1992), dangerous leisure (Olivier, 2006), risk sport (Breivik, 1999b), extreme sport (Le Breton, 2000), and lifestyle sport (Wheaton, 2004). A recent addition to this list is Stebbins' (2005) nature-challenge hobby. Climbing and mountaineering have probably received the most academic attention to date, but sky-diving has attracted a 
certain amount of interest, followed by the likes of kayaking, spelunking, rafting, scuba diving, sailing, surfing and bungee-jumping.

Depending on the perspective taken, adventurous leisure activities such as mountaineering are viewed as having a range of characteristics. Common to almost all approaches, and central to many, is the characteristic of risk taking. For example, Ewert (1994:4) defines risk recreation as 'recreational activities containing risk or danger that are experienced in a natural environment, in which the actions and abilities of the participant play important roles in the final outcome of the experience'. The main themes of the literature that treats adventure activities as a general category with particular characteristics are: personality theories of risk taking, or sensation seeking; the identification of motivations; dimensions of adventurous activity and experience; and voluntary risk taking as escape from, or compensation for, rationalised society. I consider these themes in the general literature on adventurous leisure, before turning to their more specific application to climbing and mountaineering.

\section{Personality theories}

Conventional personality theories maintained that the natural inclination of healthy individuals was to avoid tension and risk, and early psychiatric opinion understood participation in high risk recreation as the result of some form of psychopathology (Donnelly, 1981a; Roberts, 1994). The opinion of behavioural psychologists has now swung towards the concept of voluntary risk taking as being hard wired into the brain, linked to arousal and pleasure mechanisms and serving an evolutionary purpose (Roberts, 1994; Schueller, 2000; Zuckerman \& Kuhlman, 2000). A prevalent approach by psychologists has been to consider activities such as mountaineering to be motivated by a personality predisposition for risk taking (Breivik, 1999a, 1999b; Farley, 1986; Levenson, 1990; Zuckerman, 1979, 1983). Personality predisposition theories generally take a mono-dimensional approach focused on individual character traits as the determinants of behaviour.

One theoretical approach which has inspired a body of supporting research is Zuckerman's (1979:10-11) concept of sensation seeking: 'a trait defined by the need for varied, novel, and complex sensations and experiences and the willingness to take physical and social risks for the sake of such experience'. Breivik (1999a:2) finds sensation seeking theory more predictive than any other general trait theory, and concludes from a series of studies that high sensation seekers are 'attracted to high risk sports with strong and intense 
sensations and experiences, with unstable and unpredictable environments, like parachute jumping or high mountain climbing’ (Breivik, 1999a:52). In particular, Breivik (1999a:53) finds that high sensation seekers have a 'need for strong physical sensations of height and speed' and a 'strong need for new types of experiences, new landscapes, new people, new dreams and feeling'.

While it has been suggested that a growth in risk taking may be linked to external factors that everyday life may be too predictable and that high risk takers have trouble deriving purpose and meaning from it (Roberts, 1994) - little psychological research attempts to elucidate this connection. Indeed, discussion of the social and cultural context of personality traits is noticeably sparse in this area of research, resulting in accusations of a failure to provide a multi-dimensional approach (Ewert, 1994; Storry, 2003).

Another commonly supported finding in personality studies - that risk takers are generally young, middle class males (Schrader \& Wann, 1999) - points to the possibility that what is being described is predominantly the culturally-defined behaviour of a specific gender and socio-economic group, along the lines of Fromm's (1994) theory of social character. In other words, Zuckerman's concept isolates and describes a limited and specific form of 'sensation seeking', developed by a particular social group in response to particular social conditions, rather than an immutable and biologically determined character trait.

\section{$\underline{\text { Identifying motivations }}$}

An early and much broader examination of the motives for adventure is that undertaken by the British mountaineer, scholar and poet, Wilfred Noyce (1958). He identifies the end of the eighteenth and the beginning of the nineteenth centuries as the time at which the idea of adventure for its own sake 'crystallised in the minds of men; when they began to stop regarding more material motives as a necessary justification' (Noyce, 1958:5). While he thus places modern-day adventure within the broad realm of leisure (in the sense of unobligated, intrinsically motivated activity), he distinguishes adventure from sport by its 'sense of bigger things and the zest of the unknown' (Noyce, 1958:51). As a means of critical analysis, Noyce categorises adventures according to various underlying motives, while acknowledging that it is somewhat artificial to separate them out in this manner.

There are those, according to Noyce, who undertake adventures for the very reason that they are unpleasant and that by, in a sense, donning a 'hair shirt', they can gain some mastery of the self and prove that they are capable of doing something previously 
considered impossible. Another incentive is the need to undertake arduous tasks, to take leave of the comforts of the everyday, in order to more fully appreciate what is worthy and what is worthless in civilised life. There is also the attraction of danger in order to display courage, although Noyce maintains that this is seldom sought for its own sake. There are some who have nothing left to lose, and for whom danger is 'the companion to difficulty' which affords an opportunity for some form of redemption through self-proving or showing off. But for most, danger is merely 'accepted as necessary in some responsible tasks and as faintly inevitable in certain adventures, but controlled as far as possible by skill' (Noyce, 1958:45).

Pleasure, according to Noyce, also provides some of the lure of adventure: the sensual pleasure of movement, the joy of physical self-expression and the zestful feeling that comes from good healthy exercise. Then there are factors in the social and natural environment which form some of the attraction of adventure, whether it is in companionship or solitude, exotic locales or desolate wilderness. Escape is another of Noyce's (1958:81) categories, often born of a restlessness that is 'a symptom of a deep uncertainty about oneself and one's purpose'. He argues that adventure can 'harness' restlessness and direct it towards effective action. Noyce warns, however, that escape can sometimes lead to a desire to get back, to escape from where one has escaped to - while it is often the case that an escape is hard to escape.

There are those who are driven in their pursuit of adventure because they have become obsessed with their own 'lodestone' and cannot rest until it has been realised. Such people, says Noyce, have a streak of madness in them. Fame, however, in Noyce's mind, is seldom the spur and more often a drag: the rewards of an adventurous life are inherent in itself and the genuine adventurer would do it whether anyone knew about it or not. The commercialisation of adventure Noyce sees as a 'marriage of convenience', necessary in order to fund certain projects, but which leaves him 'filled with no joy' (Noyce, 1958:125). Competition and conquest play their part for some, particularly if coming out on top is thought of as the sine qua non of struggle.

Science is an often stated motive, though Noyce holds that the objective (the Pole, the summit or some other) provides the original inspiration while scientific considerations come later 'lending added and weighty arguments' (Noyce, 1958:154). Also, in the end as with Cherry-Garrard (1937) and the torturous 1911 Antarctic winter journey in search of Emperor penguin embryos - science can offer the hope that, no matter what, something 
will come of it all. In summing up, Noyce searched for a thread which would tie all the motives together. Though not particularly satisfied with the outcome, he came up with one word - expansion - and elaborated thus:

In pride of our humanity, and because we are made that way (I am not now asking why) we go for the new and so add, or endeavour to add, cubits to our stature. It is an old story, this proud instinct that brought man above the other competitors; this urge to expand into the world along paths of power and pleasure and curiosity. It is not always pleasant, but it is very human. Mankind has never been modest.

(Noyce, 1958:225)

Noyce's categories provide a useful map of the breadth and diversity of motives for adventure activities, and his reflections on the nature and weight of each motive provide insight into the complexity of the phenomenon and the difficulty of generalising about motivations.

\section{Dimensions of adventurous activity and experience}

Vester (1987) also takes a broad view of adventure, although his interest is not in motivations, but in the dimensions of adventurous activity and experience. He identifies these as: territoriality, duration, transcendence, risk, coping and routinisation. Vester's treatment is also pertinent because he positions his discussion within the context of leisure. Adventure, he claims, is not identical with leisure, but 'there are many adventurous forms of leisure, and in many social worlds adventure appears to be central, such as youth subcultures, sports bound to the natural environment, sexual relationships, or tourism' (Vester, 1987:247).

Vester (1987:241) suggests that in adventure, the experience of time and space may be essential: 'In contrast to continuous routine life, adventure interrupts the succession of events and seeks to establish the event that is rooted in discontinuity, seemingly beyond history'. While the experience of duration in adventure is subjective, this could be measured on a scale, from the fleeting adventurous moment to a lifetime conceived of as adventurous. In terms of the territoriality of adventure, places are ascribed by users with particular perceptions, expectations, preferences and feelings. The optimally adventurous environment is impossible to define:

one individual may find adventure in a waste land, where landscape and body territory tend to merge, while another may find it in overcrowded discotheques, where body territories are closely intersected and intimate intrusion may be desired.

(Vester, 1987:240) 
In discussing transcendence through adventure, Vester draws on Csikszentmihalyi's (1975) concept of flow experience - the merging of action and awareness achieved through the appropriate balance of challenge and skills. While many leisure activities could be described as transcendent (such as listening to music), only those which entail some risk appear as adventurous. According to Vester (1987:242), the comparative uncertainty of adventure gives it a 'liminal' flavour, something he believes every culture needs in some form or other, in order to fulfil 'the romantic desire for a more fascinating state of being which is relatively independent of social structure'. In order to master uncertain situations, competent adventurers employ strategies for coping. Adventurous individuals will seek to develop their coping techniques to a higher level, before testing them with ever more demanding adventures.

The romanticism of adventure, Vester (1987:245-246) argues, may be one of the last available opportunities in modern culture to experience 'an authentic state of being'; the possibility for 'true self-actualization, [as] opposed to the inauthentic ordinary everyday life'. As such, he believes, adventure as a form of experience 'plays a significant part in providing an opportunity to compensate for the boredom and lack of authenticity felt in ordinary life' (Vester, 1987:238). But Vester (1987:245) warns against perceiving adventure as 'an extra-mundane field of experience' and assuming a dichotomy between adventure and routine. While adventure offers, for some, an opportunity to experience 'the essential sphere of existence and meaning', it may simultaneously contain a less attractive character which is routinised, standardised and ritualised. Indeed, its lasting effect may be to make one more acutely aware of the tedium of everyday life, and if adventure is commercialised and rationalised 'little room is left for risk, daring, and uncertainty' (Vester, 1987:246).

In the interests of further understanding adventure, Vester (1987:247) suggests that it be investigated 'both in relation to the participants' perspectives and to the broader context of contemporary societies'. For him, 'the crucial point of interest is not the mechanics of drives and motives but the system of meaning ... This does not exclude the possibility that in adventure human beings are in an emotional state oscillating between anxiety and excitement; but even more important are the different meanings emerging out of different situations' (Vester, 1987:245). 
Lyng's (1990:852-853) starting point is voluntary risk taking rather than the notion of adventure per se, but he focuses on a similar range of activities to Vester's, and he is concerned with explaining them in terms of 'a socially constituted self in a historically specific social environment'. Being uncomfortable with psychologically reductionist accounts of risk taking behaviour which assume that it is 'impelled by factors that are constant across time and space', Lyng (1990:854) offers as an alternative his concept of edgework, which combines factors internal to the individual and factors in the external social environment, and views such behaviour as a negotiation of the boundaries between chaos and order. To illustrate this concept, he presents his own data collected during a study of skydivers, and supports this with illustrative material from a selection of secondary sources dealing with activities which he considers comparable: climbing, scuba diving, downhill skiing and endurance sports, aircraft test piloting, motor sports, combat soldiering, gambling, prostitution, drug use and criminal behaviour.

The central common feature of activities which qualify for Lyng's (1990:857-858) classification as edgework is that they 'all involve a clearly observable threat to one's physical or mental well-being or one's sense of ordered existence':

The "edge," or boundary line, confronted by the edgeworker can be defined in many different ways: life versus death, consciousness versus unconsciousness, sanity versus insanity, an ordered sense of self and environment versus a disordered self and environment. ... In abstract terms, edgework is best understood as an approach to the boundary between order and disorder, form and formlessness.

While edgework involves the development and execution of special skills and has this in common with many activities, the special additional skill of the edgeworker 'is the ability to maintain control over a situation that verges on complete chaos, a situation most people would regard as entirely uncontrollable'. In order to maintain focus and nerve under these conditions, Lyng's (1990:859) edgeworkers feel they have a particular capacity for 'mental toughness'. They believe that what they do is only dangerous when undertaken by people not possessing this capacity. A 'general principle of edgework' is 'the commitment to get as close as possible to the edge without going over it'. The experiences of edgework, though not all identical, involve such sensations as self-realisation (or its close associates: self-actualisation and self-determination); altered perceptions and states of consciousness; and a kind of hyper-reality or out-of-the-ordinariness (Lyng, 1990:862). In conceptualising high-risk activities as edgework, Lyng (1990:864) seeks to shift the emphasis 'away from fear, arousal, and preoccupation with death and toward the 
spontaneous, anarchic, impulsive character of the experience', which he considers to be the central feature of voluntary risk taking. As to why people are driven to pursue edgework, Lyng (1990:865) believes that the key to this is the polarity between spontaneity and constraint which lies 'at the heart of many important problems that confront members of modern postindustrial society'. Lyng (1990) argues that the individual in capitalist society is engaged in 'an incessant search for self'. Like Vester, he sees contemporary society as lacking in opportunities for 'spontaneous and self-realizing action' and believes that this propels some to search for it in 'the leisure-time pursuit of play, particularly those forms of play that involve both risk and skill' (Lyng, 1990:870-871). This allows edgeworkers to experience 'the illusion of controlling the seemingly uncontrollable', and to understand their achievements as 'unambiguously' their own, giving them a sense of competence denied to them in other fields of endeavour. From this perspective, Lyng (1990:874) argues, edgework 'is a rational and therapeutic way to respond to a sense of helplessness in the face of social-ecological threats'. What's more:

behavior in edgework appears to the individual as an innate response arising from sources deep within the individual, untouched by socializing influences. Thus edgeworkers experience this action as belonging to a residual, spontaneous self the "true self," as it were.

(Lyng, 1990:879)

Another theorist who draws on Lyng and pursues a similar interest in risk taking behaviour and its connection to social and cultural processes is Le Breton $(2000 ; 2004)$. He examines the published accounts of 'amateur sportsmen' (including climbers) that he sees as being engaged in 'long and intensive ordeals where [a] capacity to resist increasing personal suffering is all-important' (Le Breton, 2000:1). Such endeavours, he argues, are an attempt by individuals to "prove themselves in a society where reference points are both countless and contradictory and where values are in crisis ... through a radical one-to-one contest, to test their strength of character, their courage and their personal resources' (Le Breton, 2000:1). Le Breton (2000:7) interprets 'extreme' sports as a means of 'playing symbolically with death', as 'playing on the razor's edge' in order to have, if only for a moment, the sense of triumph and validation of being able to escape death's clutches. In this way, he sees a 'physical limit has come to replace the moral limit that present-day society no longer provides' (Le Breton, 2000:1). ${ }^{6}$

\footnotetext{
${ }^{6}$ Unfortunately Le Breton's full exposition of his research in this area is published in French, and only two short, summarising articles have appeared in English to date. Consequently I am not familiar with the detail of his argument, and cannot discuss it in any more depth. 
In summary, while personality theories are limited by their failure to account for the impact of social conditions on behaviour, the theories of Noyce, Vester and Lyng provide the basis for a more comprehensive understanding of adventurous leisure within the context of socio-cultural forces. While the scope and approach taken by these theorists differ, common elements do emerge. Firstly, there is the importance of a sense of mastery, competence or control, and the need to acquire and exercise special skills in order to achieve this. Secondly, there is the role of an element of uncertainty, whether it is the acceptance and controlling of danger which accompanies the 'zest for the unknown' that Noyce describes, the prerequisite for Vester's 'liminal' experiences, or Lyng's 'clearly observable threat to one's physical or mental well-being', which the edgeworker deliberately approaches. And finally, there is the tension that exists in the contrast between 'the adventure' and everyday life. This relationship appears to be one of complexity and some ambivalence; to compare the two 'states of being' may give one a clearer sense of what is worthwhile and what is not, or it could be a perhaps less noble need to escape (Noyce) or to cheat death (Le Breton). As the analyses of Lyng and Vester maintain, it is possible that, under current conditions, the desire to escape from a sense of inauthenticity in a highly commercialised and rationalised society is the prevailing impetus to adventure.

\section{Mountaineering-specific research and theory}

Although the literature relating specifically to mountaineering is quite limited, I include in my discussion a number of studies of rock climbers which I consider to be relevant to my research - either to the theoretical perspective, methodological approach, and/or the style of climbing under consideration. As mentioned earlier, research and theory pertaining specifically to mountaineering tends to echo (and draw on) the themes already identified in relation to adventure and voluntary risk taking. Thus, as with the previous section, I begin with research focused on personality theories, followed by considerations of the motivations of mountaineers and climbers, and move on to studies more concerned with the nature and meaning of the climbing experience, in particular its contrast with rationalised society.

Psychological studies of mountain climbing have been concerned primarily with motivations, and have tended to involve either one of two approaches - personality predisposition or goal-directed behaviour (Ewert, 1994). Climbers have been subject to psychological research attempting to measure personality traits and compare them with those of the general population (for example, Feher, Meyers, \& Skelly, 1998; Rossi \& Cereatti, 1993). The outcomes of such studies have generally held that climbers score 
more highly on sensation seeking traits than many other groups, and that otherwise they can be considered 'psychologically healthy' (Lester, 2004:88). Slanger and Rudestam (1997), however, have questioned the relevance and explanatory potential of the sensation seeking tests in relation to climbing. There is one study which has applied personality tests to a sample of New Zealand climbers (Monasterio, 2005). This study found that relative to the 'average person', 'serious and committed' climbers scored more highly on Novelty Seeking and Self-Directedness, and lower on Harm Avoidance and Self-Transcendence (in the sense of being prone to 'impatience, pride and personal unfulfilment'). As with the studies discussed in the previous section, research such as this has limited explanatory potential beyond its clarification of certain personality characteristics among various populations of climbers.

Lester's (1987) study of mountaineers on Mount Everest utilised clinical psychological tests, but went beyond these to include observations and interviews. Consequently, his research has greater relevance to my study. From the data he collects, Lester (1987:175) concludes that there is a paradox between self-assertion and self-transcendence in mountaineering, and that 'the devotee of climbing seems ... to exemplify often the most exquisitely balanced struggle between "proving self" and "losing self", with every exertion serving both ends'. For Lester, this conflict is an inner drama which is inherent in mountaineering, and comparable to (although, he suggests, much faster than) the process of psychotherapy. ${ }^{7}$ One of his subjects in particular described in detail his feeling that he was constrained and 'burdened by his "social" self or selves' and that this separated him from his real self(Lester, 1987:176). Lester (1987:178) summarises the reasons for participating in an activity such as mountaineering as 'a desire to pare life down to something essential, and thereby to experience living more vividly and intensely', and to experience a focus and wholeheartedness not easily achieved in everyday life.

In a later study, Lester (2004:87) examines the mountaineering literature of the past 150 years, treating it as a collection of 'published self-reports' of 'those rare people whose passion for climbing is the central fact of their lives'. Here Lester is primarily interested in the cultural context of climbing and in particular the impact of romanticism in shaping the 'actions and motivations' of climbers. He goes as far as to say that 'without the culturally shared outlook of romanticism, which is still alive today, climbers would have had no way of making themselves intelligible to themselves or to others' (Lester, 2004:89). The major

\footnotetext{
${ }^{7}$ Phipps (1985) also discusses the relevance of adventure for the process of individuation - the unity of multiple selves into a single whole - as described by the Jungian approach to psychotherapy. 
themes that Lester (2004) finds include a sense of freedom in climbing, and a sense of power, energy and vitality. He also identifies a number of themes relating to self within the literature 'which seem to work towards enhancing a sense of integration and diminishing a sense of fragmentation'. On the basis of this he suggests that 'mountaineering may have its strongest appeal to especially divided selves' (Lester, 2004:97).

The second approach to motivations for climbing, the goal-driven approach, suggests that participation is motivated by 'an individual desire to achieve a high level of arousal or to satisfy a host of other needs and goals' (Ewert, 1994:6). An early example of this type of study was conducted by Bratton, Kinnear \& Koroluk (1979) among a diverse population of Canadian mountaineers. They concluded that 'an everchanging mosaic of primary and secondary motives for climbing exist', and age, ability and gender were strong determinants of motivations (Bratton et al., 1979:23). Their overall results showed that 'appreciation of the outdoors' was given high importance as a reason to climb, while 'selftesting or achievement related reasons' were considered to be of only moderate or minor importance (Bratton et al., 1979:30). Only three young male climbers felt that 'flirting with danger' was an important reason to climb, and in general recognition and competition were also given very low ratings.

Ewert (1994:15) also takes a goal-directed approach and concludes, from his data collected from high altitude mountaineers, that 'as climbers grow in experience, they appear to move along a continuum of motivating factors from items relatively mechanical (e.g. learning how to climb) to those items that had greater intrinsic and autotelic meaning (exhilaration and self-expression)'. In addition, his respondents rated 'because of the risk' as having low motivational power. On the basis of these conclusions, Ewert (1994:21) suggests that 'a person engaged in the activity does not necessarily view it as risky or dangerous.... a more appropriate term for these activities may be adventure or challenge recreation rather than the more daredevil connotation, risk recreation'. Allen (1987) supports this view and presents the argument that it is uncertainty rather than physical risk per se which constitutes the central motivating force in such recreational pursuits.

In another study, Ewert (1993) attempts to elucidate the relationship between reported motives, the outcome of events, and the experience and type of group involved. He confronts the issue of when precisely one should measure motivation in recreational studies, as such timing would influence whether or not stated motives reflected a 
participant's current needs, anticipated needs, or needs that were actually realised.

Motives are typically treated as 'antecedents that create behaviors which lead to desired outcomes'. However, the concept of motivational matching suggests that while people may strive to achieve experiences which fulfil their motives, if an outcome is less successful than anticipated, participants will report their most important motives as those which were fulfilled (Ewert, 1993). While Ewert's (1993) study was not extensive enough to provide conclusive evidence of this phenomenon, he felt his results were suggestive enough to recommend further research and to question conventional approaches to researching motivations.

An alternative approach to motives is taken by Loewenstein (1999). He considers mountaineering from the perspective of utility theory, seeing it as an activity that evades tidy classification within materialistic notions of human motivation, and thus as an enlightening illustration of non-consumption-related sources of utility. From his reading of mountaineering literature, Loewenstein (1999) concludes that it is an activity that is rarely thrilling and involves a generous amount of misery. Such misery, however, 'has no real meaning to [mountaineers] when it comes to deciding whether to expose themselves to the misery again' (Loewenstein, 1999:319).

The non-consumptive motives illustrated by mountaineering are, for Loewenstein: selfsignalling or prestige (the need to impress both oneself and others); a drive towards goal completion; mastery (or at least the illusion of control); and meaning:

Just as people aren't certain about who they are (and so attempt to signal, both to themselves and to others that they have desirable traits), many people also don't have a good understanding of what they want out of life and what they value.

(Loewenstein, 1999:331)

The new perspectives offered by mountaineering are, according to Loewenstein (1999:332), 'actually quite predictable. Almost invariably they involve an enhanced appreciation of human relationships and a demotion of professional and material ambitions'. That such insights occur during the act of climbing mountains is not surprising to him either, as the 'prospect of death produces a powerful form of attention focussing' (Loewenstein, 1999:333). Loewenstein concedes that the determinants and consequences of meaning, as a non-consumptive motive, are not well understood, although in concluding, he hints that the manner in which people invest sequences of events with meaning is through constructing autobiographical accounts of their lives. 
Storry (2003:133) also examines motivations, and deals with the difficulty of capturing them by constructing a story in order to 'make transparent the process of creation'. The story he tells elucidates the diversity of motives in terms of four 'games' climbers 'play': social bonding; deep play; personal achievement; and nature life (an appreciation of wilderness landscapes). The concept of deep play - that is, an activity 'involving an extreme wager which acts as a vehicle for the deeper personal and cultural interests of the participants who risk it' - was earlier related to the nature of the experience of climbing by Macaloon and Csikszentmihalyi (1983:362). While in terms of economic utility and existing cultural values, deep play is 'useless, if not subversive', 'the artificial sheltered universe of climbing can assume a reality of its own more meaningful to the actor than the reality of everyday life' (Macaloon \& Csikszentmihalyi, 1983:361-362). Interviews with thirty rock climbers and mountaineers in the United States yielded descriptions of an experience which is its own reward, involving exploration, discovery, companionship and problem solving. While a degree of uncertainty was critical, the authors concluded that 'physical danger ... functions principally as a compelling motivation to attend to the immediate situation' (Macaloon \& Csikszentmihalyi, 1983:368).

Thus, the outsider's focus on the risk and irrationality of climbing is, they argue, misplaced, as physical danger 'stands neither as an end in itself nor as a dominant preoccupation of the climbers'; rather, 'danger is accepted and utilized as a part of the gestalt of climbing, in which feelings of control and competence predominate over voluntary risk' (Macaloon \& Csikszentmihalyi, 1983:369). For some of the respondents, the state of concentration afforded them by climbing allowed them to achieve 'deep-flow' - a state in which action and awareness merge and the ego is seemingly transcended. Such experiences are described as intensely emotional, sometimes religious or spiritual in nature, and allowing climbing to function as a vehicle of cultural meaning, rendering it 'in this sense a form of art, though one which produces events and not objects' (Macaloon \& Csikszentmihalyi, 1983:374).

In line with Huizinga's (1950) observation that play offers us an opportunity to experiment with new ways of living and new patterns of experience, Macaloon and Csikszentmihalyi (1983:377) examine the extent to which rock climbing can provide 'a base from which one can perceive culture more clearly'. They found that the stories rock climbers told were antistructural: in climbing they found a depth, meaning and morality which was lacking in 'real' life. A deeper understanding of intrinsically rewarding activities such as rock 
climbing, the authors argue, may be the solution to the alienation and meaninglessness of daily activities, and the key to making ordinary life more enjoyable.

Mitchell (1983) is also interested in the meaning and morality of experience in mountain climbing, and while he draws on the work of Csikszentmihalyi (1975), his perspective is predominantly sociological. He found that a search for balance - both physical and moral - by matching challenges with tools and techniques was a recurring theme in the data he collected. The meaning of mountaineering emerged from the 'reflective discussion and debate' that followed specific events, during which considerable effort was made 'to render untoward occurrences understandable' (Mitchell, 1983:72-73). Through the successive recollections and anticipations of mountain adventures, experiences were blended together in such a way as to allow participants to develop 'new patterns of relationships' and self-images which were 'special and apart from conventional ones' (Mitchell, 1983:77).

Mitchell also found that mountaineering literature was an important forum in defining the social meaning of mountain climbing for its protagonists, and while clubs and organisations provided 'regularized schemes of identity development', more subtle and informal 'impression-management techniques' lay in the collection and display of an array of 'souvenirs' (Mitchell, 1983:116). After considering various explanations for why people climb mountains, Mitchell (1983:153) maintains that people climb 'because it is somehow fun'. To explain this he utilises Csikszentmihalyi's (1975) concept of flow. In particular, Mitchell focuses on uncertainty as a critical precondition of flow. Uncertainty, he argues, makes the creation of new combinations possible and plays an important role in motivating climbers in their endeavours. When there is an optimal balance between challenge and skill, flow will result, while an imbalance will result in either too much or too little certainty. Although temporary imbalances are common and easily rectified, prolonged imbalances can affect our lives in more disconcerting ways.

Based on statistics collected among mountaineers in Southern California in the 1970s, Mitchell ascertained that the 'typical' climber is a white, middle class male who is married and established in a respectable career. He argues that the engineers, technicians and professionals that make up the majority of climbers in the social context he is examining, have high expectations that their work will be creative and meaningful and, when it fails to measure up, the resulting sense of alienation leads them to seek compensation in mountaineering, which offers more profound gratification than daily routines: 
[Mountain climbers] see themselves as capable, even exceptional persons whose talents are in part repressed by bureaucratic regulations and organizational regimen. ... [they] are not looking for greater security, stability and certainty in their lives. ... they are seeking in their leisure a test of their limits in a gratifying nocompromise situation where their behavior is meaningful and outcomes depend upon their perceived capabilities.

(Mitchell, 1983:224)

In a 'rationalized world of amoral inconstancy' mountaineers infuse their chosen leisure activity with meaning, and hence create the purpose and direction that the world is lacking (Mitchell, 1983:214). This is not possible, according to Mitchell, in those sports which have become too rationalised and institutionalised to allow the achievement of flow, or in commercialised adventure where the actions and abilities of the participants have little impact on the outcome.

Heywood (1994:179) uses a cultural studies approach to critically examine the notion that climbing offers an avenue of escape from the demands of 'an increasingly rationalized lifeworld'. Following Taylor's (1989) proposition that two modern notions of the self the self of disengaged reason and the expressive self - oppose each other, Heywood is interested in the extent to which sport offers opportunities for the development of the latter in a world which seems to favour the former. For Heywood (1994:190), 'escape attempts' remain the domain of the expressive self, and although postmodernists treat the self as 'obsolete, an anachronism', he argues that it is 'a central and indispensable idea, crucial to any critique of late-modernity's disastrous excesses'.

While Heywood (1994:186) argues that 'as a cultural phenomenon, adventure climbing represents for many participants a genuine escape attempt, a small but important challenge to the encroachments of rationalization', he also questions how 'adventurous' much climbing is, given the encroachment of rationalisation even into this realm. In an examination of the 'multiple lifeworlds' of climbing, Heywood (1994:187-189) finds contradictions between the subjective, even mystical, experiences of climbers, and the 'objective, sober, more detached' aspects of the sport, and concludes that ambivalence is an 'understandable' strategy for coping with such seemingly contradictory features of climbing, as much as it is a reasonable response to 'cultural life in general'.

Climbing as resistance to rationalised society is also critically examined by Kiewa (2002). Like Heywood (1994), she finds the notion of being able to escape to be problematic, given the power of rationalisation to find its way into the climbing world through forms of 
regulation, commercialisation and commodification. Attempts to resist such rationalising processes by adopting certain symbolic behaviours have resulted, Kiewa (2002) argues, in some climbers becoming dogmatic and oppressive as they attempt to enforce these codes of behaviour on all those who enter into their shared climbing environments. In this sense, Kiewa (2002) believes that the climbing community she studied can be seen as a 'neotribe', with a 'metanarrative of oppression', which demands conformity rather than accepting diverse perspectives and trusting others as independent moral agents. De Léséleuc, Gleyse and Marcellini (2002) give another example of territoriality within a French rock climbing community.

A number of other studies consider various additional aspects of climbing. Vanreusel and Renson (1981) focus on climbers as members of a socially stigmatised subculture which bestows a social value on risk. Kiewa (2001) considers personal control within rock climbing, and the desire to experience competence and a sense of mastery. Lewis's (2000:58) study of British rock climbing is concerned with climbing as a 'form of embodied awareness', with the potential to 'thwart the desensitizing and pacifying proclivity of the body under modernity'. Meier (1976:58) explores the nature of climbing partnerships, and Pereira (2005) the perceptions of risk among high-altitude mountaineers.

Further studies have analysed mountaineering literature, reflecting Barcott's (1996:65) claim that mountaineering has become 'the most literary of all sports'. Manning (1999), in his analysis of adventure narratives (including popular best-selling books on mountaineering), identifies the pursuit of risky experience and the social construction of risk as distinctive features of postmodern cultures, particularly our appetite for the vicarious experience of risk through narrative. Slemon (1998) explores the ways in which mountaineering tales reveal more about the 'mountaineering self' than about mountains themselves. Meanwhile, McCarthy (2002) examines North American mountaineering literature with an interest in connections between the human and the natural world.

The final area of research of relevance to this study, and recently expanded to include a study of mountaineers, is serious leisure (Stebbins, 2005). Stebbins' study includes a comparison of three groups of 'nature-challenge hobbyists' active in the Canadian Rockies: mountaineers, kayakers and snowboarders. His focus is on the meso-structural aspects of these hobbies - namely, the leisure careers and lifestyles they involve - which he identifies as an under-researched area. He also considers social psychological aspects of the activities as they relate to the costs and rewards of participation. In addition, 
Stebbins (2005:17) expressly rejects 'the idea of high physical risk as a general descriptor of these activities'. He ultimately concludes that for nature-challenge hobbyists 'excitement includes courting manageable risk in the search for flow, but seldom entering voluntarily into anything more hazardous than that' (Stebbins, 2005:134).

Elements of Stebbins' broader theory of serious leisure were touched on in the introduction to this chapter. There is common ground between his recent study and my own, particularly in his description of the 'social worlds' of serious leisure hobbies, and the 'unique ethos' that grows up around them, as well as his contention that a 'single-minded concentration on high risk' has led to the 'neglect' of other salient aspects of these activities (Stebbins, 2005:22). A more detailed outline of these similarities, however, will not be given here. Suffice it to say that the mountaineers in my study can be considered serious leisure participants in the same vein as Stebbins' nature-challenge hobbyists. There is also overlap here with what has elsewhere been termed recreation 'involvement'; that is, 'the personal meaning or affective attachment an individual has for an activity' which at a high level leads people to find 'enjoyment from participation, view the activity as important, find it self-expressive and see it as the central focus of their leisure life' (McIntyre, 1992:69).

In the next section, I position my study in relation to the main themes and issues identified through this review of the research and theory on adventurous leisure and mountaineering.

\section{Discussion of research aims}

My decision to examine the narrative construction of meaning and self or identity through a commitment to mountaineering emerged from a number of issues identified in my review of the relevant research and theory. Firstly, I was concerned with the need to move away from identifying motivations. A number of scholars have found motivational research on adventure pursuits unsatisfactory. As discussed, Ewert (1993) finds the measurement of motivations challenging to the extent that some variation is dependent on when the measurements are recorded. Lipscombe (1999) considers that current motivational scales fail to adequately acknowledge the importance of the experiential perspective for recreation participants. Vester (1987) suggests that in order to understand adventure we should abandon the search for drives and motives and, instead, investigate participants' perspectives and ask questions about systems of meaning. A focus on narrative is a means of overcoming the problems encountered by trying to identify motives as antecedents of behaviour, as Storry (2003) has tentatively attempted to demonstrate. It is also an 
appropriate way to seek an understanding of meaning. My rationale for examining mountaineering through narratives will be more fully discussed in the final section of this chapter, and in the following chapter on the research process.

The second problematic area of climbing research is the role of risk. Although researchers such as Pereira (2005) and Le Breton (2000) see risk as a central and defining characteristic of activities such as mountain climbing, the way in which it is perceived and accommodated by mountaineers themselves appears to contradict this to some extent. Mountaineers and other adventure recreationists have been reported as claiming that their activities are not risky as long as one has the appropriate ability and that risk is not an important motivation for participation (Bratton et al., 1979; Donnelly, 1981b; Ewert, 1993, 1994; Lyng, 1990). These reports are supported by psychological research (Boone \& Gerits, 1996; Breivik, 1999a, 1999b; Franken, Gibson, \& Rowland, 1992; Rossi \& Cereatti, 1993; Zuckerman, 1979).

For Macaloon and Csikszentmihalyi (1983), Mitchell (1983) and Loewenstein (1999) physical danger is a means to an end - that of deepening concentration, testing oneself and focusing attention. There is further supporting evidence that it is the psychological rewards of differing states of consciousness which people are seeking in mountaineering and other adventurous leisure pursuits, and which may only be accessible in situations where the stakes are high. These psychologically rewarding states include selftranscendence (Matous, 1992; Messner, 1979; Richard, 1992), self-actualisation (Lipscombe, 1999; Lyng, 1990; Vester, 1987), flow (Csikszentmihalyi, 1975, 1990) and hyper-reality (Lyng, 1990) or liminality (Vester, 1987).

An additional problem with risk is that it is an ambiguous term, depending on context. The nature of this ambiguity will be discussed in more detail in Chapter 5 where it is relevant to my interpretation of the biographical narratives. However, risk is not central to this study and I am not attempting to explain mountaineering as risk taking behaviour. There is a tendency to see many aspects of contemporary society through the lens of risk (Giddens, 1991), and adventurous leisure is perhaps particularly susceptible to this preoccupation. As Manning (1999:286) says, risks - both created and sought - are 'windows into modern experience' and, through dominating institutional discourse and the mass media, they 'appear to shape modern consciousness'. To focus on this dimension of the phenomenon of climbing mountains is thus symptomatic of a prevailing worldview, leaving us open to 
over-emphasising its importance at the expense of other elements and processes, such as the construction of meaning and self or identity.

Loewenstein (1999) maintains that the 'determinants and consequences' of meaning are not well understood, and this applies to our understanding of adventurous leisure, although writers such as Vester (1987) have hinted at the potential value of better understanding these processes. Loewenstein (1999) suggests that people invest experiences such as mountain climbing with meaning in the process of constructing an autobiographical account of their lives, and attempting to come to grips with who they are and what they value. In his study, Mitchell (1983) found that, for mountaineers, meanings emerged after the experience, during reflection and in the effort to make sense of the problematic and the 'untoward'. Lester $(1987 ; 2004)$ suggests that mountaineering may be particularly suited to the 'integration' of 'divided selves'.

While a number of studies have concluded that issues of meaning and self or identity are related to participation, an in-depth enquiry into the ways in which they are constructed within the lives of adventurous leisure participants, and the means by which they are sustained by those who have a high level of commitment to an activity such as mountaineering, has thus far been lacking. Such enquiry begs a narrative approach. Studies to date that have drawn on mountaineering narratives have limited themselves to published accounts of climbing exploits and autobiographies (for example, Lester, 2004; McCarthy, 2002; Slemon, 1998). While this is certainly a valid area of investigation, it covers only a specific sector of the climbing population; that is, high profile individuals and those whose stories are dramatic and/or noteworthy enough to attract a wide readership. Further, such books are written in accordance with a particular literary genre, the adventure auto/biography, and must be understood in this context. Mountaineering literature, as Mitchell (1983) found, emerges from, and contributes to, the social processes of meaning and identity construction. However, in order to learn about how a more 'typical' mountaineer engages with these processes in order to define life-meaning and self at the individual level, it is necessary to examine the biographical narratives of those who may never step into the limelight.

In framing my research around meaning and self I have also been influenced by the early sociologist Simmel's (1959) essay, 'The adventurer', which I have chosen to discuss separately from the other literature, as Simmel was not concerned with adventure as a particular cluster of activities. Instead, he argued that it is not the content of an experience 
which designates it as an adventure but that adventure is a form of social interaction and the adventurer a social type (Ritzer, 1988). Forms, in Simmel's sociology, are 'the synthesizing principles which select elements from the raw stuff of experience and shape them into determinate unities' (Levine, 1971:xv). Forms of experiencing, in short, are what people use to organise the overwhelming and diverse facets and events of daily life into manageable and recurring patterns. Simmel identified a number of different forms of social interaction and corresponding social types or 'orientations to the world' including the 'miser', 'stranger', 'spendthrift' and 'adventurer' (Ritzer, 1988:143). In the essays he wrote on each form, it was, Ritzer (1988:151) argues, 'characteristic of Simmel to offer a profusion of insights'.

Simmel's sociological thought, according to Beilharz (2000:113), 'is manoeuvred through the perspectives of the human condition', and addresses 'the most fundamental of questions about personality: what does this (or any other form of) culture do to character? What is the relationship between social form or institutions and soul, or personality? How can we connect the social outside with the human inside?' (Beilharz, 2000:133). In addition, a major contribution of Simmel's sociology has been his analysis of modernity (Taveira, 1991). Because of these preoccupations of Simmel, which foreshadow the theories of meaning and identity that I discuss in the next section, his approach to adventure is particularly pertinent to my enquiry.

Simmel (1959:256-257) argues that the fundamental elements of adventure - the tensions between the accidental and the meaningful, certainty and uncertainty - exist to some extent within the content of all experience, but adventure arises when they reach a certain level of intensity. And so it is that an adventure is an experience, with 'a beginning and an end much sharper than those to be discovered in other forms of our experiences', which stands outside 'the continuity of life', and 'is yet somehow connected to the center' or 'the character and identity of the bearer of that life' (Simmel, 1959:243-246). As such, Simmel (1959:244) argues, adventure 'is given a meaning in and of itself'.

In their widest sense, Simmel (1959:255) maintains that the symptoms of adventure are 'admixed with all practical human existence', that we can take any part of life out of 'the total context of life', and we can examine and identify 'the intrinsic value of that segment of life'. It is this dichotomy of value - between the accidentalness and the unity of all individual human experiences - which accounts for both 'the wealth and the perplexity of life' (Simmel, 1959:256). For Simmel (1959:256) a continuity runs through all the 
phenomena of life whereby they can be seen to rest somewhere on a scale 'on which every point is simultaneously determined by the effect of our strength and our abandonment to impenetrable things and powers'. This existential problem allows us all, in a sense, to become adventurers. Whether we view the sum total of life as comprehensible and meaningful or incalculable and insoluble may depend, he says, on the quantitative analysis of individual experiences falling into either category. Having said this, Simmel (1959:257) adds that:

none of us could live one day if we did not treat that which is really incalculable as if it were calculable, if we did not entrust our own strength with what it still cannot achieve by itself but only by its enigmatic co-operation with the powers of fate.

So Simmel (1959:257-258) sees us all as 'the adventurers of the earth: our life ... crossed everywhere by the tensions which mark adventure'. Using Simmel's interpretation as a guide, it is possible to approach adventurers such as the mountaineers in this study as essentially no different from anyone else, except in terms of the intensity and frequency of one particular form of experience: adventure. Hence, the processes by which they construct self and life-meaning, and grapple with such existential challenges, arguably should not differ in form, except perhaps that the intensity and frequency of their experiences of adventure may throw such processes into greater relief. This would render them a particularly illuminating case study for examining meaning and self.

This brings me to the final spur to my interest in such issues; that is, the suggestion that at this specific juncture in history, the question of meaning is particularly pertinent. As noted, it has been argued that the pursuit of adventure is growing because a lack of constancy and authenticity in contemporary society makes escape more necessary than ever before, and adventure is an antidote to alienation and meaninglessness (Macaloon \& Csikszentmihalyi, 1983; Mitchell, 1983). While Maccoby (1995), among others, maintains that meaning is elusive in contemporary society, Rojek (1993:132) argues the point - first made by Baudrillard - that the problem is not a lack of meaning, but rather that the world is 'awash with meaning'. The ways in which mountaineers navigate this sea of meaning is the theme of my research. The research asks not why people climb mountains, but how people give meaning to this adventurous leisure pursuit, and how it is integrated into a coherent 'narrative of self' and sense of purpose in their lives. With this in mind, I now consider additional theory relevant to my study that falls outside of the bounds of current research relating to mountaineering and adventure. 


\section{Further relevant theory}

In this section I consider theories of the human need for meaning, and thereby introduce the way in which I have approached meaning for the purposes of this study. This is followed by a discussion of theories of self and identity in contemporary society, and a consideration of the role of narrative in the construction of meaning and self.

\section{The human need for meaning}

It is widely acknowledged that human needs extend beyond 'mere survival' (that is, the satisfaction of only physiological needs), if we are to live what could be termed a fully human life (Dube, 1984). A range of needs have been identified and categorised (see, for example, Dube, 1984; Heller, 1993; Maccoby, 1995; Rouse, 2004), and included among these, in varying ways, has been the need for meaning or purpose in life. Maccoby (1995:59), however, argues that 'All other needs are eventually shaped by the drive for meaning'. Thus, my interest here is in a number of theories that place the need for a sense of meaning in one's life as a central - if not the central - need in terms of our ability to live a healthy and satisfying life. The theories of Fromm (1956b; 1994; 1999), Frankl (1992; 2000) and Antonovsky (1987), and related themes in the work of Bauman (1995; 2001) and others, underpin my approach to meaning and the related sense of self in this study.

Frankl (1992) argues that the search for meaning in one's life is 'the primary motivational force'. More than gaining pleasure or avoiding pain, we are concerned with finding meaning in what befalls us, even if this is dominated by suffering. He sees a prevailing feeling of 'total and ultimate meaninglessness' in contemporary society as being the result of an 'existential vacuum': a kind of 'collective neurosis' stemming from a 'private and personal form of nihilism'; that is, 'the contention that being has no meaning' (Frankl, 1992:131). This he believes is the result of two processes: the first being when humans lost 'some of the basic animal instincts in which an animal's behaviour is embedded and by which it is secured'; and, secondly, the more recent process whereby the traditions that constrained behaviour have diminished. Without instinct or tradition to guide us we are left to make our own decisions about what we should do, which requires knowing what we wish to do, which is not always easy. When we feel adrift, there are two options, according to Frankl (1992): to follow what others are doing down roads of conformism or to submit to what others wish us to do, which takes us in the direction of totalitarianism. 
For Frankl (1992), meaning is not something that falls at our feet. Neither is it some magic, universal formula. Its construction is an individual task or challenge that life throws at us:

The meaning of life differs from man to man, from day to day and from hour to hour. What matters, therefore, is not the meaning of life in general but rather the specific meaning of a person's life at a given moment.

(Frankl, 1992:113)

So we do not so much find meaning, as make or construct it out of the bits and pieces that come to hand: our life experiences. And it is a daily labour, not something we can accomplish and be done with, because as long as we live there will always be more pieces to fit into the puzzle. There are three different ways in which we can find meaning in life, according to Frankl (1992:115): '(1) by creating a work or doing a deed; (2) by experiencing something or encountering someone; and (3) by the attitude we take toward unavoidable suffering'. 'Experiencing something' may be goodness, or truth, or beauty through the experience of nature, or we may 'experience' another human being, through loving them. But if our life experience is permeated by unavoidable suffering, as it was for victims of the Holocaust including Frankl himself, then, he maintains, we must strive to find meaning there also. Even if all other freedoms are taken away from us, we can still choose to be 'worthy of our sufferings'. Whichever path we take to meaning, it involves directing ourselves to something or someone 'out there', and in so doing we transcend ourselves. By this process we actualise our potentialities, and thus self-actualisation, Frankl (2000:84) argues, is the 'unintentional by-product' of self-transcendence.

There is a strong synthesis between the work of Frankl and Fromm with regard to meaning. Fromm (1994) points out that the doubt and nihilism of the current age were predictable. Indeed, they were foretold by Nietzsche and Kierkegaard in the nineteenth century. Like Frankl, Fromm (1994) sees the anxiety of Western individuals as stemming from the freedoms gained in the breakdown of traditional society, a process which has been underway in Europe since the sixteenth century. There are two sides to this freedom, Fromm maintains. While it has brought us 'economic liberalism, political democracy, religious autonomy, and individualism in personal life', it has also resulted in isolation and insecurity: 'By losing a fixed place in a closed world, man loses the answer to the meaning of his life; the result is that doubt has befallen him concerning himself and the aim of life' (Fromm, 1994:62). Such a condition is hard to endure due to what Fromm (1956b) describes as our 'tragic fate', or the 'inner contradictions' of human existence: by being part of nature and yet transcending it, by being mortal and yet aware of our own mortality, we have a fundamental need (indeed, the fundamental need beyond the physiological) for 
'meaning and direction', to avoid feeling like a 'particle of dust', and to escape being overwhelmed by doubt and a sense of our own insignificance (Fromm, 1994:19-20).

According to Fromm (1956b), all our 'passions and strivings' are an attempt to find a solution to this existential problem that arose when 'life became aware of itself'. All needs which are 'specifically human', our need 'for relatedness, transcendence, rootedness, the need for a sense of identity and the need for a frame of orientation and devotion', arise from a central striving to avoid feeling separate and alone (Fromm, 1956b:67, 1999). Cultures are the formal organisation of certain solutions to the awareness of our mortality, this 'condition' that makes us human, as Bauman (1992a:7) has also noted: 'Without mortality, no history, no culture - no humanity'; 'culture is what happens when human beings create order and meaning for themselves. It is an active process of 'making' the world' (Smith, 1999:20). Fromm (1994) argues that 'a feeling of communion and belonging' is what we are essentially looking for in order to overcome our doubt as to who we are and what we are doing here. And as there is no going back to the security (and constraints) of our pre-individualistic past, we need to find new ways and means.

While making do with what is available to us as individual and cultural beings, Fromm maintains that there are healthy and unhealthy ways of relating ourselves purposefully to the world. Submission and/or domination (the totalitarian solution), conformism and compulsive striving (for example in work or consumption) are the unhealthy options; they may succeed in obscuring the 'awareness' of our doubt, but provide no long term solution. This is escaping from our freedom, rather than embracing it and making it our own. The 'healthy' solution to the dilemma of human existence is, Fromm (1994:139) suggests, to relate ourselves 'spontaneously to the world in love and work', in the 'genuine expression' of our 'emotional, sensuous and intellectual capacities'. In this way we can find 'communion and belongingness' without having to sacrifice the 'independence and integrity' of our individual selves.

The medical sociologist, Antonovsky (1987), does not delve into the contradictions of the human condition and its potentially disastrous side-effects to the same extent as Fromm and Frankl, but he does consider meaningfulness to be central to a healthy life, and has made a detailed and extensive study of what it entails. He began with an interest in why some people survive with their health intact, and even flourish, despite highly stressful, even traumatic experiences, while others do not. His research in the area led him to develop a central concept which he believes encompasses what is required for people to 
deal successfully with the numerous and inevitable 'life stressors' that confront them: a sense of coherence (SOC). He sees SOC as having three components: comprehensibility (the extent to which things seem 'ordered, consistent, structured, and clear'), manageability (the extent to which one feels that one has adequate resources at one's disposal with which to deal with life's demands), and meaningfulness (the feeling of being 'a participant in the processes shaping one's destiny as well as one's daily experience') (Antonovsky, 1987:1618):

Consistent experiences provide the basis for the comprehensibility component; a good load balance, for the manageability component; and, least clear of all, participation in shaping outcome, for the meaningfulness component.

(Antonovsky, 1987:92)

Of the three components of SOC, Antonovsky (1987:18) concludes from his research that meaningfulness is central, due to the fact that those who he felt could be considered as having 'a strong SOC always spoke of areas of life that were important to them, that they very much cared about, that "made sense" to them in the emotional and not only the cognitive sense of the term'. Therefore, while:

Many life experiences can be consistent and balanced but not of our own making or choosing in any way. ... When others decide everything for us - when they set the task, formulate the rules, and manage the outcome - and we have no say in the matter, we are reduced to being objects. A world thus experienced as being indifferent to what we do comes to be seen as a world devoid of meaning. ... It is important to stress that this dimension is not control but participation in decision making.

(Antonovsky, 1987:92)

Antonovsky, therefore, approaches meaning in terms of coherent, meaningful and selfdetermined action. In the course of his investigations he came across people who he considered to have a strong sense of coherence, and yet they did not see that their whole lives were highly comprehensible, manageable and meaningful. From this he concludes that people establish boundaries around what they consider important to themselves, and outside of which a lack of coherence is unimportant. These boundaries may be broad or narrow, but they must at least include, according to Antonovsky (1987:23), 'one's inner feelings, one's immediate interpersonal relations, one's major activities, and existential issues (death, inevitable failures, shortcomings, conflict and isolation)'. Beyond these critical areas, Antonovsky (1987:24) suggests that flexibility about what one includes and excludes from one's boundaries may be 'one of the most effective ways a person with a strong SOC maintains her or his view of the world as coherent'. 
Indeed, Antonovsky is somewhat suspicious of people who maintain that they find almost everything coherent almost all of the time. This leads him to conclude that there is such a thing as a 'rigid' or 'inauthentic' sense of coherence. In attempting to find what distinguishes a strong SOC from an 'inauthentic' one, he suggests an examination of the relationship between the sense of self and the sense of identity: ${ }^{8}$

Whereas the former refers to the basic layers of the personality which provide a central purpose, a sense of abiding sameness and continuity, identity refers to the social role complex of the individual. A strong self makes possible a firm identity; but it is not basically dependent on the explicit identity in which at any one time the self is manifested. Should superior force intervene, one is likely to seek and find alternative identities. Should one find that the specific role complex has become inadequately expressive of the self, one will have the strength to give it up and locate alternative identities. In our terms, then, the person with a strong self and a firm identity will be the one with a strong SOC. ... a person with a weak self may, in frenzy, latch on to a given identity in rigid fashion, seeking to allay the terrible anxieties that prey on one precisely because the self is weak. Such a person will have a rigid SOC, whose substantive perceptions of high comprehensibility, manageability, and meaningfulness allow of no substitutions.

(Antonovsky, 1987:25-26)

Interestingly, Antonovsky (1987:26) concludes that the only way to identify a rigid as opposed to a strong SOC would be through 'serious qualitative depth research'. He also raises the possibility that whereas work life may have once been of high relevance to one's sense of coherence, in a post-industrial society with a diminishing work ethic, a new pattern may be emerging where 'One does one's work, defines it as at least giving one the wherewithal to turn to important things, and then turns to experiencing life' (Antonovsky, 1987:118). Antonovsky also emphasises that his is not a theory of personality, but a 'dispositional orientation', which he believes becomes more or less established in early adulthood. In this sense it is perhaps comparable to Simmel's contention that we consider our lives in terms of the overall tally of experiences that we have found meaningful and comprehensible, compared to those that have been for us insoluble and incalculable.

Both Fromm (1956b; 1999) and Frankl (2000:140) argue that contemporary society frustrates the human need 'to find and fulfil meaning in our lives'. Bauman (1995; 2000; 2001) has made a particular study of the sociological conditions that render meaning problematic, and the ways in which people cope with this precarious situation (Smith, 1999). He also sees the spur to meaning as originating in the knowledge of our mortality, and citing Becker, declares that society is 'a living myth of the significance of human life, a defiant creation of meaning' (Becker in Bauman, 2001:2). So it is that Bauman (2001) sees societies as 'factories of meanings' necessitated by the need to transcend the

\footnotetext{
${ }^{8}$ Antonovsky is drawing here on the theory of the psychologist Heinz Kohut (1982). 34
} 
'grotesque fate' of humankind. He also sees the anxiety and ambivalence of the current age as having been prompted by the freedoms gained through the processes of individualisation and the privatisation of our lives, such that we would often gladly accept the offer of some 'great simplification'. In the wake of modernity, Bauman (2001:70) argues, the shape that this sought-after simplification comes in is the 'neo-tribal and fundamentalist sentiments', whose appeal is 'the promise to put paid to the agony of individual choice by abolishing the choice itself; to heal the pain of individual uncertainty and hesitation by finishing off the cacophony of voices which makes one unsure of the wisdom of one's decisions'.

According to Bauman, modernity and its aftermath have been particularly inhospitable to a sense of coherence, such as Antonovsky describes. Modernity's 'overwhelming and endemic urge for creative destruction', its unrelenting desire to keep clearing the decks in order to make way for the new in the name of progress, has resulted in a sense of the 'crumbling of time', of fragmentation, of life 'lived in episodic time' rather than as a 'continuous, cumulative and directional' whole (Bauman, 2000, 2001:103, 127). Under these conditions, when events are disconnected episodes, a 'cohesive historical narrative' becomes possible only after death: 'as long as it is being lived, each episode has only itself to supply all the sense and purpose it needs or is able to muster to keep it on course and to see it through' (Bauman, 2001:127).

Bauman has looked to the Holocaust for answers to questions about 'the human condition in modernity ${ }^{9}$ (Beilharz, 2000:88), as this was the rationalisation and bureaucratisation of society taken to its terrifying, yet logical extreme. What it leaves us with is a growing if uneasy resignation to the idea that "not only is Being underpinned by Chaos and Absurdity rather than pre-ordained Order and Meaning, but it is going to stay that way for the duration, and nothing we can do will change it' (Bauman, 1995:23). 'Moderns' lived their lives as pilgrims: their trajectory towards a fixed destination was established at an early stage - both because it could be and because it had to be - and they could head off with reasonable confidence that the end-point would not shift, nor would their path deviate unexpectedly (Bauman, 1995). But the world is no longer conducive to such pilgrimages,

\footnotetext{
${ }^{9}$ Bauman also has a personal connection to the Holocaust, as his wife survived the Warsaw Ghetto. Others with an interest in meaning and the human condition have a connection to the Holocaust. Antonovsky was born in the US, served in the US army during WWII and immigrated to Israel in the 1960s. His work included, and in many ways was inspired by, the experiences of Holocaust survivors. Frankl survived Auschwitz and developed his ideas with reference to his experiences. Fromm was a German-Jew who fled Nazi Germany in the 1930s, and also discusses the psychology of Nazism extensively (Fromm, 1973, 1994).
} 
and Bauman's (1995:91) post-modern personages have 'a horror of being bound and fixed':

One can plan one's life as a journey-to-a-destination only in a world of which one can sensibly hope that its chart will remain the same or little changed throughout one's life-time - and this is blatantly not the case today. Instead, the life of men and women of our times is more like that of tourists-through-time: they cannot and would not decide in advance what places they will visit and what the sequence of stations will be; what they know for sure is just that they will keep on the move, never sure whether the place they have reached is their final destination.

(Bauman, 1995:268-269)

The challenges we face in constructing coherence and meaning in our lives also pose problems for our sense of self and identity. The nature of this interdependence, the conditions that influence it and their implications, have also concerned Bauman and other theorists, as discussed below.

\section{Problems of self and identity}

To the question of what the healthy state of a person should be, "what identity feels like when you become aware of the fact that you do undoubtedly have one', Erikson answered: it makes itself felt 'as a subjective sense of an invigorating sameness and continuity'.

(Bauman, 2001:148)

The psychologist Erik Erikson $(1959 ; 1965)$ undertook one of the most extensive analyses of identity in the twentieth century. ${ }^{10}$ He noted that 'we begin to conceptualize matters of identity at the very time in history when they become a problem' (Erikson, 1965:274). In his psychoanalytic practice he observed that 'the patient of today suffers most under the problem of what he should believe in and who he should - or, indeed, might be or become' (Erikson, 1965:271).

The processes of individualisation which have accompanied modernity have transformed human identity 'from a 'given' into a 'task' (Bauman, 2001:144). According to Taylor (1989), the 'search for self in order to come to terms with oneself ... has become one of the fundamental themes of our modern culture'. Taylor (1989) also contends that the question of identity is one of knowing not only who you are, but also where you stand, and thus that our contemporary crises of identity are underpinned by a deeper instability in the sources of our moral values. To know who you are requires an understanding of what is of primary importance to you, and what is secondary or trivial; that is, a kind of orientation in moral

\footnotetext{
${ }^{10}$ While Erikson's work has been subject to inevitable reviews and critiques, the central tenets of his theory of identity are still held by many to have enduring validity. See, for example, Lightfoot (1997) and Slugoski and Ginsburg (1989).

36
} 
space which provides a framework within which decisions can be made with regard to what is good or bad, worthwhile or irrelevant. Constructing a workable framework has become much more of a personal quest, thanks to 'our post-Romantic understanding of individual differences as well as to the importance we give to expression in each person's discovery of his or her moral horizon' (Taylor, 1989:28).

It is also a quest that we are fated to embark on, as not having a framework is not a viable option, as much as not having a coherent identity is unworkable. I am a self, according to Taylor, only to the extent that certain goods matter to me. Having ascertained what such goods may be, I must move towards them; to do otherwise would be 'devastating and insufferable'. Alternatively, 'the assurance that I am turned towards this good gives me a sense of wholeness, of fulness of being a person or self, that nothing else can' (Taylor, 1989:63). As Levi (2002:171) concluded from his experiences in Auschwitz, in order to retain one's humanity in troubled times, one needs 'a very solid moral framework'.

Although Giddens (1991) contests the view that life in late or high modernity is inherently any more anxious or insecure than in any other period of history, he nonetheless considers that the nature of our troubles today is fundamentally different from what has come before. It is the reflexivity of modernity - infused as it is with the radical doubt characteristic of the scientific method - including 'the reflexive project of the self', which renders a coherent narrative of self-identity if not impossible then 'inherently fragile' (Giddens, 1991:185).

As mentioned above, while the construction of identity in the early modern era had the nature of a 'life project' characterised by a sense of continuity and evolution over historical time, Bauman (2001) sees the post-modern experience as one of fragmented time, life as discontinuous episodes; in response to this, identity has become flexible and contingent. This tendency has also been noted by Gergen (1991:80), its impact being that 'the relatively coherent and unified sense of self inherent in a traditional culture gives way to manifold and competing potentials'. As Taylor (1989) argues, modern moral culture is one of 'multiple sources' and therein lies the problem - which one to choose? Similarly, Bauman (2001:43) locates the anxiety of contemporary men and women in the lack 'of firmly fixed and steady orientation points, of a predictable destination for the life itinerary'. As a result, he argues, the prevailing mental conditions of our times are impotence and inadequacy. The freedom granted us by the loosening of external moral strictures is experienced as a mixed blessing: it allows us to go off in search of our 
distinctive selves, but denies us the means by which to evaluate the adequacy of what we find. As Bauman (1988:62) puts it: 'Self-construction of the self is, so to speak, a necessity. Self-confirmation of the self is an impossibility'.

The solution proffered by modern capitalist society to the enigma of self-construction, Bauman suggests, is an endless array of consumer goods capable of functioning as 'symbols of identity', conferring on their owners an identifiable image with which their self can be associated. The seeming abundance, range of choice and ease of adoption of such off-the-shelf identities is countered by their lack of permanence - with a foundation often no more solid than the whims of fashion, identities become 'successively worn masks' - 'continuously negotiated, adjusted, constructed without interruption and with no prospect of finality' (Bauman, 1988:41, 2001:87). Identities are taken on only tentatively so that they can be switched with ease when they outlive their usefulness. The implications of such processes for our leisure lives are described by Rojek (1993:212216):

We shrink from deep commitments and cast our energies in leisure out toward reassuring, consumerist experience which requires passive involvement or transitory relationships which avoid putting ourselves on the line. ... Dedicated leisure activity is quite rare, which is why the compulsive hill-walker, the serious amateur musician, or even the serious reader of fiction, stand out so starkly. ... The ephemeral, the fugitive and the contingent describe our experience of leisure just as they are at the heart of the phenomenology of Modernity.

Against such undercurrents of anxiety and 'liquidity', the struggle to construct meaning and self goes on. While many battles may be lost, the war is by no means over. As the preceding discussion suggests, we either construct self and meaning in some form or other, or we suffer some unpleasant consequences. A primary tool at our disposal is narrative.

\section{The narrative construction of meaning and self}

Articulation of life stories is the activity through which meaning and purpose are inserted into life.

(Bauman, 2001:13)

Narrative plays a prominent role in the construction of meaning and the process of selfmaking (Bruner, 1990, 1996; Funkenstein, 1993; Holstein \& Gubrium, 2000). Stories are about 'what things mean' to us (Bruner, 1990:51). We understand our lives, according to Taylor (1989:47), as an unfolding story: in order to have an understanding of who we are we have to have a sense of 'how we have become, and of where we are going', and a coherent narrative provides such an understanding. Bruner (1990:20), a psychologist who 
rejects biological determinism as an explanation for human behaviour, arguing instead that 'culture and the quest for meaning within culture are the proper causes of human action', explores the relationship between narrative and the way in which we 'achieve' self or identity:

We achieve our personal identities and self-concept through the use of narrative configuration, and make our existence into a whole by understanding it as an expression of a single unfolding and developing story ... Self, then, is not a static thing or a substance, but a configuring of personal events into an historical unity which includes not only what one has been but also anticipations of what one will be.

(Polkinghorne in Bruner, 1990:116)

The work of the neuroscientist Damasio on the role of memory and narrative in the making of the self resonates with the analyses of Taylor and Bruner. In his enquiry into the biological underpinnings of consciousness, Damasio (1999:11) explores the mental patterns which give us 'the sense of self in the act of knowing'. Damasio argues that there are two kinds of consciousness: the core consciousness through which we have a sense of self in the here and now - a transient core self; and an extended consciousness which allows us a complex awareness of ourselves - an autobiographical self - with a lived past and an anticipated future based on a stash of 'systematized memories of situations in which the core consciousness was involved' (Damasio, 1999:17). This 'organised record of the main aspects of an organism's biography' Damasio (1999:18) terms the autobiographical memory. This storehouse grows throughout our lives as more experiences are added to it, and to some extent it can be reshaped in the light of new experiences.

There still appears to be much that is not known about the complex process by which experience is stored in, and retrieved from, the autobiographical memory; certainly it is not always something over which we have conscious control. ${ }^{11}$ Not all memories are treated equally. Some are available for immediate and consistent retrieval, while others lie out of reach, for long periods, or forever. In the reconstruction process involved in retrieval:

some autobiographical events may not be fully reconstructed, may be reconstructed in ways that differ from the original, or may never again see the light of consciousness. Instead, they may promote the retrieval of other memories which do become conscious ... [and] may appear unmotivated, although a web of connections does exist sub rosa, reflecting either the reality of some moment lived in the past or the remodeling of such a moment by gradual and unconscious organisation of covert memory stores.

(Damasio, 1999:227)

\footnotetext{
${ }^{11}$ See for example the discussion by Reid (2005:685), who states that our brain hemispheres are not only 'capable of making selective contributions to experience, they are adept at hiding that they do this'. A life event, he claims, may be recognised in our brains as being significant, without our conscious awareness, such that this significance becomes apparent to us only in the process of recollection.
} 
Levi (1987:15), speaking of coming to terms with his experiences as a Holocaust survivor, noted that the need to tell one's story to others can have the 'character of an immediate and violent impulse'. ${ }^{12}$ He was also acutely aware, however, of 'the problematic rapport between narration and reality’ (Belpoliti, 2001:xxiii). For Bruner (2002:22) it is an 'ontological dilemma': this problem of the extent to which we may have unintentionally 'imagined' the stories we tell. Moreover, any criteria by which one might judge the 'rightness' of a life narrative are decidedly 'slippery' (Bruner, 2004). But then again, there is not necessarily a wholly 'correct' version of the story of self, and largely because we are not following any script; we are improvising, making do, trying to keep all the balls in the air at the same time. And this requires that we be bricoleurs (Lévi-Strauss's term), as Bruner (2002) points out, taking what we can from what has happened to us, and to those around us, plundering our cultural stock of stories and cobbling together something that will do, in the meantime.

Memory, therefore, is vital, even if in some sense 'unreliable'. Impaired memory of the past can result in dysnarrativia, a neurological disorder which causes a 'severe impairment in the ability to tell or understand stories', and which is 'highly disruptive of one's sense of self' (Bruner, 2002:86). In one of its manifestations, Korsakov's syndrome, both memory and affect are so severely impaired that 'selfhood virtually vanishes'. And so, while our life stories are undoubtedly selective re-tellings - they do not contain everything that happens to us - it seems safe to assume that they do contain those things which are most important to our sense of who we are, and that they may also gloss over the things that are not. It can also be said with some confidence that the end result - the autobiographical self - is the product not only of a narrative fashioned from our life experiences, but also our innate and acquired personality traits, intelligence, knowledge, and our social and cultural environment.

MacIntyre (1981:202-203) is another theorist who examines the 'narrative unity' of individual lives. He describes the nature of the narrative concept of self-hood as being 'two-fold': 'I am the subject of a history that is my own and no one else's, that has its own peculiar meaning' and 'I am not only accountable, I am one who can always ask others for an account, who can put others to question. I am part of their story, as they are part of mine. The narrative of any one life is part of an interlocking set of narratives'.

\footnotetext{
${ }^{12}$ Bruner (1999:7) argues that the 'Willingness or eagerness to "story" one's life is tantamount to the desire to live'. 
Ricoeur (1992) too notes the way in which our life histories are 'entangled' in the histories of others; they are never entirely our own. The essence of narrative identity, according to Ricoeur (1992), is the 'dialectic of selfhood and sameness'. Narrative, or 'the specific model of the interconnection of events constituted by emplotment', allows us to give our identity a sense of permanence in time despite 'diversity, variability, discontinuity, and instability' (Ricoeur, 1992:140). Bruner explicates another principal function of narratives. In the course of interacting with each other we form 'a sense of the canonical and ordinary'. Narrative is a way of interpreting and giving meaning 'to breaches in and deviations from "normal" states of the human condition', and rendering them manageable and benign (Bruner, 1990:67). In this sense, Bruner $(2002: 15,28)$ argues, 'narrative in all its forms is a dialectic between what was expected and what came to pass', and a way of reconciling ourselves with 'the uncertain outcomes of our plans and anticipations'.

While narratives are a means by which 'the self seeks its identity on the scale of an entire life' (Ricoeur, 1992:115), it is also important to make the distinction between different forms of narrative which co-exist in an overarching personal history. These may correspond to different life events and differing ways of looking at our lives. They are woven together in complex ways, and not always as smoothly as we would wish. Denzin (2001a:61) talks of three forms of narrative which combine to give us the story of a life in its broadest sense. These are discussed in the next chapter.

\section{Summary}

If theorists such as Bauman and Rojek are correct, then committed mountaineers are something of an anomaly and certain questions immediately present themselves: how do their identities and, by association, their commitment to a leisure activity, maintain an intensity and durability that elude others? Have they found for themselves some 'fixed points of orientation' from which they can navigate towards a 'predictable destination'? Theories about the centrality and the nature of the search for meaning in life provide clues as to where to look, particularly when these are read alongside literature that points to the importance of narrative in these processes. Bruner's (1990:118) insight is especially relevant to the framing of my study:

there are no causes to be grasped with certainty where the act of creating meaning is concerned, only acts, expressions, and contexts to be interpreted.... These contexts are always contexts of practice: it is always necessary to ask what people are doing or trying to do in what context. We also need to ask "When is "Self" invoked, in what form, and to what end? 
So, as I have argued, in the interests of elucidating a practice such as mountaineering, the search for causes and motivations can take, and has taken, us only so far. Releasing ourselves from this concern also allows us to take off our risk-oriented lenses, and thereby to see things which have been missed before or only hinted at; in particular, the processes by which mountaineering is a means to construct meaning and shore up a sense of self or identity. An enquiry of this nature may not lead to the pronouncement of a correlation of mountaineering with this or that variable. What it may point to, though, is the positioning of the 'art' of climbing mountains within the context of human endeavours which aim at the resolution of the existential dilemmas of our existence: the striving for freedom and relatedness; our wish to know our 'Selves'; and our need go on trying to fit all the pieces together into an integrated whole. Thus, the questions that underpin this research are:

- What kinds of meaning do committed New Zealand mountaineers attribute to climbing mountains?

- How do these mountaineers integrate their experiences of the practice of climbing mountains into a 'narrative of self' and a sense of purpose in their lives?

- What are the processes (individual, social or cultural) which influence and sustain (or constrain) this?

My research takes an interpretive hermeneutic approach centred on biographical narratives: the collection and interpretation of stories told by mountaineers themselves about their lives. The rationale for choosing this method has been explored to some degree in this chapter but is more fully explained in Chapter 2 , in which I also discuss the practicalities of how I conducted the study, prepared and interpreted the narratives, and addressed important issues that arose during the research process. In Chapters 3 to 5, I present and interpret the findings from my study. Chapter 6, my concluding chapter, draws the threads of the three preceding chapters together in order to consider their combined strength in meeting the aims of this study, as well as their significance for, and contribution to, the wider study of contemporary social life. 


\section{Chapter 2}

\section{The research process: approach, methods and interpretation}

\section{Introduction}

Chapter 1 outlined the background to the study, presenting my aims and the reasons for framing them around the narrative construction of self and meaning. I noted that a biographical narrative approach was the most appropriate methodology for an enquiry of this nature, and that no documented studies of mountaineering had adopted this approach. Past methodological approaches to the study of mountaineering have included the use of questionnaires (Bratton et al., 1979; Ewert, 1993, 1994) including various personality tests (Lester, 1987; Monasterio, 2005; Rossi \& Cereatti, 1993), standard qualitative interviewing (Kiewa, 2001, 2002; Macaloon \& Csikszentmihalyi, 1983; Pereira, 2005), and a variety of other methods drawing on ethnographic and cultural studies. While a number of studies have analysed mountaineering narratives in the form of published biographies and autobiographies (Lester, 2004; Loewenstein, 1999; McCarthy, 2002; Slemon, 1998), written accounts of life stories differ in nature from oral accounts, having been produced for different purposes and under different conditions (Linde, 1993). Beginning in the 1980s, however, narrative approaches to research have gained an increasingly enthusiastic following (Elliott, 2005). Narrative studies have begun to appear in the related fields of tourism (for example Elsrud, 2001; Noy, 2004), and sport sociology (for example Denison, 1996; Denison \& Rinehart, 2000).

In Chapter 1, I referred to the hermeneutic approach which has informed this enquiry. Strict adherence to the principles of hermeneutics may lead one to eschew the use of a conventional social science 'method', holding such methods and their meticulous documentation and vigorous defence to be ontologically and epistemologically flawed (Blackshaw, 2003; Rabinow \& Sullivan, 1987). I have nonetheless trod a more conventional path in conducting and writing up this study. In this chapter I outline my research process, beginning with an overview of the biographical narrative approach and a discussion of its appropriateness for this research. Following this I describe the research population and the specific methods used to gather my empirical material. ${ }^{13}$ In the final section I 'tell the story' of the process of interpreting this material, so as to set the scene for the chapters that follow. This involves an introduction to the 'protagonists' of this study

\footnotetext{
${ }^{13}$ Following Jennings (2005), and in accordance with the interpretive research paradigm in which this study is situated, I refer to empirical materials instead of data, and use the term interpretation, rather than analysis.
} 
(which include myself as researcher) and a discussion of the interactions that led to the production of the empirical material presented in this thesis, and impacted upon its interpretation. To close this chapter I reiterate the advantages of my chosen methodology, and summarise a number of limitations and problematic issues which should be borne in mind as the reader proceeds to my discussion of findings.

\section{The biographical narrative approach}

Narrative research is underpinned by the claim that we are, by nature, meaning-making beings, seeking coherence amidst chaos and multiplicity (Cary, 1999), through the means of narrative (Bateson, 1990; Ceglowski, 1997; Roberts, 2002; Widdershoven, 1993). In addition, this meaning-making process is intimately connected to, even necessitated by, the ways in which we interpret and 'make' our selves, and our identities (Denzin, 2001a; Ellis \& Bochner, 2000; Rosenwald \& Ochberg, 1992; Schwandt, 1999; Tierney, 2000). Indeed, these are not discrete processes - they happen as we speak, as we narrate: 'there is no silent act of comprehension followed by a public recitation' (Schwandt, 1999); 'Life both anticipates telling and draws meaning from it' (Ellis \& Bochner, 2000:746). Denzin (2001a:60) goes so far as to suggest that 'we do things because of the characters we become in our tales of self'. Similarly Ellis and Bochner (2000:746) maintain that:

In the final analysis, the self is indistinguishable from the life story it constructs for itself out of what is inherited, what is experienced, and what is desired. ... thus personal narrative is part of the human, existential struggle to move life forward.

It should also be noted that our stories are not frozen in time. They are revised and recreated in a multitude of ways, each time we retell them. Hence, the narrative approach treats interview material, not in the 'realist' tradition, as directly 'mirroring' a fixed, external reality, but as collections of stories and narratives that give access to the descriptions and explanations with which people make sense of their lives (Denzin, 2001b). Within these stories, we can also find traces of the cultural (and subcultural) meanings with which people construct them (Linde, 1993; Silverman, 2000), and the social worlds within which such a project may take place (Miller \& Glassner, 1997). Elsrud (2001) contends that cultural narratives are articulated in the magazines, books and other media that surround us, and that these pre-existing narrative structures become the resources with which narrators construct coherent accounts of their lives, in turn through diaries, articles, books and verbal accounts. It may also be the case that collective narratives of social groups can come to challenge more mainstream cultural stories (Miller \& Glassner, 1997). 
The primary advantage of collecting biographical narratives in order to achieve the aims of my research rests upon the claim by narratologists that people reveal details about assumptions, purposes and feelings in narratives that they will not reveal if asked directly particularly if these are controversial or exist at an unconscious level (Wengraf, 2001).

When asked directly, people have the opportunity to give consciously-constructed answers - in the manner of justifications or defences - or desired 'presentations of self' as described by Goffman (1959):

precisely by what it assumes and therefore does not focus upon, narrative conveys tacit and unconscious assumptions and norms of the individual or of a cultural group. At least in some respects, they are less subject to the individual's conscious control.

(Wengraf, 2001:115)

Such stories allow the researcher 'to consider both the conscious and the unconscious contexts and conditions of action as well as the observed and the less observed consequences of action' (Wengraf, 2001:118). The biographical narrative method of interviewing also assumes that any life history will contain a 'gestalt', or theme, which underpins the way in which the narrator reconstructs past events (Rosenthal, 1993). This theme may not necessarily be consciously accessible to the individual, but can be revealed if the story is told in full, according to the design of the teller, rather than being distorted by the concerns of the interviewer (Hollway \& Jefferson, 1997). The richness of the data that can be achieved by this means, along with the potential to also attend to and learn from contradictions and consistencies which may be contained within a story, are highly valued by the biographical interviewer (Hollway \& Jefferson, 1997).

This approach deviates significantly from a positivist interest in, and seeking out of, motivations as a means of explaining behaviour (Denzin, 2001a). The neatly conceived logic of causation that lies behind motivational research is deceptive in its simplicity, and is challenged by biographical researchers for the reason that, if we ask people about their motivations, it is not always easy to know what we are getting. As Mills (1940) observes, the notion of motives does not arise until they are questioned, either by an individual, when their actions are frustrated, or by a curious other (or earnest interviewer). Then, once the process of questioning motives is underway, the 'differing reasons men give for their actions are not themselves without reasons. ... Motives are words. ... They stand for anticipated situational consequences of questioned conduct' (Mills, 1940:904-905). 
Jarvinen (2000) argues that motives are most often constituted in retrospect, and serve the purpose of giving meaning to events. As such they are influenced by the consequences of any said event, as well as the different types of motives that are 'culturally available' to explain particular types of experiences and events. In addition, they are tailored to contribute to the 'biographical illusion' - a concept Jarvinen (2000) borrows from Bourdieu, describing our sense that our lives are coherent, progressive processes, consisting of linked sequences of events and experiences. From this perspective it is difficult to assert that 'real' motives exist, much less that they have anything to do with the ‘causes' of human behaviour (Jarvinen, 2000).

Arguably, however, stories are the closest we can come to what is referred to as human experience (Denzin, 2001a). Experience is 'the stories people live' (Clandinin \& Connelly, 1998:155). In addition to lived experience, what biographical narrative interviews can provide is an insight into the cultural repertoires of motivation - 'culture speaks itself through each individual's story' (Jarvinen, 2000) - and the dynamics of the process by which they are utilised in an individual's search for self and meaning. Also, they may give us glimpses of cultures in motion (Gergen \& Gergen, 1993, 2000), and of the ways in which people contribute to the cultural narratives that in turn shape them.

The three key features of narrative, according to Elliott (2005), are their chronological, meaningful and social nature. While detailed structural analyses of narratives are undertaken by socio-linguists, in its simplest form a narrative contains 'complicating action, i.e. a temporal component', and an evaluation, which assesses the 'point or the meaning of the story' (Elliott, 2005:9). Denzin (2001a:61) makes the distinction between three forms of narrative within interpretive biographical studies: self-stories, personal experience stories and personal histories. Personal experience stories are exclusively concerned with past experiences, while self-stories range across the past, present and future as the tellers communicate the 'ongoing problematic occurrences' in their lives. A personal history reconstructs a whole life and consists of multiple narratives set within a broader narrative structure. Self-stories and personal experience stories are often only fully understood within the context of a more complete personal history.

Because of the interrelationship between these three forms, Denzin (2001a:62) argues that interpretive biographical studies should include:

- individual personal experience narratives connected to the life story of the teller; 
- a collection of self-stories and personal experience narratives grouped around a common theme; and

- a criss-cross analysis of collected materials which focuses more fully on the process being studied than on the people whose lives are influenced by these processes.

Collecting biographical material from a number of individuals in this way allows for a form of triangulation, or multi-method design, that ensures that 'history, structure, and the individuals studied receive fair and thorough consideration' (Denzin, 2001a:62).

Having given a broad outline of the biographical narrative approach, I now discuss its application in this study. The primary research method for this study was biographical narrative interviewing. The interviews were designed to facilitate the collection of a personal history of the interviewees' involvement in mountaineering, as well as to elicit their views about the significance of this activity in their lives. In addition to the interviews, which produced multiple forms of stories and narratives for interpretation, various supporting empirical sources were used in order to contextualise the interview material. These include additional personal records; supporting literature such as mountaineering books, films and videos, and New Zealand Alpine Club publications; key informants; and autobiographical experience or 'prior ethnography' (Lincoln \& Guba, 1985). In the following section I discuss the research population, before describing in more detail the various methods used to gather my empirical material.

\section{Research population}

The research population for my study was New Zealand-based mountaineers whose commitment to mountaineering warranted it being considered a 'central life interest' (Dubin, 1979). As discussed in Chapter 1, mountaineers were differentiated from other kinds of climbers (for example sport climbers and boulderers), as those who climb predominantly in an alpine setting. The other characteristic of my research population was that they primarily climbed in non-commercial settings. By this I mean that they do not make a living from their climbing, nor do they climb, for the most part, as the clients of professional guides. ${ }^{14}$

\footnotetext{
${ }^{14}$ Some flexibility in the application of these criteria was necessary. One of my interviewees had worked as a guide in the past, but had stopped due to his decision that he preferred to have mountaineering as a leisure activity rather than a profession. Some received sponsorship in various forms, mostly through donated equipment for expeditions. While a number of international climbers are able to support themselves with sponsorship, this is not possible in a small country such as New Zealand where sponsorship sources are limited. In addition, some of my interviewees had, on occasion, been on expeditions where they were accompanied by professional guides. However, I knew from my own involvement in mountaineering that a
} 
There is no way of knowing precisely the number of people fitting these criteria, but two sources exist which can provide certain indications. Firstly, there are the membership data of the New Zealand Alpine Club (NZAC). This body is the only national club for climbers/mountaineers in New Zealand. There are a number of regional mountaineering clubs, and a large number of tramping clubs which include mountaineers among their membership, but as members of these smaller clubs may also belong to the NZAC, the membership data of the national group are the best available indicator of the numbers of mountaineers in New Zealand. It must be taken into consideration, however, that some mountaineers are not members of this club, that an unknown number of club members are not active climbers, and that club membership includes professional mountain guides. In 2006 the NZAC membership stood at 2906, of which 631 (or roughly one fifth) were women. ${ }^{15}$ New Zealand's population is currently 4.1 million, so NZAC membership represents a very small percentage of the population.

Another source of statistical information about climbers in New Zealand is a study carried out by the market research company NFO/CM Research ${ }^{16}$ in 2001 (Diamond, 2001). The data collected in this random, nation-wide telephone survey with 14,400 respondents suggested that half a percent of the New Zealand population considered themselves 'regular' climbers. While this is a higher figure than NZAC membership, it also includes those who are regular sport climbers and boulderers, ${ }^{17}$ and thus represents a broader population than the focus of my research. The study concluded that $79 \%$ of regular climbers were less than 34 years old, 54\% were single, $81 \%$ were male (indicating a similar gender ratio to NZAC membership), and that climbers were ethnically representative of the New Zealand population.

My study involved the collection of detailed qualitative materials and this necessitated the involvement of a relatively small number of participants. Due to this limitation, I was not aiming to gain a statistically representative sample of my research population. However, the available data on climbers in New Zealand provide an interesting 'benchmark' against which to consider the characteristics of my interviewees.

strong distinction is made between those who consistently climb with guides and those who do not. I also did not feel that my sample would be large enough to include both groups and attempt a meaningful comparison. For these reasons, climbers who use guides were excluded from the current study.

${ }^{15}$ See Appendix A for a graph showing NZAC membership numbers since 1938. The NZAC was established in 1891, with a period of inactivity between 1900 and 1931. Consistent annual membership figures have been available since 1938 .

${ }^{16}$ Now renamed TNS.

${ }^{17}$ Personal communication: Carol Diamond, Project Manager, NFO/CM Research, 8 November 2002. 48 


\section{The interviews}

In this section I discuss the interviews, including the sampling methods, the sample size, the characteristics of the interviewees, the structure of the interviews and, finally, other possible methods for collecting narratives.

\section{$\underline{\text { Selection of interviewees }}$}

The principles of purposive and theoretical sampling ${ }^{18}$ were followed in the process of selecting interviewees fitting the criteria of my research population. Mountaineers were sought across a range of ages, gender, length of climbing career and family/relationship situations. Also sought were interviewees from backgrounds that reflected New Zealand's multi-cultural and migrant populations. Technical ability was not a criterion in my selection, but targeting people with a high level of commitment resulted in a sample of mountaineers who tended to climb (or have climbed) at a high level of difficulty.

Potential participants were identified via the 'snowball technique', beginning with contacts already known to me through my personal involvement in the New Zealand climbing community. Once I began interviewing, further potential contacts were given to me by interviewees. As illustrated above, the population of mountaineers in New Zealand is small, and the number who could be considered committed mountaineers is even smaller. Consequently this small group, though geographically dispersed and mobile, is generally tight-knit and its members well-known to each other.

The area of New Zealand that has the highest concentration of committed mountaineers is, for obvious reasons, in and around the Southern Alps in the South Island. In order to undertake the interviews I decided to base myself initially for six weeks in the small town of Wanaka, near the Southern Alps. This area is a popular region for mountaineers to live in due to its alpine setting, its close proximity to the mountains, and its local tourism industry (including ski resorts) which provides seasonal work. During these six weeks I stayed with a friend and climbing partner of mine, and her husband, who is a professional mountain guide. Over this period a number of climbing friends and acquaintances passed through to visit my friends, as they came and went on mountaineering trips. This gave me

\footnotetext{
18 'Sampling on the basis of emerging concepts, with the aim being to explore the dimensional range or varied conditions along which the properties of concepts vary' (Strauss \& Corbin, 1998:73). See also Denzin (1970).
} 


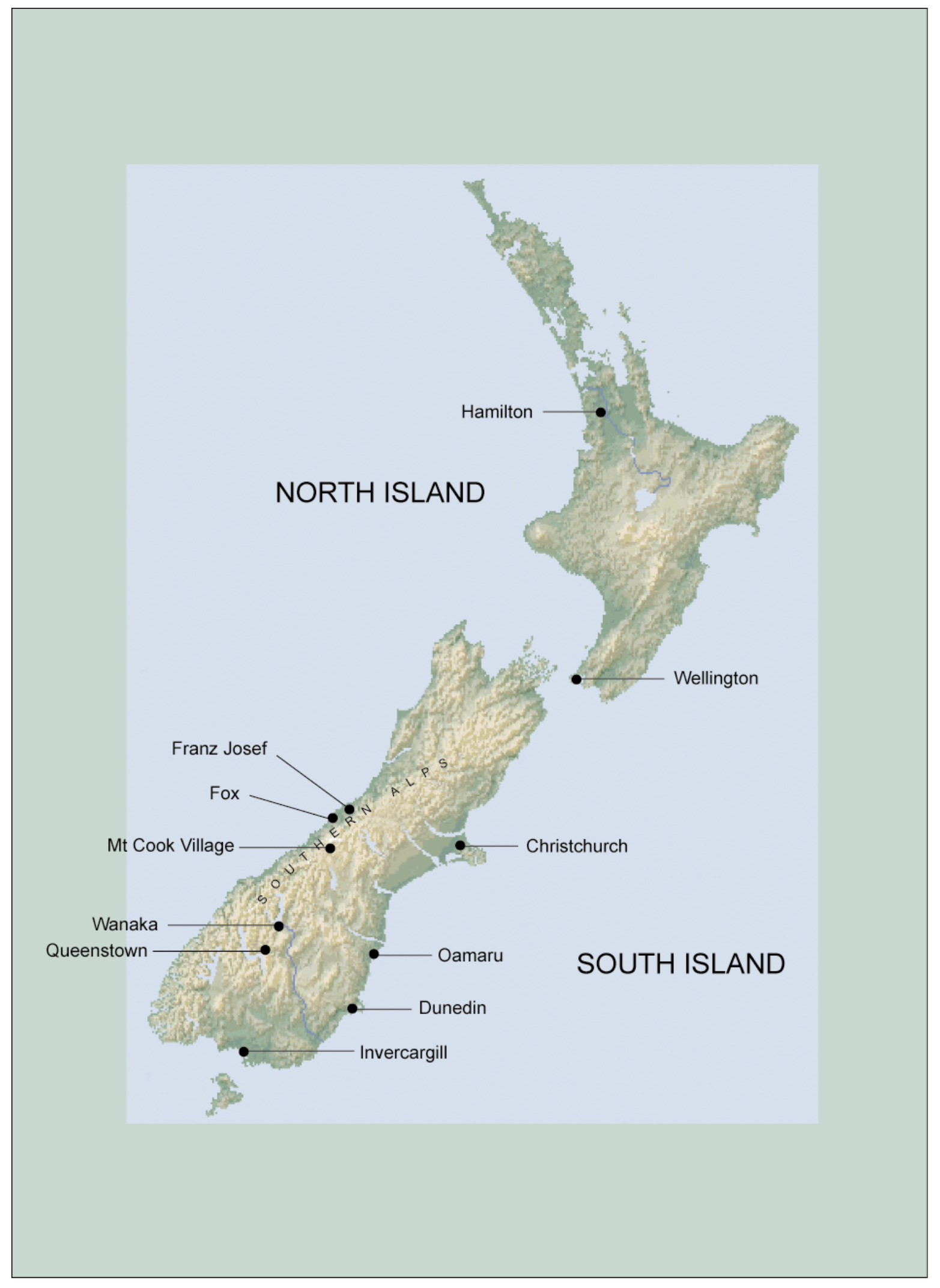

Figure 1: Map of New Zealand showing research locations 
access to potential interviewees who would otherwise have been difficult to contact, given their high mobility. Aside from the opportunity to interview a number of them, during this time I was able to have many informal conversations with mountaineers.

While based in Wanaka, and as I made my way north again to Wellington where I live, I travelled to other areas around the South Island to interview mountaineers. This ensured that the range of people I interviewed extended beyond the community based in and around Wanaka (see Figure 1, page 50). Some of the interviewees were people I had previously met, either on climbing trips or in social situations, and others I knew 'by reputation'. This would have been difficult to avoid entirely because of the size of the climbing community in New Zealand. However, I deliberately did not interview anyone who was a close friend of mine or a climbing partner. This meant that I could hear my interviewees' life stories without, in a sense, having been a participant in these stories myself. As Linde (1993) points out, if we know a person well, we may feel we have both the opportunity and the right to have our own account of their lives. I felt that this would be problematic, particularly in terms of my interpretation of their narratives. I also surmised that people I knew well might not tell such a full and complete narrative, as they would assume my prior knowledge.

Potential interviewees were approached in person, by phone or by email, whichever was the most convenient. Most were either very enthusiastic about being involved or readily agreed to participate, prompted by a desire to assist with my study. Two of those I interviewed required some initial encouragement that their stories were interesting and relevant to my study. At least four people who agreed to participate were not eventually interviewed because, for various reasons, it proved too difficult to find a suitable time and/or place. Three people I approached did not respond to either a phone or email message and another two responded with some reluctance. Only one person directly refused to participate when approached. None of these six people was pursued. For ethical reasons I did not want to apply any undue pressure to gain agreement to participate. As most people were happy to be interviewed, there was no need to pressure anyone in order to gain a sufficient number of participants for the purposes of this study.

Nevertheless, this means that my sample is limited to those who were 'willing' to tell their stories. As becomes evident from the findings, those I interviewed, on the whole, had happy and positive experiences of climbing. Some had experienced traumatic events, but managed to make sense of negative experiences in a way which allowed them to continue 
feeling positive about mountaineering. Because of my awareness of this limitation in the sample, I attempted to find potential interviewees who had been committed mountaineers but had stopped climbing. I was interested in interviewing a mountaineer who I had heard had stopped climbing due to the deaths of friends. Although I approached him as sensitively as possible through mutual friends, he was unwilling to be interviewed. Another mountaineer who had given up was very reluctant to be interviewed and I did not pressure him. Finally, I approached someone who had been seriously and permanently injured in a mountaineering accident. In this case also, I approached him tentatively through a mutual friend, and he agreed to an interview.

Thus, it is important to bear in mind that this study is 'weighted' towards the 'success' stories of on-going commitment to mountaineering. A number of times throughout my discussion I refer to aspects of this commitment that are problematic, particularly in Chapter 5 where I discuss the themes of safety, danger and death in the narratives. I also come back to this 'darker side' and consider its relevance and how it might be examined, when making my concluding comments in Chapter 6.

\section{Sample size}

In total, I interviewed twenty-two mountaineers. Nineteen were interviewed during the initial six week period in the South Island during January and February of 2003. Following these interviews, I began the process of preparing the transcripts for interpretation and making an initial assessment of the range of the narratives I had collected. As a result, I decided to interview three more people, in order to make the sample more inclusive. For this reason, in late 2003 I interviewed a mountaineer injured in a climbing accident, and returned to the South Island to interview a woman mountaineer in the late stage of her career. In 2004 I returned once more to the South Island to interview a participant selected because I knew he had been active among a prominent group during the 1970s. Having completed these interviews I felt that, for the purposes of this study, I had reached theoretical saturation (Strauss \& Corbin, 1998). ${ }^{19}$ The detail provided in the twenty-two narratives collected, and the time consuming process of narrative interpretation, meant that further participants could not have been included in the study in a meaningful way. Rather than collect more interviews, I decided to focus on the thorough

\footnotetext{
${ }^{19}$ As described by Rubin and Rubin (1995:47), theoretical saturation is the point at which 'each additional interview adds no more ideas or issues to the themes on which you are now questioning'. The accuracy of this sampling method is evaluated in relation to the quality of the theory produced, rather than the rules of sampling theory applicable to quantitative research (Wengraf, 2001:99).
} 
interpretation and contextualisation of those collected, using the methods described in later sections of this chapter.

\section{Characteristics of the interviewees}

Individual profiles of each of the twenty-two interviewees will be given in the final section of this chapter. In this section I give a brief overview of the characteristics of my sample. Fourteen were male and eight were female. While the proportion of females interviewed exceeds the proportion of females in the general mountaineering population, I interviewed eight in order to ensure that a range of female perspectives was included in the sample in relation to age, length of climbing career and family/relationship situations.

With regard to the related characteristics of age and length of climbing career, I decided to approach the selection of interviewees in terms of three broad age/career stage categories. $^{20}$ As most of the interviewees began climbing in their late teens or early twenties, I considered those aged 20 to 35 to be in the early stages of their careers as mountaineers. Six of the interviewees were in this age bracket, with the youngest being in her early twenties and the least experienced having climbed for approximately 4-5 years. Ten of the interviewees were in the mid-career bracket, between 35 and 50 years of age. A further six were over 50 (with the oldest being in his early seventies) and I considered these to be in their late career. This range allowed a reasonable representation at each level, while also reflecting a focus on those who have successfully sustained their commitment to mountaineering over the course of various life stages.

By including those in the late stages of their mountaineering careers, several of those I interviewed were now far less active than they once had been. Three interviewees in particular had replaced all but some relatively undemanding mountain climbing with activities such as trekking, rafting, cycle touring and flying in the mountains. However, all still considered themselves mountaineers in the sense that will become apparent in later chapters.

Thirteen of the interviewees were in long-term committed relationships (either married or de facto), and nine were single. Five of the six in the youngest age bracket were single.

\footnotetext{
${ }^{20}$ These are only very broad and somewhat arbitrary categories that I have used to give a general sense of the age/career range of the mountaineers. However, there is some overlap as one of the interviewees began climbing at a very young age, and another somewhat later than the majority, which means that they have more/less experience (respectively) than others around their own age.
} 
Exactly half of the interviewees had children. Of the eleven without children, six were under 35 years of age.

The employment situations of the interviewees were quite diverse, but the majority fell into two broad groups: those with professional careers or skilled work, which require a relatively high degree of commitment in terms of time, and possibly 'occupational devotion' (Stebbins, 2005); and those with 'throwaway jobs' (Stebbins, 2005:130), which give a much greater degree of flexibility as they are 'relatively easily acquired and abandoned', including seasonal and casual work. Eight of the interviewees were in Stebbins' first category. Six supported themselves predominantly through a variety of seasonal forms of employment, and fitted Stebbins' second category. The remainder fell somewhere between these two ends of the spectrum. Four were involved in skilled work, but were essentially self-employed, which allowed them a high degree of flexibility. A further two had previously been engaged in professional careers, and had 'downshifted' (Breakspear \& Hamilton, 2004) to part-time and/or less skilled work in order to suit their mountaineering lifestyles. This work nevertheless still provided a degree of satisfaction and was on-going in nature. One was retired and another a part-time student and sickness beneficiary.

Five of my interviewees were immigrants, from Switzerland, England, Ireland, Australia and South-east Asia. For four of these five, mountaineering opportunities were at least part of the attraction of coming to New Zealand. While the nation-wide survey discussed above indicated that the climbing population was ethnically representative, there are very few mountaineers from New Zealand's indigenous Maori population. ${ }^{21}$ Unfortunately, I was not able to interview any Maori mountaineers, and this is a limitation of my study.

\section{Structure of the interviews}

While interviewing techniques vary widely from highly structured to more open-ended formats, in a typical interview, Bruner (1990:115) explains:

we expect respondents to answer our questions in the categorical form required in formal exchanges ... we typically interrupt our respondents when they break into stories: they do not fit our conventional categories. So the human Selves that emerge from our interviews become artificialized by our interviewing techniques. ${ }^{22}$

\footnotetext{
${ }^{21}$ Two per cent of NZAC members whose ethnicity is recorded are Māori (Personal communication, Carol Diamond, NZAC National membership and Promotions Convenor, 7 November 2002).

${ }^{22}$ See also Mishler (1986) for a discussion of how the typical interview format tends to suppress stories. 54
} 
In an attempt to avoid this 'artificialisation', the interviews in this study followed a structure informed by the principles of the biographical narrative in-depth method as described by Wengraf (2001). Such interviews are organised into three basic phases:

Phase one: a narrative prompted by one initial question from the researcher. Any further interventions from the researcher must be non-directional. It is intended that this narrative should be told according to the participant's own 'system of relevancy', rather than that of the interviewer, as would be implicit in a structured set of questions (Wengraf, 2001).

Phase two: following the initial undirected narrative, the researcher asks 'narrativepointed' questions, designed to elicit further narratives based upon the themes introduced in phase one.

Phase three: in the final phase the participant can be asked for points of clarification, and other direct, non-narrative and follow-up questions on issues not covered in the initial two phases.

While Wengraf (2001) recommends that the third phase of the interview be conducted at a later date, after the initial analysis of the first two phases, I distilled this process down to one three-phase session, sacrificing Wengraf's methodical and time consuming process for pragmatic reasons. As described above, my participants were spread over a wide geographical area (see Figure 1, page 50) and I often had to organise interviews to fit with their 'rest days' between climbing, which were frequently weather dependent. At times I would have half a day's notice to drive up to four hours for an interview. The logistics required to organise a second interview with many of the participants after a regulated interval were beyond my resources. During the initial six weeks of interviewing I covered almost 4,000 kilometres by road. Later I flew back twice to the South Island, and a further interview in the North Island involved two days travel by road. Frohlick (2003) highlights the need for a 'flexible methodology', not only for research on 'itinerant subjects', but also increasingly in the general context of globalisation. In this context, an 'ideal' method often has to give way to the practicalities of time and space.

I began my interviews with a narrative-prompting question along these lines:

Ok. To start with I would like you to tell me about your climbing, starting from when you first became interested in climbing and then how your climbing developed from there. I'm particularly interested in the trips or experiences that you think have been particularly important or memorable. Or maybe there have 
been some particular events that have been sort of turning points in your climbing. ${ }^{23}$ That sort of thing. Just to start with I won't interrupt you, so you can just talk and give as much detail as you like. I'll make a few notes and then I'll ask some more specific questions after that.

As the interviewees responded to this initial prompt I took brief notes of themes and points covered. Once they had finished telling their initial story, I returned to these notes to ask for clarification and elaboration, keeping to the original sequence in which themes were raised by the participant. At the end of this process, I asked further questions covering themes set out in the interview guide (see Appendix B), designed to prompt responses to specific issues, where these were not already covered by participants in the earlier parts of the interview.

Following each interview I undertook a self-debrief of 30-60 minutes, recording all the details and impressions of the interview that I could remember. ${ }^{24}$ These debriefing notes were then used to provide context for the interpretation of the interview data, as well as to give an understanding of the interactional processes involved in the interview situation (discussed below).

All interviews were tape-recorded and transcribed in full. ${ }^{25}$ Transcripts were sent to the interviewees for checking and comment. One was returned with additional reflections on the narrative. Two more were returned with minor corrections.

While there are other potential methods for capturing narratives, such as accessing diaries (Wiener \& Rosenwald, 1993) and recording conversations (Linde, 1993), I decided that for the purposes of this study the most effective way of gaining a personal history was by interviewing. One limitation of this method is that individuals differ in their willingness and ability to narrate a detailed account of their lives, as I discuss in more detail later in this chapter. Another limitation is that an interview is in a sense only a snapshot, a version of a narrative as told at a particular time, to a particular audience (Gubrium \& Holstein,

\footnotetext{
${ }^{23}$ In asking for the memorable, the important and the life changing, I was seeking the epiphanies that Denzin (2001a:34) describes as transformative experiences 'that radically alter and shape the meanings persons give to themselves and their life projects'.

${ }^{24}$ Occasionally, when I had to drive to another destination immediately following the interview, I did my debrief into a tape recorder as I drove and wrote up my notes later.

${ }^{25}$ The interviews were first transcribed by a professional transcriber. Secondly, I checked the accuracy of all the transcripts myself against the original recordings. This was a very time-consuming process, but deemed necessary due to the degree of detail and accuracy required for the interpretation process. Originally, I included in the transcripts all hesitations and repetitions in order to maintain their integrity as spoken texts during interpretation. Later, when including quotes from the transcripts in this thesis, the text was 'cleaned' (Elliott, 2005) to a certain extent, that is, enough to make the reader's task less arduous, but not so much as to lose the sense that these were oral accounts (Jennings, 2005).
} 
1998). So rather than the on-going, living, breathing, constantly revised magnum opus that a life story is, this research must be seen as recording personal histories which are, by necessity, fixed in time and place. It may be possible to compensate for the situated nature of a personal history by collecting a number of versions of one story, constructed by various means and in a variety of social settings. One possible way of avoiding the frozenin-time nature of biographical narrative interviews would be to re-interview periodically, to get a sense of how a life story moves across time. Neither strategy was considered feasible for the current study, but they are potential options for future research.

\section{Contextual material}

As mentioned above, Denzin (1989) suggests that various additional materials relating to the process under consideration can be included in the design of narrative research in order to achieve a form of triangulation or, more appropriately for interpretive research, contextualisation. For this reason my research included the use of a number of additional sources which both produced empirical material (contributing to the content to be interpreted) and aided my interpretation of this material.

\section{Additional personal records}

Where available, I augmented the interviews with additional personal records from the interviewees. Sometimes these were volunteered by the interviewees and predominantly they took the form of articles they had written about various climbing trips. In some cases I accessed these myself by searching relevant publications. While these articles contributed to my understanding of the personal history of the interviewee, they could not be directly referenced in the thesis as this would have compromised anonymity. None of the interviewees volunteered a personal diary or journal for inclusion in the study and indeed none mentioned keeping such a record, beyond factual lists of climbs undertaken. One interviewee volunteered a copy of a life history that had been written about him as part of a student project and also gave me a copy of an autobiographical manuscript written by a friend. As I did not have the permission of the author of this manuscript, it has not been included as part of my empirical materials.

\section{Supporting literature and other media}

The books, journals, magazines and films produced by and about mountaineers are what Antonovsky (1987:176) refers to as the 'cultural productions of the group'. Through a familiarity with these I was able to gain an understanding of the broader narratives which 
exist at the cultural and subcultural level about mountaineering. They provide important background and context to my interpretation of the personal biographical narratives, and my understanding of pertinent influences.

I have read extensively about mountaineering over the past twenty years out of both personal and academic interest. Specific to this study, I read a number of books recommended to me by mountaineers I had spoken with, as well as those that were mentioned by interviewees as having been influential for them. While this literature provided a useful 'backdrop' to the study, only some of it is directly referred to, where appropriate, within the thesis. I also took the opportunity to view mountaineering and climbing videos and films where these were topical. In particular, I purchased a copy of The Fatal Game, a documentary about Mark Whetu, a prominent New Zealand mountain guide whose client died on Mount Everest. While this story also does not appear in the thesis, it has been influential in my understanding of how mountaineers deal with traumatic events and I have referred to it elsewhere (Davidson, 2004). ${ }^{26}$ Other films I watched at this time included Southern Faces, a locally produced DVD about rock climbing (including alpine rock) in New Zealand, and Touching the Void, a docu-drama based on the book of the same name (Simpson, 1988) about a British climber, Joe Simpson, who survived a gruelling ordeal after injuring himself while descending a mountain in the Peruvian Andes. This book is one of the most widely read (and discussed) of mountaineering books, by both mountaineers themselves and the wider public.

Among the most relevant of the 'cultural productions' of New Zealand mountaineers are the NZAC publications. These include the annual New Zealand Alpine Journal (NZAJ), the NZAC Bulletin (published in a newsletter-type format twice annually until 1971 and six times annually until 1992), and The Climber (a colour magazine published quarterly which replaced the NZAC Bulletin). These publications include articles written by mountaineers about climbing trips, opinion pieces and letters to the editor, club news, climbing information and obituaries. My reading of these publications from 1949 until the present day (that is, roughly covering the time since the oldest of my interviewees began climbing) provides important contextual material for the interpretation of the biographical narratives. It is referred to in Chapters 4 and 5.

\footnotetext{
${ }^{26}$ This conference paper included the analysis of newspaper articles about a tragic mountaineering accident in New Zealand on 1 January 2004 which led to the deaths of three mountain guides and one of their clients. This incident attracted a high degree of public interest and generated much discussion in mountaineering circles around safety, danger and death in the mountains, particularly where this involves paying clients. While this particular incident is beyond the scope of the current study, and is not directly referred to in this thesis, it has been influential in my understanding of these issues. 


\section{$\underline{\text { Key informants }}$}

In addition to my interviewees, a number of people spoken to during the course of this study can be considered key informants. In particular the mountaineer and scholar, ${ }^{27} \mathrm{Dr}$ Aat Vervoorn, was consulted at various times throughout the research process, most critically in the final stages, in order to provide comment on my interpretation of the mountaineering narratives. ${ }^{28}$ As a philosopher, the author of two autobiographical accounts of climbing in New Zealand (Vervoorn, 1981, 2000), and a mountaineer who knows its mountains and its climbing community intimately having climbed among them for forty years, Dr Vervoorn was ideally placed to critique and comment on my study. Others who were spoken to as key informants and provided various perspectives on my study include: James Heywood, an adventure film documentary maker based in Queenstown (and the maker of The Fatal Game); Colin Monteath, mountaineer and professional photographer, based in Christchurch; Dr Erik Monasterio, mountaineer and psychiatrist, who has undertaken a psychological study of New Zealand climbers; Dave Bamford, mountaineer and former president of the NZAC; and Judy Reid, mountaineer and current president of the NZAC. For a slightly different perspective, an early draft of my findings was read and commented on by the partner of a mountaineer. Aside from these, many others participated as more informal key informants; my friends and climbing partners discussed, debated and shared their views with me throughout all stages of the research process.

\section{Autobiographical experience or 'prior ethnography'}

The final source of contextual material for this study was my own experience as a climber and mountaineer, and my involvement with the New Zealand mountaineering community. I was introduced to tramping and climbing by an older brother while in my late teens. When I was eighteen, my brother took me on my first 'real' alpine trip onto the Bonar Glacier beneath Mount Aspiring in the Southern Alps. I was overwhelmed, not only by the stunning beauty of the alpine environment but also by the enormous excitement of having been on such an adventure, and the sense of achievement at having made the journey. We did not reach the top of any mountains, but I climbed over difficult terrain with a heavy

\footnotetext{
${ }^{27}$ Dr Aat Vervoorn is Head of Centre, Centre of Asian Societies and Histories, Australian National University, Canberra.

${ }^{28}$ I first met Aat Vervoorn at his home in Canberra in December 2002 before undertaking my interviews. We met again in New Zealand to discuss my research in July 2004, and again in December 2005. Throughout this period we also stayed in touch by email and he provided comment on my early interpretation of the interviews, as well as later drafts of my findings chapters.
} 
pack, traversed a glacier, slept in a crowded, smelly mountain hut and made it out again, blisters and all. The beautiful leather climbing boots that my brother had bought for me at a second hand shop had been slightly too small and my blisters were so bad that I walked the final painful two hours down the valley barefoot. But I was hooked.

In the twenty years since that early experience, the mountains have been a central point of reference in my life, whether climbing, skiing, tramping, travelling, working among them, or studying aspects of the human relationship with mountain environments. My level of commitment to mountaineering as such has not been comparable to that of the participants in this study; nevertheless, my relationship with the mountains has been an enduring one and I can empathise with my participants. As for lifestyle, in the three years before I began this study I sustained a degree of commitment to climbing approaching that of my research population but I was unable to maintain this while working and studying part-time. In addition, many of my friends and acquaintances are committed mountaineers and I have remained within a social group of climbers, even though my active participation has lessened.

Thus I see myself as being in one sense an 'insider' and in another sense an 'outsider', in relation to my research population. Indeed, during the process of conducting this study, I have felt a certain drift from the 'inside' to the 'outside', partly through taking on the mantle of 'researcher' and partly for the reasons described above. However ambivalent my position may have been, it is important to the context of this study, as my experiences and my feelings about mountaineering can never be removed from it. As suggested in the title of this subsection, my autobiographical experiences and the 'prior ethnography' of being involved in a climbing community fed into my research in a number of important ways. Firstly, they influenced the choice of topic and the framing of the study. Secondly, in my interactions with my participants, I was positioned as at least a partial insider and this had implications for the research process. And finally, my personal perspective has inevitably came into play in my interpretation of the empirical materials.

Working within the interpretive paradigm permits me to acknowledge this personal perspective through reflexivity, rather than obliging me to make claims to absolute neutrality or objectivity (Berg \& Smith, 1988; Brown, 1996; Elliott, 2005). During the research period, I kept a research journal containing: my interview debriefing notes; references to my personal feelings about the interview situations; personal reflections on my own experiences that were prompted by the collection of empirical materials and their 
interpretation; details of informal conversations with climbers encountered during the research and my reflections on these. As I prepared the biographical narratives for interpretation, I included personal reflections on interactions where I considered these were relevant to my interpretation. I also returned to my journal in the final stages of the research process in order to reflect on the conclusions I had reached. Although I discuss my personal reflections in the next section on interpretation, in the chapters that follow I include such observations only infrequently, where I believe they have a direct and important bearing on the material under discussion. This is done to avoid what has been referred to as 'unfettered reflexivity' (Elliott, 2005) or what Van Maanen (1988:92) calls 'the black hole of introspection', where the researcher takes centre stage and detracts attention from the subject matter of the research.

\section{Credibility}

It is possible to deduce from the preceding discussion that mine would be a potentially sympathetic reading of the biographical narratives of mountaineers. It is evident that I have not come to this research with a negative perception of mountaineering as others have, for reasons made apparent in their own studies (see, for example, Coffey (2003) and Ortner (1999)). To allay concerns regarding a personal 'bias', I can do no more than state my 'intellectual autobiography'; that is, to acknowledge and reflect upon aspects of my personal and academic history and theoretical perspective, and consider the impact of these on my approach to and interpretation of the material (Elliott, 2005). Beyond this, I have endeavoured to ensure that I have been objective, not in the sense of detachment, but in terms of respect, as described by Fromm (1956a:105-106):

Objectivity does not mean detachment, it means respect; that is, the ability not to distort and to falsify things, persons, and oneself. ... The idea that lack of interest is a condition for recognizing the truth is fallacious. There hardly has been any significant discovery or insight which has not been prompted by an interest of the thinker. In fact, without interests, thinking becomes sterile and pointless. What matters is not whether or not there is an interest, but what kind of interest there is and what its relation to the truth will be. All productive thinking is stimulated by the interest of the observer. It is never an interest per se which distorts ideas, but only those interests which are incompatible with the truth, with the discovery of the nature of the object under observation.

Where the concepts of validity and reliability are considered relevant to quantitative data, researchers argue that the credibility of qualitative material can be ensured through the principles of transparency, consistency and communicability (Rubin \& Rubin, 1995). Accordingly, it is the responsibility of the researcher to ensure that the processes of collecting and interpreting empirical materials are clearly presented; to demonstrate that 
the material was treated with consistency and that the ideas produced are coherent; and finally, that the description of the world that is revealed by the research 'rings true' for both the participants and the readers; that is, it achieves 'verisimilitude' (Ellis \& Bochner, 2000).

In this study I sought to follow these principles throughout the collection, interpretation and presentation of the empirical material. The foundations of credibility were initially laid through the methods outlined above; that is: the inclusion in the study of multiple sources of evidence; rigorous recording in a research journal of the process followed and the reasoning guiding my decisions in relation to this process; the checking of transcripts by interviewees; and the incorporation of key informant comments. To build on this, in the next section I describe the processes used to interpret the empirical material. I also discuss a number of general 'interactional issues' that arose during the interviewing process and are pertinent to the nature of the biographical narratives collected. In the chapters that follow I have sought, as much as possible, to provide the reader with sufficient detail and quotes of an adequate length to allow them to follow the logic of my interpretation. Thus I have endeavoured to orient myself in as 'truthful' a manner as possible to the subject matter of this research.

\section{Interpretation of empirical material}

[S]tories are not waiting for social scientists to endow them with sense. Narrative analysis needs all possible humility when asking what it can bring to stories.

(Frank, 2002:13)

In this section I discuss my approach to the interpretation of the empirical material that form the basis of this study, as well as describing the interactional and ethical issues I encountered along the way and their possible impact. Then, I introduce my interviewees before summarising this chapter on the research process.

The interpretation of biographical narratives is itself a meaning-making process, essentially involving the construction of a 'second order narrative' (Elliott, 2005). According to Clandinin and Connelly (1998:170), one searches for 'the patterns, narrative threads, tensions, and themes either within or across individuals' personal experiences'. There is, however, no one accepted analytical technique for the interpretation of narratives (Elliott, 2005). Hence, in my interpretation I have used a combination of the concepts and techniques recommended by Denzin (1989; 2001a), Wengraf (2001) and Pamphilon 
(1999), which I consider most relevant to the purposes of my research. ${ }^{29}$ Denzin (2001a) suggests identifying the problematic events or epiphanies that structure the subject's life, and capturing these with a personal experience story or a self-story. Epiphanies are the transformative experiences that 'leave marks on people's lives'. Often moments of crisis, they allow for the display of personal character and the altering of 'fundamental meaning structures' (Denzin, 1989:70). Once this has been achieved, the researcher can interpret the basic features of the narrative.

Wengraf (2001:232) recommends asking the following questions: What is the pattern of the lived life? What is the pattern of the told story and the self-presentation? What is the relationship between the two? In answering these questions, Wengraf uses a system based on grounded theory (Glaser \& Strauss, 1968) to reveal the 'factual' events of a life as presented by the participant and to produce a thematic analysis of the text to illuminate the way in which the participant tells the story of their life - recognising that there are many different ways in which a given life (and given sequence of events) could be told. This process understands such a personal history as being:

constructed by, and consequently expressing, a gestalt or pattern or structure that has to be detected. The told-story is the surface under which is detected a flow in and/or of thematic fields, under which a deeper structure is then postulated to explain the upper two levels.

(Wengraf, 2001:272)

In addition to the 'assumptions and asides' of the narratives, they contain the explicit theories with which people understand their lives; what Bruner (1990:43) calls the 'configuring plot'. The triangulation of these multiple sources of meaning can reveal, with careful interpretation, complex layers and nuances of meaning (Wengraf, 2001). These meanings can then be contextualised by the additional sources of empirical material collected during the research process, as Denzin (1989) also recommends.

Another useful approach is Pamphilon's (1999) 'zoom method' which prescribes the exploration of four different levels of meaning in life histories: macro, meso, micro and interactional. The macro-zoom examines the manifestation of collective narratives, cultural patterns and shared discourses in the individual's biographical account. At the meso-level, the researcher pays attention to the individual's narrative processes - the key themes and phrases. On the micro-level, 'emotional and affective complexities' reveal still

\footnotetext{
${ }^{29}$ Another common approach found in narrative research comes from socio-linguistics in the tradition informed by the work of Labov and Waletzky, and described by Linde (1993). While there is some overlap between Linde's approach and my own, I was not primarily concerned with the linguistic structure of the narratives.
} 
more about the meaning of the story (Pamphilon, 1999). The interactional-zoom acknowledges the impact of the dynamics between the researcher and researched on the formation of a narrative.

The interpretation of my empirical material was not a discrete process with a clear beginning and an end, although it can be seen to have commenced with my first encounters with my research participants. It continued on into the writing of this thesis and potentially will stretch on into the future as I reflect back on it. Despite the amorphous nature of this process, I outline here the various stages as they are conventionally perceived, between the collection of the material and the writing up of the research. As Elliott (2005) points out, with qualitative materials the earliest stages of interpretation can be the most difficult to convey as a structured process, because of their reliance on the researcher's intuition. These stages I have already touched on in describing my use of a research journal to reflect upon the material I collected and the nature of the collection process. Later in this section I further describe a number of interactional issues that arose during the interviewing. Additional observations are provided in Appendix C. I include these observations in the 'impressionist' style advocated by Van Maanen (1988:102-103); that is, not so much to 'interpret or analyze' the process, but to invite the reader to 'relive the tale' with me, and thereby endeavour 'to keep both the subject and object in constant view'.

In dealing with the transcripts throughout the interpretation process it was my intention to retain, as much as possible, the narrative integrity of the whole. I wanted to avoid breaking the transcripts down into 'units' for coding, as is done, for example, using the constant comparative method (Maykut \& Morehouse, 1994). As Bruner (1990:43) explains, the 'principal property' of narrative 'is its inherent sequentiality' and none of its parts have a meaning independent of the plot they comprise within a given narrative; that is 'the overall configuration of the sequence of the whole'. Thus, instead of breaking the narratives down into parts that no longer stood in relation to the whole, I 'distilled' the narratives into a manageable size and worked through my interpretation processes, as much as possible, with the whole narratives in mind. There was a distinct advantage here in having a smaller sample size, as I could avoid using a computer and instead, through constant re-reading, develop a high degree of familiarity with all twenty-two narratives, such that the use of qualitative data analysis software was not necessary.

The process of distillation involved reducing the transcripts into a condensed version which included the main self-stories and personal experience stories, evaluations and other 
opinions given. The sequentiality of the interview was maintained, and the main parts of the narrative were connected with linking summaries in my own words. Each condensed version was introduced with an overview of the interactional aspects of the interview, and a summary of the main narrative themes, and any problematic events/issues and/or epiphanies the interviewee had had, followed by an outline of the 'told story'. An example of a condensed narrative is given in Appendix D.

Each narrative was then examined for the way in which self or identity was constructed from the biographical particulars of a life. In particular, I noted the self-stories relating to how respondents became mountaineers and what made them mountaineers. Also pertinent were the personal experience stories describing formative events in these processes and illustrating certain points about who they were and what it meant to be 'mountaineering selves'. This interpretation forms the basis of Chapter 3. My second 'reading' of the narratives was for the shared meanings: the communal narrative about what it meant to be a mountaineer - Pamphilon's (1999) macro-zoom - and the moral dimensions of this narrative, as recommended by Frank (2002). This forms the basis of Chapter 4, and my reading of the NZAC publications contextualises and informs this interpretation. Finally, I examined the narratives for stories about the calculable and the incalculable nature of experience, and stories about death and mortality. This interpretation is presented in Chapter 5.

The writing of the three findings chapters was, of course, another phase in the interpretation process, particularly as the empirical material was interwoven at these points with relevant theoretical perspectives. The inclusion in these findings chapters of theoretical literature, which is foreshadowed but not fully discussed in Chapter 1, is intended to reflect the nature of this process. Finally, the approach I took to the interpretation of the narratives was inevitably directed and informed by the aims of this particular study, and my enquiry is constrained by the way in which the research was framed around the construction of a sense of meaning and self. There are, however, many additional 'readings' that could be made of these narratives and many other contexts in which they could be explored, as exemplified in related studies of mine (Davidson, 2004, 2005). Narratives, as discussed above, contain complex layers of meaning open to interpretation. The nuances in the narratives I collected have not been exhausted by the current study. 


\section{$\underline{\text { Interactional issues }}$}

Atkinson and Silverman (1997:314) caution against the uncritical use of interviews in social research, arguing that 'interviewer and interviewee collaborate in the reconstruction of a common and unitary construction of the self'. As Clandinin and Connelly (1998) point out, the way in which individuals tell their stories will be influenced by their particular purposes or intentions at the time, and by their interpretation of the position, purposes or intentions of the listener. As a result, the nature of any biographical narrative interview rests upon the extent to which interviewers are able to successfully communicate their intentions to the participant.

Some of my interviewees responded well to the initial narrative prompt, launching themselves into their story and talking freely and fluently. ${ }^{30}$ Others needed a little more encouragement or reassurance that I wanted them to tell me their story in detail. With a few, it required a great effort to encourage them to tell me any stories at all. They would sum up their lives in a few sentences, and wait for the next question. They gave short, succinct answers. As I conducted more interviews, I gradually learned to prompt more successfully in these situations.

As the interviews progressed I began to realise that, no matter how carefully I avoided any suggestion that I was interested in 'why' they went mountaineering, to a large extent, the interviewees still presented me with rationalisations for their climbing. This seemed to be a result of their assumption that this is what I was interested in - probably reinforced by the fact that this is the most common question posed to climbers. It is also perhaps linked to a personal need that we all have, when telling our stories, to give evaluations and rationalisations for actions and decisions. I occasionally sensed that an interviewee was concerned that I would judge them negatively based on the kinds of decisions that they had made in their lives. In such cases, I tried to reassure them that this was not the case. My intention was to demonstrate empathy, while not compromising my role as researcher. Patton (1990) terms such a stance 'empathetic neutrality', and Bondi (2003) describes it as 'the capacity to understand the experiential frame of reference of another ... empathy provides space for difference, while enabling the researcher to communicate respect and recognition'. Further details of the interactional aspects of each interview are included in Appendix C.

\footnotetext{
${ }^{30}$ To begin with, when this occurred, I found that I had to consciously stop myself from interrupting the narrative, as it felt rather unnatural to sit quietly and not make any verbal contribution. 66
} 
One of my interviewees remarked that "interviews are funny because you tend to tell things to a sort of complete stranger". In working through the transcripts I was struck by how often people had used phrases such as: "you know what I mean”; "does that make sense"; "is that what you mean". Sometimes they appeared many times in the same paragraph. While I have edited quite a number of these phrases out of the final quotes in the interests of readability, I have left some of them in because I believe they are deeply significant, particularly to an enquiry concerned with the construction of meaning.

To tell one's story means taking the risk that one may be misunderstood by the listener (Frank, 2002). That we nonetheless strive to be understood demonstrates the profound way in which comprehension is the basis of 'human solidarity' (Bruner, 1995). These insights, I think, help to explain the dynamic behind many of the interactions in my interviews and the frequent use of the phrases mentioned above. They may also account in part for the interviews that never took place because of reluctance on the part of those approached. The strength of our desire to make ourselves understood and to link our stories with the stories of others, is counter-balanced by our anxiety that what we say may be met with indifference, misconstruction, or even condemnation. In each individual case the balance will be different. If anxiety outweighs the impulse to meaning, then silence is the likely result, as Wajnryb (2001) found with survivors of the Holocaust. If the balance is tipped the other way, then a biographical narrative interview will likely result in an intricate and lengthy personal history.

\section{Ethical issues}

Given that the authentic representation of the Other is always problematic, Lincoln \& Denzin (2000) argue for a 'moral' approach to research through exploring the ways in which people 'take control of their lives' by constructing their own stories and meanings. It could be argued then, that an ethical stance is already implicit in my choice of research approach. Additionally, throughout this chapter I have referred to a number of ethical issues encountered in the course of this research; namely, non-coercion of participants, declining to use unpublished material for which I did not have the informed consent of the author, and omitting reference to material that would compromise anonymity. This last issue warrants further discussion before I introduce my interviewees. In research that focuses on the details of an individual's life, it is notoriously difficult to protect anonymity and confidentiality (Elliott, 2005). While real names are not used, decisions regarding the inclusion/exclusion of personal details which might allow identification of the interviewees have been extremely difficult. I have excluded precise details such as age, place of 
residence, and names and dates of particular climbs which would lead to easy and unequivocal identification. To exclude all potentially identifying characteristics, however, would have rendered the material meaningless.

Given this situation, my strategy has been to focus my ethical responsibilities on ensuring that the biographical narratives have been presented in the most sensitive and appropriate manner possible. In some cases, interviewees asked that certain information they shared with me not be included. I respected these wishes, and in other cases made my own decision not to include details that I considered overly personal. I believe it has been possible to do this without compromising the integrity of the interpretation, and where this is particularly pertinent, I have made reference to it in the following chapters. I have also endeavoured to undertake an interpretation that does not pass moral judgment on the interviewees or attempt anything resembling a 'psychoanalysis' of their actions. This was neither appropriate nor necessary, and certainly unjustified given the potential impact of such an interpretation upon a participant (Elliott, 2005).

This brings me to the final ethical issue in this discussion: the 'transformative potential' of the narrative research process (Elliott, 2005; Hones, 1998). ${ }^{31}$ I was aware going into the interviewing process that telling one's story, while often a pleasure, is not always so. It was not my intention to ask interviewees to discuss aspects of their lives that were painful or difficult for them. Nevertheless, such issues did arise in the course of some of the interviews, particularly during references to the deaths of friends and the breakdown of relationships, but never at my prompting. In encountering the strong emotions associated with these accounts, I felt sympathy and concern at the distress of the person involved. While the interviewees were always free to end the interview at their discretion, in all cases they regained their composure and continued their narrative with little apparent difficulty. I was often touched and surprised that interviewees should share so openly with a 'virtual stranger' such intimate details of their lives. These experiences affected me profoundly, and I acknowledge the possibility that the interviewees did not go unaffected either. A number had obviously spent some time before the interview thinking about their mountaineering and wondering what I might ask. Many commented at the end of the interview that they had enjoyed the chance to talk about their lives in such detail, or that it had prompted them to think about things in particular ways.

\footnotetext{
${ }^{31}$ Denzin (2000) argues that all research could, or should, be transformative, that is, not just engaged in interpreting but also in changing the world. 68
} 


\section{Profiles of interviewees}

These profiles are provided as a means of introducing the reader to the protagonists who 'people' the remaining pages. It is my intention to give an initial sense of the 'story' of each particular individual, in preparation for the discussion which elaborates on these first impressions, and lays various stories side by side in order to answer the research questions outlined in Chapter 1.

A few words of clarification are also required regarding the formatting style for the presentation of the empirical material. In these profiles and the chapters that follow, the spoken text from the biographical narratives and extracts from the NZAC publications appear as italicised text in quotation marks or indented paragraphs. In places, relatively long quotations are included in order to give the reader the sense of a whole story and its meaning. In such cases, to assist in directing the reader to pertinent themes in the story, key words or phrases are in bold type. In some cases, where a shorter or condensed version of a story is used, the reader is directed via a footnote to the Appendices for the full version. In this way, I have attempted to maintain the flow of the following three chapters, without excluding the possibility of examining the full context of my interpretation of particular stories.

\section{Chris (19 January 2003)}

Chris is in his forties, and has been climbing since he went to university and joined the tramping club. Although he was somewhat "loose" at the beginning, and he had some “early epics”, he describes himself now as "pretty conservative". Chris feels "right at home" in the mountains. He appears to have an enormous amount of energy, saying that he gets quite restless and frustrated by periods of inactivity. Chris loves the "ambience" of the mountains, and particularly enjoys the exploration aspect of mountaineering - doing things no-one else has, original and slightly "edgy" or "obscure" things. He and his partner are both climbers and they have a lifestyle which is "pretty flexible", allowing them to pursue their passion, raise their young son, and operate their adventure tourism business.

Dave (22 January 2003)

Born in the early sixties, Dave grew up in a small town close to the mountains. While at school, he was taken rock climbing and up into the snow where he first tried some basic mountaineering. He left school and continued tramping. After travelling overseas, he 
returned to New Zealand and took to mountaineering in his early twenties. Dave has been climbing consistently ever since, supporting himself with various forms of casual employment. He recently married Trish, who is also a climber, although she does not climb with the same "hell-bentness", according to Dave. According to his narrative, Dave grew from a shy and "skinny" child, into a "really good" mountaineer. He speaks of a deep love and commitment to climbing.

Bob (22 January 2003)

Bob grew up on the "adventure-type stories" of his father who had worked in East Africa. He "stumbled on the mountain thing" through being a Boy Scout and being taken tramping in the local ranges, and after that "every weekend I just went into the hills". After leaving school he started working in an office, but realised that was not what he wanted to do and made the decision to go "off down south to go climbing”. Bob later took up flying, which means he is "still able to get around the hills" even though he is "physically not as fit". Bob owns his own company and is in his fifties. He speaks of a deep love and attachment to "the land ... my land". He sees mountaineering as about exploration and travelling in the hills, as "journeys of discovery", through which “one can discover one's self”. Bob told stories that displayed a sense of irreverence for the conventional way of doing things. The motto of his life is that "there are many windows to look out of": one should not restrict oneself.

Jess (23 January 2003)

Jess was introduced to the outdoors by her parents, who took her caving from the age of five. At high school she began rock climbing, and when she went to university she became immersed in the climbing club 'scene' and was introduced to mountaineering. She moved to the South Island four years ago with her partner, who is also a mountaineer, after they both spent two years climbing in Europe and South America. Moving south was " $a$ lifestyle decision" to be closer to the mountains. Jess stressed that she loved the "clarity" of "being in the hills", which was "almost a spiritual thing”. Other themes in Jess's initial narrative were the desire to control her fear (she liked to feel in control and she didn't like "being afraid unreasonably"), and the need to "address" the deaths of friends in the mountains. Jess is in her thirties and does some work in architectural design (in which she is trained), as well as working part-time for a guiding company. 
Pip (30 January 2003)

Like Jess, Pip grew up in a family that did a lot in the outdoors, and she was introduced to tramping and walking from a very young age. Subsequently, "one thing just led to another" through spending time with "like-minded people that were into the outdoors". When Pip went to university, she joined the tramping club and developed " a good grounding in mountaineering". Since then, she says, "I never really stopped climbing”. It is important to Pip that she climbs the 'right' mountains for the 'right' reasons, and she speaks of feeling “called to" climb in particular areas, and developing a strong connection to and familiarity with these areas. Pip often goes on solo trips and she enjoys the sense of self-reliance and competence. The beauty of an area and a sense of remoteness are also important for her. She is critical of the commercialisation and regulation of the wilderness. Pip is in her late-thirties and does seasonal work in the tourism industry.

\section{Sue (31 January 2003)}

Sue grew up in a large family in Ireland, and was introduced to hill walking by her older sister. From her early experiences at the age of eight or nine, Sue "absolutely loved it". She joined the mountaineering club when she went to university to study medicine, and began going away on trips to Scotland and Europe. After working as a doctor for a few years she came to New Zealand to climb, and met her future husband. Family life was organised to give both Sue and her husband the opportunity to climb while raising their three children. While Sue clearly loves climbing and the beauty of the mountains, she talks about her experiences in a matter-of-fact manner, rather than perhaps painting a 'rosy' picture. She speaks of experiencing weakness and uncertainty, being scared, embarrassed and exhausted, and often made seemingly harsh assessments of her confidence and competence. Sue is in her forties and practises medicine.

Mike (31 January 2003)

Mike began tramping with his family as a young child, and then as a Boy Scout and on school trips. He became involved in climbing when he went to university because it seemed to be "the next thing". From there, it was "a natural progression" to take on harder and harder things, including a number of trips to climb overseas. For three or four years after he met his future wife, his climbing "died out". He spent more time with his new girlfriend and did some kayaking. In the last few years Mike has started climbing consistently again, although now his climbing is more focused on the "enjoyment" and the 
"social interaction" than on always trying to "do something harder". Mike is in his thirties, lives with his wife and has a professional career.

Simon (5 February 2003)

Simon's father was a mountaineer and was very keen for his son to "get into it". So when he was eight years old, Simon started climbing mountains. Doing such unusual things in his school holidays gave him the sense of being a bit special. Throughout his high school years Simon "climbed heaps", though no longer with his father who was injured in a car accident. He lost some motivation when he went to university, spending a year "having a lot of fun, partying" and then he "got back into it". Simon has a full-time job and is in his twenties. Although he sees mountaineering as "a way of life", he likes the contrast between work and climbing, the latter being what he chooses to do in his spare time. His preference though, would be to work less than he currently does. He considers himself " $a$ very solid mountaineer" who "gets out and does things".

\section{Dan (7 February 2003)}

Dan was introduced to mountaineering through a basic 'snowcraft' course when he went to university in his late teens. Since then it has been something he has become "more and more passionate about”, and he has been on climbing trips to Australia, Pakistan, India and the United States. Over the last few years Dan has come to realise that climbing is what he wants to focus his life on, although he has struggled with the idea that he should be doing something less "selfish". He believes that it is important to "follow your heart", but he also feels a need to do something "for the benefit of others". Recently Dan has decided to balance climbing and life by becoming an outdoor instructor, and sharing his skills and appreciation for the outdoors with young people. The mountains are a good place, he says, to reflect on "life and the way you want to live it and [to] question what you're doing”. Dan is in his twenties and was at the time doing seasonal work for an adventure tourism company.

\section{Adam (7 February 2003)}

While Adam grew up in Australia, the story of his beginnings is not so different from those told by his New Zealand counterparts. As a child, he spent a lot of time walking in National Parks, and his sister took him along with her to a local climbing gym. When he discovered climbing, it seemed the perfect way to extend his love of "exploring the bush" by "learning some new skills". With a friend from university, he began exploring the local 
crags, and when they became too familiar for him he decided to go to "more adventurous places". Adam came to New Zealand for a mountaineering course and has returned several times to climb, before making his recent decision to move here: "to get as much personal experience as I can in the Alps". He loves the "creative” aspects of climbing being able to "climb something entirely in my own way" - and the beauty and solitude of the mountain environment.

Tim (8 February 2003)

Tim is in his twenties and started climbing at high school after winning two hundred dollars in a raft race and using it to buy a climbing rope. At university he "hooked up" with some "quite sturdy climbers" who became his mentors. Through his desire to climb alpine rock he branched out into mountaineering. He took a year off university when he was twenty and went overseas to be a "climbing bum". He "lived off nothing for six months and did nothing but climbing". After that trip he realised that he was "at heart always going to be ... a climber”. He came back to New Zealand and went straight back into the mountains for two months. At the time of the interview Tim was part-time selfemployed, but in a few months time he was off to work at Outward Bound for three years.

Jane (10 February 2003)

Jane loved climbing trees as a child, and although her family was not particularly 'outdoorsy', she felt "there was something about the mountains" and she "always sort of wanted to be a climber". From the beginning she did not want to be introduced to it by a father or boyfriend, "which often happens to a lot of girls". Instead she did a course while still at school, and was nurtured by a strong female climber as part of a group of young girls. She took a year to work and climb after finishing school. Seven years later, in spite of her original intention of going to university, she is still travelling, working and climbing. Being independent and doing things on her own is very important to Jane. She finds it empowering to find herself getting "better and better" as a climber. I had the sense that she was thoroughly enjoying her life. The only tension noted was through her admission that she sometimes feels as if she is "this girl, that doesn't look very strong” and that she has to "prove" herself.

Kath (11 February 2003)

Kath is in her forties and was introduced to tramping and climbing at high school. As soon as she left school she gave herself a "good kick start” by doing three mountaineering 
courses back to back. After that she "mountaineered fanatically for quite a few years".

She married another climber and they went overseas climbing together. After she returned to New Zealand her marriage broke up and she felt "really burnt out a little bit on mountaineering”, so she took up kayaking "for a few years". When she came back to climbing it was through competitive rock climbing and she found that this made her "really strong" and helped her mountaineering. A few years ago she started ice climbing and when she found that she could 'hold her own' in this "really macho scene" she decided that she would focus on "steeper technical mountaineering". She has re-married, and her current husband is a rock climber but not a mountaineer. Kath is self-employed, which gives her the time flexibility she needs to go climbing.

\section{Pete (11 February 2003)}

Pete was first exposed to the outdoors by his parents and when he went to university he met a group of climbers who inspired and encouraged him. During his university years climbing became his main focus and he "bailed out of varsity basically because I was so keen on it". For a number of years he made a "lifestyle" out of climbing, by working for a guiding company, but he made the decision as he grew older that he didn't want to have to go into the mountains to earn a living. He eventually went back to finish his qualifications and worked for a number of years as a surveyor, before taking a job with the Department of Conservation, working around his local National Park. Pete is now in his forties and married with a young child. He climbed together with his wife when they first met, and she goes on her own trips into the hills. They are "both perfectly relaxed with each other going off and doing their own thing”. Pete seemed to be a person who was comfortable and happy with his lifestyle, and the "mountain environment" was a central, life-long passion.

\section{Terry (13 February 2003)}

Terry is in his late fifties and originally from England. He began rock climbing when he went to a secondary school where the headmaster was a mountaineer. From his first experiences of climbing, he thought “'yes'. [laughs] And it's been 'yes, yes, yes' ever since". Every weekend for "years and years and years" he climbed all over the United Kingdom, "right up until I got married". In the early 1970s he came to New Zealand for a two-year working holiday with his wife, and having fallen in love with the mountains here, decided to stay. Since then he's "climbed and climbed". For Terry climbing mountains is "a way of life", and he obviously gets huge enjoyment from it even though as he has 
grown older he has had to 'tone it down'. Terry has a new partner and they enjoy going into the hills together.

\section{Thomas (14 February 2003)}

Thomas grew up in Switzerland and was taken into the mountains by his parents from an early age. When he left school he joined the junior section of the local alpine club, and under their supervision "very slowly and very gently" his skills increased. By the time he was twenty he was doing "some very big climbs". In the early sixties Thomas emigrated to New Zealand, bringing new techniques from Europe and making some difficult ascents in the Aoraki/Mount Cook region. Thomas climbed less once he got married and had a family, but sees climbing as part of his life, which sometimes he has been "fanatical about" and other times "more relaxed". Now in his sixties, he has begun climbing more regularly again, including climbing with his son, which he finds very enjoyable. Thomas is a professional artist and he sees the creative aspects of art and climbing as being interconnected. For Thomas, the most important aspect of doing anything is to do it in the right "style".

\section{Steph (14 February 2003)}

Steph started tramping and skiing with her family when she was "quite little”. Her brother taught her to rock climb when she was sixteen, and she started tramping "higher and higher" until she was climbing mountains. After leaving school she went to polytechnic and trained to be an outdoor instructor. Since then she has done seasonal work to support her climbing, as well as starting a university degree. Steph enjoys feeling independent, gaining confidence and feeling comfortable in the mountains. While she is sure that mountaineering is what she wants to be doing, she is still trying to find the right balance in her life. While she is studying at university she feels frustrated at her lack of time for climbing, but when climbing is her "main focus" she begins to feel after a while as if she needs "some other stimulation" for her brain. Steph is in her mid-twenties.

\section{Bill (15 February 2003)}

Bill is the oldest mountaineer I interviewed. The mountains have been part of his life from a very young age. His father belonged to the local mountaineering club, and Bill joined while still at high school. In the mountains Bill found freedom, friends, exploration and a reason for being; everything else seemed like drudgery. An expedition to the Himalaya was an important learning experience for him, reinforcing his ethic that mountaineering 
was about "going there with your friends and enjoying the mountains", rather than the ambition of reaching a particular summit. Bill continued to climb after his marriage, but found it difficult to balance his responsibilities towards his family with his inability to say 'no' to adventure. This tension pervaded his narrative: that because of his love of climbing he had made decisions that would seem self-centred to others; that he could not fit into the 'mould'; and that this had ultimately cost him his marriage. Although in his seventies, Bill continues to go on adventures throughout New Zealand and the rest of the world.

Lyn (16 February 2003)

Lyn is in her forties and grew up in South-east Asia, with no family background of interest in the outdoors. She trained as a lawyer and had established a successful career in Auckland, before being introduced to rock climbing in the late 1980s by a friend who is a climber. From that time, climbing changed her life, and rock climbing led her into mountaineering and ice climbing, which has become her "big passion". Three years ago she moved to the South Island to be closer to the Southern Alps. It is important to Lyn to have a goal or challenge in her life. Without such a focus, she feels unsettled and restless.

\section{Mark (10 September 2003)}

While at high school, Mark went on an outdoor pursuits course which included a trip into the alpine environment and it was "the most amazing experience" he had ever had. From there he began to "venture into a bit more wilderness" and met up with some members of the Alpine Club who took him rock climbing. The next five or so years involved many trips to the mountains and rock climbing areas near where he lives in the North Island, and down to the South Island. It was 'down south' that Mark fell while climbing and injured his back - an injury that left him a tetraplegic. Maybe it has intensified since he has not been able to climb, but Mark still feels a deep emotional attachment to the mountains and relishes his memories of them.

\section{Jan (23 October 2003)}

Jan began scrambling up small hills as a young child on family holidays. A desire to be an explorer and "to climb to the top of the hills and see what was over the other side", seems to her always to have been there. After high school she went to Teachers' College, where she joined the tramping club. Tramping provided a "good apprenticeship" for mountaineering, and it was through the club that Jan met her future husband who, like her, was "always keen ... on going up and having a look over the top”. After they were 
married, Jan and her husband went climbing "virtually every weekend”, with longer trips over the summer. Later she participated in a number of expeditions overseas. Jan is in her sixties and continues to climb, trek and cycle all over the world. She made an effort a number of times to sum up for me why people climb. At the end of the interview she said there are two reasons to climb a mountain: because of the appeal of a particular mountain or a particular route; or because you loved "just being there". She said it is the latter reason that keeps you climbing all your life.

\section{Phil (14 December 2004)}

Through an active childhood in the North Island climbing trees, Phil progressed to Boy Scouts and later joined the local tramping club. There he met rock climbers and was initiated into the world of climbing. Trips to the mountains followed, and when he moved south to study medicine he began exploring the mountains of the South Island. At university he met a group of climbers through the tramping club and together they started climbing bold, new routes in Fiordland. After he finished his qualifications, Phil and his wife, who is also a climber, travelled overseas to work and climb for several years, before returning to New Zealand to raise their young family. Phil has continued to be very active within climbing circles in New Zealand, in particular helping to develop new climbing areas and encouraging young climbers to develop their skills. He is now in his fifties, and practices medicine.

\section{Summary}

Were it practically possible, the ideal method by which to enquire into the construction of meaning and self might be to observe or interrogate people throughout the course of their whole lives. However, Bruner (1990:119) argues that a 'viable alternative' for understanding these processes is retrospective autobiography, not in the sense of a 'record' of a person's life, but in terms of 'an account of what one thinks one did in what settings in what ways for what felt reasons'. This, he continues, 'will inevitably be a narrative ... [and] its form will be as revealing as its substance. It does not matter whether the account conforms to what others might say who were witnesses'.

Although standard qualitative interviewing would also undoubtedly have collected much valuable data, biographical narratives allowed for the capture of multiple layers of meaning, far exceeding a more conventional format. In addition, a strong argument in support of the use of a biographical narrative approach in this and other areas of leisure 
studies, is its value as an alternative to the use of self-reported motives, and a concern with causative explanations of human behaviour. To quote Bruner (1990:122) again:

The presuppositions that we lace into the telling of our lives are deep and virtually limitless. ... And why things are included remains mostly implicit ... And if you should ask that reasons be made explicit, your question will surely steer that account in a direction that it would not have taken otherwise. For the interviewer becomes part of that "swarm of participations" that distributes Self across the occasions of its use.

The biographical narrative interviewer remains deeply implicated in the 'swarm of participations'. In this study, however, I have attempted to reflect critically upon my participation and to account for it in the interpretation process. While some of my experiences 'in the field' may appear to have frustrated my chosen method, they in themselves have made contributions to my understanding of meaning-making processes in the lives of mountaineers. People's reticence or discomfort in talking about certain parts of their lives, and their interpretations of what I wanted to hear, are as much a key to meaning as the full narrative that flows effortlessly from beginning to end. In reflecting upon this, and in accepting that some people are more gifted and enthusiastic story-tellers than others, I have endeavoured in the following chapters to weave together the various stories in a manner that reflects their peculiarities and their particular contributions to my understanding of the processes under consideration. In doing this I strive to tell their stories in a way which illustrates their 'warts and all' nature, but also in an ethically responsible and respectful way. I therefore 'walk the line' between presenting their stories in a manner which is not 'incompatible with the truth', but which also acknowledges the good faith the interviewees have shown in relaying to me their personal and sometimes tragic stories, in generous and detailed ways.

Ultimately, however, it must be acknowledged that the central story told by this thesis is not the only version that could be told, as is true of all stories. Any story, Bruner (2004:709) tells us, 'is better understood by considering other possible ways in which it can be told'. Thus this study can make no claims to generalisability or replicability. It aspires instead to 'speak for itself': to tell a story against which past and future stories about the meaning of mountaineering can be read, and to contribute to an on-going 'creative conflict of interpretations'. As Kearney (2004:8) explains:

Because we are finite beings, our understanding always remains within the historical limits of the hermeneutic circle. The myth of absolute reason must always be resisted in favour of a plurality of critical debates and detours. 


\section{Chapter 3}

\section{The narrative construction of mountaineering selves}

\section{Introduction}

In this chapter I consider the construction of a sense of self in the mountaineering narratives. The chapter is divided into two sections. The first discusses stories about becoming a mountaineer, and the significance of these stories in terms of a sense of being, or identifying as, a mountaineer. As will be seen, the need to establish a durable identity and a 'true' sense of self is an ever-present subtext in the narratives, and the second section of the chapter outlines in more detail the ways in which mountaineering is seen to fulfil this need. Finally, I consider the efficacy of the mountaineering self as a response to the 'identity crisis' discussed in Chapter 1.

Throughout the chapter I focus primarily on the way in which the biographical particulars of a life are woven together to give an individual sense of meaning and self centred on mountaineering. In Chapter $4 \mathrm{I}$ shift the focus to the communal narratives of identity and the meaning of mountaineering. I am aware that any attempt to distinguish between individual and communal meanings and identities is a fraught and somewhat dubious process, as neither exist independently of the other. Rather than suggesting that these are separate constructs, I am utilising here Pamphilon's (1999) 'zoom' technique, discussed in Chapter 2, to examine two interacting phenomena which are intertwined within life histories. In this chapter I take a micro-zoom: a 'close-up' of the biographical details of the narratives, to understand more fully the processes at work in the construction of an identity from the events and circumstances of a mountaineer's life. My intention is to determine what, if any, commonalities exist between the narratives in this regard commonalities that could be seen to account for the durability of the narrators' commitment to mountaineering. A macro-zoom is taken in Chapter 4, in order to examine the ways in which cultural patterns and shared discourses shape meaning and self in the biographical narratives.

As discussed in Chapter 2, Denzin (2001a:61) describes three forms of narrative which combine to give us the story of a life in a broad sense. In the following discussion, a variety of personal experience stories and self-stories appear. I have added as much context as possible to give the sense of their place within the spoken autobiography from which they have been taken. Connections between the various personal stories of 
individuals are indicated as the interpretation progresses. At the beginning of the second section of this chapter I discuss one particular narrative more fully, in order to give an example of how the themes in this chapter are woven through a personal history.

\section{Emerging identities: becoming and being a mountaineer}

While the events and circumstances of our particular lives provide the raw materials for our life stories, we construct these stories, according to Taylor (1989:289), in two 'interwoven' and 'inescapable' senses. We see the shape of our life as being determined by those things that have happened along the way, and at the same time, 'since the life to be lived has also to be told', we 'see this shape as something already latent, which emerges through what comes to pass ... We are made what we are by events; and as self-narrators, we live these through a meaning which the events come to manifest or illustrate'.

In the biographical narratives of the mountaineers interviewed, identities emerged in the two-fold sense that Taylor describes: their experiences in the mountains shaped the person that they are; and the person that they are led them to the mountains. Being and becoming are in many ways so interconnected that they cannot be prised apart without leaving each piece of the puzzle broken and incomplete. The narrative emphasis can shift subtly during the telling of a life history between 'I became a mountaineer' and 'I am a mountaineer'. But when one takes centre stage, the other often lurks in the background. Together they imply: 'I became a mountaineer because I did such and such, and I met so and so'; 'a mountaineer is who I am, always have been, and always will be: I cannot imagine not being a mountaineer'.

Although most of the mountaineers did not actually start climbing mountains until their late teens or early twenties, their narratives about how they became mountaineers often locate beginnings in certain events or tendencies earlier in life which foretell or foreshadow their later desire to climb. There are variations to the story of an awakening identity as a mountaineer: it may be a penchant for climbing trees as a child, or hearing one's Scottish father tell of adventures in East Africa. In the biographical narratives of my mountaineers, however, a number of important themes form the base ingredients. In any particular narrative the quantities and the process of their blending may differ, so that one or other may dominate, but otherwise they are remarkably consistent: getting a "mountain feeling" (falling in love with the mountains); entering the social world of mountaineering (being nurtured and finding like minds); and making choices (more or less consciously deciding: 'this is who I am; this is what I want to do'). 


\section{Getting a "mountain feeling"}

It sort of feels like, a, just like a calling or something. It's just the place I want to be in and, when I'm up in the mountains I feel, like I'm at home or something, just really calm and, peaceful ...

Having considered the many available conceptualisations and possible nuances of the self, Levin (1992) finds the most relevant meaning of self to be experience, a meaning which is associated with the idea of self as process. In emphasising the primacy of experience, Levin concurs with William James who wrote: 'the central part of self is felt, ... something directly experienced' (Levin, 1992:79). Levin makes the personal observation that having a coherent sense of self, and reinforcing and developing that sense of self, feels good. It follows logically then that we should seek out experiences which can contribute to this:

Certain kinds of experience increase my sense of ongoingness, of continuity in time, of being the same self now as I was then. I enjoy those experiences; they feel good. I value them and find that experiencing myself more integrally is intrinsically worthwhile. ... Certain kinds of aesthetic experiences, the ones I go back to again and again, also give me a feeling of cohesion and continuity ... the feeling that I am the same person, that I have been here before, and that I have endured, and at the same time give me a sense that I have changed, that I am understanding, hearing, or seeing differently. I like that feeling.

(Levin, 1992:207-208)

While there are those, such as the philosopher Bergmann (1977), who dispute the notion of an irrevocable, genuine self existing at the core of our being, waiting to be discovered and expressed, it remains a notion with considerable currency in lived experience. Whether we see it as something innate, or something arrived at via the complex processes of our extended consciousness (as Damasio (1999) does), there is without doubt a feeling that we get when there is the right 'click' between who we feel ourselves to be and what is happening around us. Bergmann (1977:91) associates this correspondence between action and the 'real' self with an experience of freedom as 'the expression of qualities with which we identify' - a concept which he argues is far more useful and constructive than the traditional association of freedom with the removal of constraints. This could be described as the experience of 'true self', or the sense of authenticity described here by William James (cited in Levin, 1992:109):

I have often thought that the best way to define a man's character would be to seek out the particular mental or moral attitude in which, when it came upon him, he felt himself most deeply and intensely active and alive. At such moments there is a voice inside which speaks and says, "This is the real me!" 
Self as feeling or experience is evident in the mountaineering narratives, particularly in stories about early mountain experiences. I asked Dave to tell me about when he first became interested in climbing. He began his story with a reference to the first time he could remember being aware of the mountains: spending time looking at them through a small pair of binoculars, from the kitchen window of the house in the small town where he lived as a child. Then he recalled a critical moment on a tramp with his Boys Brigade group in the foothills of his local mountains:

I remember going off by myself and, I might have not even been by myself, but I don't remember anybody else being there, and standing at the entrance to this valley ... and just getting this ... what I call, umm, mountain feeling. ... it's not something you can put into words ... it's quite emotional. You can stand at the entrance to a valley, or you can stand on a mountain and stuff and you get this wave of ... good feeling, or whatever, it's quite a euphoric sort of thing. I remember that feeling at ten or so.

Similarly, Jan's story begins with the exhilaration she has felt in the mountains from a very young age. She describes her first experience of becoming involved with climbing when she went on a family holiday and struck out on her own: an aspiring explorer in the body of a small girl:

we went up to a little place in the foothills and my brother and sister were happy playing around in the little creek and all the rest of it. But I would always climb to the top of the hills and see what was over the other side ... my one ambition was to get to the top of the hill, to see what was on the other side.... So that was my, my initial spur was always to, to look over the mountain.

To Jan, the climbing urge was there, unprompted and unquestioned, something you either had or you lacked:

I remember coming back and saying to my sister, who wasn't at all, outdoor inclined, that how hard it had been and sometimes some parts of it, you'd almost feel your lungs were going to burst, you could hardly keep going and she said 'well why did you bother? Why did you bother?' And I can still remember my shock at her reaction because, it was something that had never occurred to me, to stop, or not go on, or why bother. And yet that was her reaction. ... it was really strange the difference in perception between two kids brought up in the same family doing the same things, and that's the way we were.

From her first experiences of hill walking and rock climbing at about eight or nine, Sue "absolutely loved it" and from then on she always wanted to climb. The story of a young girl instinctively drawn to the mountains has even entered her family lore. When I later asked her if she could imagine her life without mountaineering she said:

I've never thought about it. Because it was always, it was always there. My brother, my oldest brother, tells me that when I was about four and we were travelling through this sort of hilly country to get to my Uncle's house that I looked 
up at the hills and said 'oh I wish I was up there' and like I have no recollection of that but I think that I must have always had this yearning to be on the heights. So it is strange isn't it? ... I've never really questioned it, it was just me, ... I just knew when I first went to the mountain centre that was me, that was what I wanted to do.

Family stories of the depth of Sue's passion for climbing are important not only for shaping her own narrative of self, but perhaps also in helping her family accept the choices she has made. To deal with the anxiety of having someone you love climb, it can be easier to resign yourself to the inevitability of it.

My mother didn't like it at all when I started getting into climbing at university and she tried hard to persuade me not to do it ... I think she came to a point where she just accepted that that was me and I was going to do it and she just let me get on with it. ${ }^{32}$

Much later in her life story the acceptance of a mutual 'need' to climb is central to Sue's relationship with her husband, and when I asked her how she would feel about her own children climbing she conceded that the same logic should apply:

if they get into harder alpine climbing, Himalayan climbing, I think I'd be quite worried. ... But I had to do it and so you know if the kids really want to do it then that's their life you know.

For Bill and Mark an important trigger that led them to the mountains was encountering, and surviving, the forces of nature. Bill's "appetite for more adventure" was whetted when he was caught in a flooded river while tramping with his brother and father as a young boy. Mark sees his beginnings in playing outdoors as a child: "always into exploring and chasing up and down the riverbanks and, doing stuff like that. Climbing trees, falling in the river". But the critical "romantic" experience came on a school outdoor pursuits programme:

It was one of those experiences that everyone hated at the time, but as soon as it was over everyone thought 'oh you know that was so cool we did this and we did that and it was so cold, everyone was freezing to bits and we were going to get lost but we didn't' And yeah, and I thrived on it, I thought it was just the most amazing experience I'd ever had. Yeah. It was kind of unreal really. And so that got me into the outdoors, that made me want to go tramping and, camping and, doing stuff. ${ }^{33}$

Chris begins his story in an unassuming way: "I'd done a bit of tramping, been in the snow a bit.... [pause] I don't know - I guess I just ended up hanging out with the climber types in the tramping club”. But how he feels when in the mountains is crucial. On Chris's first

\footnotetext{
${ }^{32}$ When reviewing her transcript Sue added that her mother, who was Catholic, also prayed a lot as a response to her climbing. For full story see Appendix C, number 1, page 265.

${ }^{33}$ For full story see Appendix C, number 2, page 265.
} 
climb, his companion, who Chris had assumed was more experienced than he perhaps was, took a big fall, pulling out the equipment anchoring them to the mountain. The following weekend Chris took a fall and had to be rescued by helicopter. Still, Chris "just loved it, got right into the mountains, being in the mountains ... it never became too hostile, I mean, you know, felt right at home, which is obviously why I got into it”.

The New Zealand artist, Max Gimblett, says home 'is where your sense of self is deeply stirred', ${ }^{34}$ and this is an apt description of how mountaineers feel about the mountains. However it comes about, this "mountain feeling” - being comfortable, at home, or exhilarated in the mountains, feeling as part of the landscape, or that the mountains are part of you - ultimately it is the most durable aspect of the climber's identity and even, some would argue, the only criterion necessary to call yourself a mountaineer. It provides the life-long basis to the identity, even when climbers are well past their prime; as long as they keep 'appreciating' the mountains in whatever capacity they can, their identity is intact.

I return to the centrality of the "mountain feeling" in Chapter 4. It is important to note at this point, however, that there are obvious echoes here of a Romantic sentiment: that growth of feeling for nature which emerged in the eighteenth century, with Rousseau at the forefront, and concerned itself with an intensely emotional response to nature. Such noble sentiments as awe and astonishment provided a counter-balance against the 'too pressing regulative control of an analytic, disengaging, order-imposing reason' heralded by the Enlightenment (Taylor, 1989:297, 301). In the mountaineers' narratives, however, there is less of the Romantic evangelism concerning the universal potential for nature to direct us towards the 'fundamentally good'. There are a number of recurring moral messages, but I will discuss these later also. Of relevance here are those aesthetic experiences described by Levin (1992): the ones that give us a sense of 'coherence and continuity' and for that reason make us feel good. We seek them out again and again, because when we experience them we get that sense of 'yes, this is me'. As Simon told me, "some pretty amazing times, yeah definitely the best times in my life have been in the mountains".

Thus it is the story of a deeply felt personal, as opposed to universal, passion, which both marks one's story as different from others' stories (whether of siblings, spouses, parents or childhood friends), and aligns one with those who profess a similar feeling for the mountains, such that they will orient their lives towards them. It is a story of belonging to a world demarcated by emotional and social boundaries. The following section discusses

\footnotetext{
${ }^{34}$ Max Gimblett is quoted in Wedde (2004).
} 84 
how the climbers encounter and enter the social world of mountaineering, and the importance this has for the shape of a narrative about becoming a mountaineer.

\section{Entering the social world of mountaineering}

The social worlds of serious leisure activities have been extensively discussed by Stebbins (1992; 2001), using Unruh's (1983:14) definition as a basis, according to which a social world is an 'extremely large, highly permeable, amorphous, and spatially transcendent form of social organization wherein actors are linked cognitively through shared channels of communication'. A social world encompases four types of members: 'strangers', who exist on the fringes without necessarily being active participants (for example, equipment suppliers and book publishers); 'tourists', who are the spectators or observers of an activity; 'regulars', who are the active and routine participants of the social world; and finally, the 'insiders'; that is, 'the small number of outstanding participants who show exceptional devotion to, and personal development in, the social world' (Stebbins, 2005:114). Stebbins' (2005) recent study of the mountaineering social world in the Canadian Rockies found that it operated primarily at an 'informal level', organised around small groups and social networks through which participants shared information and identified potential climbing partners.

A similar observation could be made of the mountaineers in this study. In relation to the current discussion on becoming a mountaineer, most speak of entering the social world through connections with family and friends. This often later leads to joining a club or taking a course. Through these networks the young, aspiring mountaineers find like minds who nurture their development. Often, particular people are seen to have a pivotal influence, and these become role models as the mountaineers consolidate their identities.

Pete says he did not have any interest as a teenager in "going into the hills or climbing or tramping, other than being dragged along with Dad every now and then”. But he starts his story there, with his parents exposing him to the outdoors at an early age. The turning point came when he started university and went on a tramping trip into an alpine area with a friend. Here they met a couple of experienced climbers who lent them their ice axes so that they could explore higher up. They "got into a bit of crevasse country and poked around and had a good look around and I just came out of that and that's just what I wanted to do. I just wanted to get back into that country at every opportunity I could". The older brother of one of his friends was an active climber, one of the "hard men" of a 
local group climbing new routes and 'pushing the boundaries' in New Zealand during the 1970s. Pete and his friends were taken "under their wings" and he feels fortunate to have been exposed to good climbers at an early stage. He improved quickly, "always aspiring to the stuff these guys were doing”, and this was the focus of his life for the next fifteen years.

Asked to talk about his most memorable climbs, Pete describes his first ascent of Aoraki/Mount Cook, and the profound imprint left on his life story by his early role model becomes evident. He begins the story by apologising in advance: "it probably sounds a bit corny”. When his friend's brother was killed in a climbing accident in the Himalaya, the two young men honoured their mentor's wish to have the keys to his motorbike taken to the top of Aoraki/Mount Cook in the event of his death, and they further honoured him by climbing it in the manner and spirit in which he himself had first climbed it. As Pete told me this story, it clearly brought back his depth of feeling at the time.

And, yeah, um, that's what we did. ... that was quite emotional really and Nick and I did that. We decided we'd climb Cook the way that Sam climbed it the first time he climbed it and, ah, of course he didn't go and do the easiest route on Cook. So here we are a couple of young, budding climbers and we went off on our own and retraced his steps up the um - it's not really an overly technically, difficult climb but it was, a harder climb than anything we'd done ... a route on the Hooker Face which, um, led us out through onto the High Peak and, ah, dropped his keys off and came down and had $a$, had a really great climb. So that was a real significant one.

So Sam's story became the blueprint for Pete, demonstrating the way in which life narratives of others are critical: by interpreting them in the light of our own stories we are engaged in the 'fine tuning' of our identities (Cottle, 2002). Thus it is inevitable that our narratives come to reflect the kind of social milieu or 'habitus' with which we associate ourselves, because other selves are required in the process of self-definition (Bruner, 1990; Levin, 1992; Taylor, 1989):

Feelings of aliveness, cohesion, agency, continuity (ongoingness), and self-worth come from both within and without ... I become a self by being treated as a self. I learn who and what I am by the ways in which I am treated.

(Levin, 1992:207-208)

Almost without fail, the mountaineers, like Pete, tell of formative experiences with various people in the outdoors which preceded their introduction to climbing, suggesting that this is seen as an important prerequisite, or apprenticeship for a budding young climber, even if it is not recognised at the time. For Mike, early tramping trips with his family, then the Boy Scouts and, later, on school camps, made the progression to climbing pretty much 
inevitable - a kind of natural progression: "I sort of thought, 'well what's the next thing from tramping?'” As with Pete, Mike met like minded people at university and headed for the hills. Early exposure to the physical and social environment of the outdoors is followed by the meeting of other selves with whom they can consolidate their process of self-definition as mountaineers.

Simon has perhaps the most dramatic story of early nurturing. His father was a mountaineer and he was taken up his first small mountain at the age of eight. They slept on the summit and he "threw up on a can of sardines". He still thought it was a "pretty good time". Other trips followed in successive summers: "I was pretty much just a normal, school kid, and did normal things but, secretly, I was becoming a mountaineer in my school holidays". By the age of fourteen, after a ten-day "epic", Simon stood on the summit of Mount Aspiring, a 3,000 metre peak. His memory of this climb stands out starkly for its emotional intensity, and it becomes pivotal to his sense of the kind of climber he aspires to be:

I've done some quite big technical climbing now but, that really stands out for me as a, as a big one. And I try and, every time I go climbing now I try and capture that same enthusiasm ... So I have to keep reminding myself. That was a good day. ... I still remember the planes circling around Mt Aspiring, as we were all on the summit.

That was the last time Simon climbed with his father. Three weeks later his father was injured in a car accident and was never able to climb again. By the time he went to university Simon had lost much of his enthusiasm for climbing, until he met another young climber that he recognised as having a prodigious talent. They struck up a partnership, until tragedy struck again. On a climbing trip together, they decided to climb separately for a day. Simon returned and his friend did not. Of this he said there was " $a$ lesson to be learned", which is also a role the story of another can play.

I take up Simon's story again, but here it is my intention to show how significant characters emerge and play pivotal roles in the narratives about becoming mountaineers. Sometimes they present a general background rabble. For Chris, it was the "climber types”, “all these bushy hairy guys”. Other times they appear (by chance, as a lucky occurrence) and make their exits without much drama. For Sue it was a "climbing nun" who'd been on an expedition to the Hindu Kush, and a "good female climber" gave the teenage Jane "a real good base". And then there are those, as in the stories of Simon and 
Pete, who make their mark and then punctuate the narrative with tragedy, becoming an almost haunting presence in the story thereafter.

As a final variation on this theme of the importance of having the self-narratives of others intersect with our own, and spur them on, this story of Sue's is an extreme example of what happens to your sense of the norm when you are exposed to the life stories of mountaineers, and no others:

I just thought of a wee story when you asked if I'd like to see my children climbing. When we lived at Mt Cook the boys were two and three and when we left they were three and a half and nearly five. And so they didn't really remember anything about life before Mt Cook and everybody there, you know, where you'd go to anybody's house there's always an ice axe and boots and coats and maybe skis and stuff in the entrance hallway and that. So that was the sort of environment they were growing up in and my mother was coming out to visit. And we were going to be collecting her and we were talking about how much luggage she might have. You know whether we could fit it in the boot of the vehicle and I said 'oh Granny won't have much luggage with her' and one of the boys said 'oh but what about her climbing gear?' And I said 'no Granny won't have any climbing gear'. And he thought about it for a wee minute and then he said 'oh I suppose not she can just use yours when she's here'. So that's what it's like when you grow up in a climbing household.

I return, in Chapter 4, to the social construction of the identity of a mountaineer. This section, however, demonstrates the way in which an early entry into the social world of mountaineering complements the "mountain feeling" in developing a mountaineering self. Spending time in the outdoors as a child, in particular involvement in an activity like tramping, serves as a 'natural' prerequisite to feeling comfortable in the mountaineering world. In addition, certain people can take a special place within a narrative, similar to the way in which certain events come to be associated with epiphanies, or turning points in people's lives. Such people are perhaps embodied epiphanies and, as in the case of Pete and Simon, the later 'absence' of these people in a physical sense can heighten their narrative presence.

Once an identity as a mountaineer has begun to consolidate through a strong sense of attachment to the alpine environment and an immersion in the social world of mountaineering, the third narrative element of becoming a mountaineer is making choices that commit one to a mountaineering lifestyle. What these choices entail and how they are made, are discussed below. 


\section{Making choices}

Making mountaineering the centre of one's life is often seen as being the result of choices, and not always easy choices. Often it is narrated as a choice between doing what you love and being who you want to be on the one hand, and doing what is expected of you and being who other people want you to be on the other. So, in many respects it is presented as a 'Clayton's' choice, in the sense that trying to be the person you are not is no real choice at all.

For Adam it is a difficult decision to quit his doctoral studies and go to New Zealand to climb. He knows his decision will disappoint people, but he feels he has to make it in order to be a better person: the person he wants to be.

I found it really hard throughout the ... whole two years [of working on my PhD] to, to get my mind properly on my work and I was constantly thinking of, of coming over here and climbing over here. But I was sort of too afraid to leave behind something that everyone expected me to kind of do. And something that I sort of deep down thought perhaps I should really be doing as well. So anyway it took those two years to sort of build up the courage to decide to come over here ... [but] there's no point in sort of, racking your brain over something you're not wanting to do. [You're] just a much happier person, a much more efficient person and more pleasant person to be with if you're doing what you really enjoy.

Dan reaches a similar conclusion, following a comparable and in some respects on-going struggle between what is "expected" and what he is "really passionate about". He gradually comes to the realisation that climbing is not something that he is "going to be happy doing on weekends".

I guess it's something I've kind of always known but ... I guess I've just been admitting it to myself really. ... More of a confirmation within yourself of what you really want to do ... that it's alright to feel like this. ... [it's] been a process over a couple of years of, experimentation really, you know, trying different things, ways of living, different jobs and travelling. ${ }^{35}$

In Bob's narrative, his decision to 'go south' to climb in the 1960s is the result of an epiphany which has become, in many respects, the leitmotif of his life, the moral to his story:

I'd flopped at school because I was busy looking out the window. 'When's the next trip going to be?' In fact I use that expression a lot - windows to look out of.... I started out in advertising after flopping at school. I had some artistic talent and, I ended up working as an artist in a big advertising agency in a studio with, all down one wall ... the workstations, in a great long line and I was busy working ... And I can remember sitting there, I looked out the window, I saw all these windows in town, [then at] the line of people and there was the head artist right at the top.

\footnotetext{
${ }^{35}$ For full story see Appendix C, number 3, page 265.
} 
And I started to do some counting and I thought 'gee you know it's going to take me a long time to get there and that's not really what I want to do'.... and then I looked out the window and saw all these windows and that's how I formed that ... to me it was quite a revelation to suddenly realise that there are many windows to look out of, and that one shouldn't restrict oneself, so I think at about that point I decided that was it. I was off down south to go climbing. And, I did.

Chris also has a story about doing what you love rather than what is expected of you, but rather than a single defining moment like Bob, or a drawn out struggle like Adam, his is a joke he shares with his mother:

my mum always laughs ... she always remembers when I was twenty ... at varsity everyone was talking about settling down, getting a job, you know. I said 'mum, mum I've got all this climbing I want to do, by the time I'm thirty I won't be able to do it any more. I've gotta get it done now'. So now I'm forty [laughs]. There's still heaps to do.

For Kath it was a "conscious decision" to "put everything else aside" to climb mountains. She says: "I decided I didn't want a career. I just wanted to be a climber". It was an "easy" decision to make, but that did not mean that it was necessarily an easy life she had chosen, and it certainly was not the life she was expected to have. While her friends from school were all at university "going to parties" and "meeting boys", she was living in "dead end places" near the mountains and taking unskilled casual work. ${ }^{36}$

For a number of the mountaineers, notably of the older generation, the consequences of their decision to put mountaineering ahead of other things in their lives have been harder to resolve in their narratives, because for them the cost was higher. Terry sees his mountaineering lifestyle as having cost him his marriage:

climbing mountains was, was - I have to say 'was', because I've slightly changed now actually - climbing mountains was, as equal in life to being married. Isn't that awful. Is it? I don't know. ... Yeah but it was, and it was to a lot of us. ... the separation rate amongst my climbing buddies has been exceptionally high. Very high indeed. I happened to hang on, a lot, lot longer than most. It's true though. ... The bloke shot off at the weekends doing his climbing and leaving his missus at home. It's not fair, you know I mean I have to say it's, it's pretty arrogant of us mountaineers to think like that.

To Bill, mountaineering was freedom from boredom and drudgery in post-war New Zealand of the 1950s. But his desire for escape set him apart from those who were "getting on with life": people to whom the decisions he had made in his life would seem self-centred. He saw his inability to "say no to adventure" as having cost him his business

\footnotetext{
${ }^{36}$ For full story see Appendix C, number 4, page 265. 
and his marriage, and for this he has a sense of guilt. Not that he feels his reasoning has been wrong - that life is too short to put off the "real" things in it - merely the timing. ${ }^{37}$

Jan, who also began climbing in the 1950s, has a supportive husband who is also a climber, but still feels a tension between her climbing and what is expected of her as a wife and mother:

I was off doing things which lots of people criticised behind my back. 'How can she do this, how can she do this with a baby, how can she possibly go off on an expedition ... with a little three year old?' And of course it was hard and I had nightmares about things happening to him while I was away and all the rest of it. But, Bruce supported me.

In her narrative, Jan is able to resolve this tension somewhat by talking about the people that have supported her, and explaining some of the unusual circumstances behind her decision to priorise climbing in her life. Like Bill and Terry though, she does not defend her decisions on the basis of 'this is who I am' and 'this is what makes me happy', as many of the later-generation climbers do. Nonetheless, there is evidence in her story to suggest that this is how she felt (see her earlier story about how she became a mountaineer, page $82) .{ }^{38}$

The stories of Bill and Jan demonstrate the way in which our narratives, and the messages and explanations they contain, are constrained and shaped by the kinds of narratives that dominate the societies in which we live. New Zealand in the 1950s was a relatively conservative society with few recognised outlets for creative expression (King, 2003). People who were 'different' often struggled with their difference, and to make decisions in accordance with their individuality, if this contravened certain social values and expectations. A well-known 'casualty' of this time was the writer, Janet Frame, who was misdiagnosed as a schizophrenic and spent time in psychiatric institutions, before her 'difference' was recognised as being originality and creative talent, rather than mental illness.

A personal history which illustrates the influence of socially-sanctioned narratives on the construction of identity in a different way is that of Thomas. In his story there is much less

\footnotetext{
${ }^{37}$ Both Terry and Bill gave me the impression that they thought I would judge them harshly for having jeopardised their marriages for their climbing, and spoke with difficulty about this aspect of their lives. I never pressed them to talk about such things, although I did endeavour to convey to them that I was not judgemental. These issues are discussed in more detail in Chapter 2.

${ }^{38}$ Like Terry and Bill, Jan seemed concerned about being judged harshly for having put climbing ahead of other things in her life. She went to some lengths to describe to me the reasons behind the decisions she made, even though some of the details were very personal, and while she spoke of them in the interview, she asked me not to divulge them in this thesis.
} 
tension between climbing and other aspects of his life, although he began climbing at the same time as Jan and Bill, and also went on to marry and have children. But Thomas grew up in Switzerland, where people climbed mountains as "a matter of course":

My grandfather, my mother's father, he was a climber, and so we always heard about the climbs my mother did when she was a child and it was something which we, took for granted. ... I mean the mountains are there, I mean you can't get away from them, so you might as well go up them [laughs] and see what's on the other side.

Thomas moved between phases of his life when he climbed quite "fanatically", and times when his trips to the mountains were less frequent and more relaxed, but not being able to climb due to other commitments did not create tensions for him, "it was just automatic". He does not see any inherent difficulties in balancing family and climbing; in fact he is critical of those who stopped climbing and "blamed" this on their family responsibilities. This is something he has "never done":

for me that was not a problem because, if I couldn't go then I couldn't go. ... I worked for myself too so I think I had plenty of, of challenges actually, so it was no problem. ... I think either we want to go climbing or we don't. But I think to find all sorts of reasons why we are prevented, I think that's, that's a bit too cheap and I think it's been used a lot. I know a lot of people of my age [say] 'I'd love to you know, how do you do it? Don't you feel a bit irresponsible?', you know. I mean, that's not what it's about I think.

He also describes the situation of a friend in Switzerland: "he had family at home and I think his thing was, and his wife too, it's better he is home, not every weekend, but when he's home he was actually happy to be home, he doesn't think he wants to be somewhere else, and you are responsible when you go". The essence of this story is closer to the narratives of younger climbers like Dan and Adam, than to those of the same generation as Thomas who grew up in New Zealand.

The art of creating a self, according to Bruner (2002), is to get all the many 'self-making' stories we create to coalesce into one identity. Damasio (1999:225) has also observed that while a number of possible 'drafts' may be scripted, our tendency is to select those that contribute to a continuous, unified self. This tendency appears to have significant advantages in terms of psychological health and well-being. So while Expressivism, as Taylor (1989) argues, has made it possible since the late seventeenth century for us to talk about living our lives in accordance with our innate originality and creative potential (and the narratives of the mountaineers certainly tend to be shaped in such a way) it undoubtedly helps if this story can be reconciled with other simultaneous stories of identity, such as mother, or husband, or son, or 'useful' member of society. The ease or difficulty with which this is achieved is influenced by the kinds of narratives those around 
us are telling, and thus depends upon the society in which we grow up, and/or the particular company that we keep.

\section{Summary}

The stories of our lives are not just told, but also lived, in ways that make it virtually impossible to distinguish the living and the telling as discreet processes. As Bauman (2001:7-8) explains:

One lives one's life as a story yet to be told, but the way the story hoping to be told is to be woven decides the technique by which the yarn of life is spun ... One can say, paradoxically, that the stories told of lives interfere with lives lived before the lives have been lived to be told.

Or, put another way, the conviction with which we tell a story of our lives as having a particular flavour, a particular shape, the more conviction we will have in living our lives in accordance with the story, the more convincing the story will become ... and so on. Having become mountaineers, and as long as we remain mountaineers, we will tell as convincing and coherent a story as possible about how mountaineering defines us.

Becoming is also being. And if our story stretches back as long as we remember, and has a sense of inevitability about it, there is a good chance that it will stretch on into the future.

Ricoeur (1992:122) describes this process as the 'dialectic of innovation and sedimentation' which underlies the acquisition of habit:

habit gives a history to character, but this is a history in which sedimentation tends to cover over the innovation which preceded it, even to the point of abolishing the latter. ... It is this sedimentation which confers on character ... [a sense of] permanence in time.

(Ricoeur, 1992:121)

I have considered here the stories that were told to me about becoming a mountaineer, highlighting the common narrative elements through which a sense of self as a mountaineer emerges in a personal history: as early experience which engenders (or illustrates) a strong emotional attachment to and sense of ease and exhilaration in the mountains; as the intersection of the life story with others engaged in a similar process of self-making, their stories inspiring and nurturing their own; and through making choices that lead them to 'follow their hearts', along paths less conventional (to varying extents), and climb mountains.

Given that these are the life stories of committed mountaineers, these themes - getting a “mountain feeling”, entering the social world of mountaineering, and making choices that 
lead to becoming a mountaineering 'devotee' - can be read as narrative elements that lend themselves to durability and commitment. In the next section I expand on how a durable and 'true' sense of self is constructed through a 'folk psychology' (Bruner, 1990) of mountaineering, which emerges from the narratives as the mountaineers describe aspects of the activity that enhance and validate their sense of who they are.

\section{The durability of mountaineering selves}

\section{$\underline{\text { Introduction: Dave's story }}$}

[W] ith true mountaineers when, when you go into the mountains you are yourself, you aren't anybody else, ... there's just those total moments of clarity. You know that, this is where you belong, it's, it's funny. ... and it's weird because we weren't born there or whatever, ... but you just feel so at home, you just feel grounded ... mountaineering gives me so much that I wouldn't want to give it up. I don't, there's nothing else that I can conceivably think of doing that would give me as much as mountaineering has ... if I couldn't go mountaineering then, you know, it's like, like gnawing my right arm off, you know [laughs].

In the previous section I discussed the ways in which the mountaineers I interviewed came to see themselves as climbers, and consolidated their commitment to the identity and lifestyle associated with mountaineering. This section further examines the way in which they see mountaineering as the means by which they understand and express their 'true' selves, and how and why this sense of self is seen to be a durable one. By way of introduction and to show how these themes are constructed in a full personal history, I take up again the story of Dave who, as we heard earlier, stood at the entrance of a valley at the age of ten and fell in love with the mountains.

From being a self-described "skinny, asthmatic, sickly and wouldn't-say-boo-to-a-fly" boy, Dave became a mountaineer who climbs technical and difficult routes. Also, he is now "less polite", cares less about what people think of him, and admits to being a little eccentric. Dave tells this story about the fears and doubts he has had to overcome in order to become a mountaineer:

[I was] sitting here, like, sitting at this bivvy rock with all these huge mountains around, I just felt gripped, you know, I was just like really scared and really sort of shaky and stuff, it was horrible. ... what I'm trying to get at is ... I get these feelings quite a lot with mountaineering but you sort of just move on from them a little bit, or you relax about it and it comes right - the fear kind of goes away. It doesn't mean you're never not scared of them or intimidated or whatever, but ... you kind of move on. But I've had that a lot through my mountaineering - getting quite intimidated and quite sort of shaky and ... wondering [laughs], wondering actually if I'm ... if I can actually go mountaineering. It's sort of a ... it can be quite scary 
because you know you love it and you know you want to do it, but it can be quite... a fearful thing.

In fact, Dave later discovered that he can use his fear to "tap into" an extremely focused state that allows him to succeed on difficult and dangerous solo climbs:

I just walked up to the base of this thing ... and I just started climbing. And I got to the point of no return. I couldn't turn around and go down. But above me was this vertical step and ... it was melting. So I was, I was really hosed [laughs]. I didn't have a rope, so I couldn't abseil. So I was really really committed there was no, no way out of it. So I stood at the bottom of this melting thing for, I don't know it must have been a long time, I think it was probably an hour or so. Until I got to the point where I couldn't stand there any longer, 'cause ... my calf muscles were, pumping. ${ }^{39}$ So I just started up this thing and ... once I'd committed to it I don't remember umm ... any doubts. There was, there was nothing, I was just climbing, and there was just a purity, ... it's a distillation of everything, it's like, pure alcohol, you know it's clear, everything's just this, you're zoning, it's amazing. ... and I got to the top of this thing, and down climbed - it's a really dangerous place, it's like big avalanche country, you'd you know die untold times - but I even you know down-climbed these nasty slopes and got back down to the car.

Between these two stories lies a narrative about the evolution of Dave's sense of self through mountaineering. His personal history involves a detailed account of a mountaineering 'career path' with small steps of increasing difficulty as he gains more skills and courage to try harder things. This was largely self-taught, from reading books, and through trial and error. The goal of this "natural progression" was to find the ultimate limit of his potential. It was a process of setting out to learn what he was capable of, both physically and emotionally, and attempting to expand this by pushing his limits through a series of challenges.

The difficulty with constantly climbing harder and harder, however, was recognising when he had pushed his limits too far and should "pull back". Sometimes Dave makes mistakes and gets "spanked", but that is part of the process of being self-taught - learning from experience, as on one climb:

I remember abseiling off and Paul ... we put a sling around a rock, and the sling is connected, you know, joined together with a ... it's a tape knot, it's a square knot, and Paul, when I got half-way down he said - 'Oh, hang on, the ends are slipping through'. So the knot was actually coming undone at the time.... but the thing is ... nothing happened, like the rope didn't ping, I didn't die and Paul fixed up the knot and it was all fine ... I've never had an abseiling accident and I've been mountaineering for 20 years nearly, and I'm always really careful with tape knots and stuff. So ... it teaches you really good lessons. And I think that's the whole

\footnotetext{
39 "Pumping": Where the muscles are in pain and 'pumped up' with lactic acid through the effort required for extreme exertion. Being "pumped up" can also refer to the mental state of excitement or anxiety experienced, for example, before or during a difficult climb.
} 
thing about learning as you go ... if you can survive the little things that crop up and recognise them as being formative things then ... you'll come out stronger for it.

At the same time he has been driven on by the fear of selling himself short, of ending up wondering 'what could have been':

I don't want to end up a, a grizzly old, umm, 65-70 year old lamenting the loss of what I didn't do, or what I didn't achieve. I think I've pushed it as hard as my technical and mental abilities and physical, you know, ability. I mean there'll always be that little bit of doubt that, you know, 'gosh maybe I could have pushed it that little bit harder', but, I'd probably be dead, I would imagine [laughs]. So, you know, there's, there's that toss up really. I'd quite like to live to be an old man and, you know, be able to sit under a tree and go 'wicked, that was awesome', you know, just go 'that was just the most insane time I've ever had', you know.

For Dave, any suffering endured due to the challenges of climbing are insignificant in relation to his love of and sense of commitment to being a mountaineer. He was once stranded for four nights in a crevasse - with a broken hip and nothing to eat - waiting to be rescued. At the time he was rescued, Dave does not think that he could have survived much longer. But he does not tell the story of this accident as part of his initial narrative, though it is the worst experience he has had in the mountains. Instead, he talks of it later in the interview when I ask him if he has ever felt the mountains to be a hostile place. While he describes the experience as a hideous "nightmare" at the time, of the aftermath he says:

I had to deal with that little bit of, post traumatic stress syndrome or whatever. But, you ... just move on and that's cool. ... I don't have any lasting scars from that, you know sitting in the, snow thinking badly about the mountains. I realise that, it's not the mountains it's me, you know.

Thus, despite fear and injury, mountaineering is for Dave both the expression of his 'true self' and the means by which he has found it:

it's my individuality as, who I am, but, an honest benchmark is when ... you know you're going to die, you know that's who you are and I've, I've seen that and I've felt it. ... it's a definite form of expression, mountaineering. I mean it does express my true, personality I think. ... You've got to, know yourself pretty well to, to go away mountaineering.

Dave is a particularly engrossing and reflective story-teller, but the others told stories with a similar message: that certain characteristics of the mountain environment and mountaineering as an activity allow them to construct a 'true' sense of who they are. Pete for example, cannot imagine not being a mountaineer:

it's always there, won't um, never stop climbing sort of thing. I just can't imagine not being in or around the mountains. 
When asked directly if they ever think about giving up, others responded that they sometimes feel like taking a break, or as they grow older feel they have to lower their ambitions, but generally the answer to this question was an emphatic "no" or "never":

Oh never. Absolutely never. No, never. [laughs] There's been no reason to. You know you, you break a bone, you, have an arthroscopy on your leg, twice on your knee and, twist an ankle and, your mates die. You know they're dying around you. Never. Never ever. Yep. See, because ... it's a, a part of you, you see.

Thus the desire to climb, and the sense that mountaineers are who they - irrepressibly are, is so strong that it over-rides bad experiences. As Dave says, "I love it so much that, you just work through those things”. Early in her climbing career Sue had a traumatic experience but, like Dave after his rescue from the crevasse, she found the desire to climb soon overcame the trauma of the event. She could not imagine, she later said, what else she would do in her holidays:

Had a few scary experiences in my first couple of trips to the Alps, being inexperienced, and got caught in storms and being unfit and not moving fast enough, things like that. There was one occasion when I considered giving it up which was when I was due to go out and join up with my regular climbing partner. She'd gone out a couple of weeks before me and then I got news that she'd been killed. So I had to go and tell her parents and that had a really big impact because I realised what the impact would be on my family if I died. So for about a week or two I thought maybe I wouldn't go to the Alps after all, and maybe I'd give up climbing. But it didn't last very long.

Jan expresses a similar feeling after encountering her first huge crevasse field at Aoraki/Mount Cook: "I remember sort of having nightmares ... But, it didn't put me off. Nothing put me off. Nothing deterred me from, wanting to climb”. Although Steph said that she had never felt like giving up, she sometimes wishes that her 'need' to climb was not so strong:

there have been times where I've, I've often thought - gosh it would be nice if I didn't, if I wasn't into climbing but I was into, knitting [laughs]. Life would be so much easier. And I wish I wasn't this sort of person 'cause it's, sometimes it's just you know, it's quite a big effort to, go and climb a mountain. And I wish I could be content, to sit around at home, sometimes. But I've, I've pretty much gotten over that [laughs], yeah. I think that usually strikes me the most when I'm, living in the city and studying or something like that and I just really, start to get really itchy feet and want to be up in the mountains, and that's when I think - oh if only I was a different sort of person, I wouldn't be feeling like this. But it doesn't make me want to give it up. It just, sometimes I just feel a bit, frustrated, yeah.

Indeed, to have survived such adverse conditions and events, the mountaineering selves of those I interviewed are remarkably durable. The characteristics of mountaineering that aid the construction of a durable and 'true' sense of self are expressed in the narratives as a 
kind of 'folk psychology'; that is, as stories containing certain beliefs about the way in which 'being in the mountains' is experienced, and how it should be experienced, particularly if one wants to stay alive. Bruner (1990:35) describes folk psychology as 'a system by which people organize their experience in, knowledge about, and transactions with the social world'. As such, it is 'one of the most powerful constitutive instruments' of culture, comprising:

a set of more or less connected, more or less normative descriptions about how human beings "tick," what our own and other minds are like, what one can expect situated action to be like, what are possible modes of life, how one commits oneself to them, and so on ... its organizing principle is narrative rather than conceptual.

This is similar to what Ricoeur (1992:164) describes as 'the popular exercise of practical wisdom' in his discussion of Walter Benjamin's essay "The Storyteller". Benjamin sees the art of storytelling as 'the art of exchanging experiences', which always includes evaluations of actions and agents.

The following stories are about three important dimensions in the construction of a durable sense of self: discovering one's self; expanding one's sense of self; and expressing this self. Mountaineering allows mountaineers, according to their 'practical wisdom', to discover their capabilities and their limitations, through self-reliance and action in an environment which does not forgive inaccurate assessments of the self; to expand their sense of self by progressing through a series of ever-increasing challenges, and through experiencing committing situations in which they must, by necessity, 'tap into' resources they did not previously know that they possessed; and finally, to express their individuality through the style in which they climb. These characteristics make mountaineering, for these mountaineers, particularly conducive to the construction of a durable sense of self $-\mathrm{a}$ solid identity in a liquid world. In the summary of this chapter, the durability of the mountaineering selves is considered in the light of discussions surrounding the problematic nature of identity in contemporary society.

\section{Discovering self}

The discovery of self through mountaineering is achieved through two aspects of climbing mountains according to the stories mountaineers tell about it. Firstly, mountaineering demands self-reliance, and by being 'left to one's own devices' mountaineers feel that they gain a sense of their true capabilities. Secondly, the 'unforgiving' nature of the mountain environment means that mountaineering provides an 'honest test' of self, and of one's strengths and weaknesses. 


\section{Self-discovery through self-reliance}

The remoteness and wildness of the mountains fosters an intense sense of self-reliance in mountaineers. The nature of the environment, and the nature of the relationship between mountain and mountaineer is critical here. Places must be approached "purely on nature's terms", as Bob says, then "through the discovery of land ... one can discover oneself ... on the real terms that are not contrived".

That whole business of being able to equip yourself and go and live out there. And experience what, what that means. And that's the guts of it. That's the raw guts of what it's about really. We live such cloistered lives.

There should be no 'crutches' or undue 'outside' assistance - then there can be the pleasure of a sense of control in a demanding environment, and a sense that survival came down to one's own resources and skills. The feeling of self-reliance is particularly intense when climbing solo, as then all credit and sense of achievement belong to the self. As Jess says, "I climb it. It's me climbing it". For Pip, climbing is "about being in wilderness areas ... I really love just moving in the mountains ... moving over territory":

the thing that means the most to me is being able to survive, for a week or two, in the mountains. ... Those sorts of trips are really good. They're much more adventurous ... where you've got to pick your own route.

Steph pauses when I ask her what she feels are her most satisfying mountaineering achievements.

A lot of people ask me that actually. ... It's a difficult question. ... I don't know, I'd maybe say things that I've done by myself, which haven't been nearly as hard as things that I've done with other people. ... but just doing things by yourself ... it's a way to sort of prove to yourself that, yeah, that you've done it all, been in control and, it's really peaceful as well, really quiet. ... [and] it shows me how far I have come 'cause it's easy to, feel like, you're not really improving somehow. But if I go by myself and, I realise that I've got a whole new level of confidence than last time I went somewhere by myself, then that's really cool.

One of the experiences she feels best about in this respect was when she was on a long trip with a couple of friends, and they ran low on food. Steph offered to walk out of the mountains, down a river valley, and leave the other two to continue with the remaining food. So she spent two days alone, making her way out of the mountains, without a map or a compass, a cooker or a tent:

suddenly I found myself, sort of in the middle of, nowhere, well quite high up this gnarly West Coast river with a, couple of big days of walking ahead of me, just by myself ... it was kind of a bit of a shock, suddenly being, left to my own devices, but once I got into the swing of it I found little things really satisfying like, 'cause I'd given them everything, all the gear, I didn't have a cooker, and um, I had to just 
make a fire so I could cook my dinner and, I got to a hut the first night, and I, opened up the, it was this pot belly stove to, so I could light the fire and it was full of water, so I had to spend hours just trying to get this fire going and emptying out the water and gathering up heaps of wood and, but eventually I did, and by the time, I had this fire going and it was blazing away and the hut was all warm and I had a billy of tea on the go and I had my dinner and I just felt so satisfied, yeah just really simple things ... just yeah, having adventures like that when you're by yourself somehow are more, once you've done them they're just so satisfying ... by the time I came out I felt really, really, really good, really calm ... Somehow it's just, spending lots of time by yourself makes you, sort your head out a bit and, yeah it's good.

Mark also feels that, being alone in the mountains, "you can, centre yourself so well because you're self-reliant; you're independent”. He likes the feeling that he can look after himself and that he has everything he needs to survive in a potentially hostile yet beautiful place. For him, it is the "remarkable" feeling of having the world to himself and quietly trying to make sense of his place in it:

the self-reliance thing ... I just think it's so good for your soul. And you also get in touch with who you are and ... why you actually do this ... you start thinking about, how self-sufficient you are and, and how nice it is to be just on your own, alone with your thoughts, all this beautiful landscape. Whether it's soft beautiful snow or whether it's wicked wind howling and you know Nature at its best. At its finest. At its most powerful. And how fragile this frail little human body is in this environment and, and you start to reap the rewards of, you know, spending those hours and hours of sweat and tears. ${ }^{40}$

Adam also finds that in soloing he has "a greater awareness, of the environment. The beauty of things around me ... and also that sort of funny excited feeling you get in your stomach when you realise you're totally alone". He thinks "more clearly" too when he is on his own, and he likes to be able to do things in his own way as this means "you become more self-reliant”.

When climbing with companions, mountaineers rely on one another's resources as well as their own, but they often speak of the importance of the right balance in skills so that there is still the feeling of relying on self. For example, Jess finds that the ideal climbing partnership is one in which the skill levels are similar: "it's not one person's role to lead and one person's role to follow". Steph prefers climbing with someone who is "on an even footing in terms of making the decisions and, responsibility":

it's nice being with somebody who's, not necessarily physically stronger than you or, ... you know that, when you've done it, that you weren't being buoyed along by somebody else.

\footnotetext{
${ }^{40}$ For full story see Appendix C, number 5, page 266.
} 
The egalitarian nature of climbing relationships seems particularly important for the women mountaineers: the sense that their achievements are their own, and that they do not fall into a role of being dependent on their climbing partners, who are frequently male. Jane decided from the beginning that she did not want to be introduced to climbing by a boy-friend, or a father, as happened to other girls, so she took a course instead where she was mentored by an experienced woman climber. Later, she found that she improved faster when climbing with other women, because it inspired her to try more climbs herself; whereas, climbing with "blokes", she tended to assume they were stronger, even if they were not, and let them take the lead. Similarly, when Sue climbs with men, she prefers that they are on an equal footing, so that she does not feel inclined to defer to their leadership. She is happy, however, to let a female partner lead if she knows that she is more experienced.

The women never explicitly hold their male climbing partners responsible for their feelings of dependence on them. They see it more as a result of their own perceptions and something that is their (self-)responsibility to manage. Although Jan says she herself never feels dependent on her male partners, she recognises this tendency among other women and sees a need to help them:

I started up a little group for women enjoying the outdoors, because I, realised after not many years at all that women, who climb, or learn to climb, with their emotional partner, stay emotionally dependent and they stay physically dependent on that partner ... I wasn't a women's liberationist, I'd never even heard that word until I went to the States in 1970 [laughs].

Another aspect of self-reliance, for both men and women, is a preference for being selftaught and relying on experiences gathered through gradual steps to be the teacher, rather than depending on instruction courses and professional guides to transmit 'correct' techniques. Being self-taught is seen to be both more satisfying and more nurturing of self-reliance, thus encouraging a resourcefulness in problem-solving which is extremely valuable for coping with the unpredictability of mountain environments.

Mike, like Dave, considers himself to be largely self-taught. His first trip into the "big mountains" was particularly formative. He and his friend took longer on the climb than a more experienced party but that did not matter to them:

we didn't have that much experience ... we were just finding out how things worked as we went along, ... we just had an epic day out in the hills and did what we wanted to do and, it was quite satisfying. 'Cause we'd sort of done it, pretty much ourselves. 
Pete is also proud of the fact that he is largely self-taught: "we didn't get into climbing through going through instruction courses or anything. We, we just found our own way”. Pip feels that there is an "over-reliance" by some people on official instruction courses as a means of learning mountaineering. She thinks that having had to work things out for herself has made her more innovative and resourceful:

when I first started climbing it was like oh, you just went off and did things. And you went off and you had adventures and you read the odd book and talked to a whole lot of people about how you might do something and you worked out a way, ... there's a lot of, a lot that experience can teach you ... you just remember back on trips where, 'but I thought you were planning the food'. 'Well no you were planning the food'. It's like, 'well hope we've got enough food'. [laughs] ... Yeah. 'But it's your stove'. 'No you were bringing the stove'. 'Oh no. Got no stove. Oh no, it means we're going to have to camp here where there's water'.... You know you learn lots of different ways you can manage ... and then it means that sometimes in certain conditions you go 'well we don't need to take a stove. So we'll be lighter, we'll be faster'.

To summarise, a sense of self-reliance in a potentially hostile environment is important for the discovery of who one is, and what one's capabilities are. This sense is particularly intense when a mountaineer is climbing alone, but also occurs when climbing with someone of equal ability. Another aspect of self-reliance is the way in which it is facilitated and enhanced by learning for oneself and developing resourcefulness. Then one's achievements feel as if they are one's own and hence a measure of one's self.

Self-discovery in an "unforgiving" environment

It is the great leveller, there's no question about that, and you can have the smartest piece of bloody gear on you, but if you've done the wrong thing and you're in the hills, it's so unforgiving.

In addition to the sense of self-discovery through self-reliance discussed above, the mountaineers tell stories about how mountaineering puts them in situations in an "unforgiving" environment, where if they make a mistake they pay for it. This, they say, provides the conditions for an "honest test" or an "honest benchmark" of who they are. If they always have something or someone to fall back on, then they will never know what they are capable of. As Pete says:

it puts you on edge and tests you really and I like being put in those situations ... it's an honest test too. It's not sort of a contrived, ah, thrill sport type of test where I mean sure you might fall off but everything's all protected ... nothing's going to go wrong. So you're not really, out there on the edge ... I think that test, that ultimate test of climbing's one of the big attractions and underneath it all. 
Terry expresses the same sentiment by reading to me from one of his favourite mountaineering books:

there is always a question mark about how you will perform. You have an idea of yourself and it can be quite a shock when you don't come up to your own expectations. If you just tootle along, you can think you're a pretty slick bloke until things go wrong and you find you're nothing like what you imagine yourself to be. But if you deliberately put yourself in difficult situations, then you get a pretty good idea of how you're going to be, that's why I like feeding the rat. It's a sort of annual check-up on myself. The rat is you really, it's the other you and it's been fed, by the you that you think you are and they are often very different people, but then they come close to each other and that's smashing that is, then the rat's had a good meal and you come away feeling terrific. It's a fairly rare thing but you have to keep finding the brute, just for your own peace of mind and even if you did blow it, at least there wouldn't be that great unknown, but to snuff it, without knowing who you are and what you're capable of I can't think of anything sadder than that. $^{41}$

By the end of this extract, Terry's voice is filled with emotion. For him, this is the last word on mountaineering, and what keeps him going.

Isn't that lovely? [laughs] ... That's beautiful ... It sums it up. Simple. That's, that's it. Fantastic. Yeah. Yeah. ... In a nutshell. ... That's one of my favourite little bits of, um, you know, any sort of, obviously we all get in the dumps at some time, but you know ...

But not only is climbing a means by which mountaineers can come to 'know' themselves, by testing their perceptions of "who you are and what you're capable of"; it is also imperative that they do. Under the kinds of conditions that climbing in the mountains presents, it is essential that they exercise precise judgement regarding their abilities. Pip says, “you don't want to stuff up at all. I mean you can't afford to do that”. If they pretend to be better than they are, or miscalculate their ability, they can pay a high price. As Tim says, it is important to know "where you're at", so that he's not too "pigheaded" to turn back when he has reached the limit at which he can climb safely. Sometimes it takes "balls" to go home having failed, rather than to not go home at all.

Also, if someone is climbing for the 'wrong' reasons - for fashion, to impress people, for fame and glory - then, it is generally felt, they will not last the distance either. Adam finds that "you tend to come across a lot of people who like talking about themselves", but he thinks "testosterone-charged climbing” can lead to mistakes. Such people have a different attitude to the environment, and their behaviour can be inappropriate and insensitive, including littering and altering rock climbs artificially:

${ }^{41}$ Terry was reading from Feeding the Rat: A Climber's Life on the Edge by A. Alvarez. 
they're not really there for the environment in any way. They're just there because it's a challenge in front of them.

Steph makes a similar observation:

Sometimes I meet people and I just, don't, don't like their approach to climbing at all, and that's generally people who are, really, bolshie, really kind of, think that by climbing, something, like a mountain, or a hard route, or you know, they just get on a real ego trip and that's why they do it, and you can just see it in people that, they just love talking about themselves and, and they use the mountains as a way to make themselves feel more, powerful or more, I don't know like, um, they're usually men - 'I'm the man' - kind of thing - 'shit I'm good'.

But it is an activity in which an over-inflated ego is a liability, or at least an embarrassment, because if someone pretends to be something they are not, then, according to Mark, they'll soon be found out:

it's an equaliser, there's no room for ego. There's no room for, for competition or anything like that. ... if you've got an ego there's somebody that's going to chop it down to size in no time flat. ... I think there's a lot of guys out there that have got huge egos and a big chip on their shoulder and they're out there to perform.

They're not out there to climb for climbing's sake, they're there to say 'look I can do this and no one else can'. I think if you get away from sports routes and gyms and things and get out into the mountains, a lot of those guys start shaking at the knees.

The mountains can also deliver a judicious number of humbling experiences to keep the ego in check, as they did for Bob.

If anybody ever thinks they're invincible, if they get caught high on the hill in a big storm, particularly an electrical storm, you're likely to get your comeuppance. I can remember being caught in such a storm on Malte Brun and I thought I was going to die, I really did you know. It was such a wild thing. It came out of nothing, and it was upon us. We knew it was coming, the temperatures had dropped, yeah it was pretty, pretty exciting. The ice axes were sparking bloody flames off the end of it you know sparks and everything was buzzing.... It's a hum, you know, before the discharge. Ear splitting discharge, bloody fireball things bouncing down the ridge. We threw all our ironmongery down one gully and, we dived under, down another little one, cowering with our packs over our heads, yeah. ... And we lived to come out the other side. You're never, I don't think you're ever the same again. You realise that the planet can actually shake us off like a dog shakes fleas from its coat, if it so chose. And I suppose it's a, it's a lesson in humility, and I'm ever so humble. [laughs]

In addition, mountaineering is not just about impressive feats of climbing, but also inevitably involves enduring hours in miserable conditions, and it is then that people are seen to show their "true colours". It is by their behaviour in such trying circumstances that Steph judges her climbing companions:

I see them at times when it's, just miserable, you know, we're really cold and we've run out of food and, we've lost the way or whatever, and, and you look over at your 
mate they've got a big grin and make a joke or something, and yeah, and so, you sort of see people's true colours really, in that sort of situation. ${ }^{42}$

And so mountaineering is seen to provide ideal conditions for action through which one's 'true' qualities and abilities will be revealed. It puts people in situations where artifice and an over-estimation of one's abilities will be unmasked. If climbers are sufficiently sensible and humble, they will recognise this and turn around, if not, they may pay for it with their lives.

\section{Expanding self}

The expansion of one's sense of self through mountaineering occurs primarily in two ways in the narratives. Firstly, mountaineers expand their climbing abilities by a series of progressively harder challenges, in an attempt to find the limits of these abilities.

Secondly, as they age and the potential to expand their physical abilities wanes, there is a change of focus and expansion occurs at the level of judgment, self-assuredness and deepening enjoyment of the pleasures of mountaineering not related to physical challenge.

\section{A "natural progression": Finding the limits}

While it is important for mountaineers not to over-estimate their abilities, if they underestimate their potential they risk never 'getting off the ground' at all, and never knowing what they might have been capable of, like Dave's grizzly old man lamenting the loss of what he did not do. So climbing is not only about knowing where their limits are, but trying to push them out a little bit, and thereby to expand their sense of what is possible for them; like Adam, to see if the imagined might not become the real:

I don't think I'll rest until I've explored, explored my own abilities a bit further. I want to see how I, how I work in some of the more demanding, mountains of the world. Just sort of improve my overall abilities and go to places where, you know, that I'd only sort of imagined really.

Like Dave, Mike sees his climbing career as a "natural progression”, of gradually climbing harder and harder things, and becoming more experienced. Dan wants "to climb nearer what I feel like my potential is". Tim sees himself as "always trying to climb a bit harder", and "wanting to see how far I can get". He thinks that climbing lends itself well to this because it gives you "immediate feedback of where your strength's at", and because it is "very even between the physical and the mental", it "contribute[s] to your understanding of yourself" more than other sports. It also has the advantage that:

\footnotetext{
${ }^{42}$ This is also a very frequently expressed sentiment in the obituaries of mountaineers in NZAC publications.
} 
you don't get to twenty-two and reach your peak and then you know get worse,... lots of the guys I've been climbing with in Dunedin, they're like getting close to fifty and they're climbing harder than they ever have before ... just because it seems experience counts for so much.

In the context of these progressions, the most memorable climbs are those in which the next 'step' is taken:

some of my most satisfying achievements have been ... climbing that next harder grade when I least expected it. And also yeah, also sort of mastering techniques that I thought were only sort of things that other people had and I'd never be able to achieve kind of thing.

In the stories of such climbs, the thrill of taking climbing to the next level tends to outshine any difficulties encountered along the way. One of Simon's most satisfying climbs was a 1500 metre ice route, when he and his two companions had to spend the night part way up the route. On this climb he "learnt how far you could go in a day, and, sleeping out with no sleeping bag in winter, and being comfortable. Yeah it was pretty amazing”. For Pete, the most significant climbs occur when he makes a "threshold breakthrough" in difficulty or technicality, or climbing a new route:

you'd all of a sudden do a climb that was a lot harder than anything you'd done before ... [a] really significant one was when Nick and I did the South Face of Hicks. ... it was a step up from what we'd been doing and again we just went off and did it ourselves you know so we were always sort of, finding our own way through these climbs and, ah, we had a really good climb on that too, but, um, we did it through probably a little bit of an experience ... we ended up, um, with an unplanned bivouac up on top but the weather was fine and it was just cold and, quite a neat experience.

So while sensible, sober assessments of climbing ability (or as Pip says, being able "to admit that you have shortcomings") are seen to be essential for survival, also admired is the quality of being a bit "go-ey", and being able to back oneself for a bit of a leap into the unknown. Early in his climbing career, Chris went to the alpine region of Aoraki/Mount Cook, but it took a while for the breakthrough to come:

I did about three trips there - huge pack hauls up the glaciers ... and got blisters ... had a bad time - the weather was crap and just, oh, found it really hard work and then, didn't climb anything the first few trips in there and then met up at one time there with, um, Sarah Jones ... and we went and climbed the East Ridge of Cook, ... and neither of us had ever climbed a 10,000 foot peak before. We never told each other. It was fantastic.... and then it all picked up from there ... started climbing harder routes ... it felt quite cheeky to go off and climb Mount Cook, especially by the East Ridge. 
But it is a delicate balance between being "cheeky" and being foolhardy, and there is much that hangs in this balance for a mountaineer - their sense of who they are, as well as life and limb. As Dave finds, knowing when to "push it out a bit" and when to "pull back", is problematic:

you keep pushing it to this point where you either kill yourself or you find your limit and you just pull back a little bit, and then you can carry on. ... I think now I've kind of ... I've reached that point, I don't know if I recognise it totally, but once again it's that learning thing. You get spanked, and you recognise that you got spanked or ... you've got into your pinnacle or whatever, and can just pull back from it.

For Adam, it is about remembering what you are there for and gradually building up the experience required to make good decisions:

I have a friend, who I think has a very good attitude, I think he's very aware of his, of himself, and very aware of the mountains and what he's in them for, you know. And I learn a lot from him. I've learnt, that, you know, the thing that attracts us to the mountains in the first place, if you want to maintain that, at times you've got to, sort of pull your head in and not push yourself so hard. ... you've got to be someone who exercises good judgement. It's hard to exercise good judgement without experience. But then it's hard to get good experience sometimes without good judgement you know so, sort of like a, cyclical thing really. Just something you need to take one step at a time.

Thomas too believes the answer is not to be overly ambitious:

some people think you have to make big steps, you know, dramatic steps, and I actually think learning and growing is just in tiny little increments ... I should never feel it's difficult. I should always feel I'm actually in control, I have to stretch myself, I have to concentrate, but I don't have to go beyond what, ah, what I feel comfortable with.

Kath says that she makes the decision to go on or go back based on how she feels about a particular situation but, as her story here illustrates, a number of different things may influence such a decision, including the relative value of success and the extent to which she feels her luck may be running out:

it's just something, it's something I weigh up at the time. And if I feel oh this is just too scary or too, this feels too out of control or too, you know then go down. Turn around and go back. But it's something that I put on, like I just take it on an individual climb, the feeling with each individual climb not an overall kind of thing. Does that make sense?

I asked Kath to tell me about a time when she did make the decision to turn around. She told a story about a climbing trip on which she attempted two difficult climbs in rapid succession. On the first climb, she says, "we were at our limit and the weather turned bad but we made this decision to go on because we wanted to do it basically [laughs]. And 
things were just in control but only just you know and then we, but we got to the top and we came down". On the second climb:

we got sort of two thirds of the way up it and the conditions started to deteriorate and they weren't as bad as they were on the climb that we'd done previously that we'd finished. But things started to deteriorate, the clouds started to come over, it started to snow but, and even though things weren't terrible we decided to come down. So I think we thought that we'd, that if we did this twice in a row that maybe this time we wouldn't be so lucky.... And we just sort of thought 'okay we really pushed it out on that last climb. Perhaps we shouldn't, the gods won't be with us on this one. Perhaps we should just turn round', so we did. ${ }^{43}$

Also, because the mountain environment is so difficult to predict, and because sometimes even the most cautious may inadvertently find themselves out of their depth, situations arise where mountaineers are committed: there is no backing out or turning back, much as they might like to. Instead they are forced to 'dig deep', as Dave did on his solo climb, in order to get themselves out of a difficult spot and, in doing so, they find resources and abilities they did not previously know they possessed, and their sense of self grows in accordance. This also happened to Jess on her first "big climb” when she admits to being "a bit out of my depth", but the 'crunch point' came on the descent:

I can remember quite vividly doing the traverse ... I remember being really, really focused and really scared. And getting, and for me it was the ability to channel the fear into a really kind of almost aggressive attitude. It's like I'm not going to make a mistake, right I am going to do this. And it was real kind of, really placing your ice axe really strongly because 'fuck this, I'm not going to ...' kind of thing, just talking to yourself a lot.

From this, Jess learnt two important things which influenced her climbing from then on: that she does not like being in a situation where she does not feel that she is in control; second, that she has a way of dealing with it. Following this experience, her most memorable trips are those in which she feels challenged but confident in her abilities.

It's all about testing your limits and kind of getting an idea of where they are but not pushing them too hard you know what I mean. So it's not desperate but you kind of, you know you've seen how much further you can go which is further than you've been before which is quite neat.

Lyn experienced a similar kind of epiphany on her first "big mountain" in Nepal:

that was my first experience of being on a real mountain, and yeah it was, it was pretty amazing because, I mean I wasn't as fit as I, should be really to climb such a big mountain ... and the only reason I got to the top was, through sheer willpower. ... It was ... also the altitude. I ... felt that I was physically, um, completely unable to get to the summit. But I was tied to ... Suzie and Liz and I knew if I turned back they would miss out on the summit. And to me that was the

\footnotetext{
${ }^{43}$ For full story see Appendix C, number 6, page 266. 108
} 
worst possible thing that you could do to your fellow human beings, deprive them. So that was the thing that kept me going.

From then on, the ability to overcome physical limitations comes to epitomise the meaning of climbing for Lyn:

being able to use your mind to make your body move when physically it's not capable, any more so, I think that was probably one of the, yeah, most memorable, experiences ... and this is what climbing's about, whether it's mountaineering or rock climbing is that, pushing your physical and mental limits and transcending them. You know that's what, so when I came back, yeah I was really, you know, had this renewed energy, and life felt, $\mathrm{mm}$, you know [laughs], that energy, that aliveness.

The trips that Sue talks about in the most detail are those that have been the most demanding: when things have been 'touch and go', even 'mis-adventures' in some respects. The ones that are more straightforward and pleasant she mentions more briefly, just to note how much she has enjoyed them, although in telling some of her 'epic' stories, she does confess that they were 'memorable' rather than enjoyable necessarily. One of the "highlights" of her climbing in New Zealand, and a trip that she describes in great detail, is a climb on the South Face of Mt Douglas. She starts out confidently, but is stretched to the limits of her ability and becomes unsure if she can do it or not. She feels her fingers "uncurling” from the handles of her ice tools and, she says, "I just thought 'I can't do this'.... my feet came off at one stage I remember, but I managed to get up there and it was just so nice to get up ... I really was sure I was going to take a whopper. ... it was definitely the hardest ice climbing I've ever done and I've never done anything as hard since". ${ }^{44}$

Likewise, the climbs that Jane enjoys the most are those she has to "fight" to finish. She finds much pleasure in the feeling that she is getting "better and better" and "stronger and stronger":

Most of the climbs I've really enjoyed have been fights. Yeah. I love a good fight. Like, if there's a hard climb and I've been anticipating it, and it goes a bit easy I feel real disappointed. But I like, when I'm really pumped and, it's really hard or something ... it's like that love-hate thing. I'm loving it, but really wanting to get it over with at the same time.

Jane tells a story to illustrate this "love-hate thing". Its setting is an atmospheric spot in Montana ("Montana feels real big. Real vast, in a way"), and one particular pitch on the climb "just looked, like nails-hard" and she has been anticipating it with some trepidation. But once she gets on it, there are:

${ }^{44}$ For full story see Appendix C, number 7, page 267. 
just those moves where you, you can't define whether you're sort of coming off or staying on. You're, you're somehow staying on, but you're not quite sure how, and just sort of keep going another move, and there's nothing to say, you know, whether you're coming off or not, apart from, I don't know, you I guess. And Lisa's sort of yelling, I'm grunting, got this massive pump going ... you can kind of tell it's going to [get] a bit easy, easier than what you've come up, so you're torn ...I want to have finished it, so that you've done it, but then another part of me never, wants to finish. Wants it to kind of keep going. And ah, I managed to get through that, it's just the most amazing feeling of, just, I don't know, you're battling, it's not, not like you're battling the rock or, any sort of thing like that but, you're battling yourself I guess, just to stay on. Yeah, I love that [laughs]. ... It was just a magical day. Yeah. That was one of the best. It's not like the hardest route I've ever done, or it's not the most famous, it was just fantastic. And every time you do something it just makes you feel like a bit better, and just empowers you a bit more I guess. Yeah. $^{45}$

Jane admits that to some extent she wants to push her climbing in order to counter her selfimage:

I think I've got it in my head that I'm this girl, that doesn't look very strong, and so I get quite 'oh I can climb that', and I want to sort of prove myself.

Now, she says, she is better at thinking "oh well, it doesn't matter” if she fails or backs off a climb. Dave too, as described in the introduction to this section, has changed the way he feels about himself through his climbing experiences:

When I was at school I had very low self-esteem, and would cower from anything, and everybody, but going mountaineering and knowing what I can put up with, and hardships and, problem-solving, it teaches you intense, it's an ability to problemsolve, [it's] sort of given me really good self-esteem. So that I don't really care what people think as much as I used to.

Through mountaineering then, people are able to expand their sense of what they are capable of, through a "natural progression" of gently increasing difficulty as they endeavour to keep within their 'comfort zone', and sometimes through finding themselves in a situation where they are so committed that they must find reserves of strength they did not previously know that they possessed. The enjoyment and fulfilment they find in these challenges are reminiscent of Csikszentmihalyi's $(1975$; 1990) theory of flow. In addition, this gradual progression over years may change not only their sense of competence and skill as mountaineers, but also enable them to transcend their self-perceptions in other contexts, as it did for Dave.

It is worth noting here that stories of progress and linear development are, as Taylor (1989:105-106) points out, a typically modern form of narrativity:

\footnotetext{
${ }^{45}$ For full story see Appendix C, number 8, page 267. 110
} 
Rather than seeing life in terms of predefined phases, making a whole whose shape is understood by unchanging tradition, we tell it as a story of growth towards often unprecendented ends.

Bateson (1990) also observes the predominance of this narrative form in the biography of our lives, and sees it as problematic to the extent that it may obscure or devalue the art of improvisation which more accurately describes the process of constructing a meaningful life under current conditions. We have, she says, 'overfocused on the stubborn struggle toward a single goal rather than the fluid, the protean, the improvisatory. We see achievement as purposeful and monolithic ... rather than something crafted from odds and ends .. [this] may create inappropriate expectations and blur our ability to see the actual shape of our lives' (Bateson, 1990:4-6). Indeed, the sense of progression is qualified in these biographical narratives, perhaps first and foremost by growing older, which will be discussed later in this chapter, and also by the many compromises which 'real life' often prompts us to make. These are examined in Chapter 4.

Finally, there are moments when mountaineers feel that they are playing " $a$ mind game" in which the odds of success are greatly improved if they keep their heads and back themselves to get through a difficult patch. As Adam says, "It's amazing how much you can achieve when you just decide or expect a successful outcome”. Thus, while the mountaineers suggest that there is some innate limit to their abilities, there is also the sense that their limits are determined by what they believe themselves to be capable of. In this context, doubt is the enemy, and physical limitations can be overcome by having sufficient 'mental strength' and focus.

Jan considers climbing to be eighty percent "in your head ... you say you're going to fall, you will", and Simon thinks that having the right "head space” is, in some respects, more important than physical prowess:

the main thing is your head space. Like I'm not, you know the biggest creature on earth ... but it really comes with your, your head space, and the motivation. I think that's why mountaineering's really good because anyone can do it. There's no real, athletic sort of, type of build that you need. It's a mind game. And I reckon that's just great.

Adam describes it as sometimes needing to "bluff yourself into believing" that everything is okay, because "not panicking is, is the only way out ... if you let yourself get too much into a panic, you start making irrational decisions and, and end up doing yourself some permanent sort of injury”. Dan also feels that letting doubt creep in can have undesirable consequences: 
climbing is very much, in a lot of ways a mind game, and, a lot of it is getting your head around it and just, having, having confidence and faith in yourself ... it kind of expands the horizons ... you might get scared and you might come up to the, you know difficult section ... just back yourself and just be confident to move through it and climb it smoothly. Or else if you let your head start playing games with you and start worrying about what will happen if you fall and all that kind of thing then, you're just making life really difficult for yourself.

Thus, in the 'folk psychology' of mountaineering two theories co-exist: that overconfidence and 'testosterone-fuelled' ambition lead to mistakes and culprits being 'cut down to size'; and that quiet confidence and the exclusion of doubt promote success and lead to 'expanding horizons'. Obviously, at times, determining which theory applies in a particular situation is a matter of perspective, greatly enhanced by hindsight. I discuss this further in Chapter 5 in relation to narratives of safety, danger and death in mountaineering. Nevertheless, by balancing these two theories, the mountaineers feel that they can expand their sense of who they are and what they are capable of, and find the limits of their potential in the mountains.

\section{Growing older; changing focus}

As mountaineers grow older, they are generally not so able to have a sense of selfexpansion through increasing their physical climbing abilities. Some stories are told about mountaineers of relatively advanced years who are climbing harder than ever, but mostly the mountaineering self expands and develops in different ways as they age. In particular, greater maturity is achieved through: developing better judgment, more experience and patience (this is further examined in Chapter 5); gaining more confidence and feeling more self-assured; and focusing on the pleasures of the social aspects and enjoyment of the mountain environment.

As he ages, Pete is no longer inclined to "push the margins as much". He is becoming more moderate in his ambitions since he no longer feels "bullet proof", and as he is not anymore "out there to prove anything”. When he was younger, he says, he put much more pressure on himself to achieve:

as you matured or got more experienced you were quite happy to say oh today's not the day, let's just flag it and go back. Come back another time'. And you, when you were young and really trying to establish yourself sort of thing you would still, you would really beat yourself up, thinking you're bloody hopeless if you didn't, do it sort of thing. And so you'd tend to, um, yeah but that's an experience thing I think, as you learn more about it. 
Simon also says that he has learnt to be patient, and to know that if he does not feel good on a climb on any particular day, instead of pushing on whatever the cost, he can go home and come back another day. Jan explains that as she grew older her sense of being a "real mountaineer" no longer depended on someone else's criteria. Similarly, Jess has focused more on enjoying herself and less on how others see her:

when I was 18 [it] would have been much more important, to do something because I didn't want to look silly rather than because I actually personally wanted to do it. ... now you have to focus more on just being in an environment you enjoy being in and enjoy the movement over the rock ... when I first started it was, that progression thing was quite important, climbing something new, something harder, climbing something in a better style, you know it was all that, much more competitive, with myself and with other people. Whereas now it's more oh yeah go out and have a good time.

Likewise, Mike has changed his focus over the years, as youthful aspirations to become a 'rock climbing god' have diminished:

in the early days the main objective was to see how hard you could climb: I think I probably get a lot more enjoyment out of my climbing now, well I did enjoy it when I first started out, but in those early years, ... you climbed to try and, improve, at climbing, and, um, whereas nowadays I'm, I'm more content to do things that, I know I can do comfortably... I guess it's all just part of growing up, you don't feel like you need to prove yourself, or, I guess, you sort of realise that you're not going to be the next Wolfgang Gulich, ${ }^{46}$ rock climbing god, you know or whatever. Um. It's never going to happen so, you change your focus. I just do what I can do really, yeah I'd still like to get better, I'd still like to improve.

Nearly all of the mountaineers, even some of those still in their twenties, spoke about how their focus had changed from their early days of climbing. Indeed, it seems to be a broadly accepted principle in the folk psychology of climbing that people 'push harder' when they are younger. When beginning to climb, aspiring mountaineers feel strongest the need to "prove" themselves, to live up to either their self-imposed aspirations, or the perceived expectations of their climbing peers, in a desire to be accepted as a 'real' mountaineer within the climbing community. The way in which the 'real' or 'true' mountaineer is constructed is discussed in more detail in the following chapter.

In addition, as people age they gain more responsibilities which temper their aspirations in the mountains, as having children did for Sue, which I discuss in Chapter 4 in the context of the maintaining commitment. Moreover, it is seen to be part of the process of "growing up” to relinquish one's youthful enthusiasm for pushing the boundaries of one's strength and technical abilities, and instead to focus one's energy on enjoying the pleasures that

\footnotetext{
${ }^{46}$ Legendary German rock climber Wolfgang Gulich set a number of world climbing records in the $1980 \mathrm{~s}$ and early 90 s.
} 
come from the strong bonds formed with climbing companions, and "just being there" in the mountains. So when mountaineers do 'slow down', for whatever reason, there is what could be considered an expansion of a different kind: of the depths of one's feeling for the mountains and the fun that can be had there with like-minded friends. As Dave says " $I$ don't think I'm as willing to suffer as I used to and also it's got to be, sort of fun".

Thomas also admits that in the past, much of the enjoyment of climbing was in retrospect: you had to get up in the middle of the night, it was really horrible to get up out of bed, and in the end you're bloody tired, and so a day later the whole thing actually looks so much better and you go again next weekend. But often I think that, the actual doing of it, I think there are times can actually, be a pain. It is. Crouching on the glacier in deep snow, it's horrible, and then we're even proud of it. We say 'it was up to the knees deep, we had to walk three or four hours through it'.

Now in his late sixties, Thomas recently began rock climbing again. He jokes that his ambition is to climb a grade lower every year, but he is having trouble achieving this, because despite his best intentions, he is still improving. One of his favourite places to climb these days is Mount Arapiles in Victoria, Australia, where he feels that the emphasis is on enjoyment rather than competition, and where there is a real camaraderie among climbers of all ages and skill level, who camp together at the base of the rocks:

it's such a nice atmosphere, and when they see I enjoy myself they're enjoying themselves, with it. When I come back from something and I say that was fantastic, they're pleased for me as well, and that goes in all directions and I think that's, it's like a playground in a way ... yeah so I want to go again.

\section{Expressing self}

The third way in which the construction of self emerges from the folk psychology of the narratives is in terms of self-expression. The way in which someone climbs mountains is seen to reveal aspects of the self that can be read and interpreted by others. In this way, mountaineering is considered a medium for self-expression, and those I interviewed talk about styles of climbing and types of trips which they feel express their particular identity or style within the broad landscape of mountaineering. For example, Kath likes long technical ice routes, whereas Pip enjoys long solo journeys through the mountains, for the sense of isolation, and the sense of moving through territory that she feels intuitively drawn to.

Indeed, styles of climbing are seen to be indicative of someone's motives for climbing. Thomas is critical of styles that represent, for him, an egotistical and purely technical approach in climbing: 
there's lots of pictures of heroes in difficult situations without a context ... I think [it's] so self-centred and ... it has nothing to do with mountains. It has to do with gymnastics maybe ... [but] I think there needs to be more to it.

Thomas makes a connection between art and climbing as forms of self-expression:

if you only take pictures of yourself on, on a difficult pitch on a boulder, you say something about yourself, ... the way you go to the mountains I think says a hell of a lot about people, yeah. And to me I think that's what all art is, is always about I think, we say something about ourselves, which we don't express in words or writing or so we, we do a thing in a particular way, and this says more about us ... and climbing would be part of that.

Adam also sees a link between mountaineering and his self-expression in other aspects of his life. As a scientist, he connects his two passions in terms of his need for originality, for finding his own way of doing things:

that's what I've found to be similar between science and, and climbing, and also, I've learnt that, simply doing things the way everyone has done them in the past, or, or just following protocol, is quite commonly not necessarily the best way to go, you know. And that's exciting because I, I'm not really a leader. I guess I tend to follow more than lead. I don't know and that's where it's exciting for me to realise that, you don't have to do things the same way that everyone else is doing them ... you can advance your own ability one step further by developing your own methods of doing things and, I've found climbing has helped me become just more aware of that in my mind and I've been able to apply that in my research in the lab. I've been able to, to sort of think outside the square a little bit, yeah. ... I find them both satisfying when I'm able to do things my own way.

Originality is important to Jess too, who is proud of the trips that she has done that are "slightly different". Chris also likes doing climbs that are "fully obscure". He prefers to do first ascents on new routes and is very critical of the "ninety percent of climbers [who] go and climb the same old things". He finds this "basically uninspiring". 47 Good style for Pete is "efficient, fast climbing", just an "ice axe and ice hammer and crampons and, go for it":

style's important in climbing. How you do a climb, and I've always really, enjoyed the alpine style of climbing where you go, ah, reasonably lightweight and climb quickly as opposed to say a siege tactics on a big mountain. ${ }^{48}$

\footnotetext{
${ }^{47}$ For full story see Appendix C, number 9, page 268.

${ }^{48}$ Pete is referring here to the tactics used by big expeditions (also described in Chris's story Appendix C, number 9, page 268). This is the style used by the majority of Himalayan expeditions, that is, using fixed ropes (ropes left 'fixed' on the mountain for ease of ascent and descent) and establishing a series of progressively higher camps on the mountain, before a final summit attempt is made. This style of climbing requires a large support team (and associated logistics and expense) as a number of trips are made up and down the mountain carrying the necessary supplies. Alpine style climbing involves the climbers carrying all the equipment they require themselves, and climbing the mountain in one 'push' from the bottom to the top, generally without using fixed ropes or pre-stocked camps.
} 
Climbing in this style - "strong and fast and get things done" - is something that Pete thinks New Zealand climbers are particularly good at. The mountains in New Zealand are not as accessible as they are in other parts of the world, such as the European Alps, so equipment taken has to be minimised, and speed maximises the opportunities presented by short periods of settled weather in the temperate, island climate:

the big attraction to climbing to me was, that, it wasn't just being on the mountain. It's the getting in and getting out, um, that side of it, and New Zealand climbers generally, they grow up having to do that ... you do these big long, sort of missions and, and that was, they were, yeah, really satisfying, but there doesn't seem to be that sort of style of climbing done now.

This style of climbing is less reliant on modern forms of technology, for example helicopters or télépheriques, or less modern labour, such as porters and sherpas, in order to get climbers and their equipment to and from climbs. Thus it is a more self-sufficient and economical exercise, which is consistent with the theme of self-reliance discussed earlier in this chapter.

In his autobiography, the Italian mountaineer Giusto Gervasutti likened mountaineering to art and poetry when he described it as a means for 'man' to transcend the 'banality of his everyday existence' and 'create for himself a higher mode of life'. He felt that the creative potential of mountaineering was such that, indeed:

there is no such thing as objective mountaineering, there is only a form of activity, generically termed mountaineering, which enables certain people to express themselves ... just as there are other forms of activities and other means by which other people may try to attain the same ends.

(Gervasutti, 1979:197)

Climbing in a certain style allows mountaineers an outlet for their creativity and a means of self-expression, with the ultimate arguably being to make a first ascent of an unclimbed mountain, or a new route on a mountain. It also provides a means by which they can distinguish themselves in terms of personal and national identity. In particular, these mountaineers wish to differentiate themselves from those who are unoriginal, those who are not self-reliant, and those who are seen to climb for the 'wrong' reasons; that is, recognition and self-glorification.

\section{Summary}

I began this section with a quote from Dave, in which he says that if he could not go mountaineering, it would be "like gnawing my right arm off". That is, it would be like losing a part of himself in quite an unimaginable, self-inflicted way. A number of the 
mountaineers made similar comments about how unimaginable their lives would be if they did not climb. As discussed in Chapter 1, conditions in contemporary Western society are not considered to be conducive to establishing a consistent sense of self linked to a stable identity, as the traditional anchors for this have been undermined by prevailing economic, social and cultural forces. The best contingency under these conditions, it is argued, is a preparedness to change identities as situations dictate, and to shrink from seeing any one identity as fundamentally and inescapably synonymous with one's sense of self.

Nevertheless, in the narratives I collected a sense of self was constructed that was indeed synonymous with one's identity as a mountaineer, and consistently so. In the folk psychology of these mountaineers, climbing helps them to discover, expand and express their sense of who they are; and who they 'truly' are, is who they are when they are in the mountains. They struggle to imagine themselves any differently. This is not to say that these mountaineers are entirely impervious to contemporary dilemmas of identity. Perhaps it is more accurate to say that their narratives represent a coherent alternative response to the identity challenge of current times. Such a conclusion is supported by Bruner's (2002:28) argument that 'the impetus to narrative is expectation gone awry', or what Kenneth Burke referred to as 'Trouble with a capital $T$ '. Stories then, are both coping mechanisms and a means of rectifying an untenable situation, of 'reassert[ing] a kind of conventional wisdom' (Bruner, 2002:31). If nothing has 'gone awry', there is no call for a story. Thus, stories about the durability and authenticity of one's sense of self suggest that while such a self is expected by conventional wisdom, it cannot, or can no longer, be considered a given. If who one is could be taken for granted, and is unlikely to change, there would be little need to talk about it.

But it is not merely conventional or practical wisdom which dictates that we work to remedy any tendency towards fragmentation of the self; it may also be something more essential to the human condition and therefore more inescapable. Damasio (1999) argues from the perspective of neuro-science that while we may experience the self as possessing some degree of permanence and concreteness, we are in fact being deceived by the nature of consciousness:

The story contained in the images of core consciousness is not being told by some clever homunculus. Nor is the story really told by you as a self because the core you is only born as the story is told, within the story itself. You exist as a mental being when primordial stories are being told, and only then ... You are the music while the music lasts. 
The 'story of consciousness' is, however, an illusion with its uses. Damasio (1999:31) suggests that it evolved because it was 'indispensable to the art of life' - an evolutionary success story which facilitated human development. The flip-side, of course, is the knowledge that comes with it, creating the 'drama of the human condition' (Damasio, 1999:316), and the spur to find coherence amidst contingency and contradiction. So it seems that we are fated, or pre-determined by nature, to create a constant and authentic sense of self through narrative, no matter what conditions may mitigate against it.

Ricoeur's (1992) philosophical discussion of narrative identity and its dynamics further illuminates the reasons why notions of durability and authenticity are critical to the construction of self and identity. There are, he argues, two 'poles' of identity: identity as sameness (idem) and identity as selfhood (ipse). While in conventional wisdom and the experience of everyday life the two poles merge - particularly in our understanding of character as 'the set of lasting dispositions by which a person is recognised' (Ricoeur, 1992:121) - selfhood, he maintains, is not sameness. That selfhood is not sameness, but that selfhood without sameness is by all accounts an undesirable state of being, is demonstrated by Ricoeur with examples from literary fiction concerned with the loss of identity, in which fictional characters no longer possess a definite character. Indeed, the loss of a sense of the constancy of the self would conceivably be an unbearably precarious predicament and render an individual unable to function as a person in the normal understanding of the word. Ricoeur (1992:118) in fact argues that the "entire problematic of personal identity [revolves] around this search for a relational invariant, giving it the strong signification of permanence in time'.

Ricoeur (1992:140) hypothesises that it is narrative, or more specifically emplotment (the configuration of 'heterogeneous temporal elements' into a whole (Kearney, 2004:6)), which 'allows us to integrate with permanence in time what seems to be its contrary in the domain of sameness-identity, namely diversity, variability, discontinuity, and instability'. In telling the story of a life then, it is possible to reconcile change and contingency with a sense of permanence and self-constancy by correlating the development of character with the plot of the story. Dave, as he has described, changed considerably over time from a weak and timid child, to become a bold and aggressive solo climber. In his narrative, mountaineering was the vehicle or action required for this transformation, not as something that he chanced upon by accident, but as something he was irrevocably, fatefully, drawn to, despite fear and hardship. When he came to the end of telling me his personal history he said: “So that's pretty much the end of the Dave Wood history of natural progression". It 
is not so much a story about transformation then, as it is about the gradual realisation, through mountaineering, of latent aspects of character: of the self that was always there, constant but hidden, authentic but not always manifest.

Similarly, the other mountaineers tell narratives in which plot and character are mutually dependent. The dominant theme of these narratives is that certain characteristics of mountaineering enable them to understand and be their true selves, through a sense of selfreliance and an unforgiving environment which precludes the possibility of 'faking it'; through the potential to progress through successive challenges in order to learn where the limits of one's abilities are, and to transcend perceived limitations by setting one's mind to it; through being able to change one's focus as one grows older and still to identify oneself as a mountaineer; and through being able to express one's individuality and fundamental values by the style in which one climbs. Of course, one test of authenticity is durability: if mountaineering was never really you, then you would never have stuck with it. The subtext to these narratives is the proposition that, for these people at least, mountaineering appears to provide a rich and fertile setting for the construction of the self that few, if any, other settings could provide. The world of mountaineering may then, for them, be an antidote to the kinds of social forces that render identity formation problematic in contemporary life. This suggestion is examined in more depth in the next chapter.

Narratives, as Bruner (2002) tells us, are not only about how the world is, but how it should be. The mountaineering self that is described here is, in many respects, an ideal type, to which one aspires but may not always measure up. In Chapter 4 , I examine the way in which this ideal type - the 'true' mountaineer - is constructed within mountaineering culture in New Zealand and provides a requisite moral framework for this identity. I also consider how this ideal, like all ideals, can be difficult to live up to and creates certain challenges for a number of the mountaineers. 



\section{Chapter 4}

\section{The 'true' mountaineer: communal narratives of identity and mountaineering as moral source}

\section{Introduction}

[Mountaineers are] people that love the mountains ... [and] love the environment and nature in general. They love life and they love people, and you, um, won't find many true mountaineers that are bastards. They may be hard mentally, but they'll always look after you, and there aren't very many nasty, nasty, people that climb mountains, because, they depend on, you know, others that they're with, so you just can't afford to be...

(Terry)

Up until this point I have, in the main, focused on the biographical narratives as individual stories of self and identity, and considered the commonalities in the way in which they are constructed. But as MacIntyre (1981:122) observes, we are, at best, co-authors of our lives and it is a fantasy to believe otherwise. For Ricoeur (1992:161) we are 'caught up, entangled' in the life histories of others. In this chapter I explore the extent to which the personal histories reflect and embody a 'communal narrative' about what it means to be a mountaineer. ${ }^{49}$ I noted in Chapter 2 that our self-stories are influenced by the cultural meanings circulating within the social worlds we inhabit. Cultural narratives of identity are communicated in interactions between members of social groups, and articulated in the 'cultural productions' of these groups (Antonovsky, 1987). Adopting Pamphilon's (1999) macro-zoom, I now examine the biographical narratives for traces of the shared discourse which forms the boundaries of the mountaineering social world (Unruh, 1980), and consider the implications for meaning and self.

As intimated at the end of the previous chapter, my discussion here includes the moral dimensions of the narratives, following Ricoeur's (1992:115) assessment that 'there is no ethically neutral narrative'. Or, as Bruner (2002:51) puts it, 'to tell a story is inescapably to take a moral stance'. MacIntyre (1981:135) elaborates:

Each human life [embodies] a story whose shape and form will depend upon what is counted as a harm and danger and upon how success and failure, progress and its opposite, are understood and evaluated.

\footnotetext{
${ }^{49}$ Different authors talk of collective, communal or cultural narratives. I have predominantly used Frank's (2002) term 'communal narrative' in my discussion.
} 
It was noted, in Chapter 1, that having a stable identity is dependent upon a stable moral framework, and it has been argued that moral frameworks are no longer as stable as they once were (Bauman, 1993, 1995; MacIntyre, 1981; Taylor, 1989). MacIntyre (1981:52) locates the problems of contemporary morality in an historical context encompassing the rejection of Aristotle's ethics by science and philosophy, and the secular rationality that deprived religion of its moral role, which together left ethics bereft of a 'teleological context'. The sense of man's telos or 'true end' as the foundation for moral injunctions was to have been replaced by reason as the basis of morality. However, in this Enlightenment project, the philosophers, according to MacIntyre (1981:48), inevitably and 'decisively failed'. The result of this failure was:

the loss of any authoritative content from the would-be moral utterances of the newly autonomous agent. Each moral agent now spoke unconstrained by the externalities of divine law, natural teleology or hierarchical authority.

(MacIntyre, 1981:65-66)

Today, then, 'there seems to be no good answer to the persistent and pertinent questioning of the source' of moral value (Bauman, 1995:61). However, if we look to Heroic Greek society, MacIntyre (1981:119) suggests, we learn that morality is invariably and to a greater or lesser extent linked to the 'socially local and particular', and to think that it could be otherwise - that is, modernity's aspirations to universality - is delusional. In addition, we possess virtues only to the extent that they are passed on to us through a tradition, associated with certain practices, and the goods (that is, what is valued) and virtues (that is, the special qualities required to excel) associated with these practices. Mountaineering fits the requirements of such a practice, as MacIntyre (1981) describes it, with its own 'living tradition' delineating a certain telos, or notion of what constitutes the 'good' life (a life that is 'higher or better' as Frank (2002) puts it), and the virtues required for its attainment. As such, it is among the subcultures maintaining 'versions of the traditional scheme of the virtues' and destined, consequently, to exist on the periphery of a dominant culture which is inhospitable to such conceptions of morality (MacIntyre, 1981:210).

Orienting one's life towards 'things that matter' requires, according to Frank (2002:10), 'on-going dialogical recognition from others that one's life expresses values they share'. And it is through stories that the 'local and contingent solutions' to the question of how best to live one's life are expressed (Frank, 2002). Thus, within the mountaineering community in New Zealand, the 'central bond is a shared vision of and understanding of goods' (MacIntyre, 1981:240), and these goods, or values, are embodied in the narrative 
theme of the 'true' mountaineer. As I show in this chapter, while some aspects of the practice of mountaineering and its associated values have been challenged at various times and evolved historically, there is a general agreement among the mountaineers I interviewed that being a 'true' mountaineer means certain important things. There is also a strong articulation of what mountaineers are not, by contrasting their values and lifestyles against the representation of climbers in the media, and against others involved in various 'risk' sports or adventure tourism activities with whom mountaineers feel they are sometimes confused.

Hence, it can be said, a well-defined moral code surrounds the being of a mountaineer. This provides an anchor of sorts and basic navigational equipment as they steer their way through life, although, as we shall see, it is not all smooth sailing. As Bauman (1995:14) argues, 'self-grown islands of meaning need support from outside'. Such support, however, is not always forthcoming for mountaineers, and there is some ambiguity and contradiction for many of them between their lives as mountaineers and their lives outside of mountaineering, which have to be accommodated. In their favour though, it seems that certain characteristics of mountaineering provide a conducive environment for feeling competent and in control, and responding to basic moral impulses.

To support and contextualise the analysis of the biographical narratives in this chapter, I draw from my analysis of these themes in NZAC publications. These materials represent the 'cultural productions' of New Zealand mountaineers, and within them can be found evidence of the narratives constructed at the level of the social group (see Chapter 2). This helps to situate the personal stories within the broader communal narratives from which they draw. In particular, I have found that the editorials and letters in these publications, posing and responding to challenges both from within and beyond the climbing world, gave me insight into the way in which mountaineering constitutes a tradition as 'an historically extended, socially embodied argument ... in part about the goods which constitute that tradition' (MacIntyre, 1981:207). In addition, I often found the obituaries to be the place where the virtues or qualities of the 'true' mountaineer were most eloquently articulated. ${ }^{50}$

The over-riding themes outlined above are discussed in this chapter in four sections. In the first I examine the way in which mountaineering in New Zealand is a 'living tradition' as

\footnotetext{
${ }^{50}$ As with the interviews, when quoting from the sources described here I will use italics (with bold text for important themes), in order to indicate that this also represents empirical material. Early editions of the NZAC Bulletin had no page numbers. In referencing these I have given section headings.
} 
MacIntyre (1981) describes this; that is, a community with a sense of shared values. I also consider the ways in which this community has been challenged from within at times by younger generations with innovative ideas, and how it has gradually come to absorb and incorporate such innovations into its communal narrative. In the second section I discuss the importance of the 'true' mountaineer within the moral life of the New Zealand mountaineering tradition, and explore the four primary virtues associated with this ideal identity, and their expression in the narratives.

The third section considers the ways in which the world can be an inhospitable place for mountaineers to pursue their ideals, due to clashes between the demands and values of mountaineering, and life in the 'everyday' world. In the final section, the discussion centres on how the world of mountaineering is seen to provide a sense of 'solidity' in the lives of the mountaineers, which helps them to counter the 'liquidity' of life outside of the mountains. This chapter demonstrates the extent to which the practice of mountaineering, and the communal narrative of identity that it involves, can provide a relatively stable or 'solid' moral source against the background of liquid modernity.

\section{Mountaineering as a 'living tradition'}

No man's friends are as dear to him as a mountain man's; for they are friendships born in adversity and common endeavour, where a man is stripped to what he is and not what he appears to be, or what he would like to be.... A mountain friend is a friend for ever, for he is part of the memories of the mountains.

(Nolan, 1953)

I began my research using the nouns climber/climbing and mountaineer/mountaineering interchangeably. While my participants often did the same, a distinction emerged regarding a special set of qualities or virtues associated with being a mountaineer, that were not necessarily encompassed by the label of climber. Climbing is the activity, but mountaineering is more value-laden: a 'true' mountaineer is far more than just someone who climbs mountains, as Dave articulates:

I find it's a total life experience ... it's not a sport ... that's why I was kind of making the differential between mountaineering and climbing. Like, if you say you're a climber ... you're a recreational climber or whatever, it's not, it's something you do like rugby, or golf or whatever. With mountaineers, if you're a mountaineer it's kind of, what you base your whole spirituality, your philosophies, your everything around. [Although] probably not everybody does that, and probably it's done in certain degrees ... 
Having identified this theme within the narratives, I then read the ethical philosopher MacIntyre's influential work on moral theory, After Virtue. As MacIntyre (1981:180, 175) describes a practice, it 'is never just a set of technical skills', but a:

coherent and complex form of socially established cooperative human activity through which goods internal to that form of activity are realised in the course of trying to achieve those standards of excellence which are appropriate to, and partially definitive of, that form of activity, with the result that human powers to achieve excellence, and human conceptions of the ends and goods involved, are systematically extended.

In this section I first describe the way in which mountaineering in New Zealand constitutes a 'living tradition', centred on a 'cooperative human activity', which engenders a sense of community and shared values, incorporated into one's identity through participation in this social world.

\section{Community, identity and shared values}

Meanings refer to unique situations - and the equally unique persons confronting them. In contrast to the meanings, which are unique, values are more or less universal in that they are shared by whole segments of a given population. I would define values as meaning-universals.

(Frankl, 2000:118)

The relationship between people engaged in a particular practice, a "common endeavour", is a special one: a friendship, as Aristotle defined it, based upon shared 'goods' or values (MacIntyre, 1981:213). When the mountaineers speak about their relationships with climbing companions, they describe having "a connection" with them, being "on the same wavelength", and being "there for the same reasons". "You understand each other", Dan says. For Jan, "it's all to do with having the right companions, having the same feelings about doing things and what's important and what isn't":

the bond with your rope mates is the real bond that really stays there forever and then there's the bonds with the others in your climbing group, and then the wider circle of those in the same climbing hut with you time and again and you meet up with them in different places. Yeah it's a fellowship. ${ }^{51}$

By virtue of what they share amongst themselves, mountaineers feel in some way apart from those 'outside' their world. As Dan says, "often you find you have more in common with, climbers than, I don't know, other people you might bump into”. This is to be expected if MacIntyre's (1981) argument is correct: that the only means of coming to understand the goods internal (that is, 'pursued for their own sake' (Honderich, 1995)) to a

${ }^{51}$ For full story see Appendix D, number 1, page 269. 
practice such as mountaineering, is to participate in that practice. Outsiders may

understand external goods (that is, 'things pursued for their consequences' (Honderich, 1995)) such as fame and fortune, but mountaineering is, by its nature, not particularly conducive to the accumulation of such goods. Climbers with renown beyond the world of climbing are few and far between. To make a profit from climbing is virtually, if not entirely, unheard of, and viewed with some suspicion by other climbers. Therefore, those on the outside can, perhaps understandably, misunderstand mountaineers: a situation which causes Steph some discomfort:

I feel really, really happy and comfortable when I'm amongst other climbers, but when I'm in, other social circles like at university or in the city with my old school friends and stuff, I find I get on with people and I have fun but, I also feel like I'm not really understood ... that I'm just a bit different somehow. ... Yeah, so sometimes, if I'm not amongst other climbers for a, for a long time I begin to feel a bit, lonely sometimes. A bit like, am I a bit of a freak [laughs] wanting to go and do this stuff that everyone thinks is crazy?

Thus, they see their relationship with each other as involving a common sense of what is worthwhile:

You go down to a crag and there's people there that you know and you hang out and you talk. But not all of them are close friends. But they're all into doing similar kinds of things and similar kind of objectives. ... So it's very much I suppose the social scene. ... you go and talk about climbing and what you're going to climb and where you're going to go. You know make plans and from that trips will develop.

In Chapter 3, I considered the ways in which narratives about becoming a mountaineer typically include stories of being nurtured by older and more experienced climbers, and finding people of like mind. In this way, becoming a mountaineer involves an immersion in some way in the social world of mountaineering, and learning the lore of what it means to be a member of this world. This can involve such things as finding a mentor, joining a club, identifying role models, and devouring books about the climbing 'legends'. As a result, one comes to understand the 'unique ethos' that surrounds the activity of mountaineering (Stebbins, 1992).

This process has important implications for the construction of self. Indeed character, that is, 'the set of lasting dispositions by which a person is recognised', according to Ricoeur (1992:122), is in part composed of 'acquired identifications' by which an individual or a community absorbs, by a process of internalisation, the 'other' into itself: 
To a large extent, in fact, the identity of a person or a community is made up of these identifications with values, norms, ideals, models, and heroes, in which the person or the community recognizes itself.

Many of the mountaineers talk of being influenced by the mountain literature they read. When Pete first started climbing, he "just devoured" climbing books and became inspired by those considered "the gurus" in the New Zealand climbing scene at the time. Adam too speaks of climbing heroes that he aspires to emulate:

I really admire some of the older, older generations in climbing, for some of their achievements and the equipment they used. And the amazing sort of courage they had when they were pursuing things that were truly unexplored ... I find that kind of really admirable. I find that exciting too. I guess I'd like to think of myself as being as adventurous but of course that's not the case... I get just a general feeling about people after reading about them ... I find people like Ricardo Cassin ... really inspiring. Someone who, did things his own way, and, was a, a motivated person and also a very, very tough sort of a person. He managed to endure some pretty amazing conditions and put up some routes today that are even considered very challenging, you know. I find that quite inspiring.

Even if we play alone, we normally do so on the basis of practices that have been learnt from someone. Similarly, even the act of violating the codes of a tradition depends upon having previously learned these codes, as 'the reference to others has itself become internalised' (Ricoeur, 1992:156). The self, Bruner (2002:66) tells us, 'is also other'. The raw materials of meaning from which selves are moulded include 'the historical circumstances that gave shape to the culture of which they are an expression' (Bruner, 1990:138).

The internalisation of values in the process of the narrative construction of self and identity is particularly pertinent to the following discussion. As the quote from Adam demonstrates, his admiration for the older generation of climbers relates to certain qualities they exemplified: courage, exploration, endurance and toughness. By identifying with certain values, Ricoeur (1992:121) argues, '[an] element of loyalty is thus incorporated into character and makes it turn toward fidelity, hence toward maintaining the self'. We construct our stories, and our selves, with others in mind, and in the light of 'what we think they think we ought to be like' (Bruner, 2002:66). Hence character, which Ricoeur (1992:122) sees as a process, with a history, not a given, is instilled with 'aspects of evaluative preference which define the moral aspect of character, in the Aristotelian sense of the term'. 
People ... form communities based on agreements about what is better. These communities are reaffirmed in shared stories that display those values, even as new stories question old values and propose revisions to what is considered better. Values in this sense reflect not only individual preferences but communal narratives.

(Frank, 2002)

In this section I examine New Zealand mountaineering as a 'living tradition' that has withstood the questioning of 'old values' and 'proposed revisions' to its communal narrative, and survived the historical period relevant to this research with a communal narrative about 'what is better' that is remarkably consistent.

As described in Chapter 1, the tradition of mountaineering as a practice was introduced to New Zealand in the late nineteenth century by visiting members of the British Alpine Club. While the young colonials can be said to have overlaid this Victorian heritage with a local flavour, by the mid-twentieth century the tradition was sufficiently intact for the eminent English mountaineer Geoffrey Winthrop Young to write, in his message to the NZAC for their sixtieth Jubilee, that from reading the publications of "your young climbing Clubs" he had begun "really to understand that there was something among your young climbers and in your atmosphere of mountaineering out there which had got the values right" (Young, 1951).

Jan, who began climbing in the 1950s, describes climbers during that time as a small and tight-knit "community":

everybody who was anybody in the climbing world went to the ... the Mt Cook national park for the climbing summer season. And so we virtually knew all the other people that were sort of going to be in the area and you'd meet them in the huts or you'd hear them on the radio. ... the active high alpine climbers were a community.

Within the next few decades, however, elements of the tradition and the general consensus and tight-knittedness of the "community" were to be challenged by new, and growing ${ }^{52}$, generations of climbers, as the values of wider society were also challenged. This caused some friction within the New Zealand climbing scene, as Jan goes on to recall:

But there came a point, and I can't just remember where this was, where even in the Alpine Club it became hijacked by rock climbers, who started being very derogatory about mountaineers. ... They got a lot of really good rock climbs done, alpine rock climbs too, but a lot of them fell off and killed themselves, in the

\footnotetext{
${ }^{52}$ Membership of the NZAC increased from 631 in 1948, to 1438 in 1970. In 1970 there were 82 additional members, at that time the highest ever annual increase ("Annual meeting," 1970). 
process. Yes, that period's past now. But it was a period where, there was that divisive feeling, quite strange. ${ }^{53}$

MacIntyre (1981:207) observes that it is also considered a virtue to have 'an adequate sense of the traditions to which one belongs or which confront one'. By the late 1960s a young generation of climbers were challenging mountaineering traditions in New Zealand, particularly regarding what constituted safe climbing, and acceptable equipment and technique. The precise nature of the ensuing debate, particularly surrounding the issue of safety, is discussed further in the next chapter. Here I limit myself to considering how the dialogue between the 'old' and the 'new' demonstrates that, indeed, a tradition existed and functioned in the sense that MacIntyre describes.

Advances in equipment and technique led to a series of 'breakthroughs' in the standards of New Zealand climbing, including two New Zealanders being the first to climb the six European 'north faces' in one season in 1969. In 1970 the Caroline Face of Aoraki/Mount Cook, touted by many to be 'the last great problem' in the Southern Alps, was climbed. By the end of the 1970/71 summer climbing season six new 'face' climbs, including the Caroline, had been made and the editor of the Bulletin was calling it "probably the best ever in the history of New Zealand mountaineering" ("The way ahead," 1971).

While the 'old guard' could hardly quibble about the significance of these achievements, there was some ambivalence in terms of what it meant for the tradition of mountaineering: namely, did the new attitudes represent a radical and irreconcilable break from the old values, or were they "just the old ones dressed up in fancy gear and new technique”? ("After Caroline, what?," 1970). Should they be addressed and absorbed, or rejected? In December 1969 the Bulletin's editorial claimed that the success in Europe of Graeme Dingle and Murray Jones rendered necessary a "thorough reappraisal of what we are doing as mountaineers and a realisation of basic objectives" ("Pause and reflect," 1969). The NZAJ editorial in 1970 gave credit for their achievements to "a movement in attitudes" and "the intelligent questioning of old values and standards by the younger generation". While warning of "a real danger of losing perspective”, the editor conceded that it was "no longer reasonable to accept implicitly the traditions and unwritten rules that govern the course of mountaineering" ("Into the mainstream?," 1970). Following the further successes of the younger cohort in New Zealand the next summer, the Bulletin's editor outlined the friction between the generations, and grappled with the achievements that had come to those who had, it seemed, broken with tradition:

${ }^{53}$ For full story see Appendix D, number 2, page 269. 
The questioning of authority and accepted values, the so called generation gap, the revolutionary fervour to change the world almost seems to go hand in hand with the philosophy of harder and more technical climbing ... We hear younger members complain that older members are out of touch, not interested in what they say ... Then we hear older members complain that today's climbers are irresponsible, arrogant, wanting something for nothing, critical of all that is done for them, unwilling to contribute and destructive in their attitude.

("The way ahead," 1971)

The editorial called for more tolerance and better communication as a solution to the tension between the club members, and to avoid alienating the younger members. There is a similar vein in the NZAJ editorial of 1971 which, while speaking of "a new and dramatic change of direction" and "the emergence of a new tradition", simultaneously advocated being "flexible enough to accommodate not only the achievements but also the ideas and viewpoints of a rapidly growing group of young climbers who, at first sight, appear to have little in common with presently accepted mountaineering traditions" ("How conservative are we?," 1971).

The pace of change in ethics and standards slowed in the second half of the seventies, and the controversies died down, in the NZAC publications at least. By the late seventies, some of the earlier vanguard had died, others had simply 'cut their hair' and settled down into more 'conventional' lives (Prebble, 1980). This later period came to be seen as one of "consolidation", and the rebels of the late sixties and seventies became the heroes of the next generation, retrospectively deemed to have been 'ahead of their time' (Logan, 1980). In addition, the economic climate in the latter half of the decade made it increasingly difficult to live as a "climbing bum", as many of those at the cutting edge had (Logan, 1980). Ultimately, the tradition outlived the turbulence of the sixties and seventies, and the incarnation in the eighties of the "sneering" rock climber that Jan describes, though not unchanged.

Such episodes are evidence, nonetheless, that tradition is powerful, and even those climbers who challenge it are also irrevocably part of it, and it part of them, as Ricoeur (1992) reminds us. Indeed, tradition and innovation exist, Ricoeur argues, in a dialectic relationship. Kearney (2004:6) summarises Ricoeur's view of this inter-dependency:

Tradition needs innovation in order to sustain itself as a living transmission of meaning capable of being reactivated in its inaugural moments, while innovation needs tradition in order to make sense as a form of expression governed by rules. Even in its deviant or transgressive guises, it is always a matter of 'rule-governed deformation'. 


\section{The 'true' mountaineer and the mountaineering virtues}

In spite of such challenges to the tradition as experienced in the late sixties and early seventies, I found a strong degree of continuity in opinion regarding what constituted the fundamental values of mountaineering, and the kinds of virtues or qualities one should possess in order to be a 'true' mountaineer, during the half century in which those I interviewed have been climbing. In some cases language has changed, and the virtues are articulated in differing ways, but essentially the mountaineers talk of very similar things. In 1950, the renowned English climber, Frank Smythe, active in Himalayan climbing in the 1930s, died. His obituary in the NZAJ described him as a "true" mountaineer who fell in love with the mountains as a boy. He was "first and foremost, a mountaineer", an "allround exponent of mountain-climbing" who was "fully alive to the responsibilities and difficulties" of high altitude climbing, but for whom "success and fame" was not the goal. Rather, he "was always content to be among the hills" ("Frank Smythe," 1950).

MacIntyre (1981:178) describes a virtue as an 'acquired human quality' or 'disposition'. The virtues relevant to a particular practice, he argues, are those which:

not only sustain practices and enable us to achieve the goods internal to practices, but which will also sustain us in the relevant kind of quest for the good, by enabling us to overcome the harms, dangers, temptations and distractions which we encounter, and which will furnish us with increasing self-knowledge and increasing knowledge of the good.

(MacIntyre, 1981:204)

Gordon (2001) distinguishes 'ordinary virtues' from those related to the realms of politics, war or heroism. Ordinary virtues are 'private but fundamentally social'; they are concerned with 'responsiveness and responsibility, awareness (of self and others), pragmatism, [and] uncertainty'. Of particular relevance to the current discussion, they also 'work themselves through in experience and in stories about experience, rather than in codes, and they use experience and stories to refine themselves' (Gordon, 2001:29-30).

Frank Smythe's obituary, though written in the 1950s, contains in a succinct summary the same ordinary virtues of the practice of mountaineering as expressed by the New Zealand mountaineers whom I interviewed: love of the mountains, deep commitment to being a mountaineer, the centrality of internal rather than external goods, and a sense of responsibility and level-headedness in the face of difficulty. That these virtues should be consistent for an English mountaineer active in the 1930s and 1940s, and for New Zealand mountaineers today, suggests the strength of the mountaineering tradition in maintaining an internally stable and coherent moral source for members of this tradition. The primary 
virtues of mountaineering in the New Zealand tradition are discussed below as: enduring commitment to mountaineering as a way of life; humility; non-materialism; and responsibility for one's companions.

\section{Enduring commitment}

I don't call climbing mountains a sport. Rock climbing is a sport. Climbing, climbing mountains is a way of life. Yeah, climbing mountains has got to be your soul, you know. ... Maybe technical ice climbing can be a sport, maybe technical mountaineering can be a sport, but being, in the mountains, walking, tramping, sitting down looking, listening to birds, getting high, in the snow, that's, you know, a way of life. It's got to be, you've got to live it. You haven't, you know, you haven't necessarily got to be a, a huge, um, successful mountaineer to do that.

(Terry)

The single most important criterion for being a 'true' (as opposed to 'great') mountaineer, is not the height of one's achievements but the durability of one's commitment to mountaineering as a way of life; and an enduring commitment is underpinned by a deep love of the mountains:

it feels like your soul's expanding, when you get up into the unbuilt landscape.... lifelong climbers don't, you never get over that joy of being - it's just being there. Being among it, okay, being part of that landscape, that's so fulfilling.

As Thomas says, "just being in the mountains" is the most important thing. He recounts a story that is told of the famous Austrian climber of the 1950s, Hermann Buhl, who after returning from "the big climbs" met an old man who told him how much he loved the mountains and wished that he could climb them. Buhl reportedly assured the old man that indeed he was a mountaineer, simply by virtue of the way that he felt: ${ }^{54}$

it's the being there and love for the, yeah for the country, for the mountains and all, and that makes us mountaineers. ... I don't think you're better mountaineers if you climb grade 20 or 30. I think that has nothing to do with it, it's in what we bring to it and what we get back from it and we can do it in our own stages.

(Thomas)

Frank Smythe was admired for being a mountaineer "first and foremost", and his love of the mountains, which he is said to have acquired from a young age, was described as being central to his desire to climb. Indeed, a “deep and reverent”, even "spiritual”, “love of the hills" was the most often repeated quality praised in the obituaries of mountaineers in the NZAJ throughout the last fifty years. For those who suffered an accidental death while

\footnotetext{
${ }^{54}$ The story Thomas is referring to appears in Buhl's (1956:239) autobiography. 132
} 
climbing, solace was often said to have come from the fact that they died doing what they loved, in a place that they loved.

In emphasising the importance of how they feel about the mountains, the mountaineers differentiate themselves from others who climb but who are, as Pip puts it, "often, not really focused on the environment they're in; they're really focused on, ah, the technical side of the climb and achievement". Adam says, "you do come across people whose attitude to the environment is, sort of not related to ... how I envisage climbers to be".

For mountaineers, the mountains are central. Pete feels that, for him, the mountains are "the real essence of your being" and that "just doesn't go away". Even though he hasn't been climbing as much recently as he used to, "in my mind I haven't left it":

[it's] quite an emotional attachment to the mountains and, um, I'll keep, yeah keep going back and I have to get onto the high mountains like Cook and Aspiring and Tutuko... it's just like going back and seeing old friends sort of thing, it's great.

Simon has a similar feeling:

I don't know what life would be like without, appreciating the mountains, whether your climbing them or, or viewing them or, enjoying them in some way or another. I mean that's the essence of mountaineering really you don't always have to be climbing, to enjoy it. You know you can do trans-alpine trips and, take in the views and, carry a light pack and, eat good food.

This aspect of the identity allows for its durability over a life-time, and is closely linked to themes already discussed in Chapter 3. As mountaineers grow older, Thomas says, "we adjust our ambitions to our capabilities”. Terry explains that “Sometimes you haven't got the desire to, um, cart a heavy pack up a mountain, you just want to wander up a piddly little old valley, spend a night in a hut and just have a, take a bottle of wine and just enjoy the thing”. If someone gives up because they can no longer "keep up", or do what they used to do, according to Thomas "that's not, that has nothing to do with mountaineering". The commitment can be, and must be, for life:

mountaineers keep trooping away, keep, you know, keep ticking away at you know, the odd tramp, the odd walk in the Silver Peaks, right until he drops dead, he will.

(Terry)

Those who are not "real mountaineers" will burn out after a few years and give up; or people will try it because it is fashionable and then give it up and try the next thing when that comes along. 
The young climbers who did extreme things when they're very young, ten years later, they don't climb any more you know.... I think the measure is, I think is when fifty years later there's still a few guys around who I knew from, and to me, I think they're the real mountaineers. They go on, just because we can't do the difficult thing any more, doesn't mean you should stop, you know?

(Thomas)

Two of those I interviewed were no longer climbing. While Bob swapped climbing for flying as he grew older, his life is still intimately connected to the mountains as he lives in them and runs his business of ski-planes and scenic flights. When he sees climbers from the air, he feels an affinity with them:

I do feel quite a strong, strong bond, you know, that I know exactly why they're there and what it's about. And that's pretty neat. In fact I'm a very lucky man to be able to, as you get older and physically not as fit and agile, to still be able to get around the hills and I mean I guess I did that deliberately.

Whether climbing or flying, for Bob “it's very much a business of knowing the land, knowing my land. And I relate to that totally”. As for Mark, a climbing accident left him with debilitating and permanent injuries. While he will never climb again, and has great trouble even getting back in and around mountains, the way in which he describes them in his interview suggests a strong and enduring connection. In telling his story he seems to almost get lost in the telling, pausing at times and closing his eyes, as he takes great care to vividly describe experiences and intense emotions. One thing is clear: deprived of the practice, Mark still embodies the tradition. The mountains remain pivotal to his life, and he sees them as potentially both benevolent and malevolent. They are, he says, sometimes "out to teach you a lesson ... if life before I broke my neck was a chapter in the book, it just changed chapters on me. It said it's time to go a different way. And face up to some different challenges”.

A mountaineer's commitment must not only infuse the length of her or his life, but also its breadth. For Terry, a mountaineer is someone who "lives, eats, sleeps thinking, you know, mountains”. It is an indivisible part of his life, “you've got to live it”, constantly. For Thomas too:

it's part of my life. It's one activity which sometimes I have been doing more and sometimes less. And I've been fanatical about it at times, and more relaxed about it ... I can't single it out of part of my life. Just one of the things I did, and I'm very glad I did because I think it has helped me, for me I think all activities feed together. ... You know when I go climbing, my climbing activity must, it must have some influence on the [my art]. I don't, won't see it necessarily, but it must do. My life influences it, so in order to make [art] I have to have a life, which will influence the [art], so my life, my life is work. You know, I call everything work or I call everything life, yeah, so, not separated. 
Being an "all-rounder" is a related quality admired among the mountaineers, as it was for Smythe earlier in the twentieth century. Its praise can also be found in the New Zealand climbing literature of the 1970s. As Dingle describes it, mountaineering is "a much broader field" than "alpine climbing". While they demand the same basic skills, a mountaineer "must also have a deep feeling for the mountains. He should be a good skier, be able to carry a heavy pack over difficult ground, and be able to coax wet alpine scrub into a life-giving fire - he must be a mountain jack of all trades" (Dingle cited in "Editorial," 1972).

While specialisation and an emphasis on technical proficiency might lead to someone 'standing out' in one particular aspect of climbing, being a mountaineer is not about “whack and dangle”, as Terry describes it. Rather, "it's a bloke that likes getting into, into the hills.... a person who, keeps going back to the mountains because they love being there", and someone:

embracing the whole spectrum, somebody that can rock climb, somebody that can perhaps ski, somebody that can handle themselves on the snow, somebody that can navigate. Somebody that knows the weather, somebody that knows the technical aspects um, somebody that is interested in mountain literature.

A love of the mountains renders comprehensible the capacity to persevere and overcome obstacles in the pursuit of climbing mountains, in a way that such exploits are not always comprehensible to outsiders. His “mountain feeling”, Dave says, allows him to suffer, and mountaineering would be a "weird experience" (that is, an incomprehensible thing to do) without it. To explain this Dave tells a story about an expedition during which he had to spend a lot of time walking up and down a glacier. To begin with, it was a grind and he “didn't really get it [laughs], didn't feel anything for the place”, until he stopped to watch the light changing across the landscape:

I just sat there for ages and I felt that, that feeling and felt really good about the place and, got my mountain feeling back, and ... I mean that's one of the lasting memories I've had of that trip, is of the light changing and me sitting there in the middle of the glacier with all these big mountains around, and feeling really nice. Feeling really sort of, well at home I suppose and grounded with, with the place. ... If you can't go into the mountains and feel, get something from them, like that, amazing feeling then, it'd be a fairly weird experience going mountaineering. ... that's kind of what, allows you to suffer a little bit and put yourself through quite a lot of, ah, angst and suffering, pain and, all the rest of it. ${ }^{55}$

\footnotetext{
${ }^{55}$ For full story see Appendix D, number 3, page 269.
} 
A love for the mountains, therefore, provides a source of 'narrative unity' in the lives of these climbers. This renders their enduring commitment to a life of mountaineering including not just the technical feat of climbing mountains, but also a passion for "just being in the mountains" - meaningful. Having such a unity, according to MacIntyre (1981), runs contrary to the forces of individualism and bureaucracy which dominate in modernity, and tend to compartmentalise our lives. Indeed, the rise of modernity so eroded the potential to conceive of a life as a unified whole, MacIntyre (1981) argues, that by the eighteenth century it could no longer be taken for granted. As evidence, he cites the novels of Jane Austen, in which constancy (in actions and not just words) emerges as a central virtue, essentially in response to the necessity of continually demonstrating what can no more be considered a given.

Constancy is so crucial to a stable moral life because in the absence of narrative unity, which bestows a telos at the level of a human life in its entirety, individual virtues lose their context, without which they cannot be fully understood. This leaves us vulnerable to 'a certain subversive arbitrariness' in our moral lives (MacIntyre, 1981:189). In mountaineering, as in Jane Austen's novels, constancy - or an enduring commitment as I have called it here - underpinned by deep feeling, is a central virtue.

\section{Humility}

They're doing it in a very, in a humble way and not making a big thing about it. Just getting around and enjoying places and living the experience. And, people may never know about that, but that's fine. And then on the other end of that you've got the people, it becomes an ego thing, and it's a big thing, that's the driver.

If the existence of a deep love of and enduring commitment to the mountains is the most crucial signifier of the 'true' mountaineer, then also of high importance is the absence of a desire for recognition or glory. For 'true' mountaineers, the enjoyment of the activity itself should be enough to sustain them. A desire to push one's personal boundaries and the boundaries of climbing is admired, but the highest respect among mountaineers is reserved for those who do this without seeming to be egotistically inclined; that is, with humility. As it was said of Frank Smythe, success and fame were not what interested him. Along with love of the mountains and commitment to being a mountaineer, humility and a lack of interest in external goods, such as popularity or public recognition, were frequently mentioned in mountaineering obituaries. Being "unassuming”, "modest" and "selfless", for example putting one's ambitions aside in the interests of others, were qualities that 
were highly praised. Most admired were those who were "understated" about their achievements (one climber was even described as "endearingly naïve” about his abilities), and climbed for the love of mountains and adventure, not "credit" or "egoistic drives".

The importance of this quality was strongly articulated in the biographical narratives by Bill, who sees self-interested ambition as the antithesis of what mountaineering should be about. His views on this were crystallised by a pivotal experience as a young climber when he realised the damage that could be done to mountaineering friendships by a desire for glory. He was part of a group of four mountaineers actively climbing together, of whom two were invited to join a prestigious expedition. The invitation, however, did not specify which two it should be:

so we had to decide which two would go, and ah, I, I remember it was a huge jolt to my, idea of mountaineering that - you're four people on a rope ... and ah, to me it was a real bond - that when the opportunity came to go to [on this expedition], I found that everyone thought that they should go, everyone suddenly, I hadn't realised what human nature was like. I found that everyone, each of the other three people thought they should go. And ah, I pulled out of it, because ah, I couldn't cope, with that, sort of stuff. And ever since, to me going into the mountains is about going there with your friends, and enjoying the mountains. ... just being there was what it's all about. That the summit is really, as my son says, only a geographical high point, it's what happens on the way that, it's really all about. And that you should be having fun. Otherwise I don't think it's real mountaineering.

From this experience, Bill says he "learnt a lot about, ourselves, a lot, a lot about other people, and a lot about mountaineering”. Rather than those who have sought glory through mountaineering, Bill admires most those who are happy to climb small, unclimbed peaks that no-one else is interested in, but enjoy themselves in the process. This, in his opinion, is pure mountaineering. Chris claims a similar philosophy. "I climb mainly for the enjoyment of climbing”, he says, and he has turned back when he has not been enjoying himself on a mountain, though others might have slogged on for the prize of the summit.

When I asked Pete whether he ever wrote articles about his climbing he said that he did not have an interest in writing about climbs he's done, other than if people want particular information. He seems to interpret anything other than providing factual information about a climb as self-promotion, and not necessarily connected to one's skill or dedication. He says "it's interesting some of the guys that write the most ... aren't ... doing as much but they're right into writing. ... [but] I wasn't out there climbing, to put my name out in the headlines or anything”. 
Indeed, it seems generally acknowledged by the mountaineers that many of the best climbers in the country are the least likely to seek recognition for their achievements. The mountaineers most revered by those I spoke to tended to be those who were "hard-out" but "humble", "everyday guys" that when they met them climbing, "they're not guys that are unapproachable ... they were just like us, you know, everyone had the same sort of, love of the mountains". One of Pete's inspirations is a New Zealand climber called Murray Jones who was at the forefront of new ascents and styles of climbing in the 1960s and '70s described in the previous section. He sees him as "the spearhead there, the fullon guy doing the hard stuff and driving all of that" and yet "he didn't seek the limelight really".

Similarly, Dan is inspired by climbers he has met who are "talented", but "they're just really humble with what they're doing, and kind of got a really good attitude towards it all”. When Kath met the highly accomplished French climber, Catherine Destivelle, she was inspired by just how "normal” she seemed:

she wasn't thin ... she was chunky like me and she smoked cigarettes which I sometimes do and she drunk beer and she didn't sort of, you know, she was so normal. And yet so accomplished. And I thought she was fantastic and she did all kinds of climbing. ... I liked her whole, the whole package of her if you know what I mean.

In fact, Dave finds that some very talented climbers are "bloody not much fun" if they are there solely for the "hard climbing, or the ego". For him there has to be balance: "that's the whole thing, you know, the spirituality, the fun, the hard climbing, the just sitting on a peak just looking at the mountains, you know, it's all, it's all gotta be part, for me it's all gotta be part of it”. When I asked him what his main goals were, he said:

It's not, 'climb Everest' or anything like that, it's a bit more obscure. But yeah definitely to have fun because... I don't think I've ever climbed where the ends justifies the means ... it's got to be ... either fun in retrospect or fun at the time. ... I know of one mountaineer who will go on I think, if they don't die, umm, they'll be revered, you know, as one of New Zealand's great mountaineers, but, [I] don't know how much fun they had getting there ... there's kind of something missing if you're not enjoying yourself as well.

It has been suggested that a preference for modesty is something inherent in the New Zealand national character. Phil speaks about some climbers doing "amazing things but out of sight", not seeking sponsorship or publicity, just quietly doing things. "Maybe it's just the Kiwi way", he says. While humility may not have been considered a virtue in the time of Aristotle (MacIntyre, 1981), it is certainly seen as important to mountaineering in New Zealand. It is necessary to overcome 'harms, dangers, temptations and distractions', 
in particular the pitfalls of egotism discussed in Chapter 3. In addition, it demonstrates that one's dedication and commitment is founded on an appreciation of the internal goods of mountaineering - the joy of climbing, strong bonds with companions, and the aesthetics of the mountain environment - rather than being drawn from externalities such as praise and popular acclaim, or as we shall see below, material wealth.

\section{Non-materialism}

[Mountaineers are] not as interested in acquiring stuff as feeling feelings. That's more important, to have experiences than to have chattels, and crap. The mountains are a very unencumbered place. ... you can't buy the feelings of achievement and, of self-reliance.

Consistent with the view that they should be inspired by internal rather than external goods, another virtue which is seen by many to distinguish 'true' mountaineers is that they “don't aspire to great wealth". "Most mountaineers are satisfied with their lot. They're very satisfied with their existence, most mountaineers", says Terry. It is about being able to live, according to Bob, "in a relatively uncomplicated way". Dan suggests that "making do', like being modest, is part of "the Kiwi mentality", and is critical of the consumerism among some climbers that he met overseas:

I really like the attitude of climbers here ... the Kiwi attitude of 'give it a go' and, you know, do it yourself kind of thing, whereas, overseas I guess, especially climbing in America, the gear aspect of climbing gets a bit much. ... people out with all this really expensive flash new gear and, they just, you know, they've hardly used it ... I just prefer the Kiwi mentality of make the most of what you've got and, it's kind of, the old perspective of, you know, with that fifty bucks you've got to buy a new piece of gear, you could actually go away and just make do with the gear you've got and learn a lot more, and have more fun.

So mountaineers' lives, like the mountains, should be "unencumbered". Not only is this a matter of priorising climbing over the pursuit of wealth and the accumulation of consumer goods, but it is also a virtue that is seen to spring from experiences in the mountains.

Along with the obituary of Jill Tremain, a young and promising New Zealand climber who died in an avalanche in the mid-1970s, were printed extracts from diaries and letters she had written during a winter ski traverse of the Southern Alps, including the following:

The greater part of each day was spent alone ... We were able to reflect on many things and I noticed the differences between the bare essentials required for survival and the usual ideas most people have about their necessities for everyday living. We lived from a billy. Fire and nightly shelter were our only real requirements. To me, the world of everyday life seemed even more complex and cluttered by unnecessary possessions. Our whole civilisation appeared to be 
shallow, insincere and devoid of substance. Man seemed to have forgotten what is really necessary for survival and what is really important to life.

("Jill Tremain," 1974:123)

This passage can be read as reflecting the current of anti-materialism in society during the era in which it was written. But the expression of these sentiments by mountaineers can be found beyond the limits, even if perhaps influenced by, this historical period. Pete feels that having mountaineering as a central focus of his life "keeps it all in perspective" and lies behind many of the important decisions he has made. For example, he recently gave up a well-paid professional job:

I wanted to make the lifestyle change, this job got advertised and I could see it gave me the opportunity to [spend time in] the mountains, round the fringes which is my work and, ah, and that's really attractive, you know, and the salary doesn't really matter too much. So, um, that's a big attraction, yeah, and I feel like 'ah, this is good, and I'm going back into the old hills again for a bit'.

Sue too feels that the satisfaction she finds in climbing has led her to place less emphasis on the material side of life:

I've found that as I climb less the material side of life grows more around me and if I go climbing I can shed that more and get away from it. Because you just realise you don't need so much stuff and you can live at a much more basic level than most of us do. So I like that.

Pleonexia, or 'acquisitiveness', may well now be the 'driving force of modern productive work', but Aristotle considered it a vice (MacIntyre, 1981:211). Mountaineers, it would seem, are closer to Aristotle in this regard, than to many of their contemporaries who are vigorously engaged in the 'market game', as Bauman (1988) describes it.

\section{Responsibility}

I think it's a, it's an activity where actually we tie ourselves to each other for better or worse and so we do, we carry responsibility for each other.

(Thomas)

everyone helps each other and looks after each other.

A 'true' mountaineer is also someone who takes responsibility for those he or she is climbing with. As Lyn thought, while struggling up that mountain in Nepal, ${ }^{56}$ whatever her physical suffering, the worst thing she could do was let her companions down. In discussing significant experiences that she has had in the mountains, Pip tells a self-story

\footnotetext{
${ }^{56}$ See Chapter 3, page 109.
} 
which illustrates a mountaineer's responsibilities towards her companions. She was on a climbing trip with a group of people, some of whom were "a bit out of their depth".

Others, who were more competent, went ahead, and left Pip to deal with those who weren't "coping":

I find that really hard to do, to leave people ... some people can just shut down like that and just exclude, kind of, emotions from their day, and just go, 'oh it's just a climb' and just climb without ever feeling and I've, I can't do that. Um. And so I always feel I need to, stop and help. ... So that was a learning experience. ... when you're as a group in the mountains then you should stay as a group in the mountains and, it will need two of you to encourage a person that's having problems for whatever reason. ... You shouldn't just walk on ahead and leave people.

Mark also has a story about struggling with responsibility for his climbing companion, but knowing ultimately that the 'right' decision is always to put the welfare of others ahead of one's own ambitions. His climbing companion's leg was "troubling her" when they reached the bottom of the route they had planned to climb, the Sou'west ridge of Mount Aspiring. She encouraged him to go on without her, and told him she would make her own way back across the glacier to the hut, but:

she wasn't very experienced, and, I really wasn't willing to let her wander through a crevasse field on her own, and, if I'd got her to climb we wouldn't have got off the mountain again in daylight. And, yeah it just wasn't worth it. And it's one of those decisions that you sort of sit there and, I had to make the decision 'cause I was kind of a bit more experienced and, and, you know what the answer is but you've just got to take a lot of time to, to let it go. And 'cause it's a beautiful, beautiful mountain and you get that close to it and it's in prime condition and it's just, yeah, and so, we just waved it goodbye and headed back.

As Bob says, climbers often share "very intense times", and if "people have been up against it together there's a bond that never goes away, no matter what you do".

Throughout the NZAJ obituaries, climbers were praised for the qualities that made them good and responsible companions. Many were commended for their willingness to undertake mundane tasks, as well as for their "sincere concern for others", in particular helping the less experienced. "Never failing cheerfulness”, "infectious enthusiasm” and optimism were very frequently mentioned dispositions to be valued in a mountaineer, especially in "depressing circumstances", that is, being able "to laugh in the face of adversity".

Part of being a responsible companion is also being a "sensible" mountaineer: someone who does not "get carried away" and take unnecessary risks, as Pip says. ${ }^{57}$ Like Frank

${ }^{57}$ See Appendix D, number 4, page 269, for Pip's story about being “sensible” . 
Smythe, a mountaineer should be aware of "responsibilities and difficulties". Blind bravado is not admired. A good mountaineer is also patient and persistent, someone who can stay calm in an "edgy situation" and find a way out of it. Being "cool", "confident" and "unflappable" in the face of danger or difficulty is certainly an asset. Such people inspire confidence in situations where one's fate may well be bound to one's companions and their capacity for level-headedness.

Morality is, according to Bauman (1995), no more and no less than 'being-for'. In contrast to 'being-with' or 'being-aside', being-for is about 'bearing responsibility'. It involves the moral feeling or sentiment that 'I am responsible for her/him, and most of all for what my action may do it her/him' (Bauman, 1995:63). It is the realm of 'sympathy, of the willingness to serve, to do good, to self-sacrifice for the sake of the Other' (Bauman, 1995:60). This, for Bauman, is morality stripped bare: finally deprived of the robes of ethical legislation, fashioned by modernity, which gave a sense of confidence and certainty, but in the meantime smothered the basic moral impulse of being-for. Back at 'ground zero' for morality, certainty is out and ambivalence is back, but so too is the 'primal moral scene' of self-faced-with-Other, and the bare-faced moral implications of this meeting. It is not surprising then, that up in the mountains, in a world 'stripped to its bones' (Vervoorn, 1981:65) of society's trappings, moral responsibility for the Other should be hailed as a virtue, and rational ends-over-means, at the expense of one's companions, as a vice.

Not that any particular situation is exempt from ambivalence, as Mark found as he sat at the bottom of the Sou'west ridge of Mount Aspiring and fought to suppress his desire to climb it. But this is how it should be, according to Bauman (1993), as a morality that rests upon personal autonomy, rather than a legislated ethical code, can never be completely ambiguity-free. Nevertheless, to consider one's companions in the mountains as mere objects, the use of which is to fulfil one's ambitions and whose relevance ceases once they are no longer useful (as Pip found with those who could "shut down" and leave others who were struggling to fend for themselves), is clearly a dangerous game. The moral of the story is: chose your companions well, and treat them well, as they may be, one day in the future, all that stands between you and the literal and figurative abyss.

The epitome of utter reliability is exemplified by the partnership of Vernon Leader and Jim Gilkison, ${ }^{58}$ two South Island climbers active throughout the thirties, forties and fifties. Jim

\footnotetext{
${ }^{58}$ In a previous study (Davidson, 2002), I collected the oral histories of these two mountaineers.
} 142 
wrote that their "enduring friendship" had resulted in an "understanding ... such that the leader on the rope never had to look round to see what the second was doing. He had confidence the proper precautions were being taken” (Gilkison, 1965:74).

So, for mountaineers to be a good companions, they need to be responsible, reliable and sensible. In summary, they need "a good head", and that head needs to be "screwed on real tight”; not only for climbing, but for all areas of life. While it is possible to climb without being “sorted”, Simon thinks “there's no doubt that you need to be sorted in all areas of your life to be a good climber". When I asked him why he thought this was, he said "I think you just need some peace of mind you know. Yeah. I've seen amazing climbers who do amazing things but their own lives are just completely messed, but it never lasted. Like their climbing didn't last”. Clearly then, they could not be considered 'true' mountaineers.

\section{Being a mountaineer in an inhospitable world}

It is characteristic of ordinary virtues, Gordon (2001:28-29) argues, that they 'acknowledge their limits and know their impermanence'; 'they are open to unseating'. As suggested at the end of Chapter 3, the ideal identity of the 'true' mountaineer can be difficult to live up to. In a number of the narratives the mountaineers grappled with difficulties that arose from trying to be the kind of mountaineer that they aspired to be, while living in a world not always conducive to their aspirations. This led them to sometimes question the wisdom or pragmatism of strict adherence to the virtues described above. Such struggles were particularly evident when the moral imperatives of mountaineering clashed with responsibilities and norms in other aspects of their lives. As MacIntyre (1981:211) says, practices like mountaineering exist today on 'the margins of social and cultural life'. For people whose life-focus is 'on the margins', it is perhaps inevitable that they will, at times, find their lives 'out of kilter' with the centre.

I found, in the narratives, three particular areas that were difficult for the mountaineers: firstly, the question of divided commitments, between the world of mountaineering and the 'outside'; secondly, the desire for recognition (from both within and beyond mountaineering circles), which co-exists uneasily with the virtue of humility; and, finally, the 'false values' of the outside world, which appear to impinge upon the tradition of mountaineering and compromise the values that are held dear therein. These three areas are discussed more fully below. 


\section{Divided commitments}

Especially problematic was the issue of commitment. Commitment to one's life as a mountaineer is, as I have argued, highly admired within the mountaineering community, but inevitably draws people away from their co-existing commitments outside that world. Selfhood, Bruner (2002:69) tells us, 'involves a commitment to others as well as being "true to oneself"'. Thus, the 'balancing act' of the narrative construction of the self is to create both 'a conviction of autonomy' and to 'relate the self to a world of others' (Bruner, 2002:78). How can this be achieved? Each must find a unique answer to fit their storied life, but it would seem that this conundrum often lurks behind the scenes as unfinished business. Steph seems to feel she has little choice but to be 'true to herself', though she does not suggest that this is easy:

it's always, drawing me away from, from my family and, and my friends and, and the things that I feel like people would like [me] to be doing as well. Like my parents would really like me to finish my degree and, get a proper job and stuff, but, it's just not really within me to settle down in, in one place and not have the freedom to, go climbing, so, yeah it sometimes, it does feel like it's, it's an impact that it's making on me. Sometimes it just feels like, well, that's the way I am.

Guilt over the cost that their commitment to mountaineering can have for partners and families was strongly evident in a number of the narratives. In Chapter 3, I touched on the way in which Bill, Terry and Jan all feel that their mountaineering had conflicted with their family responsibilities. Pip also feels that since she has had children, "I'm really caught, between, my responsibilities as a mother, and, my desire to go and climb. ... I've tried not to feel it. But it's definitely there”.

Sue had never originally wanted to have children:

I didn't make a decision to have a family. [laughs] I never wanted to have kids and then I met Geoff and Geoff wanted to have kids and I thought 'oh well if I'm going to have him, I've got to agree to have kids. So okay yeah that's alright'. That was an easy decision to make. But not for a while, you know that was the idea. So I was 28 when we got married and I was 29 when we had our first child so that was a bit too quick, so yeah. ... but yeah I found it very difficult to cope with the restriction of being a parent. Very difficult. Yeah I guess it took years and years to accept it.

Although Sue and her husband both continued to climb while raising their three children, she found it a struggle both mentally and physically. With a two year old and a three year old, she decided to climb Aoraki/Mount Cook by the West Ridge, but did not enjoy it: "it was too easy and broken up to put a rope on, so we soloed it but it was too, it was too hard to really feel totally relaxed and comfortable. We were always sort of feeling just slightly 
on edge". Although she had felt that she "needed to do it then just to show myself I could still climb Cook even though I had kids", afterwards she decided that she would not climb Cook again while she had children. When she was younger she had not felt the need to stay alive on account of others, her love of climbing being stronger than her sense of selfpreservation. But now, she says, "as the children get older I see their need of me more and more and it just becomes less and less acceptable to take risks and especially since Geoff died I just wouldn't want to entertain the idea of the children being orphans".

Because of this she has decided to climb easy peaks, but on the only alpine climb she has done since her husband died, she struggled with her decisions:

there was one step on it where you had to make a decision, am I going to go on up here and risk slipping and there was a bluff below or will I back off? Well I went on, even though I told myself I'm not going to take risks I'm just going to be very careful. It was only one step but you know if you'd slipped on that one step you could have been killed. Yeah so it's funny I'm not sure how much control I have over my brain in those situations, over my actions. Yeah.

Later, on reading over her narrative, Sue added a reflection on this story. She wrote that this climb had been her second attempt on the peak, and the "thought of how disappointed I would be if I turned back versus how good it would feel to be successful ... made me take the risk of that step". She adds though, that she is much less ambitious than she once was:

In the past I would have aspired to doing bigger and harder climbs all the time and that changed, I guess that changed when I had kids. I just couldn't keep fit enough and ... my focus is changing more to doing easy peaks and tramping trips with the kids, to the tops of mountains but you know I don't really care whether they involve climbing or not as long as I get out there just because I feel so deprived not being able to get out at all. I imagine that if I had the time, as soon as the kids are grown up, and if my body's still in one piece I can imagine that I would get more into climbing again. Because once you do a bit you get bitten by the bug and you want to do more of it, you see all the things that you want to do. But at the moment my sights are sort of pretty low.

Dave has experienced similar conflicts. Commitment is a word he uses often in his narrative, but with some ambivalence. He is aware that much of the "magic" of climbing and the ability to perform at a high level, requires a capacity to detach oneself from the everyday world and to value the challenge - and all that it represents - more highly than survival, or the fear of dying. At the same time, he wants to live to be an old man, he finds being married "fantastic", and does not want to be portrayed as being selfish. The levels of commitment he reached when he was young and living the life of the "climbing bum", on the dole and with no girlfriend, set a kind of benchmark for his life, and when he talked about commitment he tended to return to a particular year (a date he describes as being etched more deeply in his memory than his wife's birthday), and a trip where the stakes 
were extremely high, and he realised just what was to be gained, if everything else was put on the line. He and his climbing partner did a major climb in the middle of winter, at a time that was particularly cold and had high snowfall:

we hadn't done anything like it before, nobody had, and we didn't know what we were in for and we did a few things wrong and stuff. But we ... we were totally committed to what we were doing.... three or four days into the trip we lost our tent in a big snow storm. ... we were lucky to sort of get out of the storm alive ... we dug a snow hole and we cowered in that for two days ... but then it cleared up and we dug most of our gear out ... I don't remember discussing whether or not we would bail - like we were so committed and so into it that, umm, we carried on, but with minus the tent so we had to bivvy. And bivvying in the middle of winter, back then, when we didn't have any bivvy bags, we just had our sleeping bags and stuff was full on, I mean, we, sort of, were starting to push the boat out. But ... it didn't really matter because we were ... committed, you know, it's like when you get to a level, that level of commitment in mountaineering it ... becomes magic and sort of magic happens, you know, you sort of don't really care whether you live or die kind of thing and it's really really cool. ${ }^{59}$

When I asked Dave if he has had any disappointments in his climbing, he described experiences when, for one reason or another, the level of commitment did not match the level he had achieved on the trip he describes above. On one recent trip, he says, there were "funny group dynamics", where two of them were "really committed" and the other two in the group were "kind of easy-osy 'oh, this is a good holiday' kind of thing, you know, 'we're having a good time but, we've gotta get home for our jobs'”. But, he continues:

you can't approach a peak like that. You've gotta have lots of time and you've gotta, release yourself from society. You can't have any ties, otherwise you'll, yeah, you tend to, you know, you'll rap off quite quickly. So that was a, that was a pretty big disappointment. ${ }^{60}$

So it seems that sometimes mountaineers may not just be in a double-bind (self versus others), but indeed a triple-bind (self versus others versus others). If the self is "oriented towards "reference groups" and "significant others" who set the cultural standard by which it judges itself' (Bruner, 2002:71), then the mountaineers potentially have two opposing groups of others to which they must refer: those on the mountain, and those 'back home'. Dave admits that he struggles with the ties that bind him to the world outside of his climbing trips. He likes the fact that the job he has requires "no commitment": "if [my boss] suddenly went down the gurgler and, couldn't afford to have me then I'd [say], 'see you John', 'see you Dave', you know, no love lost sort of thing, no redundancy”. But things have changed since his early carefree days, and his frame of reference has shifted.

\footnotetext{
${ }^{59}$ For full story see Appendix D, number 5, page 270.

${ }^{60}$ For full story see Appendix D, number 6, page 270. 146
} 
He says that now he is married, there is a bit more "give and take", although his wife "understands" that because mountaineering is "part of my, being you know, I have to go every now and then". He does not want to have children and, he says, "I definitely don't want three weeks holiday a year". So while his "need to go climbing” has been tempered over time, "every now and then ... you just get this, 'oh yeah, here it comes, I've got to go' [laughs] ... It's amazing that we actually have steady relationships really, sometimes [laughs]". ${ }^{61}$

But internal conflict over the all-consuming nature of mountaineering is not limited to those with family responsibilities. For Dan, a devotion to climbing clashes with his sense that he should be making a more significant contribution to society, as touched on in Chapter 3. He says he "struggled for a long time thinking that ... climbing was quite a selfish activity". Dan reconciled his inner struggle by deciding that he could contribute through climbing by becoming an outdoor instructor and working with young people, as well as just feeling more fulfilled in himself:

I've kind of, been realising that, that just by doing what you want to do and what you love to do that, you're going to be a lot happier and, more inspired in yourself all the time and, that just by living like that, you know, you are giving and helping people around you.

Some of the mountaineers simply express regret that climbing is such an all-consuming activity that it leaves them insufficient time to do other things that they have an urge to do:

sometimes I think, oh, you know, this is a bit sad, all you do is climbing, 'cause there's so many other things I want to do as well, but climbing kind of takes up every spare minute of your life, but then if I enjoy it so much I may as well keep doing it and, do something else when I get a bit sick of it.

Simon has become more aware of and attempted to ameliorate the "selfish" aspects of mountaineering as he has grown older.

I think mountaineering is quite a selfish sport actually. Like as much as it can enrich your own life, and, it doesn't necessarily mean it might enrich those around you, like partners and, friends.... if you're hanging out with a core of friends who are into the mountains then, it's great.... [but] I haven't enjoyed some of the other, things that there are to enjoy in life.... [because] it's a sport that requires, commitment ... Yeah I'm definitely more well rounded about that now though.

Tim does not think he "could be a climbing bum any more". These days he likes to be able to "switch off from climbing" at times, and to have "things to put in the gaps between

${ }^{61}$ For full story see Appendix D, number 7, page 271. 
climbing”, such as kayaking. This means thinking of himself as more than "just a

climber".62

If assessments of the postmodern condition are anything to go by, it is no wonder that, particularly for the younger climbers, they can feel pulled in many directions. Due to a process he calls 'social saturation', Gergen (1991:80, 219) argues that people today are afflicted by multiphrenia, which splits them into 'myriad, fractional relationships' and exposes them to 'manifold and competing potentials'. In a world of limitless, technologyassisted possibilities, our daily lives he says, have 'become a sea of drowning demands, and there is no shore in sight' (Gergen, 1991:75). Wolfe (2001:95) describes the effect of confronting so many choices as a kind of 'moral vertigo'. Subjected to such forces, commitment - to anyone, to anything - is seen as the exception rather than the rule, although option-overload can, according to Gergen (1991) lead to a renewed desire for the conflict-free simplicity of a single-focus life. As we have seen above, however, this is more likely to be an ideal than the reality, and a heavy-duty pair of blinkers would be required not to see all the other temptations and responsibilities that surround us on every front.

\section{Desire for recognition}

A number of the mountaineers also feel conflict over humility as a virtue. While not wanting to seem egotistical or to be accused of 'blowing their own trumpets', some confess to being frustrated at times that there is a lack of recognition for their achievements. Pete admits a 'secret' desire for acknowledgment. He says, "definitely ... you do like to be recognised for what you've done”. He thinks everyone does, “if they're being honest”:

all climbers have got big egos, ... while I don't like writing articles for example I really like to, be recognised for some of the climbs I've done ... I think if all climbers are honest they've all got pretty big egos in terms of the climbing community anyway.

It is a 'catch 22' situation, according to Simon. He thinks that there are a lot of mountaineers climbing that nobody knows about, and this fits with his idea that climbing is an "underground" activity. While some climbers express a degree of regret that they receive little recognition for what they do, if it was more publicised, it would become a more mainstream activity. For Pip it is problematic that the most easily recognisable 'benchmarks' of achievement are the well-known climbs, reputed for their technical difficulty, around the popular climbing area of Aoraki/Mount Cook. While she has done

\footnotetext{
${ }^{62}$ For full story see Appendix D, number 8, page 271. 148
} 
some of these climbs, they are not the sort of climbs that she is drawn to, preferring more obscure and unusual mountains in remote locations. But few people have heard of these climbs, and therefore they are not considered to be "major achievements". ${ }^{63}$

While they may not like to be seen to be courting praise or publicity, when it comes there can be quiet pleasure in the feeling of acknowledgment. This can particularly be the case when achievements in the world of mountaineering are translated to the world of the everyday, and measured by the criteria of that world. Chris complains that:

Most people haven't got the slightest clue about what I do. And that's fine. But, it does get at me. It's still the same old thing, you know, there's, there's money and support out there for things with a high enough profile. But the only things that really have got a high enough profile are, are the same old things. ${ }^{64}$

However, after returning from an overseas expedition, a local journalist did a feature on Chris for the region's metropolitan daily:

I sent it to my mum, or she saw it, anyway, that made quite a big difference to my mum - to see it in the printed press - my sort of achievements. Although she's seen my slide shows and she knows what I do and stuff ... it sort of helped her realise what I do, without actually explaining what I do ... just because it was a recognised, you know, forum for that sort of stuff, to be recognised, it kinda meant quite a lot to her. Yeah, she was stoked, she was really proud of me ... because it was in the paper, ... Yeah, that felt kinda weird too. She only really responded to, the fact that it was, you know [in the paper].

Dave, like Chris, has a story about the lack of maternal appreciation during his early days of climbing:

I got home and I said 'Oh mum, you know, I've climbed Mt Cook', and she goes 'You're late. You were suppose to paint your sister's bedroom ... bathroom or something, before she gets married'. And I was just like ... I think I went into the next room and had a good cry, I was just like 'But, but, I've just climbed Mt Cook. It's just like, you know, it's the most amazing thing I've ever done in my life and you're chastising me for being late' [laughs].... Yeah, so that was pretty funny.

While Dave consistently emphasises the idea that what he aspires to is "to continue having fun", he did confess that, "secretly", he'd like to leave "a lasting legacy or something" by making the first ascent of a route that will "stand apart from other routes". While he thinks it is "a funny goal because it's kind of ego-centred a little bit”, he says:

I kind of look at it like painting an amazing picture, or writing something that people will just go 'wow', you know, and if I can maybe climb something like that in the New Zealand mountains then, ... that would be a really good goal. ... I'd feel, measurably proud, if ah, yeah, sitting in my wheelchair, that somebody comes

${ }^{63}$ For full story see Appendix D, number 9, page 271.

${ }^{64}$ See a related story from Chris about people doing "the same old things", Appendix C, number 9, page 268. 
up and says 'Ah, man, I climbed that route and yours and, it was a) really good fun, b) a beautiful line, and c) really, really hard'... [but] all that is ... kind of hard to talk about, publicly. ${ }^{65}$

Dave seems particularly wary of the uneasy tension between the desire for recognition and the potential pitfalls of egotism. He thinks it can be "dangerous" to try "to get too much from mountaineering to boost your ego". It can turn you into "a twisted person" and diminish your "enjoyment of life”. If “you're always striving to belittle somebody through your major achievements or you're trying to boost yourself up by doing something amazing, then ultimately you'll come a gutzer”. Still, he admits that:

one of the reasons I do climb is for my ego ... I like the idea of being held in, in sort of higher esteem than the average Joe Blow, and I've kind of struggled with it a little bit and probably will continue, [to wonder] whether it's a healthy thing. ... But I mean ... that's not my driving force. If it was my driving force then it'd be really weird. ${ }^{66}$

External goods, such as recognition and acknowledgment, while perhaps suitably not our first or only aim, are nonetheless valid goods and in the view of MacIntyre (1981:183), 'no one can despise them altogether without a certain hypocrisy'. Though I in no way wish to suggest that mountaineers are hypocritical in their attitudes towards the virtue of humility, the existence of this dilemma is evident in their struggles with it. But such a conflict is not uncommon given, as MacIntyre (1981) points out, that virtues are notorious for standing in the way of externalities such as fame and wealth and power. We can wish as hard as we like to have both, but this is seldom the case. So we have to choose, bearing in mind MacIntyre's (1981:183) warning that: 'if in a particular society the pursuit of external goods were to become dominant, the concept of the virtues might first suffer attrition and then perhaps something near total effacement, although simulacra might abound'.

\section{"False values" of the outside world}

Too rapid an initiation, the crude and lop-sided emphasis on sporting results, the mental and emotional disregard of the alpine universe, will lead infallibly to the complete frustration and annulment of all the virtues of the alpine experience.

(Samivel, 1949:6)

Implicit in what mountaineers hold as being important values or virtues, are their opposites: the "false values" ("Wendy Butler," 1967) or vices, of the outside world. In the narratives these include 'the easy life', competition and technical specialisation, reliance on technology, the commercialisation and regulation of the mountains, instant gratification

\footnotetext{
${ }^{65}$ For full story see Appendix D, number 10, page 271.

${ }^{66}$ For full story see Appendix D, number 11, page 272. 
and self-centredness. The opposition between "two worlds", embodying two very different and incompatible sets of values, each impinging on the other, is illustrated by the following story, published in the NZAJ, about a climbing expedition to Antarctica.

Opening the door in bleary-eyed sleepiness one morning, I discovered to my horror not the usual calm of lapping water, snow and lazy penguins, but a hundred redcoated tourists walking in a line towards us. Bizarre scenes like this continued to surprise me. ... I felt caught on the border of two worlds. I had expected a world of adventure, exposure and isolation, but this was juxtaposed against sudden alarming influxes of people, catering and loud speakers. It was a struggle to maintain the feeling of adventure ... we were constantly being confronted with invitations onto superyachts for French wine and cheeses. The passengers on board took some effort over their personal appearance and in contrast we were conspicuously smelly, uncouth and scruffy.

When offered a passage back to South America on a superyacht, this climber felt that "[a]gain I was being confronted with decadence. It seemed people everywhere were conspiring to smooth my trip with luxuries” (Goddard, 2002).

So the world of adventure and mountains is threatened from without by "luxuries" and "decadence": the easy life. It takes a force of will, as Tim suggests, not to take the "easy" option:

climbing's always like going on a quest or something. I just, I guess life would be really simple, life would be quite easy if you didn't challenge yourself and so you know set these great feats to go and climb these mountains and stuff and suddenly life becomes really hard and you get hungry and sore and tired and yeah so you know it certainly hardens you up a bit because yeah life could be far too easy if you wanted it to be. So - you get a bit tougher.

The alternative, Tim told me, would be to "live in a glass jar". Instead, you have to "try and suck it all up, yeah". It seems, however, that there are fewer people willing to inhale life in this way. Bob feels that the 'purist' approach to mountaineering is something of a dying art:

It's become much more competitive I feel. ... Less of the feeling of craft I think which was once there for ... people that actually travelled in the mountains. And that to me, there are still people doing that. You don't find them round necessarily round the popular areas but you find people still doing, as they always did, the old Christmas trip starting somewhere in some obscure valley, a few passes, crossing from one to another, and then maybe a mountain included. That would have been the aim of the trip, but it wasn't the be all and end all if you didn't get up the mountain. Whereas now I think it's narrowed in its focus. I think a hell of a lot attention's gone into technique. 
Simon too feels that, regrettably, "mountaineers" in New Zealand are becoming a rarity as the focus shifts more to technical proficiency and climbing shorter routes. His role model is a contemporary climber who he describes as:

a great exponent of the modern mountaineer ... an all-rounder. He can climb hard on rock, ice, snow. At the end of the day he's, he's like, the same as me and probably the next, mountaineer, he's happy in the mountains, he feels at home. ... I think there's not many people around in New Zealand now who can, who can do it all. People tend to specialise.

Both Dave and Chris observe that there are fewer "hard core climbers" in New Zealand than there were in the seventies and eighties. Dave's theory is that:

people just don't want to, put themselves through that much, hardship or whatever, but also it's, simple too, there's lots of other fun things to do [laughs]. You can go, hang gliding, you can go body boarding, you can go surfing, you can go, you know, modern world is just so, there's so much variety of things you can do. You don't need to go and suffer on a glacier, you know, and scare yourself senseless trying to grind your way up a mountain. There's actually lots more, easy, umm, quick thrills sort of I s'pose, you know, activities that you can do that don't require quite as much [commitment], like to get good at mountaineering you've got to do a lot, a lot of it, you know, well to get good at anything.

Chris thinks that people are just "much more conservative”. The advent of sport climbing, he says, with the use of fixed bolts to protect climbers in the case of a fall, has drawn many people to the pursuit and, in doing so, "changed the flavour", and taken "the whole edge off" the practice of climbing. Both Tim and Jess complain that people are using bolt technology on rock faces where it is not needed, and thus ruining the aesthetics of the experience for those who prefer the more committed and committing approach, that relies on their skill and judgment in placing temporary 'natural protection' instead. For Tim, having a good "ethic" is to keep climbing from becoming "a man-made thing” that uses technology to alter the state of the medium: "basically if nature can provide a quality line you know spent millions of years doing it, don't blow it in five minutes". The ideal is, as Bob says, "absolute simplicity". The means is more important than the ends.

Similarly, Pip is "disheartened" by what she sees as a more conservative and less selfreliant attitude among others in the mountains: "the number of little rules and regulations", and they way in which "our New Zealand wilderness has just become so commercial". The prevalence of commercial guiding, in particular, Pip sees as the antithesis of "real adventures" in the "good old kiwi fashion". Commercialisation and consumerism - buying increasingly technical equipment and clothing - are mentioned by others as changes they have noticed in climbing over the years they have been involved. A 
lot more people, Pete says, are "paying to go into the mountains”, using guides and other 'aids' to streamline the experience and bring about a greater chance of success:

people want a package almost ... everything now is, jump in a helicopter, go into Bevan Col and, climb the Norwest Ridge of Aspiring and come out as though it's a major, mission. The actual true sort of alpine climbing, there's not as much of it getting done I don't reckon.

Bob feels that "it's the appearance thing and the instant aspect, and it's crept into the world of mountains and mountaineering". This has meant that some of the "traditions of etiquette in travelling in the hills" have been lost. There is more "messy behaviour" than there used to be, Bob thinks, such as people not leaving mountain huts tidy for those who will follow them, or destroying steps in the snow which would have made the going easier for the next people to pass that way:

I think it's become more and more focused on self ... there's always been those folk but fewer of them, ... I think it probably comes back to that instant

gratification, that whole trend that we're in. Got to have it now. ... I often wonder too whether, it's become so specialised and so focused that a lot of the other things about the makeup of the mountain, you know, people don't know.

It is important to the mountaineers that the practice of mountaineering should not be confused with "extreme sports" or adventure tourism, although sometimes it is promoted this way, which Adam thinks is done just to "draw a bigger crowd". Jess is scornful of sports such as bungee-jumping, which she sees as "an utterly ridiculous concept. It's just totally adrenaline buzz for no reason and it's like well, so what's the point of that. To prove that you can be stupid enough to jump off a bridge, okay". Bob thinks that those who consume the products of the 'adventure industry' are "people who want their creature comforts, and who aren't prepared to go on nature's terms":

I'm quite sure that a lot of people engaging in this adventure tourism will do these things once and that's it, and boast about that until it sort of gets boring. It probably won't have any ... major meaningful change or effect on their, on their character, on their strength, on their self reliance. On their ability to be a good human being, to understand other people. ... I do see a lot of, you know, really beautifully, physically, fit young people doing this stuff and yet they haven't got a clue really about what it's all about.

What is being rejected here sounds reminiscent of what Bauman (1995) describes as our postmodern leaning towards becoming 'sensations-gatherers'. The postmodern body is, he says, 'first and foremost a receiver of sensations; it imbibes and digests experiences; the capacity of being stimulated renders it an instrument of pleasure' (Bauman, 1995:116). What we end up with is a succession of episodic thrills, periods of high excitement interspersed with periods of boredom, and no "meaningful change", except that each 
successive thrill will need to be more thrilling than the last, due to our ever increasing tolerance for the intensity of these sensations. Such an attitude is clearly anathema to the mountaineers' singular commitment, and their willingness to strive and suffer for their passion, for a life-time, though to outsiders they may seem indistinguishable from the sensations-gatherers.

You can laugh, Dan says, about "climbing bums, bumming around and drinking coffee and, running around in the hills", but he sees the virtues of mountaineering "as a way to ... hold onto, some of the values and principles that are really important to people and life, and society" in a world which is "stepping away from those values". Climbing for Dan means that you are "present" and "aware of what you're doing and who you're with", which are things that we miss "in the fast track of modern life". And being in the mountains can make us "thankful and appreciative for ... the little things in life" and lead us to have "respect" for others.

Simple reliance on self, then, is best: approaching the mountains "on nature's terms"; not using too much "fancy", "artificial” equipment; not depending on guides for skill and judgment; and utilising kiwi ingenuity and resourcefulness. But the outside world impinges on the world of mountaineering. It threatens it with consumerism, commercialisation and superficiality, offering packages of instantly gratifying "quick thrills" and championing a technological, conquering attitude to the environment. The result, according to these mountaineers, is a reduction of our sense of responsibility and an increasingly seductive alternative of "a glass jar" of "decadence” and "luxury" and lifesapping ease.

However, the price that they pay for their commitment to mountaineering as the moral source of their lives, is that to the outside world they may variously appear to be "weird", “crazy” or "insane”. Reflecting a postmodern self-reflexivity (Gergen, 1991), which appeared as a "mini-explosion" of "consciously interpretive alpine writing” in New Zealand in the early seventies (Galloway, 1972), Dave's narrative was laced with irony and self-deprecating humour and playful critique, embracing, as seen here, his "weirdness":

[I'm] probably a wee bit of, quite eccentric. ... it's sort of under the surface. I mean ... I would, consider myself pretty normal, a normal functioning human being in society pretty much, but I know underneath, there's something simmering sort of thing. ... sometimes I think well, you know you're just... trying to be pretty cool and ... make yourself stand out and be an individual, you know, because [that's what] we all want to be ... I don't pierce and dress in really weird clothes to be noticed. But maybe that eccentricity is my way of being a total individual. 
So despite all the "passion" and commitment and "willingness to suffer", something of a tendency towards playfulness has emerged. ${ }^{67}$ Take, for example, the names used for various climbing partnerships in the early eighties - the "ugly sisters", the "funkadelic climbing squad”, "Nankervis climbing circus” (Atkinson, 1981; "A letter from Charlie," 1981) - and the claim from rock climber Charlie Creese, in an interview for the NZAJ, that he would "like to be the object of fear and loathing for all the alpine climbers" ("Who the heck is Charlie Creese?," 1982). ${ }^{68}$

It is the nature of social saturation, according to Gergen (1991:16), that 'as we absorb multiple voices, we find that each "truth" is relativized by our simultaneous consciousness of compelling alternatives'. Consequently, he argues, drawing on the work of British psychologist Michael Billig, 'the typical condition of the individual is internal conflict: for each belief there exists a strong countertendency' (Gergen, 1991:72-73). How do we cope with this conflict? We need a well-developed 'capacity for contradiction', and a reluctance to assert too strongly our own positions at the expense of others, as too close an inspection, too avid an articulation, will only uncover 'the hollowness of their bases' (Gergen, 1991:256).

\section{Solidity, liquidity and the world of mountaineering}

It is no wonder, given the conclusions above, that the world today, as Bauman (1995:266) puts it, 'seems less solid than it used to be'. While climbers have the tradition and practice of mountaineering to help combat the 'harms, dangers, temptations and distractions' of this world, and keep them roughly on a single path leading to a relatively well-formed destination, this may not always be enough, as the previous section has shown. However, in addition to the well-defined moral framework of mountaineers, there emerged from the narratives certain other characteristics of the world of mountaineering that contribute to its 'solidity' in comparison to the everyday world. Firstly, there is a clarity and sense of control that differentiates mountaineering from everyday life; then there is the way in which the mountaineering lifestyle can provide direction and life-focus, which can lend the sense of a central purpose and meaning to life; and finally the values of the mountaineering

\footnotetext{
${ }^{67}$ Although, New Zealanders have long prided themselves on a certain irreverence, and on their capacity for a "humorous response to the serious situation" (Wilson, 1968).

${ }^{68}$ Charlie Creese prided himself on the "fabulous" achievement of doing "absolutely nothing" on his one and only trip to Aoraki/Mount Cook (Creese, 1982). See also Jan's story about "sneering” rock climbers taking over the NZAC, Appendix D, number 2, page 269.
} 
tradition which I have been describing are seen as giving perspective to life away from the mountains, and providing a guide for acting in the everyday world.

\section{A world of "clarity" and a "sense of control"}

Jess describes a "clarity of life" that comes from "being in the hills":

a big part of climbing for me is that you put yourself in an environment that has really black and white kind of decisions. Like you really, things tend to be quite simple in the mountains. It's like 'do I/don't I?' You know there's no big moral questions in this.

On a climbing trip, Dan says, you can become "just completely involved in what you're doing and you really are in your own little world and it's so removed from anything else in normal life". "Being totally removed from, from day to day life" (Adam), being required to focus on the immediate present and to block out distracting thoughts and emotions, simplifies the world of mountaineering and differentiates it from the world of the everyday:

[There are] those moments in climbing when you're just really aware and present of who you're with and what's going on around you and, you know not distracted by a hundred and one other things, that aren't worth getting distracted about. Yeah and I think, if you can bring some of that back from your climbing to the way you live then, it can only be, be a good thing.

it just, I don't know it makes everything, yeah a bit simpler. Like as I say I get frustrated if I haven't climbed for a, few days or something. And it just, soothes you I guess, just makes you focus on what you're doing.

It's quite absorbing. I think that's probably addictive. It's escapism in some respects, you don't have to worry about what else is going on.

It's a good place to be. The mountains are really a recharging kind of place. You head for the hills - like what I was saying about it being black and white - you don't [have] all the stuff that you deal with on a day to day basis, there's so many little decisions you have to make and so many things that come together to make your day quite busy whereas in the mountains it's all just like 'here I am. No point worrying about any of that because I can't deal with any of that while I'm here. What am I going to do. I'm going to go up there'. And it's very simple type stuff. Very easy decision-making type things.

Compared with life beyond the mountains, then, there are less confusing and conflicting decisions to make when climbing. Relieved of the clouds of ambiguity and 'saturation', 
the focus can be on small, "intense moments", and these are "the things that really stand out" and become memorable in a way that 'normal' life is not:

it's amazing how vivid little things can be. You know whether it's like a single hold or a single piece of protection you've placed or, or topping out on one, on one pitch, among, you know, tens of pitches, it just becomes a, yeah you can think back on it with such, with such clarity ...

In addition to the clarity, focus and simplicity of life "in the hills", there is a kind of paradoxical sense of control in extreme environments:

that sense of control over your environment and sort of being there in this most amazing place and being in control of it and going 'wow I feel totally comfortable sitting on the side of this mountain and looking at the view and it's really nice'.

Sue and Steph find satisfaction in being able to look after themselves in an inhospitable environment, and even enjoy it. Pete describes it as a sense of feeling "solid" in "nasty" conditions, and tells a number of climbing tales similar to this one:

[On the] Sheila face on Mt Cook... [we] grovelled our way along the summit ridge in, a pretty wicked storm and ... got onto quite full on survival conditions and ended up bivvying on the Middle Peak in ... a great big crevasse up there, or bergschrund, and then got off the next day, ... [in] sort of nasty conditions but it all went fine for us. We always found when we got into those situations we seemed to work really well together and, ah, you know even on hindsight we never really felt, yeah we just felt sort of solid in, that sort of conditions.

Likewise, Chris says:

I've done some amazing trips through some potentially quite hostile-looking country, with not too much drama. Just with running shoes and travelling light.

Such a sense of control can be seen as paradoxical because, as Bob observes, part of the "fascination" is "that it is so out of our control, in any way shape or form, and with a, some rudimentary skills you can actually be part of that and experience all that stuff that is going on". Control lies, so to speak, within sight of what is 'out of control'. It is close enough to the border between order and disorder, chaos and calm (as described by Lyng (1990) in his theory of edgework) to be able to clearly differentiate one from the other. As Jess says, what one is faced with is "black and white", not grey, not ambivalent, not a confusing array of barely distinguishable options. Even when things go wrong, it is generally in a clear and unequivocal way, and the sense of that possibility, and its very clear consequences, is always near.

Pip, for example, likes the fact that climbing requires "self control", sometimes "for days 
on end". Developing the ability to concentrate and control her fear, which is imperative for safe mountaineering, has stood Pip in good stead for other life situations: ${ }^{69}$

there's nothing wrong with having a little bit of fear. And I think that's something that climbing does teach people, is how to deal with that.... We have to concentrate really hard, and deal with the fact that it's quite scary, terrain to be on ... It's a really good skill to have [laughs], because there's lots of situations in life that are really scary, and if you do concentrate, and do things correctly, ... if you're careful about things, then you will get through it.... if you can ... not let fear take you over, um, then I think that you'll, you'll finish it.

Not surprisingly, having such a strong and well-defined sense of control appears to facilitate a profound sense of competence and efficacy in the world. A need for efficacious action was a particularly strong narrative theme in Jan's life story. Hers was a 'warts and all' account in a reasonably strict chronology through different stages and events of life, both mountaineering and otherwise, both joyful and traumatic. Jan's commentary gave insight into the inter-relationship between different facets of her life, and illustrated the way in which the two 'worlds' and the different aspects of these worlds, are intimately bound together.

While Jan was originally drawn to the joy of exploring and "being there and being up in the mountains", as she became fitter and more experienced, there was also "a lot of joy with being technically competent and physically competent". She admits, in fact, some difficulty coping with the physical limitations imposed by growing older: "I don't feel psychologically well unless I'm physically fit". During a number of tragic events in her life, Jan turned to the mountains and her climbing as a way of regaining strength and purpose. One particular personal tragedy added an extra "layer" to the desire to climb: there became a different spur then to climb. I needed to climb, to show - what? that I was good at something. ... So yeah, there was an extra need then to be good at what I was previously good at. ... But I went on from there and became even ... stronger and perhaps more independent.

Competence, coping and incompetence were continuous themes and recurrent words throughout Jan's personal narrative. For her, the greatest feelings of competence came when she was in the mountains:

I just love that feeling of total aloneness, just us, and that complete, emptiness all around you. But I loved the storms and things as well because we knew how to cope with bad weather and we had some terrible storms. But we knew how to cope with all this and it never felt, endangered. ... we had some amazing experiences that didn't come off the way they were meant to come off, but that didn't actually matter, as long as we got ourselves out of our predicament. [laughs] ${ }^{70}$

\footnotetext{
${ }^{69}$ For full story see Appendix D, number 12, page 273.

${ }^{70}$ For full story see Appendix D, number 13, page 273. 
Even when she fell while descending a climb, and was rescued with a crushed spine after spending a night out on the side of the mountain in "appalling" weather, she and her climbing partner "were really, really well equipped for an emergency".

They got me down to Park headquarters and I still remember the first remark from one of the young rangers was 'you're warm!' They expected that I would be cold and suffering from hypothermia, you see, being out there all night, but of course what they didn't realise was that we had this good equipment with us. I'll never forget that, 'you're warm!'

On a climbing expedition to the Himalaya, however, Jan felt surrounded by the incompetence of others, and a tragedy unfolded when four members of the expedition were buried by an avalanche. The Sherpas who had been helping them "were not competent climbers" and the Indian co-leader of the expedition "was an incompetent right from the start”. The search team sent to help locate the missing climbers "didn't do a competent search" and they were never found. "That was all terrible", she says, "the trauma of trying to cope with that was really quite great". What made it worse was that the Indian authorities "were wanting to lay the blame on me, fairly and squarely. That it was all my fault". 71

Out of the mountains, back in the 'world', Jan's ability to cope seriously deteriorated in the aftermath of this traumatic period of her life:

I got very ill, on that trip. Picked up a bug, ... it debilitated me. ... So I was a real mess, ... it took me more than two years to get over that. ... I wasn't fit enough to climb for ages. But I did eventually get back into it. ... what I didn't know then and know now was that I was suffering post-traumatic stress, in a big way. ... nobody knew about that then, and nobody knew that you did suffer from [it] - you're supposed to get over it. That's what you had to do. Get over it ...

Nonetheless, Jan feels, like Pip, that from her experiences in the mountains she has learnt strategies that have helped her deal with other difficulties in her life:

you have to learn to pace yourself, and some of the big lessons of life that you learn are that, however, difficult or, painful the bit is, like you're pushing through bushes that are scraping you to pieces sort of thing, that will pass. You'll get beyond that, it's only one stage in the process. It's not the end. It's a lesson I think that applies to life. That, things might be difficult right now, but in the overall scheme of things, it's a passing phase, yeah.

Being able to focus on the task at hand, and block out the 'background noise' of everyday life is a welcome relief, a reprieve from the moral ambiguity and saturating technologies of liquid modernity. And being able to "travel light" through "hostile-looking country", as

\footnotetext{
${ }^{71}$ For full story see Appendix D, number 14, page 273.
} 
Chris puts it, not only gives the satisfaction of competence and control in the mountains, but is, by all accounts, a useful skill to have when traversing landscapes in which the postmodern condition is encountered.

\section{Direction and life-focus}

I always see it as being a very significant part of my life, and I find myself, almost always thinking about climbing in some way or another, you know.

(Adam)

Earlier in this chapter, I argued that a deeply felt and enduring commitment to a life of mountaineering is considered one of the marks of a 'true' mountaineer. It is evident from the narratives that such a commitment to a demanding lifestyle gives direction and a lifefocus: a point around which they can centre their lives.

You go to work, um, because you want to earn some money to go and climb mountains. You know you go, you go for a run to keep fit because you climb, go to the gym, to climb. You ah, go to the beach for a barbecue because your friends are probably, climbing mates. Um. You go into a bookshop, to buy a newspaper, you then look at the, climbing books. It's, it's totally and utterly with you, all the time.

Lyn's narrative is a particularly vivid example of how mountaineering can provide a focus and direction, without which she feels a loss of purpose and meaning. Her introduction to mountaineering differs from the common pattern discussed in Chapter 3 in that it is not preceded by the typical apprenticeship in tramping. She grew up in South-east Asia, but was living in Auckland, the most urban part of New Zealand, and had been deeply immersed in the development of her professional career, when a friend who is a rock climber introduced her to the activity she had barely heard of before. From her very first experience climbing at a local 'crag', Lyn was "hooked", and within a year or so she had completed a mountaineering course and joined an expedition to climb in Nepal: since then, it's really changed my life. Yeah, since then it has been, the biggest passion.

She describes her decision to go to Nepal as the desire to give herself something "different" to do. She was at a "crossroads" in her life, and "feeling unsettled":

my job until then had given me, most of the satisfaction in my life. By that stage, you know, it no longer gave me the fulfilment it used to so I was quite restless.

On her return from success in Nepal, Lyn experienced "this renewed energy, and life felt, mm, you know [laughs], that energy, that aliveness": 
I felt quite contented, and focused, about my life. But towards the end of, late 1990s I started feeling that restlessness once again. ... in 2000 I had another sort of life, um - what you call those things? - crises. What is life about? ... So that was part of, the main reason why I came down here to have a change.

Her decision to move south to Christchurch, where she would be closer to the climbing areas of the Southern Alps, followed a second trip to Nepal which was not as successful as the first. The expedition was to climb a mountain that was not much higher than the previous peak but more technical. After failing to acclimatise quickly enough, Lyn faced the difficult realisation that she would not succeed and thereby find the fulfilment of the earlier trip:

when I saw that peak, it's a beautiful peak, I thought I want to be standing there on top, and that moment of realisation that I was never going to, be standing on top of that, this beautiful peak. That was, that was memorable I can tell you. ... it was devastating, it was frustrating, 'cause I put so much, so much was at stake. Well in terms of, that it was going to, ah, make me feel better about my life. ${ }^{72}$

This experience was particularly frustrating for Lyn because the altitude sickness that prevented her from successfully climbing the mountain was something over which she had no control, that she could not overcome through sheer willpower. Because of this, she has been dissuaded from further high-altitude mountaineering, though she still sometimes toys with the idea. As an alternative she has decided to turn her attention to climbing more technical ice routes at lower altitude, in New Zealand. This has given her a new goal to work towards, and has made her feel "a bit more settled":

I think that really is the answer. Like having these goals, gives me a sense of direction in my life and that makes me happier, settled, more settled. Yeah, having goals.

Just as the words competent, coping and incompetent made evident a recurrent theme in Jan's narrative, there were key words for Lyn that can be seen to represent her preoccupation with the constant effort to control and direct her life towards goals that give her a sense of purpose. In her narrative, words such as "pushing”, “confronting”, “transcending”, “control[ling]” are opposed to monotony, boredom and restlessness.

When she is attempting something challenging and technical she feels "energised" and "at my best":

I'm really not that interested in ... walking up endless, monotonous snow slopes, it's just hard work without the ... exhilaration of climbing something technical. If I don't feel that I'm pushing my, my mental limits, pushing, transcending my fear, pushing my fear threshold then I don't, then it's not really that interesting to me, if all I do is just put one step in front of the other, for hours and hours. ... [but] when I have to ... mentally be in control for hours, it's that risk taking that, to me is

\footnotetext{
${ }^{72}$ For full story see Appendix D, number 15, page 274.
} 
important. ... it's not that I want to put my life at risk, do you know what I mean. ... [it's the] the experience of confronting my fear and being able to deal with that fear. Keeping that fear under control, you know, and being able to, um, do what you're supposed to do, to finish that climb. ... You know, that's why I climb.

Lyn presents here a clear evaluation of the reasons she climbs:

[the] most important thing is the fact that you've actually exerted yourself mentally and physically to get to where you are. It's not the same, driving to the top of a hill and looking down at fantastic views around. ... every time I struggle on a hard climb and I get to the top, and look down, that's, you know, it's memorable.... That's why I climb you see, that feeling of 'wow I'm here, I've done it and it's beautiful'. Yeah. Does that make sense?

To live one's life as a ‘journey-to-a-destination' (Bauman, 1995:268) is certainly no easy task, as the ground tends to shift beneath our feet. But, as Bruner (1990:22) observes, and the stories of Lyn and others demonstrate, we are prepared to suffer in order to find 'such fulfilment as we can in terms of these ways of life'. And if we did not have to suffer, the view, as Lyn suggests, may not be as good.

\section{Perspective: Determining the "real" from the "trivial"}

All we've got is what we've got right now. Not a moment more. And that's what we should be making the max out of really. Do the best we can at that point and the thing is there are a hell of a lot of people that know that and are living that and doing that. And they're not the big noters. And the hills are full of them, from time to time, and to me that's, they are the true adventurers really. This other stuff is all hype and, froth and, the like.

When I asked Sue what impact her climbing has on other parts of her life, she told the following story.

When I was at university I took a non-climbing friend along with me one weekend when we had a club climbing weekend away. And the weather was dreadful, it was no good for climbing and we went for a walk along the top of some sea cliffs and the wind was blowing very strongly offshore so my friend was getting blown towards the edge of the cliff and the rest of us had to jump on her to stop her being blown off and she was a very conscientious student so she'd get diarrhoea and all worked up when it was coming up to exam times. And she was always impressed at how calm I was about my academic work. So after that weekend she said it gave her some understanding of why I was like I was because she said when you're climbing you just have to think about staying alive so you don't worry about things like exams. So I mean I think part of it's just personality but I think there was an element of truth in what she said. So I think climbing ...takes your focus, changes your focus so that you don't worry so much about the little things of every day life. ... you just get endorphin release and feel good which overflows into other parts of your life ... you're a happier person and much nicer to be around I'm sure, and overcoming challenge ... I'm sure it gives you confidence in your every day life. Just, you know, ready to meet things head on and then on a more sort of 
practical note, I think climbing has hugely influenced my, my attitude to standard of living. You know I don't really care much about having a nice house or what I wear or how my hair looks or whatever because yeah because of years and years of just living at such a basic level when I go away climbing and realising you can do it like this. Therefore you don't need all that, and living out of a pack ... you realise you don't need so much stuff.

Repeatedly throughout the narratives, the world of mountaineering was compared with the world of the everyday. This distinction and the associated conflict have been outlined earlier in this chapter, in the section on the "false values" of the outside world. This final section considers the way in which these two worlds are not only different and in many respects oppositional, but how it is the world of mountaineering that is seen to represent and lead one towards what is "real" and "important". That is, it provides a clearer, less ambiguous moral source - a kind of solidity that is lacking elsewhere. Familiarity with the "solid" mountains and the values of mountaineering made people "happier" and "nicer" and their lives "easier", "simpler and "more sane", by changing their focus and putting things in "perspective". While the world of the everyday is "frivol[ous]", "silly", "trivial”, "the trappings", "contrived”, the world of mountaineering is "real”, "down to earth”, "basic” and, again, “simpler":

[mountaineering's] a mental and physical challenge ... it's got to make your stronger. It's got to make it easier to face life in the, in the silly world ... it's self confidence building. It makes you more willing to face up to challenges and things. It lets you know that things that look impossible, are far from it. There's always some way around it you know.

I find the climbing helps remind me of, the simpler things in life and it reminds me of, of the more important things I guess too. It just sort of brings me back down to earth and that helps you, see, some problems in a new light. A new perspective.

I've found that it's, helped keep me a bit more sane I think... little issues that really mean nothing at all, are all brought into perspective, and also the little simple things ... that make our life so much easier, you learn not to take them for granted.... I've just had so much fun and so much enjoyment and, had so many smiles on my face from, from different climbing experiences and, I think to have that whole bunch of memories I find that is, it's a little piece of joy that you carry around with you.

it's reducing things down again to basics and those survival skills really although the whole thing's not survival from the start to finish. There's times when you really are pushed to use your own resources and those of your friends and you certainly start to realise where the real values are, in the human spirit really. 
definitely climbing is, you know, gives you a heightened appreciation of, you know, what is important in life. ... It's a good time to, remember, remember, you know, life and the way you want to live it and question what you're doing ... [it's] pretty easy to kind of get lost in, trivialities really

it's a good leveller. You do tend to go and get back and go 'oh well', for a wee while anyway, [about] the trivialities of life, you know, [thinking] it's not that bad sort of thing, it puts things in perspective a little bit. It's a good refreshing thing to do, sort of healthy, yeah.

(Dave)

Pete speaks expressly of solidity, a word and theme that recurs in his narrative. It is he who feels "solid” in "nasty" conditions (see page 157).

Nothing compared to putting your life out there on a bit of a line at times climbing so ... you'd go into the mountains and that was reality, back out, back at home, back at work or varsity, that was just living you know and that put, um, everything in perspective in a lot of ways, it made life quite easy I reckon. Um. Yeah and you didn't seem to get caught up in, it just seemed to focus you on, on what was real in life, what was important in life and what wasn't. ... you can look back through your life and there's key decisions you make that take you one way or another way. I think they're relatively easy to make.... the living as opposed to the trappings ... you look at some people just totally focused on, on possessions. ... I think [mountains] make you quite solid ...

\section{Summary}

Stories are surely not innocent: they always have a message.

(Bruner, 2002:5)

Stories are oriented around 'what is morally valued, morally appropriate, or morally uncertain' (Bruner, 2002:50). Pete's use of the word "solid" to describe how he feels in the mountains became the key to my understanding of the moral dimension of mountaineering. It did not strike me as significant at first, but when I read his transcript alongside the others, while looking for clues to understanding identity, I saw the word peppered throughout his story and the 'penny dropped'. So while I have ended this chapter with Pete and his sense of solidity, he was, in a sense, the beginning, or the point of departure, for what became this discussion of the 'true' mountaineer and mountaineering as moral source. His choice of adjective was the key that opened the door for me into this dimension of the mountaineering narratives, and its significance.

MacIntyre's (1981) work on moral theory subsequently provided the theoretical framework for my understanding of mountaineering as practice and the role of the virtues. Bauman's 
(1993; 1995; 2001) elucidation of the characteristics of liquid modernity was, of course, the background against which what was solid in the narratives stood out. ${ }^{73}$ In addition to MacIntyre and Bauman, Ricoeur (1992), Taylor (1989) and Bruner (1990; 2002) contributed to my awareness of how narrative, identity and morality are irretrievably intertwined: without one another, they wither and die.

Story-lines construct not only individual, but also communal, meanings. Plots, Ricoeur believes, exist at the level of 'social imaginary', and here narrative has a 'pivotal role in providing us with ethical vision in that it enables us to see the essential connections between our actions and their ends qua good and evil' (Kearney, 2004:7, 171). But 'postmodern personal stories', Frank (2002:8-9) laments, have been accused of lacking reference to 'things that matter', of being 'a cul de sac of triviality, an abyss into which persons, politics, and thought itself threaten to fall'.

Nevertheless - and Frank would approve - the communal narrative described here is a story about "what's important and what's not". It shows that "common endeavour" results in a "real bond" that "stays there for ever", no matter what. And as it is limiting to say what is important without saying 'important to whom' (Ricoeur, 1992), this is a story about the 'true' mountaineer, a form of telos, an 'image of the future' (MacIntyre, 1981:200-201), by which mountaineers can measure their lives in terms of their progress, or lack of progress, towards it. Hindering such progress is the inhospitality of a world which casts the subculture of committed mountaineers out to the margins. There they battle divided loyalties, the myriad distractions and contradictions of 'social saturation', and the 'temptations' which make "the full realisation of mountain joys impossible national aggrandizement, self-display, publicity hunting, a neurotic search of danger for the sake of danger, attempts by artificial means to alter the conditions imposed by nature, and all the rest ..." ("The Alpine Club," 1958).

But aiding their progress are the "simple and clear-cut situations" of mountaineering, "in which features stand out which are often hidden in the complexities of real life". It is in such situations, one New Zealand mountaineer/philosopher wrote, "in the face of common and obvious danger, and for the sake of the common triumph over danger and difficulty which is the supreme joy of climbing, we do often act less selfishly, more nobly, than is our wont" (Wilson, 1968:425). Here, it would seem, is a 'primal moral scene', where being-

\footnotetext{
${ }^{73}$ Blackshaw's (2003) application of Bauman's work to male working class leisure culture in Britain has also been influential.
} 
for stands in stark contrast to being-with, and one must act accordingly. Whether one attains the hallowed ground of the true mountaineer fully or not, is not the point. The point is that engagement in the "quest" involves a sense of responsibility in landscapes of autonomous moral decisions, and a sense of belonging to a community embodying a tradition with a set of practice-specific virtues, on which one can draw when faced with these moral decisions.

This, it can be said, helps to sustain mountaineers within the moral wasteland that modernity has become, with its bureaucracies and corporations that specialise in 'responsibility-floating' and the removal of 'actions and objects of actions' from 'moral evaluation' (Bauman, 1995:149). It also provides a kind of buffer against the 'loneliness' and 'excruciating' ambivalence of the naked moral condition (Bauman, 1995:3). Mountaineers cannot, of course, make a full escape, as life on the fringes is still life shot through with ambiguity and conflicting demands. Nevertheless it serves them in a way which, under the circumstances, may be the best that is on offer, and is certainly better than many. 


\section{Chapter 5}

\section{The calculable and the incalculable: narratives of safety, danger and death}

\section{Introduction}

From the tentative beginnings of mountaineering in New Zealand in the late nineteenth and early twentieth century, climbers bemoaned the fact that they were considered by the “uneducated" non-"mountain-minded" public as "cranks, curiosities and potential suicides” (Anderson, 1953). Simmel (1959) would perhaps not have disagreed, as, writing around the same time, he argued that adventurers, by their very nature, fail to differentiate between that which they can control by virtue of their own strength and abilities and that which may be subject to the vagaries of luck. Instead, they treat 'the incalculable element in life in the way we ordinarily treat only what we think is by definition calculable' (Simmel, 1959:249). This chapter examines notions of the calculable and the incalculable, of control and chance, in the biographical narratives of New Zealand mountaineers, in order to understand how experiences of safety, danger and death in the mountains are rendered meaningful in their stories about climbing.

Few of the mountaineers I interviewed mentioned aspects of danger or death when asked to talk about their life experiences of climbing. I did not ask them directly about these issues, although I did sometimes ask them to expand if they themselves introduced them. The topic most often arose towards the end of the interview when I asked additional, but indirect, questions. For example, when I asked if their attitudes towards climbing had changed over the years, many of them spoke about feeling that they had become safer and developed better judgment. When I asked if they had had any disappointments in their climbing, some of them spoke about their regret at having lost friends through climbing accidents. Also, if asked how they felt the public perceived them, they expressed an almost unanimous feeling of being mistakenly seen as strange, irresponsible or selfcentred, due to mountaineering's reputation for being extremely dangerous, even a gamble with life. By contrast, they argue, mountaineering is a relatively safe activity in which the level of danger one is exposed to is managed in a calculated way, and safety is a primary consideration.

Whether they spoke directly about danger and death or not, a number of related narrative threads flowed through the stories: what it means to stay safe in the mountains, and to what 
they attribute accidents; how they contextualise danger, placing the dangers they face when climbing in a more acceptable frame; and how they deal with mortality, ranging from a youthful sense of feeling "bullet-proof", through to efforts to "face up" to the reality of death as a necessary aspect of participating in an activity like mountaineering, as much as it is an inescapable aspect of being human. By examining these narrative threads, this chapter shows how mountaineers' attitudes towards the dangers they face can be more fully understood. For the reasons given in Chapter 1, I have endeavoured here to depart from the common approach to adventurous leisure which views risk taking as a central motivation and/or the manifestation of a particular personality predisposition.

The picture that emerges when such an approach is taken is not as simple as is sometimes implied when mountaineers are portrayed as primarily sensation-seeking and risk-addicted individuals. Rather, there is a complexity in the ways in which they deal with issues of safety, danger and death that reflects both the biographical particulars of their lives, and broader communal narratives from which they draw and challenge ideas about what is sensible and what is not. In many respects, it is an ambivalent relationship with danger: one of both recognition and acute analysis and, at times, more or less self-conscious denial. There is also awareness both of the benefits of close familiarity with danger and the disbenefits of avoiding it at all costs, and of the need to temper one's desire for its acquaintance in order to minimise the likelihood of serious harm. The final ambivalence comes from trying to account for events as the outcome of one's actions and competence, and thereby feeling able to control and calculate these outcomes, while at the same time accounting for the apparent incalculability and random nature of some events.

All in all, the stories tell of the adoption of certain strategies to deal with the dangers of climbing mountains and to weigh the benefits and disbenefits: to piece together a sense of the world of mountaineering that contains dangers, and yet is still the world that they love and enjoy with passion, both because of the dangers and in spite of them. Successive sections of this chapter deal with the following narrative threads: survival strategies; making sense of accidents; dealing with danger; and mountaineering, mortality and death. In the first section however, as foreshadowed in Chapter 1, a brief overview is given of the theories around risk and danger which have influenced my interpretation of the research material.

Throughout this chapter I refer back to relevant themes from previous chapters. The fact that there is such overlap with my earlier discussions about the construction of self and the 
moral dimensions of mountaineering, demonstrates the way in which issues relating to danger are not disconnected from the broader construction of meaning and self or identity: indeed, for mountaineers, they are interdependent. It is central to their identities that while they may have to deal with danger and stress in pursuing their passion, they are not reckless, foolhardy or 'adrenaline-junkies'. Rather, they describe themselves as typically calm, sensible, and analytical in their approach to the dangers found in mountain environments, and their love of mountaineering is essentially life-enhancing, not deathdefying. This chapter demonstrates that an understanding of the narrative construction of safety, danger and death in mountaineering is indispensable to comprehending how the lives and experiences of mountaineers are rendered meaningful - and vice versa.

\section{$\underline{\text { Theories of risk and danger }}$}

In discussing safety, danger and death, I prefer to avoid the term 'risk'. My reasons for this are, first, my desire to differentiate this discussion from other work on climbing (and other outdoor adventure activities) which places the concept of risk at its centre; and, second, the problematic and ambiguous nature of the term. In a society characterised by Giddens (1991:3) as a 'risk culture', that is, where 'risk becomes fundamental to the way both lay actors and technical specialists organise the social world', the discourse of risk has become complex and multi-layered.

Lightfoot (1997:14) argues that, historically we have had an ambivalent attitude towards risk taking. On the one hand it is seen as 'trouble', and on the other as 'opportunity'; in various ways it is subject to both glorification and attempts to eliminate it (Beedie \& Bourne, 2005). Frank Knight, whose seminal 1921 text has become something of a touchstone for theorists considering definitions of risk, differentiated between risk and uncertainty:

risk is measurable. It means not knowing what will happen but knowing the probabilities of the possible outcomes. Uncertainty, on the other hand, means not knowing the probabilities of the possible outcomes, or, indeed, on many occasions what all the outcomes might be.

(Boyne, 2003:3)

Boyne (2003:3) concludes that 'the general diffuse meanings attached to the term 'risk' ... resist the successful imposition of precise definition'. In everyday life, 'most analyses of risk are estimates ... judgements in the context of uncertainty' (Boyne, 2003:4). 
Douglas (1992:14), an anthropologist approaching risk from the perspective of cultural theory, argues that the term, risk, has 'acquired new uses' since its origins in gambling and probability theory. While technically 'risk' is 'the probability of an event combined with the magnitude of the losses and gains that it will entail', it has been debased, in Douglas's (1992:40) view, to the extent that it is now 'a decorative flourish on the word "danger"'.

While the word danger would suffice in most situations, to talk of risk, Douglas (1992:30) argues, suggests that 'the matter is ascertainable', and that uncertainty can be taken out of the equation. Thus, the 'possibility of a scientifically objective decision about exposure to risk is part of the new complex of ideas' (Douglas, 1992:14). In the current discourse, also, risk almost exclusively refers to negative outcomes, so it is not just danger that is implied; it is 'unacceptable danger' (an observation also made by Furedi (2005) and Beedie \& Bourne (2005)). While Douglas's conclusions have been critiqued for their lack of empirical basis, her arguments regarding the cultural framing of risk have received support from a number of quarters (Boyne, 2003).

Bauman (1993:200) agrees that the shift from 'danger' to 'risk' is subtle but significant, because of risk's beginnings in the discourse of gambling; hence its resonance 'with the postmodern view of the world as game, and the being-in-the-world as play'. Also, by 'dealing with dangers as "risks", that is computing their statistical probabilities', we are deluding ourselves that we can eliminate uncertainty. Nevertheless:

Statistics is the next best thing to certainty ... Probability makes the fate of the victim neither foolproof nor doomed ... but it brings a degree of psychical comfort through the illusion of control over destiny. The risks notwithstanding, one can go on calculating, choosing, playing the game of rationality.

(Bauman, 1993:201)

From cognitive psychologists comes support for the contention that understandings of risk are influenced by subjective factors: in particular, that higher levels of risk seem to be acceptable for voluntary versus involuntary activities; that the 'acceptibility' of a risk 'is roughly proportional to perceived benefits'; and that 'the more people take a risk, the more acceptable the risk is' (Adams, 1995; Boyne, 2003:69). However, while it is 'widely assumed' that individual characteristics and circumstances have varying influences on the propensity to take risks, Adams (1995:21) argues that such assumptions cannot be tested by 'direct measurement'. Risk, he says, 'is constantly in motion and it moves in response to attempts to measure it' (Adams, 1995:29). It follows that there can be no distinction between subjective and objective (real, measurable) risk, but that all 'risk is culturally constructed ... both the adverse nature of particular events and their probability are 
inherently subjective' (Adams, 1995:9). Boyne agrees that our culture influences those risks we will pay attention to and those we will ignore, meaning that 'the question of risk is ephemeral, contingent and merely a present form of cultural variation' (Boyne, 2003:107).

The mountaineers do use the word, risk, sometimes in a reflexive manner; for example, talking of the "so-called risk factor" or of climbing as being "seemingly risky". They also speak of "calculated risk", referring to the decisions they make about risk as involving judgement, rather than risk taking as a gamble. Mostly they use it in the sense of the word described by Douglas (1992) as the dominant usage in contemporary discourse; that is, to mean danger and the potential for some kind of harm or 'negative outcome'. Hence, in my discussions I have used the word, danger, in most instances so as to emphasise that this is the sense in which my interviewees understand 'risk'.

\section{Survival strategies: staying safe in the mountains}

In the mountaineers' narratives there are a number of ways by which they account for their safety and on-going survival. In particular, they distinguish between different kinds of danger and different approaches to the dangers of mountaineering, and thereby contextualise their own approach and outline their own personal strategies for staying safe. One of the main themes of these personal strategies is the need to survive an initial period, characterised by inexperience and a lack of awareness of danger, with survival being dependent on one's ability to learn from one's mistakes. Also seen as critical and as being acquired over time were: sound judgement in the mountains; patience and a more relaxed approach; an awareness of danger and the conscious decision to climb with a "wide amount of caution"; the ability to "not panic" in stressful situations; and the ability to carefully assess and thereby avoid danger. These themes will be discussed in the following subsections: gaining experience and surviving a youthful sense of invincibility; and developing judgement and other techniques for survival.

\section{Gaining experience and surviving a youthful sense of invincibility}

A common narrative theme among the mountaineers was that, particularly among young men, there is an initial sense of youthful invincibility which, when coupled with inexperience, makes the early period of taking up climbing the most dangerous. This is a normative narrative to the extent that it is presented with a sense of virtual inevitability about it: this is just what is to be expected, another element of the 'folk psychology' of mountaineering. But it is just as strongly expected that as you grow older you will become 
safer, as a natural consequence of gaining more experience and skill, becoming more 'mellow' and having less to prove, and no longer feeling "bullet-proof”, either as a result of surviving a few "spanks" (as Dave calls them), or just developing a greater respect for the nature of the dangers involved. Pete explains:

\begin{abstract}
you go through ... the early gung-ho days when you're bullet-proof, definitely bullet-proof and nothing can happen, nothing will go wrong to you and you do climb, in a different way, ah, a lot more sort of out there, um, take more risks and then as, as your experience grows ... you don't quite, push the margins as much. You still climb just as hard, but in a more experienced sort of way ... as you get older you tend to ... chill out a bit. You're not out there to prove anything really, now it's more getting out into the mountains just to enjoy the, the environment. ... yeah definitely I'd say the old, so called risk factor, yeah definitely a bigger safety margin now. ... you climb smarter now ... when you're young you do some silly things ... that's sort of what you go through.
\end{abstract}

Dave makes a similar point with his description of the differences between being "young" and being "older", comparing his approach to solo climbing with that of an older climber:

[we] approach soloing in quite a different way. My soloing is sort of more like a young man's soloing, whereas his is sort of, a very measured, older man's soloing where, he, considers risk when he's soloing is not an issue. You know, there is no risk, because he doesn't take any. ... he can solo, no worries, because it isn't actually that dangerous. He walks across a glacier at the end of summer ... when all the glaciers are bare bones ... and you can see the crevasses and he takes very calculated risks. Whereas I tend to be a little bit more sort of, spontaneous, with my, soloing. ... you get home and go 'far out, that was pretty intense', [laughs] whereas with him it's like he just goes off and ... he's quite happy within himself and by himself, ... it would be quite a nice state of mind to be in, you know. ... you could die at any moment, but, he's not feeling it. But yeah I mean, for him there probably isn't too much risk... just because of the amount of experience he's got. ... He just spends so much time in the mountains that he's, you know that sixth sense is pretty, pretty high.

So the older climber, according to Dave, is "not feeling” the danger because he is measured and calculating in his approach, relying on a finely-tuned intuition gained over years of experience and, as a result, he feels "happy within himself”. The young climber, the one that feels "bullet-proof", may also feel happy within him- or her-self, but the happiness is based on something quite different. It is recognisable in Phil's description of a young man he climbed with, who was later killed in an avalanche:

he used to run marathons and was super fit, used to ... run everybody off their feet ... and totally without any kind of fear, or sense of, vulnerability I think. He was not worried about anything, and I remember climbing with him ... and he'd be leading up some steep rock and we'd say, 'well what about putting a runner ${ }^{74}$ in?' you know. Eventually we'd say 'well that's all the rope you're having until you put something in'. [laughs] So he just had that careless attitude. ... And [a] good climber as well, [he could] get up there and climb perfectly happily at that kind of

\footnotetext{
${ }^{74}$ Protection, or intermediary anchors for the rope that lessen the impact in the event of a fall. 172
} 
distance out. He was just in a world of his own where he could just handle it all. So yeah in terms of climbing he was great. And yeah technically quite good ... yeah but unfortunately he died.

According to "the theory", if you do survive this period, which is the most dangerous because you do not recognise all the hazards, then you should be "alright":

there's the learning [phase] where it's all just really dangerous and, but you've got the naiveté. I had quite a lot of that ... I probably didn't really take all the risks on board, yeah, and that's a, quite a dangerous time in a mountaineer's career. And normally if you get through that you're going to be alright, well that's the theory anyway, which we all talk about, but ... yeah so everyone goes through that phase.

Adam believes a climber is "fortunate" if he has a few experiences serious enough to temper his youthful enthusiasm, without severe consequences. Adam implies that he has not been lucky enough to have had any such experiences, and therefore lacks the crucial first-hand knowledge. As a result, he has to get this knowledge second-hand from his friends:

although I don't have full appreciation of the risks involved, some of my friends have been fortunate enough to find out how dangerous it can be but without you know serious consequences. So because I'm not fully aware of these risks involved, I need to sort of tell myself sometimes to, to steady on a bit. To slow down. Even though there's something pushing me on, I've needed to just sort of say okay, I don't fully understand why, but I think it's probably appropriate to, to slow down right now. Yeah. It's hard when you sort of, don't receive any warnings, maybe I'm totally oblivious to things around me.

Jane who, like Adam, is still a relatively young climber, also seems aware of having a certain over-confidence, and is self-reflexive about the need to temper her youthful sense of invincibility. In this story, her feeling that "nothing will happen" led to unpleasant consequences:

sometimes I run it out a bit, because I always think, oh nothing will happen, you know, I'll be fine. Which is probably, [I] should [have] put a bit more gear in on the way up but I was thinking, oh, aiding, no one ever falls aiding, and it was like pitch seven or something, and I had this little alien ${ }^{75}$ in, and I was thinking, oo that doesn't look that flash ... and then - ping! [I fell fifty feet].

This is part of the process of learning by experience, "surviv[ing] the little things that crop up" and putting them down as "formative” experiences, which Dave describes (see Chapter 3). For Dave, getting "spanked” and learning from it keeps him alive:

\footnotetext{
${ }^{75}$ Alien: a small spring loaded camming device, or 'friend', which provides protection from a fall when placed in a small crack and attached to the rope.
} 
I've had lots of little spanks where I haven't been killed, I've been bloody close and I know that I've been close, I've stared death in the face and it's not a cliché, I absolutely know if I made one loss in concentration or one move wrong I'm dead, you know, it's not, it's not a silly thing to say. But I'm, I've got away with it all the time so each time I've learned from it.

Dave also believes that his "love for the mountains" and his "love for climbing" have kept him “out of most trouble”.

There is a high expectation among the mountaineers, however, that while a certain amount of risky behaviour is in the nature of youth, one will heed the warning signs and not continue to "do silly things". Thomas's apprenticeship in Switzerland in the 1950s was strongly influenced by the 'gradualism' which advocated only "very, very slowly and very gently" increasing the level of difficulty of climbs attempted: "it wouldn't have been proper to go and attempt big things". However, even Thomas, a strong proponent of the "tiny little increments" strategy, was once a youngster with a rebellious streak who in his late teens was attempting serious climbs and "a lot of people didn't think that was proper". By twenty, he was doing "some very big climbs" but by this stage his regular climbing companion was an older, more experienced climber:

We did some big stuff together and I was always, yeah ... when he came with me, yeah, it was safe. We didn't do, yeah, he wouldn't do silly things.

It is noteworthy that Thomas hesitates and then refrains from going as far as to say that he was (or we, that is, both of them were) always "safe" or "wouldn't do silly things"; he leaves it at the point of conceding that the older companion was the sensible influence who kept them safe during that vulnerable period. Phil admits that on his first serious climb as a young man he and his climbing partner were out of their depth:

The first time we went onto [the face], Gus and I we just had minimal sort of gear because we had no idea what we were getting into. I think I had a homemade harness that I'd stitched up myself, one rope to lead on. I think we even borrowed a rope, I think we might have had 20 pitons, and not much else.

As a result, their first attempt became an epic. Having made it part way up the face, they spent a night hanging from their ropes on the face before they were forced to traverse off because they could not go up, and they did not have enough rope to abseil down the overhanging cliffs they had climbed:

so we traversed off the right side which was a whole series of narrow rock ledges covered in snow, very slippery. Most of the time we couldn't get any anchors, [it was a] life and death sort of situation getting off. Had a few avalanches sliding down the slippery rock and we were struggling ... we were slipping and sliding 
trying to get up the [snow-covered] slabs. So that was a, desperate escape from the face. ${ }^{76}$

But Phil and his companions were persistent and on the third major attempt three of them successfully climbed the face. While he admits they had tried to climb something "probably beyond what we should have been doing, in terms of safety and technical abilities", they nevertheless "just kept on going, [and] got away with it", and in the process gained some valuable experience:

[on the face I was] just leading out the full rope length without any runners [because there weren't any runners to find], and just developing the level of caution so you could climb with a full rope length out and still be sort of reasonably happy with myself without any gear, without any protection, like the rope wouldn't really have been any benefit to me if I had fallen. ... and that taught me to climb really you know within that sort of safety margin and not falling off.

This approach has stayed with him and been applied to all his climbing, so that although the level of difficulty has not increased, he is happy with how the quality of his climbing has improved over time: “over the past twenty years, I've probably climbed more solidly, more carefully, more controlled".

During adolescence, that period between childhood and full adulthood in which most of the mountaineers began climbing, the identities of childhood are 'remade in vital ways', as individuals 'stride toward their own agency, individuation, and mastery of circumstance' (Lightfoot, 1997:55). ${ }^{77}$ In Lightfoot's (1997:103-104) examination of American youth, she concluded that 'play and novelty' was pursued 'not for its own sake, but for its transformative power. ... [to push] personal limits, [to feel] accomplished, [and to learn] about life and responsibility'. It is also important for building interpersonal relationships and establishing a social status, which Erikson $(1959 ; 1965)$ sees as the primary concern of adolescence. That is, 'the ability to play, and especially to play deeply, has much to do with understanding, expressing, and developing one's self in relation to others' (Lightfoot, 1997:85). But, critically, Lightfoot (1997:105) brings to our attention the way in which 'deep play' among young people takes place within 'a narrative structure' which links it with 'cultural concepts of development and the timing of life experiences'. These experiences are thereby given 'a degree of coherency - they are meaningful, intelligible'.

\footnotetext{
${ }^{76}$ For full story see Appendix E, number 1, page 275.

${ }^{77}$ Lightfoot is drawing here on the theories of Erikson $(1959 ; 1965)$.
} 
In Le Breton's analysis, the youthful courting of danger is a 'rite of passage' with ontological and identity-forming significance: 'a painful response to the exclusion of meaning' with prevailing social conditions as the setting:

Putting oneself on trial on an individual basis is one of the modern forms [of] crystalizing one's identity when everything else fails.

While I did not find evidence that the 'dangerous phase' for young mountaineers was 'a painful response' (except perhaps in the case of Simon, who said that this phase for him followed his father's car accident), Le Breton's description of adolescents as having a 'vague notion' of death seems apt. Not only are young people motivated, he says, by the 'fear of losing face or the need always to show a specific skill' but they are bolstered by a 'feeling of not sharing the same contingencies as others, of being indestructible' (Le Breton, 2004:3 \& 5).

As Davies (2005:15) sees it, it 'takes time' to realise that 'death is our future': it is to be expected. Socio-cultural conditions have an influence, as death has been 'sanitized' and hidden from view but many young people have not had close encounters with death and therefore little experience by which a vision of their own mortality might be brought on. I touch on these issues again in the section on mortality and death. In the biographical narratives of most of the mountaineers, the early years are the most dangerous because they have yet to learn from experience about the nature of those dangers. As outlined here, and elsewhere in the previous two chapters, their experiences during this phase do, however, become crucial building blocks in their narratives: they cement partnerships and climbing styles, and communicate to others their passion and commitment to being mountaineers. They can also feel some nostalgia for this period of their climbing careers, as I discuss later when looking at how they deal with danger. Below, I examine in more detail what the young mountaineer must learn in order to foster long-term survival.

\section{Developing judgment and other techniques for survival}

you become a lot more experienced, and more relaxed about situations you find yourself in. ... you know I feel a real affinity, that I, hopefully, touch wood, know when things are going to happen or what I should do and how far I can push myself and whatever.

In the same way that Phil talks about what he has learnt during early climbs and how that has led to greater caution, others speak of developing better judgment and the importance 
of this for improving their long term prospects of survival. Chris had his early "epics”, but these did not "phase" him; he "just learnt to avoid that sort of situation". Now he is more "careful”, knows, like Terry, when he can "push it out a little bit", and has more knowledge about how to avoid "bad conditions" in the mountains. When I asked Chris if he felt his attitudes to his climbing had changed over the years - between the climber at twenty and the climber at forty - he replied:

Oh, yeah ... yep, definitely. They have to really. To survive ... Yeah, I'm much much more careful, I mean, I've always been quite careful ... a lot of that is just learning to recognise when it's safe to, to just push it out a little bit.

Chris has become more discerning about the kinds of danger he finds acceptable, and what he is "comfortable" with. He contextualises his choices by describing those dangers which he finds, by comparison, unacceptable. For example, he considers Aoraki/Mount Cook to be “quite a dangerous place, it's as dangerous as anywhere I've been in the world". He prefers to climb on the western side of the Southern Alps where "It's much safer and much better rock":

I don't go out there to put myself at risk, at all, or go into dangerous places. And I actively avoid dangerous places. There are plenty routes I'll never do ... the standard route on Cook is a pretty dangerous route. ${ }^{78}$

Chris also emphasises, like others, that just because he now climbs technical and difficult routes, it does not necessarily mean he is putting himself in greater danger. Indeed, he argues that the opposite is the case:

I don't find climbing harder technical routes, any more dangerous really than ... walking around in the mountains.... The more technical it is, the more gear you've got. ... you obviously get the places or bits where ... it might be hard or, but you've just got to make the best of that ... I mean, I'm pretty conservative ... That's why I like the Darrans especially. Because it's objectively so much safer.... the Darrans more than anywhere is sort of, I felt comfortable there, I really liked it, it's just a bit, it's way safer than Mount Cook. ${ }^{79}$

Phil also feels that the solid rock in the Darran Mountains make it a much safer place to climb:

Alpine climbing in Mt Cook is a similar risk to Himalayan climbing ... very similar. ... In fact it was one of my early motivations I think in developing the Darrans climbs was to, try and persuade people to climb down there and not go ice climbing at Mt Cook and falling off, at that stage two or three a year died up there, of the elite climbers, in the early 70s. ... I don't know, I still see the appeal of going to the top of Mt Cook, but you've got to accept the risk involved.

\footnotetext{
${ }^{78}$ For full story see Appendix E, number 3, page 276.

${ }^{79}$ For full story see Appendix E, number 3, page 276.
} 
Like Chris, Tim thinks he has become a safer, though bolder, climber as he gets more selective about where and with whom he climbs:

I'd say I'm always, I'm getting safer and safer with my climbing even though I'm probably getting bolder as well and certainly climbing harder things, I'm definitely getting safe and so you just, you're more picky and you know who you climb with and, and where you climb I guess. Yeah.

Tim too has found, through experience, that there are certain kinds of danger that he is not prepared to expose himself to. A trip to Kurdistan was an "eye-opener" for him. The original plan was to go big wall climbing in Kyrgystan, but the plans changed to a high altitude mountaineering trip because of political tension in their original destination. It was like "having a go at a whole new sport":

Yeah, I wouldn't say I was totally into it and you know big snowy peaks and stuff seems kind of a bit dangerous almost, snow seems to fall down quite a bit ... I guess that taught me that if I'm going to climb mountains they've got to be really solid rocky ones as opposed to loose rubbly snowy ones, yeah. And I think that's, the big lesson there was you know like just to be more picky ... I mean climbing's dangerous and so just you know lots of things you do are quite dangerous but if you peg it down to what you're really into then maybe you can eliminate the risk from some of these other facets of climbing mountains. Yeah.

Kath also puts into context the kind of climbing she has chosen to pursue by contrasting it with what she considers to be more dangerous:

the kind of climbing I do which tends to be on the steep stuff in some ways I think is a lot safer than just general mountaineering like wandering up Mt Cook or wandering up Mt Everest or whatever because you're always pitching. ... and steep things tend to be ... not so avalanche prone ... so yeah ... the type of things I do these days, the way I feel about them, they are actually safer than the stuff I used to do, ... it's easy enough if things go wrong you just abseil off again. ... this is my theory, it's a little bit more cut and dried. ... So I feel like I'm safer these days than I used to be even though I'm climbing much harder grades. Yeah [laughs].

Other characteristics that develop over time and which the mountaineers talk about as increasing their "safety margin" include becoming more 'chilled' and 'mellow' as they grow older, and developing "patience”. This theme was also touched on in Chapter 3 in relation to the longevity of the mountaineering self, but here it is relevant for increasing their safety, and contributing to their survival. As Mike says, he now climbs what he "can do comfortably", rather than pushing himself hard on difficult climbs in order to "prove" himself. Pete feels that with maturity and experience, he has become more willing to “come back another time", rather than pursue a climb under adverse conditions. For Simon, who lost his young climbing companion (see page 87):

the biggest thing I've learned is that the mountains are always there, that's probably why I'm still here. Seen a few people disappear over the years and, 
technically they're more capable, it's often they're the people that just need to be patient, yeah they're the things I've learned.

Both Pip and Dan also stress awareness of danger as being important for safety, and something else that is built up over time. As Dan says: "if you're in an alpine environment, you know, you need to be pretty realistic about the dangers you're putting yourself under". He believes:

it's knowledge that you want to build up slowly and ... I guess there's the saying, you know, there's old mountaineers and bold mountaineers, but no old, bold mountaineers.

Pip thinks it is important to be "really, really aware":

it is a sport where people do die from it. You know they push it to that level where they do die ... there is a risk involved here and there's risk involved with lots of things but the risk with mountaineering, you know, can be as such that you might be killed.

The key for her is "being really sensible", being able to "admit that you have shortcomings", and to climb with "a really wide amount of caution". "I don't climb anything too, too hard", she says. For Jan too, awareness is important, and having "enough sensible fear":

How you, structure and manage your climbing, is really in your head. ... not to say you shouldn't be scared, if you're not scared, you'll be dead anyway. I mean, who's kicking around? Old people like me. We're the oldies kicking around because, you did have enough sensible fear at times to know when you, probably shouldn't do something. You sometimes took the calculated risk and did it, but, you're very aware of the risks. Those who are not aware of the risks, I think they're all dead now, come to think of it. They did some brilliant climbing some of them, absolutely brilliant. But, you know, it's like the old pilots and the bold pilots.

When Thomas first began climbing in the 1950s, the equipment and techniques used were not as safe as those used today, and "to fall would have been quite fatal". As a result, he says "we climbed probably very safely because you just couldn't afford to fall”. To him it is a question of style that you should climb at a level where "you can do it well and with confidence and without taking undue risk actually". Thus, he argues, "It's not a dangerous sport I don't think. But we can make it very dangerous, that's up to us and danger comes in from foolishness".

Another skill, or quality, which increases safety is the ability to deal with mental pressure. According to Kath “you've got to have a good head. Not panic, you know be sort of, be able to stay calm and if things do start to go wrong be able to stay calm and fix them". Or, as Steph describes herself: “I'm, reasonably good at just, well I don't, don't tend to 
panic". It was noted in Chapter 3 that climbing is a "mind game”, and 'losing one's head' in the presence of danger is the least successful path to a favourable outcome. I return to this theme in the section on dealing with danger, when considering the way in which climbers see themselves as people who feel comfortable in an "edgy" situation. Important here though, is that this is something that grows over time and with experience, as Steph describes it:

I think I'm much more relaxed, about the whole thing than I used to be, and I think that just comes with more confidence and knowing that well, that I've got the skills and the ability to cope with more things now as well. So, um, I'm more prepared to try things that I, would have just seem ridiculously scary or, out of my league, when I started, which is sort of understandable, yeah. ... I don't have sleepless nights before I go climbing or anything. I used to. I used to get sort of, nervous, about things, but ... I've been on enough trips now that I know that, either it will go well or it won't. The weather will be good or it won't, or, I don't sort of try and predict stuff too much.

Dan has a similar feeling:

as your experience and your climbing ability develops and, I guess your perception of risk changes and, things that you initially felt [scared on], you're quite comfortable with now. ... I think naturally you do put yourself under a bit of pressure just to, just to get on with it really, to be efficient and to look after each other. Yeah. But, on the whole I don't, I look on climbing as enjoyable and as a step aside from stress rather than, being put under stress.

Part of being able to 'keep one's head', and thus a key tool for survival, is the ability to calmly analyse certain dangers and determine a strategy for avoiding them. Kath, for example, feels that the main danger she faces is injuring herself in a fall and she speaks about one particular twenty metre fall that she survived uninjured:

it didn't put me off because I could see what I'd done wrong and what had gone wrong and the chances of striking that same situation the next day were not very good, were pretty remote. ... But no it didn't seem to rattle me just because I could analyse it. And think okay this happened because I did this or this happened, that's not going to happen tomorrow. ... a lot of the risk is often perceived. I mean you know if you're roped up and got a good anchor and good gear falling is, you fall off but I mean you know you're not going to fall for far sort-of-thing.

In a similar way Tim thinks that falling rock is the greatest danger that he is exposed to, and "part of the game" he says, is to consider the likelihood of such dangers, and do one's best to avoid them:

if there's something that's probably going to get me it will be a rock fall. Like a fall, a fall might get me, might smash an ankle or something like that but I don't think it's going to kill me... I'm sure that there's definitely times where there could be really big falls but I can normally eliminate the ground fall, kind of thing. But the rock fall I can totally see knocking your head off and that definitely frightens me a bit. ... so I guess that's just something, part of the game, stick a helmet on 
your head. And um yeah just I guess just being wary of it you know and be a bit more selective about what you go up. Try and get a sheltered belay if you can, yeah.

Another aspect of developing good judgment is knowing when to "pull back", as Tim says, "just having the balls to make a call so you know 'let's can this' kind of thing”. Or as Jess says “being able to say 'I don't want to deal with this; I'm going to turn around'”. This issue arose in Chapter 3 in relation to the process of constructing a durable sense of self, and I suggested then that knowing when to "pull back" is balanced against the desire to "push it out a bit", in order to explore and perhaps expand the limit of one's potential and the boundaries of the self. Knowing where to draw the line between the two does not involve any 'hard and fast' rules; it is rather something that is sensed, or felt, and experience, humility and not "pushing your luck" are seen as contributing to an ability to make accurate assessments. But it will always be an art, rather than a science. And sometimes you can "push it out" and you will "get away with it" and sometimes you will not. As Mark says:

when I was climbing it was, you know, 'if I do this will I be safe?' or 'should I do this?' and you have to be happy to say no. You have to be, you can't be gung-ho or anything stupid. You've just got to say 'no that's not a good route I'll take the longer or harder way and go round' or whatever. But then every once in a while you feel gung-ho and you think 'no she'll be right'. So that blows that theory out of the water doesn't it?

According to Gonzales (2003:91), a journalist who has undertaken a study among those who work and play under dangerous conditions, 'Elite performers have an exceptional balance of boldness and humility'. This assessment would seem to apply to the mountaineers I spoke with. Klein (2001), who has researched decision-making processes among those working in high-stress situations (like firemen, pilots and military commanders), identified that the processes experienced people use to make decisions under such conditions are not the rational, analytical processes that many would expect, but rather a process he calls recognition-primed decision making (RPD). Klein's book was recommended to me by a mountaineer who felt that this analysis resonated with his own experiences in the mountains. RPD is typically used in situations constrained by high time pressure, dynamic conditions and ill-defined goals - where decisions need to be made in a timely fashion and in response to rapidly changing variables. The technique of surveying a range of options and weighing up their strengths and weaknesses is clearly inefficient under these conditions and, instead, experience is used by experts to identify 'a situation, even a nonroutine one, as an example of a prototype, so they knew the typical course of action right away ... so they did not bother thinking of others' (Klein, 2001:17). 
So while novices must deliberate about options, "people with experience can size up the situation and judge it as familiar or typical' (Klein, 2001:89). Here intuition, the "sixth sense" that Dave talks about, is important. While intuition is sometimes thought of as a strange, even mystical, power, Klein (2001:31) describes it as 'the use of experience to recognize key patterns that indicate the dynamics of the situation'. The problem is that the patterns can be so subtle that people struggle to explain what they have observed. Dave's understanding of intuition echoes what Klein is writing about:

to get good at mountaineering, you need to almost get a sixth sense. You need to tap into ... your intuition. To stay alive you've got to almost, umm, pre-empt things happening and by, you only get that by spending lots and lots of time in the mountains ... I reckon intuition and, and stuff is, you see things but you don't realise you've seen it but you file it away and over a while it builds up this, experience, and, you know maybe, when I go into the mountains I see something, and I don't know why it's weird or why it's dangerous but, it'll be something funny going on, so I'll go away from it.

Klein argues that experts see the world 'differently', noticing patterns that novices would not: as Adam says, “maybe I'm totally oblivious to things around me”. The ability to see patterns helps experts to make effective and timely decisions, but it can also spell 'trouble'. One of the tools used by experienced people is to construct mental simulations of a situation in order to explain what they are observing and to imagine how a course of action might be taken. The potential weakness of mental simulations is not so much that sometimes they might be wrong (though Klein (2001:68) estimates that 'most of the time they are fairly accurate'), but that 'once we have built a mental simulation, we tend to fall in love with it'. This can lead to what have been termed de minimus explanations: where further feedback that would appear to discredit the mental simulation is explained away, in an effort to minimise inconsistency, as 'disconfirming evidence'. As a result, overconfidence in our powers of initial assessment can lead us to disregard subsequent evidence that would contradict it.

So, even though experience is obviously of great importance, Klein (2001:280) is also 'troubled by the difficulty of learning from experience'. The problem is that we 'can learn the wrong lessons from experience. Each time we compile a story about an experience, we run the risk of getting it wrong and stamping in the wrong strategy'. In complex situations it can be impossible to see a clear relationship between cause and effect and, just because we "get away with it", does not always mean that we have done the right thing, or that it will work out the next time we try it. I consider this further in the next section on making sense of accidents. The point here in relation to strategies of survival is that, as Klein 
(2001:279-280) has concluded from his research, 'skilled decision makers appear to know when to wait and when to act'. Or, as the mountaineers put it: when to "push it out" and when "to pull back".

What links this section to the next is Klein's (2001:279) caution that: 'because uncertainty is inevitable, decisions can never be perfect'. Skilled decision-makers, most importantly in his opinion, 'accept the need to act despite uncertainty' (Klein, 2001:280). As Chris says, there are some situations that you just have to "make the best of". In the end, continued survival is the only indicator (though not a foolproof one) of whether or not you got it right. As Bauman (1992b:10) observes of survival: it can be more about outliving others than about our own longevity:

We never live through our own death; but we do live through the deaths of others, and their death gives meaning to our success: we are still alive.

\section{Making sense of accidents: calculable and incalculable dangers}

In this section I discuss the ways in which the mountaineers make sense of accidents. For some, their analysis of the causes of accidents is quite 'cut and dried'; that is, most, if not all, accidents are the result of "human error". As Bob puts it, "if it's become an epic in some form or another ... it's through bungling. It's through not actually knowing what you're about".

For Terry "most accidents and most things that happen on mountains are as a result of errors of judgment". Chris feels that "a few people have died who shouldn't have died... they went too hard out". As we heard earlier from Simon, people he has seen "disappear ... just need[ed] to be patient". He even admits that on the day that his climbing companion died while soloing, "we both screwed up". Thomas also reserves some of his harshest criticism for himself by claiming that the cause of the accidents he has had was “just absolute stupidity”: "I think that's what happens, I think, there was no style in it”.

But accidents can also occur when climbers appear to have 'done everything right', and yet something happens which they could not have been expected to foresee. In the first part of this section I consider the view that human fallibility is the cause of most, if not all, accidents, concentrating on its influence during the 1950s and 1960s. Here again, as in the previous chapter, I draw on the two publications of the NZAC in order to give a sense of the communal narratives which the mountaineers incorporate into their own or challenge. 
Then I examine instances in the narratives where luck, chance and uncertainty are seen to have played a role in the circumstances that have led to accidents.

\section{Human error and the causes of accidents}

As mentioned in the introduction to this section, a few of the mountaineers made comments suggesting that human error was the primary cause of accidents. In order to understand how sense is made of accidents by New Zealand mountaineers, it is instructive to go back to a debate that began in NZAC publications in the 1950s, and became more hotly disputed during the late 1960s and early 1970s, before largely dying away. The debate appears to have been prompted by a growing number of fatal accidents in the mountains in the post-war period, and involved a disagreement over what, if anything, should or could be done about it. This debate illuminates the line that has been drawn historically between the calculable and incalculable, what this has meant for mountaineering in terms of what could be considered appropriate or inappropriate attitudes towards danger and, importantly, how this line has been contested among mountaineers. A brief overview of the historical context of examining the 'cause' and response to accidents follows here. It illustrates how meaning is constructed and negotiated around accidents and just how contentious this meaning can be. ${ }^{80}$

During the 1950s there was much interest in the 'cause' of accidents and a strong feeling among influential members of the NZAC that, if these causes were known, then appropriate lessons would be learnt and such accidents avoided in the future, thereby reducing the rate of occurrence. The prominence given to the call to reduce accident numbers within the Club appears to have been at least partly a response to public pressure. A fatality in early 1953 led to public debate on the possibility of introducing some means of regulating and controlling climbers in the mountains. This prompted the NZAC to go to some lengths to demonstrate that government regulation was unnecessary because it had the matter in hand. The Club's strategy was a combination of reporting on the 'causes' of accidents and drawing attention to the "lessons" that could be learned from them, and charging every club member:

to do his utmost to climb safely and avoid risks.... No person was a good climber who suffered accidents ... the taking of calculated risks ... could not be made competently unless ... the climber had acquired the necessary judgment to estimate the risks involved.

("Annual meeting," 1954)

\footnotetext{
${ }^{80}$ For a fuller examination of this debate see Appendix E, page 279. 184
} 
At this time, increases in fatal accidents were repeatedly blamed on "a tendency for some parties to climb beyond their abilities" ("Accidents," 1955a). It was argued that people may be fit and technically competent but "in matters of judgment, of awareness of danger, of leadership, and of respect for the forces of nature about them, they may be found lacking” ("The gradual approach," 1955).

Some resistance to the 'safe-climbing ideology' appeared in NZAC publications in the early 1960 s, including a satirical piece observing that:

A whole new sport has grown up over the past few years - safe-climbing; this is climbing according to a set of laws formulated and agreed upon by sets of people in various mountaineering and tramping clubs, and not deviated from without the prospect of death.

("Safe-climbing ideology," 1961:6)

Nonetheless, the NZAC publications continued to be dominated by an 'official line' which considered accidents to be avoidable and "safe-climbing" to be ultimately achievable as long as all the rules were followed. In 1965 the national Mountain Safety Council was established, and reports in the NZAJ continued to blame climbing fatalities on "sheer ignorance or lack of understanding”, and a "lack of responsibility displayed" ("Annual meeting," 1965). With accidents and rescues receiving prominent coverage in the media in 1966, including calls for greater restrictions and controls of climbers, the NZAC President again recommended a "vigorous campaign to encourage safe climbing ... [we] cannot afford to let public opinion grow in this respect” ("Annual meeting," 1966:359-360).

In the late 1960s, a stronger rejection of the 'safe-climbing ideology' appeared through letters and articles written in the Bulletin, and a debate ensued over what in fact was 'responsible climbing', particularly with regard to solo or unroped climbing which was becoming increasingly popular with the younger generation, and whether or not the causes of accidents could be accurately determined. As one young climber put it:

The idea of 'cause' in relation to accidents is a gross oversimplification ... how can we ever know with even reasonable certainty which factors were involved? ... blame cannot be placed anywhere in mountaineering accidents: nobody can produce a list of the conditions which need to be fulfilled if accidents are to be avoided and nobody can say that even if all the conditions were fulfilled accidents would be eliminated ... [there is a] misapprehension that it is impossible for experienced climbers using sound techniques to have accidents ... there are no 'given situations' in climbing.

(Vervoorn, 1967:28-29)

By the 1970s, as mentioned in Chapter 4, a great number of "new and unusual routes" were being climbed ("Climbing," 1971), with new equipment, techniques and inspiration 
from overseas. ${ }^{81}$ Phil, who was climbing at this time, explains that it also involved a "change in attitude":

I think what happened ... [was] we tried to do things that were probably beyond what we should have been doing, in terms of safety and technical abilities and things, but we just kept on going, got away with it. And that's obviously how you make progress, by pushing things. ${ }^{82}$

Of course, not everyone "got away with it" and there was a relatively high annual accident rate in this decade. However, what had been described as the "bogged down in safety complex", which had been predominant in the publications throughout the previous two decades, seems to have faded away during the 1970s despite the number of deaths.

Furedi (2005:1 \& 7) argues that 'safety has become a fundamental value of our times' and 'risk aversion prevails in virtually every domain of human activity'. In a society in which, it has been argued by Beck $^{83}$ (1992) and others, 'human actions have more far-reaching and incalculable consequences than ever before', 'being at risk becomes the overriding determinant of the human condition' (Furedi, 2005:5-6). Whether or not this is the case, it is Furedi's observation that the army of safety experts and bureaucrats spawned by the risk reduction industry - which Adams (1995:32) believes 'almost certainly deserves to be called the world's largest industry' - have deemed 'most injury-producing events' avoidable or preventable. As Adams (1995:51) suggests, once accidents are defined as 'unwanted and unintended' - that is, there is seen to be no such thing as a 'normal' accident - then they can only be accounted for in one of two ways: 'Either they are "acts of God" - unanticipated events beyond the control of the victim - or they are the result of human error - mistakes, misjudgements, lapses of concentration'.

Both Furedi and Adams (1995:16) contend that the safety literature 'favours, overwhelmingly, human error as the cause of accidents'. What may have previously been attributed to bad luck, or an act of God, is now portrayed as 'failure to adopt the correct precautionary strategy' (Furedi, 2005:10). This description of an historic tendency certainly fits the attitude taken by officials within the NZAC during the 1950s and 60s, and those who opposed it would have supported Furedi's (2005:11) contention that it leads inevitably to a 'relentless search for someone to blame'.

\footnotetext{
${ }^{81}$ There are some who disagree about the extent and significance of the advances in the 1970s (Aat Vervoorn: personal communication, 30 November 2005), however such a debate is beyond the scope of the current discussion. What is relevant here is that it is widely held that a kind of 'breakthrough' occurred at this time.

${ }^{82}$ For full story see Appendix E, number 4, page 276.

${ }^{83}$ Beck sees this as a process begun in Western societies during the 1960s and 70s (Boyne, 2003:42). 186
} 
This highlights what Furedi (2005:7) calls 'the social dynamic behind the formation of risk consciousness', and the culturally constructed nature of risks: both our awareness of them as well as what are counted as reasonable and unreasonable risks, as discussed by both Adams (1995) and Boyne (2003). As Douglas (1992) demonstrates, explanations of misfortune and assignations of blame are used across cultures, in varying ways, to help sustain dominant ideologies and to persuade people to abide by them, in the interests of their own and the public good. Within the cultural theory framework discussed by Adams (1995), the NZAC approach to accidents during the period described above fits the 'hierarchist' view of risk taking. Hierarchists adopt a paternalistic approach and seek to try and persuade or prevent people from taking risks, being convinced that:

those under their authority, persistently have more accidents than they should. They seek to reduce risk. They usually concede the impossibility of reducing it to zero, but seek to manage it more efficiently. Implicit in their attempts to manage risk better are two beliefs: first, that through ignorance or incompetence people persistently take higher risks than they intend, with the result that the number of accidents is greater than that implied by the accepted risk level X; secondly, that many people under their authority are irresponsible and accept higher levels of risk than they should.

(Adams, 1995:57)

The opponents of the hierarchists, and in the context of this discussion these were represented by the letter-writers opposing 'safe climbing', can be categorised as 'individualists'. These are, according to Adams (1995:58), 'insidious collectors of information about risks ... But they are more alert to the rewards of risk-taking. They are self-conscious risk-takers ... They trust individuals to make their own decisions about risk and scorn the regulators of the nanny state'. The mountaineers I interviewed would, for the most part, fit this description.

It is difficult to ascertain to what extent the 'hierarchist' opinions expressed within the NZAC were deeply felt personal convictions, and to what extent those that wrote them felt compelled by positions of responsibility to adopt such a line on account of the pressure from an increasingly dominant ideology of safety (or 'culture of fear' to use Furedi's term) made manifest by bureaucrats, media and 'public opinion'. Whatever the case, their comments were in the vein of a contemporary 'moral outlook' which 'defines prevention as a virtue' (Furedi, 2005:12). An explanation for how this has come about is Bauman's (1992a) account of modernity's talent for 'deconstructing mortality', which I discuss in the section on mortality and death. 
Interestingly, however, this particular debate died out within the NZAC. Why this happened is further considered at the end of this chapter. While a number of those I interviewed consider 'human error' as the dominant cause of accidents, more speak in a manner sympathetic to comments above regarding the difficulty of ascertaining, from among the many variables involved, the definitive cause of an accident. As Klein (2001:271) says, 'poor outcomes are different from poor decisions'. The comments of some also resonated with the following quote, from a climber writing in 1970, that there can be a "luck factor" involved, and those who go into the mountains must accept that their safety can never be assured:

[a good climber is] self reliant, efficient and purposeful; accepts a luck factor but can turn it to a minimum. ... Accidents are not mistakes. Like avalanches they are events, sometimes involving hundreds of variables. There are no clearcut rules on how they happen but one can spend a lifetime learning about the variables. And so nobody goes in the high mountains to be deliberately safe - if they do they deceive themselves. $^{84}$

These comments lead me to discuss below the role of luck, chance and uncertainty in my respondents' stories about mountaineering accidents.

\section{Luck, chance and uncertainty}

In play, the world itself is a player, and luck and misfortune are but the moves of the world-as-player.

(Bauman, 1995:98)

From the discussion above, it can be seen that a 'culture of safety' has impacted upon the sense that the mountaineering community makes of accidents. In addition, as explained earlier in this chapter, the 'survival strategies' of mountaineers focus primarily on elements of danger that can be calculated and controlled, and either eliminated or ameliorated, by the competence and judgment of the mountaineer, gained over time through formative experiences and maturity. However, many of the mountaineers' accounts also contain a sense that luck or misfortune played a simultaneous role, however minor, in the occurrence of accidents. Pip in particular seems to struggle to reconcile her convictions about the importance of being cautious and sensible, with her awareness of some accidents which could not easily be attributed to a lack of such qualities:

I think that being really sensible about things is really important. Um. And I, I guess, just being really, really aware. [But] I mean some of those accidents ... just seemed to be bizarre things that have happened. They seem to have just been taken out. Um. But they're still really hard to deal with.

\footnotetext{
${ }^{84}$ For full quote see Appendix E, number 5, page 276.
} 188 
While she often repeats that it is important not to get "carried away, in the mountains ... otherwise you'll end up staying up there", that there are "more foolhardy and less skilled people than others", and that many take on "something way beyond their skill”, there are still things that are "unpredictable" and you "just might be unlucky":

I've lost a lot of young, male friends climbing, in the mountains. I mean it's a bit ridiculous really how many died ... part of that's that young, male, go hard thing. Some of them are just really unlucky accidents. ... There doesn't seem to be much rhyme or reason to it ... mountains, can just sometimes pull you out for whatever reason. ... you might be on a flat piece of terrain and, aware of the certain dangers and following all precautions and you still get wiped out you know. And I guess if you spend a lot of time in the mountains, you know, the risk does increase for sure. I mean, you know, there's things that are unpredictable but, definitely being sensible about it.

In Adam's account, while he rates himself as relatively cautious, he also feels that he has been "fortunate":

I haven't really had any major accidents myself, you know I've been really quite fortunate in that regard. Mind you I haven't pushed myself as hard as some people would. Yeah ... there's only been a couple of occasions where I've really thought that I was in a real dire situation, you know where I thought that, a wrong move here could result in, something debilitating.

Simon, like Adam, attributes his "good record" to being both "lucky" and "conservative":

I've got this kind of quite good record in the mountains ... I'm quite lucky. It might be just 'cause I'm quite conservative sometimes, but then again I have done some quite hard climbs. I'm just prepared to go back another time and, and do something when it's right. ... I've witnessed a few falls where people hurt themselves but, I've never fallen in the mountains. Um, and I hope I never do. ... Yeah I haven't had a lot of epics in the mountains. I know it'll be my turn, it will happen, yeah.

This comment by Simon, "it'll be my turn, it will happen”, with its sense of inevitability, is another theme in some of the narratives; that is, the belief that one's luck will ultimately run out the longer one spends in the mountains. Along with this was also a sense that there is a strategy they can use to minimise potential harm as a result of chance, or misfortune; that is, to recognise when they should not 'push their luck'. In Chapter 3 I quoted a story that Kath told in order to illustrate how she decides whether or not to turn around on a climb, something she finds it hard to explain. On the climb she describes, the decision came down to an unwillingness to keep 'pushing the odds'. She had "pushed it out" on previous climbs where the conditions had been no less severe, but felt that if she tried it again "maybe this time we wouldn't be so lucky", and that the chances were that "the gods won't be with us on this one". 
In talking about Bill Denz, a New Zealand mountaineer who had a reputation for doing "hard stuff" in the 1970 s and $80 \mathrm{~s},{ }^{85}$ Phil suggests that it is perhaps not necessarily that he was an "unsafe" climber that finally led to his fatal accident, but that his constant exposure to danger meant that his luck finally ran out:

he soloed the Caroline face. You can get away with a few of those things but you can't keep doing it, pushing your luck. But that might have been one of his failings perhaps, in not recognising the, limits of safety. But I think, you know, he was caught in a big avalanche on Makalu, with somebody else, his climbing partner. Yeah it's in someway hard to judge for example this avalanche, it's just part of the, in climbing when you're in a dangerous situation and, going there is part of the risk. ... I wouldn't say he was more unsafe than a lot of other alpine climbers I think.

Dangers such as avalanches, among the most difficult hazards to assess, are particularly

likely to be seen as involving an element of chance. As Dave warns:

you don't mess around with avalanches, because after a while they kill ya. You get certain numbers of chances, but after a while your chances run out.

Indeed, it would appear that Denz himself had a similar philosophy. In an interview published in the Bulletin in 1977, he articulated his survival strategy:

the name of the game is survival. If you expose yourself to a lot of hard climbing there is a 50-50 chance that you will get killed, and this is the part I am dubious about. So this is the reason that when I go climbing I like to do a good big hard climb and get right out of it, because the more you expose yourself the more likely you are to get killed, so that means when I do a climb it's a good one - a new route, simply because it is a dangerous place and if you like climbing and want to get the maximum mileage out of it you have to reduce the risk.

("An interview with Bill Denz," 1977)

Denz later told a story, not dissimilar to Kath's, about making a decision to turn back on a climb when he felt that every additional risk he took was pushing his luck:

I had to call it quits right there about sixty metres from the top [of Cerro Torre] - I just couldn't do it. I decided on the way up that this was the last attempt, because I'd strung all these tatty bits of rope over problems lower down ... they were wearing quite badly and every time I went up - I'd come down one of these hard sections and I'd look at the rope and say, do I or don't I? ... and of course I did every time. I'd clip on to those things and jumar ${ }^{86}$ straight up them and I knew that I'd do it again and I didn't want to do it - because there was so much danger in doing it - I knew that one of these days one would break - and I just couldn't keep

\footnotetext{
${ }^{85}$ Bill Denz was renowned as a fearless and persistent climber: "with a tremendous drive, he tackles, often solo, hard alpine routes throughout the world" (Whitehouse, 1982). Another climber, Graeme Dingle described his first acquaintance with Denz as "a young pusher": "I had put up a route called Dysentry [sic] Groove, the talk of the town was a crazy character who had fallen twice onto the shaky piton near the top of the route before finally getting up - Bill Denz had arrived on the scene”. Phil described Bill as "very... focused and, wouldn't give in easily, if things were difficult he'd keep on going ... not being put off, not giving up easily ... was really his strength, he wasn't a technically brilliant, proficient climber, whether he was on rock or ice but he had a stubborn streak and he'd stick with things".

${ }^{86}$ A piece of climbing equipment which grips and allows a climber to ascend a fixed rope. 190
} 
trying and trying again because I'd eventually bite the bullet, and so I decided to call it quits at that point while I was still alive.

(Denz, 1981:90)

Also interesting here is the sense in his story that up until the point where he made the decision to "call it quits", it was easy, or perhaps difficult not to, accept the dangers involved and clip on to the worn and "tatty" bits of rope. As Sue says (in Chapter 4), “I'm not sure how much control I have over my brain in those situations”.

Mark has the most extreme perspective on the role of chance, as a result of the accident that ended his climbing career. For him, misfortune is the end-point rather than another element or event to be fitted into an on-going narrative about how he continues to stay safe. Consequently, the need to devise a strategy for dealing with chance, in order to be able to continue climbing, is noticeably absent from his accounts. Instead, making sense of the causes of accidents was, for Mark, a much more urgent and critically important personal effort to give meaning to a tragic life-event. He describes an early experience to demonstrate his sense that while you can take safety precautions, there is still an element of luck or fate involved. Descending a mountain he stopped at the top of a narrow couloir to strap on his crampons. His companion had 'clip-ons' that are much faster to attach, but Mark's took longer:

Got half way through [putting on] one of my crampons, and this whole couloir just let go and disappeared down the side of the hill, this massive rock slide.

[laughing] 'Okay we'll find another way down eh?' And yeah that, that was quite sobering. ... Yeah so ... it's not all about how safe you make it for yourself, it's also about luck and, and what the mountain wants to do at the time and um, there's nothing you can do that can predict what's going to happen. So ... we went down another couloir and, got down safe and sound.

Mark never speaks directly in his narrative about the climbing accident that left him paralysed, ${ }^{87}$ but he summed up his perception of the mountains as both benevolent, and potentially malevolent, and the swift randomness with which malevolence can strike:

There's always something that reminds you that, that you've got to be on your toes all the time that, you can't just take it for granted, or the moment that you do something will kick you in the arse. ... the mountains are, they're not static, they're always changing, they're never the same. ... sometimes you get the feeling that it's just waiting for you to make mistakes so it can kick you in the arse. Or you have you know those religious moments where you're lost and everything clears for a fraction and, you can see where you're going and then it all comes down again.

\footnotetext{
${ }^{87}$ Mark did talk to me later, in an informal setting about his accident (see Appendix B, page 255). As these details were not offered as part of the biographical narrative, I have not included them here. Aside from the clear ethical implications, such details are not, I believe, necessary in order to understand his narrative, but rather the impact of the accident and the sense he has made of it, can be seen to permeate many other comments that Mark makes.
} 
The mountains are exciting. Absolutely exciting. They're kind, and they share amazing experiences and they're so cool, but they can just make you bitter and twisted, and they can kick your arse and they can kill you, in a split second. It's not about whether you are the most skilled mountaineer, the most conservative mountaineer, that doesn't count.

For Mark, even when exercising what most would consider "sound judgement", the dangers encountered in the mountains are almost impossible to accurately assess: there is always an element of uncertainty or incalculability. In describing one instance in which he had to decide whether or not a snow slope was avalanche prone, he concludes by saying:

Who knows? They say there's two people that will get caught in an avalanche, the novice that doesn't know a thing about them and the expert that thinks they know all about them. The people in between generally are too scared to, to venture anywhere. So I like to think I'm one of those people in the middle. Who knows? ${ }^{88}$

It appears then that incalculability and uncertainty do 'enter into the mix' for many of the mountaineers, and a strategy for staying safe in the face of chance is not to keep "pushing your luck". Of course many of those whose luck does in fact 'run out', do not live to tell the tale and then, subsequently, have to integrate the experience into the overall narrative of their lives. But Mark survived, just, and his narrative about danger is permeated by incalculability and unpredictability.

Bauman (1995) maintains that 'luck' and 'misfortune' are when the world makes a move in the game of life. As Klein (2001:279) puts it, 'uncertainty is inevitable'. Adams (1995:26) observes that the problems where we can realistically calculate the odds are 'trivial' by comparison with those where we cannot, because all the necessary information is just not available. There are few, if any, situations in mountaineering, as in life, where all the information is to hand, even if one is experienced enough to know precisely what information is required. Efforts can be made to reduce uncertainty; that is, to reduce the number of variables not under one's control, as Kath, Phil, Tim and Chris describe by their preference to climb in environments where the conditions are relatively stable and solid. But as Tim says, despite his best efforts he could still be hit by rock fall: the incalculable element. He may be aware of the possibility, and take steps to minimise its likelihood and potential impact, but he can never eliminate it completely, unless he stays at home.

To try to take 'risk reduction' to its logical extreme is obviously absurd. As Adams (1995:52) argues, 'Homo aleatorius' plays dice 'out of both choice and necessity'. Where uncertainty (as opposed to risk, which theoretically can be calculated) prevails, luck or

\footnotetext{
${ }^{88}$ For full story see Appendix E, number 6, page 277. 192
} 
chance steps into the breach. If Tim is caught in a rock fall, in spite of his survival strategy and because he decided not to stay home, then we may well call this bad luck or a 'genuine' accident (Beedie \& Bourne, 2005; Gonzales, 2003) or, in Klein's (2001) words, a 'poor outcome'.

In addition, as Klein (2001) suggests, we may never know that our analysis of a familiar situation was wrong, until one day when a particular cause and effect manifests itself. Gonzales (2003) discusses this as normal accident theory, otherwise know as 'the Sand Pile Effect'. According to this theory, accidents are a 'normal characteristic' of 'complex and tightly coupled' systems which, Gonzales (2003:112) contends, could be anything from a highly technological system such as a nuclear reactor or a jetliner, to a group of climbers on a mountain slope. Most failures in such systems are minor, and for the most part they are inconsequential: the sorts of things that can easily be subject to de minimus explanations. But they foretell a greater catastrophe waiting in the wings - they are the "spanks" that should not go unheeded. The upshot is, however, that ultimately and inevitably, accidents of consequence 'while rare, are normal. Efforts to prevent them always fail' (Gonzales, 2003:113). Which is not to say that everyone will come to grief, just that some will, and if Klein's (2001) analysis is correct, it is most likely to be those with least experience and/or those most likely to explain away anything that contradicts their general competence as inconsequential or irrelevant. But no-one can rule out catastrophe completely because in some cases, as Mark says, "there's nothing you can do to predict what's going to happen".

It has not been my intention, were it even possible or reasonable, to consider how 'sensible' is the sense that the mountaineers make of accidents. However, the analyses of Klein and Gonzales, of both similar and comparable realms, have helped to tease it out and give it some context. But in keeping with the overriding theme of my research, I am concerned here with how meaning is constructed and negotiated through narrative, rather than whether or not such narrative meanings correspond to any such thing as 'reality'. As I have argued in this section, while errors of judgement are seen to be significant contributors to accidents in the mountains, many see that chance or misfortune can also play a role in 'negative outcomes'. Indeed, most seem to acknowledge the existence of uncertainty and the 'world-as-player', and not 'pushing one's luck' is viewed as a wise contingency. 
Antonovsky (1987) concludes from his research that people with a strong sense of coherence are confident that 'by and large, things will work out well'. When confronted with a stressful situation, they are 'more likely to feel a sense of engagement, of commitment, of willingness to cope ... rather than [seeing it as] a burden to be escaped'. While there is always the danger that such an optimistic outlook may be misguided, in the face of 'existential uncertainty' (Miké, 2000:357; italics in original), an assessment which allows us to carry on regardless may be more important than a strictly 'accurate' one. In this context, the meanings that the mountaineers construct around safety, danger and accidents are reasonable and understandable, regardless of any conclusions about their possible 'accuracy', and this would be the case whether we were mountaineers or musicians, or mothers or mailmen. I move on in the next section to discuss stories that demonstrate how the mountaineers deal with danger.

\section{Dealing with danger}

Given the knowledge that not everything can be controlled, that uncertainty is inescapable, and therefore that chance can play a greater or lesser role in outcomes that are potentially fatal, this section examines the various strategies that the mountaineers adopt in order to deal with danger. It is evident that regardless of the difficulties involved, enjoyment rather than stress is the prevailing feeling that they have about being in the mountains. As Steph says, she always feels "calm" and "peaceful" in the mountains. Thomas argues that it should always feel "comfortable”, never "difficult”. Chris observes that although "you've obviously got to be able to cope with a bit of, pressure here and there and make decisions about, your safety", he climbs for "the positive aspects of it".

While comfort builds over time, as discussed earlier, it can also diminish with time away from climbing, as it did for Sue, whose family responsibilities have meant less time for climbing:

I've been feeling less and less comfortable in the mountains, situations where I would have felt comfortable years ago. And that's partly because of lack of exposure to it, you know so if you only go away once every two months you just, your mind's just not set up for those sort of potentially dangerous situations. ... if you're doing it all the time you become comfortable and you know that you can, you can walk in those circumstances and not fall off but if you don't do it very often and you find yourself there, I just hate it. I think 'I'm not going to do this again, I want to enjoy myself'. [laughs] 
Pete, who speaks of losing close friends in the mountains but not of any serious accidents of his own, says that although he no longer feels "bullet-proof" as he did when he was young, he still feels "solid":

[you've] got to be someone who feels happy ... in an edgy situation, enjoys that sort of situation. Sometimes I see people who go climbing and I wonder why, they want to go climbing because they seem to be, scared, well scared's not the word but not comfortable in, in that environment

It is not that he never feels afraid:

I mean you still get scared ... before you go and do a climb that's say, a bit more difficult ... you'll still be, um, pumped up that night beforehand and be thinking 'oh god I don't know if I can do this. What's it going to be like? How's it gonna be when we get to that bit?' You know, 'how are we going to get good protection there or are we gonna, conditions gonna be good, what's the ice going to be like high up?' All those sort of things but ... I think that's a psych-up mechanism, when you actually get on the climb, you're just focused and you're just climbing and ... you don't have those doubts when you start climbing, you're into it and away you go. And, it's never seemed to be as hard as you thought it was going to be.

Jess also admits to feeling nervous before a climb, but similarly her nerves disappear once she is climbing:

If I've got a big ambition then quite often the night before you know you don't sleep very well because you're all hyped. You're thinking 'oh no I need some sleep, go to sleep'. And ... you get up at two in the morning and that's the time when it's really easy to go 'oh let's go back to bed'. You start imagining all these horrible things that can happen. Yeah but once I'm actually climbing it's, there's no issues like that at all.

It is almost as if, in the act of climbing, the level of commitment and focus is so high that concerns about dangers are kept at bay. Dave maintains (in Chapter 4) that at a very high level of commitment you “don't really care whether you live or die”. For Steph:

I, you know sort of just, decide that the job's on, you know, so I'm doing what I'm doing and, just get on with it sort of thing, and think about it later, when I'm in a position to.

Jess also speaks about deferring a full awareness of the danger until "afterwards":

there is a couple of situations that have happened where it's been close ... you've fallen or there's been a situation where you just get aware of how close the edge can be in terms of falling off things or whatever and so sometimes in a situation like that at the time it's not a big issue, but like a week later you might have just the sort of flashback kind of situation and you go 'ooh, ooh that is quite interesting' ... it's a real head space thing. It depends ... there are definitely times when I'm going 'I'm actually really scared, I'm not really enjoying this, I think I'll go down'. But they're all very immediate type things. I wouldn't say long term stress situations, they're more adrenaline situations. 
For Tim it is a case of not " $d w e l l[i n g]$ on it":

[I've seen] a bunch of close calls and stuff and um you know 'ooo, that was close'. Yeah. Sort of don't dwell on it too much. Certainly think about how you sort of avoid that kind of thing in the future, yeah.

Some of the mountaineers also speak about having had a frightening experience that makes them question their desire to climb but very quickly overcoming this, as here with Dan:

you might have a particular experience where you get a bit scared or, think, 'wow that was a bit close' or something, and you'll really be questioning, you'll really be thinking 'well ... there's a lot of things I could be doing with my life' ... without having to go out and feel like you're risking your life at times. But you might ... get scared and have those thoughts, for five minutes or ten minutes and then, often a few hours later or definitely the next morning you're, you're raring to go again.

As Dave concludes of his "nightmare” experience lying injured in a crevasse, you deal with it, and you "just move on" (see Chapter 3, page 96). After a scare while climbing, Jane is put off "for one day or so, yeah. And then you forget about it pretty much". When she was young, Sue says:

I was too selfish to put self preservation ahead of pleasure because as far as I was concerned if, if I died climbing well I wouldn't know anything about it because I'd be dead.

It seems that Sue's love of climbing quickly overwhelms the memory of "scary" experiences, and she rationalises her decision to keep climbing by telling herself she will be careful and that she has learnt from her near misses:

I think you just blank them out afterwards. I mean my friend dying and me having to go and tell her parents, at the time that made a big impact because I saw what it was like for her parents. But within a couple of weeks I was off to the Alps myself and I'd sort of pushed it to the back of my mind and thought oh well I like climbing, I'll just keep doing it and I will be careful. And I had a very scary experience that same year where we got caught in a thunderstorm near the top of a rock peak ... and yet within three or four days after having a bit of a rest I was all for climbing again. So [laughs] I think you just learn a little bit from each experience. I developed a very strong fear of thunderstorms.

For Jan, recovering her confidence after two serious climbing accidents did not come quite so quickly; nevertheless, it was undertaken with a determined application of willpower. After her first "traumatic accident", she became "fearful of climbing" in case she fell, but a friend encouraged her to do a rock climbing course in order to regain her confidence:

So that's what I did ... And that got me over my psychological hang-up of feeling I might fall ... So, I worked at that and, got over that, so that was fine. ... It took about a year for it to completely get over. 
In a later accident, she fell and crushed her spine and again she became "fearful of falling”. This time a friend, and other members of her climbing club, took her climbing and "rehabilitated" her. Still:

It took a long while to come right from that. Yeah. There was a lot of pain.... [but] I mastered that [fear of heights] again. The second time, no problems. Continued climbing. ${ }^{8}$

Interestingly, Jan attributes her survival in this second accident to "a miracle": to an 'act of God'. Her fall was arrested after the rope snagged on a "heap of snow". Chance cannot only kill you, it can save you. It is easier to understand Jan's determination by considering the descriptions of other mountaineers who see overcoming fear as one of the attractions of climbing. "You feel pushed”, says Pip, “I think that's what you go for you know”. And as Lyn said in Chapter 4, she does not want to put her life at risk but "the experience of confronting" fear and "keeping that fear under control" is a large part of what draws her to climbing. For Jess also: "you learn how to deal with it and being able to deal with it is actually a really positive experience". Being "gripped" on a climb is part of what spurs Jane on to improve:

every time you do get gripped, it means you want to try it again, to try and work through it, ... 'cause I used to, well I still get real nervous and stuff, but it just makes you want to do it a bit more, to try and, 'cause that's what you're kind of after, you're kind of wanting to overcome it.

Pete is quite honest about the fact that the danger adds excitement, though he qualifies how much danger he can cope with:

you get a few scares, um, but I've always enjoyed that sort of excitement of, of climbing I think. ... some climbers test themselves you know totally they'll solo, something totally ridiculous and technically very hard. ... I can't do that sort of thing, um, but, certainly ... alpine ice climbing gets a bit thin and a bit scary at times. It's, really good, yeah, I love that sort of stuff.

Dave seems ambivalent about dangers and what he gains from them. While "there's always got to be an element of the unknown and risk", "it can be quite ... a fearful thing". Through "naivety" Dave has found himself in situations of "extreme fear" and, while he says that he would not have done it if he had known better, the outcome was that he "learnt quite a lot" about what he is capable of. There is a side of him, he says, "that only comes out in extreme situations”:

I've done quite a few solos, but they've been fairly hairy, like very very hairy solos ... [from] almost naivety. I would never have done them if I'd known what I know now, but I did and, it was okay but, I think what saved me from killing myself was I'm able to, to get this amazing focus.

\footnotetext{
${ }^{89}$ For full story see Appendix E, number 7, page 277.
} 
Jess also found herself in a situation where she discovered that she could "channel the fear into a really kind of almost aggressive attitude" (see Chapter 3, page 108). And while she likes to feel in control when she is climbing, and says she is not primarily attracted by the adrenaline, she admits that "if I didn't get scared there wouldn't be any point to it which is kind of bizarre". She distinguishes between rational and irrational fear, which she illustrates by comparing the fear involved in different situations and different activities:

To me being scared is overcoming it and not being scared if that makes sense. It's like you need to be a little bit scared and then ... you can work out why you're scared and you can control it and you can do things ... in spite of being scared. ... [it's about] getting into situations where I'm testing myself and fear is part of that test in some situations. But not getting beaten by it you know sort of saying okay fear is just one of those things and I can be afraid but it doesn't mean that I can't do it. ... I don't like being afraid unreasonably ... you're actually less safe close to the ground than you are really high. But I generally feel more scared up higher than I do close to the ground and so it's not rational and that's something I'd like to change because it doesn't make sense. So therefore being scared is not, not a buzz it's yeah it's more overcoming it and being scared for the right reasons and not scared when you don't need to be scared ... Fear stops you falling off things. And when it's like that it's quite useful, but ... [if] it actually stops you doing things at all, then it's not useful so it's getting the right balance. ${ }^{90}$

Walter (1984) has found similar evidence that climbers do not report feeling fear while they are in the process of climbing. For Walter, the crucial dichotomy is control versus passivity. When climbers feel that they are 'unable to influence events', fear enters the picture. Similarly, the 'armchair mountaineer', 'that epitome of passiveness' in Walter's (1984:74) analysis, feels fear when experiencing vicariously the act of climbing. This contributes to the misperception that 'the question of danger ... is the sum total of what climbing is about' (Walter, 1984:74-75). For climbers, experiences of danger are important to their sense of self, not because they are 'dare-devil' risk-takers, but because they can overcome their fear: they can experience "sensible fear" ( "useful fear" or being "scared for the right reasons"), and through this attain knowledge of their abilities.

Creyer, Ross and Evers (2003) conclude from their study of mountain-biking that enjoyment of an activity will moderate concerns about risks, and as one practises a particular activity, gaining experience and interacting within a particular social setting, a process of risk 'normalisation' or 'acculturation' occurs, through which fears about risks subside and expectations of pleasure increase. Albert (1999:169) observed a similar process among road cyclists, and concluded that subcultures of sports participation

\footnotetext{
${ }^{90}$ For full story see Appendix E, number 2, page 275. 198
} 
'construct normative practices that give order and place to danger and risk, thus normalizing their occurrence as taken-for-granted features of participation'.

The way in which the mountaineers talk about danger and fear adds validity to these conclusions. It is my observation that the mountaineers deal with danger, both in their narratives and in other social settings, through a process of contextualisation. By comparing various degrees and types of danger within the broad spectrum of climbing, as well as between different kinds of activities, they express their conviction that the dangers they face while climbing are not extraordinary: they are far more 'reasonable' and consciously considered than many others taken in the course of our lives. Jane expresses a sentiment common among mountaineers when she comments "you could die, but you could die driving your car and stuff". Mike, who uses words sparingly, is also speaking comparatively I believe when he reflects that "There's very little chance of dying while climbing". Pip says of her young male friends who died in the mountains: "I guess that in the walk of life they might die in car crashes". She elaborates on this theme when she contemplates how she would feel if a child of hers took up climbing:

I guess if you had a child that, was doing pub crawls and, you know, whatever, I mean there's just as big a risk. I mean I guess there's a risk for people who enter into crime, isn't there. You know, they might not come out of it alive or ... very well off. So, it's just another facet of society.

In addition, the mountaineers, like Adams' (1995:58) 'individualists', 'are more alert to the rewards of risk-taking'. They are strongly attracted by the "positive aspects" of potentially dangerous situations, rather than simply the "buzz", which is not seen to be an appropriate reason for climbing. In this sense, their approach is in a similar vein to the mountaineer who wrote in 1949:

Man has only one means of taking his own measure, and that is by pitting himself voluntarily against the external world. If the process carries the threat of destruction, the experience becomes especially complete, intense, and revealing. But the systematic search for danger and extreme difficulty is nothing but a negative and morbid tendency. It is the action of people whose nervous system, shattered by the unfortunate conditions of urban life, is eternally hunting for new shocks to give the subject the illusion of living.

(Samivel, 1949:4)

One of the "unfortunate conditions of urban life", Bob argues, is the over-emphasis on safety, at the cost of discovery, excitement, and exploration. Climbing should be about going to the edge and keeping it together, not being scared for the sake of it, as Jess also said of bungee-jumping (see page 153): 
I've had some near squeaks as anybody who has travelled in the hills ... I think... there's a tendency to try and make all these places safe ... and it's not allowing adventure really. ... and it's not a question of risk or anything, you know you live life, life is a risk. I mean if we had that, if that prevailed from way back, we'd still be in our cave, looking out fearfully wondering what might be out there that we might come to grief on. ... As important as that might be, and as honourable [as it is] to look after the public I think we can over molly-coddle ... So they contrive the adventure in terms of an activity which takes [you] safely to the edge of something, and gives you a fright. And that's called adventure. And I don't think that really is adventure.

Pip also feels that:

we live in a very safe society, there's not much risk out there. Not like our crops are going to fail and we're not going to have any food next year or, we're going to get invaded tomorrow.

She thinks that this leaves something lacking in our lives:

maybe it's a really human requirement [to] seek out some form of risk in our lives, maybe we're getting that through recreation at the moment.

Pip is speaking here of a need for 'risk', but I would argue that what both Pip and Bob mean is not so much 'risk' as 'danger' (or the sense of danger, as in "jump[ing] off a bridge"), but 'risk' as a condition under which we are enabled to act with a sense of control and personal responsibility for our own ends. This 'need' is arguably a result of what Beck (1992:131; italics in original) describes as the 'inherent contradictions in the individualization process'. While on the one hand our biographies have become increasingly 'reflexive' in 'advanced modernity' - that is, we 'must choose between different lifestyles, subcultures, social ties and identities' - on the other 'individualized private existence [has become] more and more obviously and emphatically dependent on situations and conditions that completely escape its reach' (Beck, 1992:131). We are increasingly 'at risk' from technologies and processes which 'resist any individual treatment' (Beck, 1992:131), while at the same time we are less able, or maybe less likely, to face dangers of our own choosing: uncertain situations through which we may have some semblance of being able to control the outcome. And feeling 'in control', as we saw in Chapter 4, is an important part of narratives about being in the mountains.

As Adams (1995:55) notes, 'Excessive prudence is a problem rarely contemplated in the risk and safety literature'. But in the context of climbing mountains it has its clear disbenefits, and this is certainly something considered in the narratives of these mountaineers. Indeed, they are caught in something of a bind: to some extent they seem to feel a need to defend their actions to those who might consider total 'risk reduction' as a 
desirable ultimate goal, and therefore they contextualise their experiences as being carefully thought out and relatively conservative and calculating. But at the same time they have an awareness of the rewards and benefits of facing danger and overcoming fear: the plus side of the 'risk' equation.

It is perhaps not surprising then that many of the mountaineers appear to have a more or less ambivalent attitude towards the dangers of climbing, emphasising often that they are 'safe', 'conservative' climbers, yet also acknowledging in many instances the benefits that danger offers them, or the disbenefits of being too safe. This ambivalence was exemplified by Murray Jones, one of the 'bold' climbers of the sixties and seventies, in an interview published in the Bulletin in 1973. On the one hand he said: "I'm basically very conservative”, and yet he complained that the prevailing attitude which stressed safety and caution "seems so wrong. This emphasis on 'climb safely"” ("Bulletin interviews Murray Jones," 1973). Pip frequently states that she is a safe and cautious climber, but is clear that this does not mean that she is not "adventurous":

I push limits, but only in a, certain degree, you know. I'm reasonably sensible about things ... I'm really adventurous ... but I'm not unsensible... I think I've always been reasonably conservative and I've always worked, well within my, limits. Um. And I have never had any major, major epics. ... I think I've always been a reasonably conservative climber.

Chris feels that when he started, climbers needed to be "a bit, danger oriented, you know ... the sort of person who could cope with, a bit of pressure, mental pressure", but he also describes himself as "conservative". At the same time there seems to be some regret and nostalgia about the 'old days' in his conclusion that climbers and society in general are becoming "much more conservative" (see also page 152):

There's less people pushing it, from when I started. ... Which isn't necessarily, you know, a bad thing, but ... I think climbing has lost that sort of slight ... [long pause] oh, sort of that slight alternative approach it used to have.

While Simon points out that the early phase of climbing is the most dangerous because of the naivety and lack of awareness of risk, he looks back on this phase of his own climbing with a sense of missed opportunity:

if I had a climbing partner then, I think I could have done some quite amazing things, 'cause I was just in that right frame of mind, but I never had that, until later on.

(Simon)

Phil, who also believes "you make progress, by pushing things", has a similar 'regret' about becoming safer, thanks to his early experiences: 
[they] taught me to climb really you know within that sort of safety margin and not falling off. Which I think there's, that's been a kind of a blessing and a curse in a way because it limits you to climbing within your abilities, you don't push beyond what you can do safely, but you also can climb sort of no-fall alpine style which is a good way to climb in the mountains.

Weighing up the potential gains and losses is a complex business. Kath articulates it as a need to consider "what it's worth":

I guess, I don't know, you've just got to weigh up how much you want to get up this thing, versus how much, you know there's the risk versus how much you want to get to the top and what it's worth.

For Tim it is also a case of deciding what it is worth. It is good, he says, if you are not "pigheaded" about it, then you "can say it's not worth this" if things are becoming dire. It is when you cannot clearly distinguish "what it's worth" and what "it's not worth", that you move from the realm of acceptable into unacceptable danger. Negotiating such situations, and accepting such considerations, involves understandings which are specific to the cultural context of mountaineering: they don't translate well outside of this context. As Sue says, she could accept the potential harm that her husband faced when climbing, because she is also a climber. She understands the attractions that climbing held, as well the relative safety of his approach within that context:

I could accept that risk better than someone [who didn't climb], yeah. ... I always knew there was the risk that he wouldn't come back. But as the years went on I got less worried about it because I realised he was very competent and you know, he'd be unlikely to come to grief.

The same thing would apply if her children made the decision to become climbers:

if the kids really want to do it then that's their life you know. Yeah, I mean I'm sort of thinking to myself well maybe they'd end up being a climber like Geoff and then I wouldn't have to worry about them because he was pretty safe. But there's always those formative years to go through where you have lots of near, near misses and scrape through somehow.

In summary, the mountaineers deal with danger in a number of different ways: through a sense of being comfortable in the environment, which builds over time; by putting their doubts out of their minds when climbing, by not dwelling on 'close calls', and by 'moving on' as quickly as possible after set-backs, with a determination to avoid them in the future; and finally through their attraction, however ambivalent, to the benefits of danger. In particular, they relish the opportunity to successfully control their fears and to enjoy a sense of control and responsibility for their own actions, and occasionally, if the situation arises and there is no going back, to discover strength and ability in situations of extreme danger. 


\section{Mountaineering, mortality and death}

Attitudes to death are closely related to our sense of identity, to the way we live and to the meaning we sense in the life that we lead.

(Davies, 2005:141)

In this final section I discuss the mountaineers' reflections on death: both their general thoughts about the relationship between death and mountaineering, and the ways in which they contemplate the deaths of friends and acquaintances in the mountains. It is clear that if mountaineers cannot find a way to reconcile themselves in some way to the possibility of death as the result of climbing, then long-term participation in the activity must be jeopardised. Again, I am not interested here in judging how 'sensible' any particular strategy for dealing with death may be. Rather I have concerned myself merely with examining how such strategies exist as part of a narrative, and the implications they have for identity and meaning. I make this point again at this juncture because I am conscious that one of the hardest things for 'outsiders' to understand about mountaineers is how it is possible for them to continue climbing in spite of the deaths. Even Jan's son “never wanted to go mountaineering”, although both his parents were mountaineers, because "Mummy's friends all died in the mountains". As Pete says,

I think we, as mates and other climbers could accept [the death of a friend], 'cause you were doing what you wanted to do. ... [but] friends who weren't into climbing ... were really resentful ... couldn't understand why they'd want to go and carry on climbing, you know, and be real keen to get out climbing again when your sort of mate had been just killed or whatever.

To introduce the ways in which the meaning of death was narratively constructed by the mountaineers, I start with Jess, who tells the fullest and most encompassing narrative about how she has dealt with the deaths of friends in the mountains. I then discuss the main themes of her narrative with further examples from other narratives, some of which elaborate, and some of which are variations, on Jess's treatment of death. The topic of death came up in Jess's narrative in relation to a trip she was describing. "People dying in the mountains", she said, "is a horribly common thing”:

It's not something you have to deal with all the time but I've known, there's been three or four people that I've known quite well that have died in the mountains. So you've got to, you do address that issue more than once.

Later, after she had finished her initial narrative, I asked her to talk in more detail about how she had addressed the death of friends. In response to my request she spoke about three successive instances in which she had had to deal with fatal accidents, and described how her response to each death differed, placing them within a gradual 'coming to terms' 
with death and her decision to continue climbing in spite of them. Jess's story about her experiences of death in mountaineering is quoted here almost in its entirety, ${ }^{91}$ in order to show in detail the progression of her ideas and the way in which the meaning that she has constructed around each event contributes to the development of her personal philosophy about climbing. Also of relevance to the preceding sections of this chapter, is how she describes the nature of each accident - the first is "weird" and "freaky", the second a "mistake” which unfortunately had fatal consequences, and the third a result of being in "the wrong place at the wrong time":

[Lee: You said before you had to deal with the deaths of some people, can you say a bit more about how you coped with that or what impact that may have had on your own climbing?]

The first person I knew who died climbing was when I was just getting into climbing and it was kind of weird because he died climbing Mt Haast, fell off and the rope caught on a sharp rock and cut. Like the belayer said no way any weight ever came onto the rope as far as he was concerned it was just like 'oh'. So it was pretty, pretty freaky. And because I was quite young and hadn't really met death very much, and the weirdest thing about that was how unreal it was. It was like it didn't really seem to have any impact. I mean it wasn't until about a month later when ... [planning a trip that I realised] he wasn't there and it was like 'okay, that's right, Neal isn't here'. And that was when it really began to sink in. And so I wouldn't say really I'd even really dealt with death there because I kind of ignored it.

Later on, different situations. A couple of friends died on the East Ridge [of Mount Cook] about a year after we'd climbed the East Ridge. Because I can remember saying to Liz what a good climb the East Ridge was, how great it was blah, blah, blah and you know they could definitely do it but then they fell off, anchor ripped and all sorts of things ended up down Caroline Face somewhere. And that was a lot more immediate, a lot more in my face, a lot more daily life type stuff, closer friends and the big thing there was accepting that the reason why people climb is like you feel more alive. And the reason it makes you feel more alive is because it makes you more aware of the risks, because you're closer to the edge. You can see it. But it makes you appreciate that you're not. Does that make any sense?...

People don't go into the mountains to die. ... Death was totally incidental, it just happens, it's one of the things that you know happens. People die. And climbing puts you in a situation where if you make a mistake it's a more likely outcome ... the consequences are more brutal. But because the consequences are more brutal you're more focused, you're more energised, you're more alive. And that's one of the reasons why you do it so we talked about that quite a lot and it's also an awareness that the mountains are impersonal. ... it doesn't so much make me think that it's a really dangerous activity as just highlight that punishment if you do make a mistake, type thing. So it makes you more careful. But it doesn't stop me going into the hills at all because that's the whole thing it makes you feel more alive.

\footnotetext{
${ }^{91}$ I have broken the narrative into paragraphs in order to show Jess's three 'stages' in dealing with death, and then her final 'summing up'. In order to help the 'flow' for the reader, I have removed phrases that are repetitious or where the detail is not necessary in order to understand her meaning. Otherwise I have kept the order and integrity of the narrative intact.
} 
... More recently a friend died ice climbing ... and again that was quite a close one. And that was again no thought crossed my mind in terms of, I'm going to stop climbing. It's not about that. It's more just - and the weird thing about that one was that it was really like being struck by lightning type accident. It wasn't that he made a mistake, he was in the wrong place at the wrong time. And he just got hit on the head by a large chunk of ice and it wasn't someone else kicking it off above him, you know it was just there you are. And because you're in that environment you don't get second chances in situations. ... that was more thinking about what death was and the fact that you have to deal with the fact that everyone does die. And I suppose as you get older you're going to have more and more people dying because people do.

... is there a good way to die? Is there a bad way to die? I mean dying, just because you're a climber doesn't mean you're going to die young. But definitely death makes you more aware of how precious life is and how important it is not to waste time. Not to think 'oh I can do it later'.... people have to be really aware that you don't know how long you've got and you think climbers are probably more aware of that than a lot of groups in society.

\section{Accepting death, confronting mortality and finding meaning}

Jess's early experiences equate with a youthful 'vague notion of death', where a relative distance from the event and the person involved meant that death remained "unreal". By contrast, Steph feels that she "met death" at a relatively early age, as a result of being a mountaineer and having her brother die in a climbing accident, and that as a consequence she has "grown up quite quickly":

some people ... [are] still at the stage in their lives [where] they've never really had to deal with, with people dying or, doing things that are quite risky and, and knowing that the possible consequences, you know, could be that as well. And sometimes I feel like I've, I don't know if it's just because I've had my brother die or, or because of the whole being in the climbing scene and, doing things that are, a bit dangerous, but I feel sometimes that I've grown up quite quickly, because of it.

For Jan, the deaths that have affected her the most have been of "those who you've been on a rope with", because of the "very strong bond" developed with them, "because you have to actually read their thoughts, and you have to know how they're feeling, what they're thinking”. Her way of coping with the number of people she has known who have died over the course of her long career in the mountains, was to stop "keeping a list", as "it was just too, too awful, to keep saying 'oh there's another one died'”. She could acknowledge death, but only up until a point where it threatened to overwhelm her. 
Distance from the events of the deaths of his friends helps Phil maintain a sense that death is not "part of the climbing experience". When I asked him if he had had any 'major disappointments' in his experience of climbing, he said, after a long pause:

I mean there's been those times when people have died and, I've lost friends but that's - in some ways I don't relate that to climbing so much. You know like the experience of climbing seems to be something you focus on, [when someone dies] you're sad that they've gone but I don't, I don't regard that as part of the climbing experience particularly. Actually because a lot of friends that have died, have died overseas in different places.

Pip feels that while "losing people in the mountains" has made her "rethink" the things that she does to "safeguard" against the dangers she faces, it will not stop her climbing. As in the previous section on dealing with danger, the mountaineers who spoke about death felt, like Jess, that although they knew people who had died while climbing, they still considered it something worth doing: the rewards were such that the deaths were not sufficient “justification” for giving up, as Mark explains with the following story:

you don't stop going into the mountains [because people have died]. ... it doesn't put you off. There was a death recently and one of my friends said 'that's it I've had enough. Too many people are dying I'm never going into the mountains again'. And then he went to the funeral and came back saying 'I haven't been spending enough time in the mountains. ... I have to get into the mountains. I can't not go into the mountains'. I think that has a lot to do with the passion and, and the feelings that you get from being in the mountains. From being with people in the mountains ... and all the experiences that you share in the mountains. You get so much from it, that even though it kills some people, you know they were there because they were getting so much from it and they wouldn't have been the person they were and you probably wouldn't have loved them the same, if, if their experiences had been different. Yeah. And so because somebody died up there isn't justification for saying I'm not going there any more. And indeed in some ways it's a motivation to get back up there and experience those, those profound experiences that you have ... you still have this need, this passion, this void that can only be filled by going off and, and spending time in a place where you don't need anything but yourself and a mate.

Tim has not had a "really frightening experience" and, like Phil, he has been "quite removed from all my friends when they've died". And while he also is sad about losing friends, climbing is so much a part of 'what he does', as it was for the friends who have died, that he cannot imagine giving up; rather, he feels, he has become "quite accepting of death":

I've had a bunch of mates die from it and stuff and even that's never made me think about giving up. It's certainly made me think 'bugger', but it's like, you know it's half the reason these guys are living, do you know what I mean? I guess I've sort of become quite accepting of death in a way. Maybe that's from climbing. And not that I'm you know at all looking forward to it ... or anything like that, but we're organisms and we die, that's what we are kind of thing ... So ... what it all boils down to, is living it up, you know. ... that's why I can't see myself giving it up. 
Yeah. Yeah. Like I could certainly, I could envisage possibly having a frightening experience and toning it down maybe but not giving it up, yeah. It's sort of, it's too much of - I don't know - sort of a, it's something you just do. It's like you know like eating do you know what I mean.

In addition to the theme of becoming "accepting of death", the mountaineers who speak of it feel that it has made them aware of the "possible consequences" and, as Jess puts it, of "how precious life is". In other words, through death and danger in mountaineering, they've had to confront their own mortality. Thomas believes that this is "probably a very good thing”:

I think as climbers, I think we have, we do front up to actually, potentially life threatening tasks, so we are aware actually, we are aware that something can happen, and so we have to prepare ourselves, and I think that's probably a very good thing. ... Is it that [the] only people who go there [are those] who are actually prepared to face up [to the fact] that life is not going on forever? I think you have to, I think one has to be quite clear about that, and if something happens we try to avoid it, but something can happen, and then friends of mine they got killed but in a way, you will say that's, they, they knew what they were in for, they did something they obviously enjoyed doing and it's better than being run over by a car. And so I think in a way, I think you have to face up to these things and I think, I think that's a good thing to do.

(Thomas)

There are echoes here of Jess's question: "is there a good way to die? Is there a bad way to die?" Thomas suggests that it is better to die doing what you enjoy doing, than to die "being run over by a car". In this way the mountaineers are able to see death while climbing as a more meaningful death than some other 'random misfortunes' that may strike them down. But essentially, as both Jess and Thomas argue, we have to reconcile ourselves to the ideas that we will die sometime, whether we climb mountains or not, and that being a mountaineer does not mean necessarily being "destined for an early pine box”, as Dave puts it. And while a 'premature' or 'untimely' death is typically more problematic than the death of someone who is considered to have lived a full life-span (Davies, 2005; Davis \& Nolen-Hoeksema, 2001; Giddens, 1991), these mountaineers would appear to agree with Kierkegaard (paraphrased by Davies $(2005: 134)$ ), that the 'fate worse than death ... is not to become "ourselves". As they emphasise here, and as I have argued throughout this thesis, climbing mountains is such a large part of their lives and their identities, that they can say of their friends that died, as Mark does, it was what makes them "the person that they were".

Furthermore, in celebrating the lives of those who have died, as happened to the friend in Mark's story, the mountaineers reaffirm the meanings and reasons for their pursuit. It is in 
funeral rituals, Davies (2005:12) maintains, that 'people tell their stories of the meaning of life' and express the primary values encapsulated in it. At the funerals of mountaineers, and in their obituaries, friends often talk about how much those lost loved the mountains, how 'full' their lives were, and the joy they found in climbing. ${ }^{92}$ By continuing to climb after a death, the living sustain the 'meaning' of their friend's life, and death. Not to respond in such a 'creative' manner leaves them vulnerable to the conclusion that 'life is absurd' (Davies, 2005:134), and by correlation, that mountaineering is pointless and meaningless. Murray Jones, who eventually gave up climbing, may have felt this way, when he wrote of the 1970s:

most tragic of all were the deaths. There were so many! Wives and husbands! Daughters and sons! Lovers and brothers! Still I rage, rage into the depths of dark despair at our loss. ... We survived, to ask the question, Why?

(Jones, 1980:62)

If we cannot find an answer to this question (and as Frankl (1992) argues, each of us must find our own), then meaning is lost, as perhaps it was for Murray Jones, and to stop climbing is an understandable response. Davis \& Nolen-Hoeksema's (2001) study of the ways in which people try to make sense of the loss of loved ones supports the conclusion that the ability to find meaning is crucial for dealing with death. While a causal explanation for a death may assist in the search for meaning, this is generally insufficient on its own, and people 'seek a deeper, philosophical meaning for their loss' (Davis \& Nolen-Hoeksema, 2001:730). Where people are unable to understand the event in which someone dies as having meaning, then in terms of coping they may instead ascribe 'personal value or significance to it': most commonly, benefits such as 'a growth in character, a gain in perspective, and a strengthening of relationships' (Davis \& NolenHoeksema, 2001:734-735). Indeed, Davis \& Nolen-Hoeksema (2001:736) conclude that whether or not people are successful in making sense of a particular event, they 'seem motivated to find something positive in their experience'. In this context, the mountaineers' response to the death of their friends fits within the 'normal' spectrum of coping with loss.

\footnotetext{
${ }^{92}$ I have not myself attended the funeral of a mountaineer. This description of funerals is based on anecdotes I have been told by mountaineers and is supported by newspaper reports I have read and the sentiments expressed in obituaries. Coffey (2003:169) also described how a funeral helped a father to accept the death of his son in a climbing accident:

They told stories about Seth, laughed over his quirks, described his daring climbs, his quiet understatement, his love of mountain environments. [His father] was enamoured of the climbers, and thrilled by facets of his son's life that were unfolding before him. Until then he thought climbing was selfish. Suddenly, he saw it as Seth's calling - what life had given him to do.
} 
As discussed in Chapter 1, theorists such as Lyng (1990) and Le Breton (2000:1-2) see playing on the 'edge' and being engaged in a 'symbolic game with pain, death and bodily injury' as being central to activities like mountaineering. While elements of these observations are echoed in the narratives here, I do not believe that they are central to the mountaineers' sense of who they are and what mountaineering means to them. As I mentioned in the introduction to this chapter, is was not something that most of them spoke about in their initial, unprompted narrative, and it was only considered at length if later I prompted them to do so, particularly in the cases of Dave and Jess.

The theories of Lyng (1990) and Le Breton (2000) undoubtedly have explanatory power in some circumstances and in relation to certain individuals and the activities in which they are engaged. However, I feel that they miss the sense in which the mountaineers I spoke with are engaged in an on-going struggle to derive meaning from their 'brushes with death' and "face up to" their mortality, and the way in which mountaineering is primarily lifeaffirming, rather than death-defying. This is evident in Jess's narrative about the evolution of her responses to death, and also in Dave's narrative. Dave says that because mountaineering is a "seemingly risky activity", he has:

undertaken a study to try and cushion myself from any blows that may, may come along, but ah, ... I think it's gonna help, and it has helped already. ... I've got this belief that life and death are, I look at it as sitting on either shoulder and they're equally as part of existence as each other but in modern society we frown upon death as being this horrible thing and I, I want to reach - I don't know if I'll ever reach total understanding but I'd like to, bring that into balance. ... I mean people die all the time, you know, I just want to accept it more.

Dave goes on to suggest that while mountaineering has facilitated an insight into death not easily accessible in "modern society", an acceptance of death is not easily achieved, nor is it a one-stop, fail-safe cure for fears and doubts. He thought, "naively", that he had the "whole death thing sorted", until he spent those four and a half days lying in the crevasse waiting to be rescued, with time to think about it:

and I discovered that I was actually pretty gripped about dying [laughs]. ... 'oh, damn I have to go back to the study', you know [laughs]. ... [but] I don't, dwell on it too much but whenever death is around me I'll talk about it ... I think that's a major drawback of modern society, or modern New Zealand society, is that we're shielded way too much from death. ${ }^{93}$

I discussed in Chapter 1 the extent to which an awareness of our mortality is an inescapable part of the dilemma of being human. Death, according to Bauman (1992a:95), 'was frightening at all times'. Since time immemorial, humans have fabricated 'elaborate

${ }^{93}$ For full story see Appendix E, number 8, page 278. 
subterfuges' so that they may go about their daily lives as if the finality of death would not touch them (Bauman, 1992b:1). In pre-modern times, however, death was 'tame' in the sense that it was a 'daily and highly visible occurrence' which was accepted with 'resigned equanimity' (Bauman, 1992a:96), and the Christian mind placed its hope in the eternal (Davies, 2005). The rise of a secular, modern world, while it freed us from other tyrannies, has left us ill-equipped to cope with 'the absurdity of being' (Bauman, 1992a:94). Death is the 'scandal' of reason, and an affront to the progress that defines modernity (Bauman, 1995, 1998). This has led, according to Bauman (1998:221), to the modern strategy of 'deconstructing mortality', of treating it as something external and ultimately avoidable, dispersing it into a 'plethora of single, always individual and unique, cases of death ... which human wit, know-how and dexterity can tackle'. Every death 'has a cause ... We do not hear of people dying of mortality'.

The 'modern' response that Bauman describes can be seen to explain the attitude towards the dangers of mountaineering that holds that all accidents have causes that should be identified and from which lessons should be learned so as to avoid them in the future. In mountaineering culture in New Zealand, this approach appears to have reached its zenith during the 1950s and 60s and then died away, it would seem, as modernity's power waned. What we are moving towards, Bauman (1992a:174 \& 187) argues, is a postmodern 'deconstruction of immortality', in which time is divided into 'short-lived, evanescent episodes'. With 'mortality daily rehearsed ... everything becomes immortal and nothing is. Indeed only transience itself is durable'.

While I did not find that a postmodern approach to the problem of mortality emerged from my research material, what I gleaned from the mountaineers' narratives was the sense that being mortal (and aware of it), as Bauman (1992b:10) puts it, 'gives measure to time, makes every moment both fearful and precious, makes being into action and existence into a purpose and a task'. And although they did not appear to believe that they could 'cheat' death, there was the sense that they had to carry on, like all of us, consciously or not, as if their own death were not imminent. As Pete says:

[When you're young] you did definitely, feel bullet-proof whereas not now. [laughs] I don't feel bullet-proof, although I s'pose, yeah that's probably not true really. I get up, back on a mountain and I feel in control and stuff. You don't feel like you're gonna, that anything's going to happen to you at all. You do, otherwise you wouldn't be able to, you wouldn't go there and do it I don't think. 


\section{Summary}

The narratives that were told about safety and danger centred on the development of judgement, and the ability to analyse dangers and take steps to avoid them. While many accidents are seen to be the result of human fallibility, chance or misfortune are also felt to play a role and to be part of the landscape of mountaineering, although for some more than others. Against this background mountaineers must reconcile their love for mountaineering and appreciation of the rewards that come from exposure to danger, with the inevitable accidents and deaths. It seems apparent that if they cannot do this, then they cannot climb, and I believe that this is the reason some people give up mountaineering.

The narratives presented here are the 'successful' one's - those of the survivors - with the possible exception of Mark's. They are stories about being "conservative” and "careful” and "aware" of the dangers, and choosing to climb because the benefits outweigh the disbenefits. Indeed, confronting danger and mortality are counted among the benefits for some. Beyond the dangerous phase of the young climber, they do not see themselves as 'extreme' risk takers; rather, they see themselves as Pip does: “I don't enter things, into anything in a really foolhardy way, that's just not how I do things”.

In terms of meaning, we all endeavour to engage in 'tasks' which:

are capable of giving life meaning which transcends life's biological limitations and allow us to live, to enjoy life, and to stretch ourselves to make life more enjoyable still - and all this despite what we know about the limitations, the endemic brevity and ultimate futility of life's efforts.

(Bauman, 1992a:5)

For committed mountaineers, climbing mountains provides this meaning, both because of and in spite of, the dangers it involves. And in a sense there is 'no such thing as a risk context', as Boyne (2003:75-76) argues:

Since all social contexts can be seen through the lens of risk, there is no objective criterion to differentiate risk contexts from non-risk contexts ... What is high-risk and low-risk and for whom ... are questions which go deep into our culture.

As Thomas observes, it is "non-climbers [who] always tell about risks climbers take"; that is, who see mountaineering through a 'lens of risk'. And Phil makes this point about the cultural construction of 'high risk':

[climbing's] given a separate status from other sports. ... you know like a climber falls off Mt Cook and it's on the front page of the paper but, some rugby player gets injured and dies and it's just on the sports pages. Yeah it's on, it's in a separate category, and, I think it's a perception of perhaps a higher level of risk than other sports. 
It can be argued that we are all, to a greater or lesser extent, adventurers in the sense Simmel describes, abandoning ourselves to 'the powers and accidents of the world'. We play dice in the casino of life out of both choice and necessity (Adams, 1995), and find our own ways to be comfortable with this, or at least, to go on regardless. 


\section{Chapter 6}

\section{Conclusions}

$[C]$ lose engagement with the ongoing effort to rearticulate the changing human condition under which the 'increasingly individualized individuals' find themselves as they struggle to invest sense and purpose in their lives is, under present circumstances ... the paramount task of sociology.

(Bauman, 2001:13)

This thesis has been concerned with understanding the ways in which New Zealand mountaineers find meaning or purpose in their lives and establish a sense of self through their participation in mountain climbing. I chose to focus the study on people with a high level of commitment to an adventurous leisure pursuit because commitment and continuity, as discussed in Chapter 1, are considered to be under threat in contemporary 'liquid' society. My interest in meaning and self or identity also stems from the concern that current social conditions are not conducive to their maintenance. If commitment to an activity as demanding as mountaineering is to be sustained, I surmised, there must be something to be learned therein with regard to the 'struggle' Bauman identifies in the quote above. Hence, in seeking to elucidate how New Zealand mountaineers grapple with meaning and self in this context, I have endeavoured to contribute to a larger 'task' or, as Bauman sees it, 'the paramount task of sociology'.

However, I must qualify my study in the light of certain limitations: it speaks of a particular group of people (committed mountaineers), in a specific place (Aotearoa/New Zealand), during one historical period (the mid-twentieth century until the early twentyfirst century). As such it is a window into the lives of a small number of people with a rather non-typical leisure pursuit. Nonetheless, as I argued in Chapter 1, by Simmel's reckoning adventure is a form of experiencing which is available to all of us, whether we find it through climbing mountains or not. The elements of adventure - that careful balancing act between the accidentalness of life (or the arbitrariness of fate), and a sense of unity, purpose and an individual ability to influence the course of things - can be found almost anywhere in life if we look for them. Accordingly, in the context of life-meaning and identity, adventure can be seen as being more about how we approach and interpret life, than the specific content of our daily experiences. Also, what is pertinent here is how we link the 'segments' of our lives that can be conceived of as adventures - that is, those episodes that stand outside the ordinary 'continuity of life', containing sufficient tension between the aforementioned elements and possessing their own self-contained meaning - 
back into our sense of who we are and what our lives are about. It is fair to say though, that mountaineers pursue this form of experience with a frequency and intensity that most people do not, and this renders them an illuminating case study by which to examine the existential dilemmas of the human condition, and the ingenious ways found to address them.

The importance of narrative as a means of constructing meaning and self, and hence its appropriateness as a method by which to inquire after these aspects of life, was discussed in Chapters 1 and 2. The biographical narrative approach was a distinctive feature of my study, having not previously been used to investigate mountain climbing. As I have argued, meaning and self or identity cannot be understood outside the context of our life stories and so the participants in this study were asked to tell the story of their lives as mountaineers. In interpreting their narratives, I looked for the ways in which meaning and self were woven from the biographical particulars of their lives, as well as the commonalities among the narratives in terms of the processes used to achieve this; that is, the ways in which this was accomplished within a story about being a mountaineer. I also looked for themes that crossed the boundaries of the individual narratives and thereby represented references to a communal narrative about what it means to be a mountaineer: a meaning and identity constructed within the social world of New Zealand mountaineering, and other broader social narratives.

Throughout Chapters 3, 4 and 5, I positioned my findings in relation to relevant theories concerning the social and historical conditions under which the narratives were constructed. These theories facilitated my interpretation of the narratives in relation to the research questions articulated in Chapter 1: that is, my enquiry into the kinds of meaning committed New Zealand mountaineers attribute to climbing mountains; the ways in which these meanings are integrated into a 'narrative of self' and a sense of purpose in their lives; and the processes which influence and sustain (or constrain) this integration. In this final chapter I summarise the main themes from the previous three chapters and discuss them in the light of the theories of meaning introduced in Chapter 1, in order to reach my final conclusions with regard to the narrative construction of meaning and self in the lives of committed mountaineers. In terms of the conclusions I am able to reach it is important, however, to make the qualification which, according to MacIntyre (1981), should be applied to even the 'best possible available stock of generalisations about social life'; that is: 
They will be based on a good deal of research, but their inductively-founded character will appear in their failure to approach law-likeness. No matter how wellframed they are the best of them may have to co-exist with counter-examples, since the constant creation of counter-examples is a feature of human life. And we shall never be able to say of the best of them precisely what their scope is. It follows of course that they will not entail well-defined sets of counterfactual conditionals. They will be prefaced not by universal quantifiers but by some such phrase as 'Characteristically and for the most part ...'

(MacIntyre, 1981:99)

And so, before I go on to discuss the final conclusions of this study, I must concede that, rather than being able to offer 'law-like' and generalised models about how mountaineers construct meaning and self through a life centred on climbing mountains, the overarching qualifier that applies is: 'characteristically and for the most part'. While some may see this as limiting the usefulness of the research, I stand with MacIntyre in arguing that this is in fact the best one can hope to attain in any effort to understand 'social life'. Human behaviour is not explicable in the same way that the physical world appears to be. Rather, it is in our nature to be able to rise above the 'endowment and environment' that otherwise moulds our actions and intentions, as Frankl (1992:135) has argued. My findings, nevertheless, have implications and these are discussed later in this chapter. Firstly, however, I summarise the main findings of the study and link them to the theories of Frankl (1992; 2000), Fromm (1956b; 1994) and Antonovsky (1987). In doing so, I endeavour to determine whether the meanings constructed around mountaineering can be considered, by the criteria outlined in the works of these theorists, as 'healthy' solutions to the existential dilemmas described in Chapter 1.

In Chapter 3, my first findings chapter, I discussed the narrative construction of self and an individual identity as a mountaineer, which emerged out of the biographical particulars of the lives of my participants. In this process, becoming a mountaineer and being a mountaineer were interwoven. While particular events and experiences were identified as being pivotal in the journey towards becoming, there was also often a sense that they had in fact always been nascent mountaineers. As Sue said, for her it was a "yearning" that "was always there" and she "never really questioned it, it was just me". Whether it was Dave looking at the mountains out his kitchen window, Simon on his first summit at the age of eight "throwing up" on a can of sardines, or Jan clambering alone up hills on family holidays just "to see what was on the other side", the importance of such episodes in a life narrative is lucidly captured by Frankl's (2000:141) insight that the 'perception of meaning' is 'suddenly becoming aware of a possibility against the background of reality'. Through being in the mountains, and climbing mountains, the mountaineers had a strong 
sense of possibility, of being where they were meant to be, and who they were meant to be and become. Self, here, is a feeling: it is Dave's "mountain feeling"; it is Steph feeling "calm", "peaceful"; and it is that "comfortable" or "solid" feeling that others described. Above all, self was a sense of feeling "at home" - of being "where you belong" - even if, as Ricoeur (1992) suggests, this is because our awareness of how we made ourselves at home has sunk to the bottom of our consciousness through a process of 'sedimentation'.

This sense of an innate self is important for creating a story of a continuous and unified self, as such stories are firmly rooted in the past. When they anticipate the future - as life narratives typically do - there is a strong feeling that this core self will not change, as this does not seem possible. Some of the previous research about mountaineering and adventurous leisure, discussed in Chapter 1, commented on its role as a vehicle for finding a 'true self'. However, this research overlooked the way in which this self is narratively constructed, often quite early on, and the resulting narrative anticipates future experiences of self which, when realised, in turn strengthen and confirm the narrative. The mountaineers in my study were not, I would argue, involved in an 'incessant search for self' (Lyng, 1990). Nor were they especially 'divided selves' (Lester, 2004). They already knew who they were. Hence mountain climbing may only be particularly conducive to constructing a continuous, unified self to the extent that one has already 'hung one's self on the mountaineering peg', so to speak.

What is particularly striking about the recalled experiences of self is how closely they align with Fromm's (1994:259) 'moments of spontaneity', or 'moments of genuine happiness'. As discussed in Chapter 1, relating ourselves 'spontaneously to the world' is Fromm's 'healthy' solution to the 'inner contradictions' of human existence. Fromm describes spontaneous activity as 'free activity of the self'. He opposes it to activity undertaken compulsively or in order to be one of the crowd. Neither is it activity in the sense of 'doing something'. Rather, it is the 'quality of creative activity that can operate in one's emotional, intellectual, and sensuous experiences and in one's will as well' (Fromm, 1994:257). Artists, Fromm argues, are an example of individuals who achieve spontaneity more readily than many others; that is, the sense that their 'thinking, feeling, and acting' are the 'true expression of their selves' (Fromm, 1994:258). However, spontaneity and its accompanying 'moments of genuine happiness' can be experienced by all of us in a multitude of ways:

the fresh and spontaneous perception of a landscape, or the dawning of some truth as the result of our thinking, or a sensuous pleasure that is not stereotyped, or the welling up of love for another person - in these moments we all know what a 
spontaneous act is and may have some vision of what human life could be if these experiences were not such rare and uncultivated experiences.

(Fromm, 1994:259)

Although Fromm maintains that the kind of spontaneity he describes is a relatively rare phenomenon in our society, I would argue that the mountaineers in my study often experienced climbing mountains in this way. We have seen above how it is described as the expression of their 'true' selves. While the resulting emotions can be hard to capture in words, the mountaineers often turned to the language of transcendence. For Simon, climbing gave him "the best times in my life", for Dave it was "euphoric", "a wave of good feeling”, and for Jan "it feels like your soul's expanding”. Mark "thrived on" his experiences in the mountains; they were so "amazing" that it was "kind of unreal".

The relevance of spontaneous experiences for the construction of self is that through such activity, an individual 'embraces the world' while at the same time keeping the individual self intact. In this process the self, Fromm (1994:260) argues, 'becomes stronger and more solidified. For the self is as strong as it is active'. 'Genuine happiness' is in 'the experience of the activity in the present moment' (Fromm, 1994:261): we have an awareness of our place in the world; our doubt concerning who we are and where we belong and what it all means, disappears. Such doubt about the purpose of our lives derives in part, according to Fromm (1994:267), from our sense that we are separate and alone. The mountaineers, however, experienced feelings of relatedness and belonging, not only in relation to the mountains, but also to their companions. As discussed in Chapter 4, it was strongly expressed that "true mountaineers" have a deep love and respect for the environment. Jan spoke of her joy in "being among it", "being part of that landscape", and for Pete the mountains were "old friends" and "the real essence of your being". This was a feeling, he said, that "just doesn't go away”. As Dave said, “you just feel so at home, you just feel grounded".

I also argued in Chapter 4 that there was a strong sense of relatedness to one's climbing companions. There was a "fellowship" and "community" that grew out of being part of a tradition with common values, and a shared telos or 'image of the future'. On a more personal and intimate level, there was the "real bond" that developed between people “you've been on a rope with”. As Thomas put it: “we carry responsibility for each other". This, I maintained, equated to Bauman's description of being-for, or the 'bearing of responsibility' for the other, which mountaineers hold as a virtue. As Frankl (1992; 2000) argues, meaning is found through directing ourselves to something outside of 
ourselves, by 'experiencing something or encountering someone' or through 'creating a work or doing a deed'. It is by focusing on something (the mountains or the activity of climbing) or someone other than ourselves (for example, a climbing companion) that we transcend ourselves and thus, somewhat inadvertently, find ourselves. To search for self by merely concentrating on oneself is, by Frankl's account, a potentially fruitless exercise. The mountaineers in this study seem implicitly to recognise this. They expressed it when emphasising that ego - that is, love of self rather than love of the mountains - is not an 'authentic' reason to climb mountains (see Chapter 4). To focus on self is also, they stressed, potentially dangerous, as an over-inflated ego can distort the assessment of one's capabilities and lead to poor judgement (see Chapters 3 and 5).

The other feature of life that underlies a struggle for purpose is what Fromm (1994:267) describes as the thwarting of our 'inherent tendency to grow, to expand, to express potentialities', or as Noyce (1958:225) puts it, our 'urge to expand into the world'. The pre-requisites of spontaneity, Fromm (1994:257) argues, are that 'essential parts' of the self are not repressed, and that one 'has become transparent' to oneself. In the descriptions given by the mountaineers it was more common for them to feel 'repressed' when they were away from the mountains, and not among fellow mountaineers. This was often expressed in terms of feeling misunderstood by other people. For Steph it was the contrast between feeling "happy and comfortable" among other climbers, but "a bit lonely" in the company of non-climbers for extended periods of time. For Lyn it was feeling "restless" and "unsettled" when she did not have a major climbing goal to focus on.

That the mountaineers had 'become transparent' to themselves can be seen in my discussion in Chapter 3 of how they felt mountaineering allowed them to discover, expand and express a "true" sense of self. It was emphasised that mountaineering "teaches you so much about yourself" and that, in turn, you have to "know yourself pretty well" to climb mountains. Another necessary condition for Fromm's spontaneity is a sense that the different spheres of one's life are fundamentally integrated. This was more difficult for some of the mountaineers to achieve than others, and the struggle to find integration was particularly evident in the narratives of Bill, Terry and Jan, as they felt that their mountaineering had conflicted with responsibilities towards family. By contrast, Thomas's life seemed highly integrated, as he felt that his life, his climbing, and his profession as an artist, far from conflicting, actually all influenced and fed into one another. In all cases, however, it seemed that integration was aspired to: it was a "total life experience", what "you base your whole spirituality, your philosophies, your everything around”. 
Knowing what we really want, as opposed to having the 'illusion' of what we want and avoiding it 'by accepting "ready-made" goals', is 'one of the most difficult problems to solve' (Fromm, 1994:251-252). As Steph said, she feels "lucky" to know what it is she wants to do. However, to say that the mountaineers knew who they were and what they wanted to do did not always mean that all their problems were thereby solved. There were still choices to be made and some of the mountaineers worked hard at the 'task' of doing what they felt they were meant to. As Frankl (1992) argues, finding meaning in life is often in the detail, in all the different (and often difficult) choices that we make and live with day by day.

But ultimately, Frankl (2000:32) asserts, being human is about being 'existentially responsible, responsible for one's own existence', and 'authentic existence' is achieved when we make decisions for ourselves. Making choices, as we saw in Chapter 3, was a key part of the mountaineers' narratives of self. Jim made the decision to follow his passion for climbing in order to be a "happier person", rather than to do what was "expected" of him. He felt that it was important to do "what you really enjoy". Dan had also felt torn between what he was "really passionate about", and his sense that he should be "helping people". He found a way through his dilemma by deciding to become an outdoor instructor. Bob had a "revelation" as a young man that working in an office in the city was not what he wanted to do, that there were "many windows to look out of, and that one shouldn't restrict oneself"; that is, there were alternative ways of living, more spontaneous (in Fromm's sense of the word), through which he could find greater personal fulfilment. Kath also made the decision to "give up" what her peers had-boys, parties, university - in order to follow her desire to climb.

While these choices were not always easy to make, and some of the mountaineers were quite troubled by them (particularly Jan, Terry and Bill), they were nevertheless meaningful to the extent that they were decisions in accordance with their narratives about who they were and where they belonged. 'Being true to oneself' is a 'powerful moral ideal' (Taylor in Frank, 2002). Making these decisions also constituted exercising existential responsibility for their lives, and realising or coming to terms with the idea that what they really wanted to do did not equate with a 'ready-made' goal. Assisting them with these choices, as noted in Chapter 3, was the nurturing they received and their identification with other 'like minds' who had made similar decisions. Underlying their ability to maintain their commitment to such choices was the durability of an identity based 
on a passion that could stretch the length of their lives, and provide opportunities to discover, expand and express their sense of self: a self, in other words, that becomes 'stronger' and more 'solidified' because it is kept 'active' through on-going participation. As Pete said, the mountains "make you quite solid".

'Participation in shaping the outcome' is also pertinent to the 'meaningfulness' component of Antonovsky's theory of a sense of coherence. This can be seen not only in the sense of determining the overall shape of one's life, but also as infusing daily experience. Again in Chapter 3, we saw that a sense of self-reliance, of being "left to my own devices", was central to the mountaineers' stories. They liked the sense that their accomplishments depended on their own skills and judgment (or as much as they could depend on them, given the possible intervention of the 'world-as-player', but I return below to the question of chance or luck). Climbing was seen to be an "honest test" or an "honest benchmark" because conditions were not "contrived": whether the outcome was success or failure, the responsibility was one's own. The climbers liked the feeling of "self-control". Jan, in particular, revelled in the feeling of being "competent" and "well-equipped" and of being able to get "ourselves out of our predicament". One of the most distressing times of Jan's life was when she felt that the incompetence of others contributed to a tragedy for which she was later held partly responsible.

While being responsible for the outcomes of one's actions means not only being able to celebrate our successes, but also having to front-up to our failures, it is, for that very reason, vital to the search for meaning in our lives. As Antonovsky (1987:92) puts it: a world 'experienced as being indifferent to what we do comes to be seen as a world devoid of meaning'. He stresses that the important thing here is 'participation in decision making', rather than control necessarily, and this is certainly relevant to climbing. Although one can feel 'in control' in the mountains, it is not an environment that could be considered 'under one's control'. And even feeling 'in control' is not a guaranteed outcome of making one's own decisions.

The remaining two dimensions of Antonovsky's sense of coherence - comprehensibility and manageability - were also evident in the narratives. In Antonovsky's work, comprehensibility refers to the extent to which things appear to be ordered, consistent, structured and clear. While there were aspects of the mountaineers' lives that seemed ambiguous or contradictory, they spoke about "total moments of clarity" in the mountains: of "very simple stuff", of "black and white” decisions, and "immediate feedback of where 
your strength's at". Although, when they were climbing, there were times that they felt out of control, their experiences also frequently met the manageability criteria: in the mountains they were "not distracted", "it never became too hostile", they felt "aware and present" and experienced "easy decision making". They felt that they could look after themselves in an inhospitable environment; they felt "solid" in "nasty" conditions. That feeling is epitomised in the image of Chris traversing "hostile-looking country ... with running shoes and travelling light”.

Antonovsky's observation that people can feel a strong sense of coherence while not necessarily seeing the whole of their lives as being comprehensible, manageable and meaningful, is also pertinent in terms of the narratives examined in this study. In Chapter 4, I argued that the practice and tradition of mountaineering offered a 'solid moral framework' for mountaineers, and their stories were not just about how the world was, but how it should be. Nevertheless, the notion of the 'true' mountaineer was one that was difficult to live up to and was often threatened by other aspects of life, in particular: commitment to families; desire for recognition without seeming to be driven by it; and other "false values" from both inside and outside the climbing world, such as competitiveness, technical dependence and specialisation, seductive "luxuries" and increasing commercialisation and consumerism.

As outlined in Chapter 1, however, Antonovsky argues that in order to maintain a sense of coherence it is not necessary that one's entire life-world should present as a seamless whole. Indeed, the durability of coherence may be substantially assisted by an ability to maintain flexible boundaries around what one considers important, as long as these boundaries encompass 'one's inner feelings, one's immediate interpersonal relations, one's major activities, and existential issues (death, inevitable failures, shortcomings, conflict and isolation)' (Antonovsky, 1987:23). It can be seen from the findings presented throughout this thesis, that these 'critical areas' of life are indeed those which mountaineers attempt to negotiate and address within the 'boundaries' of their narratives.

Inner feelings about who one is and what makes one happy, interpersonal relations and major activities - in this instance mountain climbing - have been covered in various ways so far in this chapter, but the existential issues of death and 'inevitable failures' warrant further discussion. While we may all find meaning in the 'moments of genuine happiness', the mountaineers also strove to find it in suffering and failures. Suffering was often 'between the lines' in the narratives, but it was certainly there, as was the meaning found 
therein. It was there in Mark's understated comment that life had changed "chapters" on him when a climbing accident left him paralysed. It was there for Simon when his close friend died in a climbing accident. The "lesson" he learnt, as we saw in Chapter 5, was that one needed to be "patient". For Jan, the meaning in her suffering was being able to say, in spite of a series of tragic life-events (described in Chapter 4), that the "big lessons of life" were that, no matter how "difficult" or "painful” it gets, "you'll get beyond that; it's only one stage in the process".

Within our 'flexible boundaries' we also need, I would argue, a means of coping with uncertainty and incalculability. As Simmel (1959:257) notes, 'none of us could live one day' without such a strategy, and perhaps the only one on offer is to 'treat that which is really incalculable as if it were calculable'. And while contemporary society endeavours to conceptualise all the dangers and hazards of life as 'risk', that is, something essentially measurable and calculable (see Chapter 5), there are few things in life or mountaineering that can be considered certain and predictable. Nevertheless, we must carry on as if we are, at least in part, masters of our fate, and I have described the ways in which the mountaineers see themselves as being able to develop the competence and ability to make sound judgements about, and avoid or mitigate, the dangers. At the same time, many of them had to account for the apparently "unpredictable", even "bizarre" nature of certain events - when people just seemed to be "in the wrong place at the wrong time" - as possibly more than just the result of incompetence or poor judgment.

While survival strategies are of considerable importance in mountaineering - that is, developing a "sixth sense" of the mountains and learning to climb with a "sensible" attitude and a generous "safety margin" - there was also for many a degree of luck involved. Some spoke of being able to "get away with" "pushing the margins" when younger. A sound strategy for dealing with a degree of randomness is to take note when you get "spanked", to climb with the 'correct' attitude (humility and love of the mountains), and never to "push your luck" in case "your chances run out". When you find yourself in situations of some doubt, sometimes you just need to "decide the job's on" and then, when even your best endeavours fail, you need to be able to accept it and "move on”, as Dave did after surviving three days lying injured in a crevasse, and did Jan, in recovering her confidence after two serious accidents.

Finally, with regards to death, those who spoke of it stressed the need to acknowledge "the possible consequences" and also the potential benefits of being aware of one's mortality. 
This awareness was something that was seen as developing over time. When they were young many saw death and the dangers of climbing as somewhat "unreal", but from their 'brushes with death', and the experiences of others, came a familiarity with death and danger which, as Jess said, "makes you more aware of how precious life is”. Frankl (1992:124) claims that the 'transitoriness of our existence in no way makes it meaningless ... At any moment, man must decide, for better or for worse, what will be the monument of his existence'. Tim decided that the alternative to "accepting death" was to "live in a glass jar”, with the result that "we wouldn't have died but we wouldn't have lived half as well". And not to have climbed mountains - if mountaineering is the means by which you (as Tim also put it) "suck it all up" - would mean "they wouldn't have been the person that they were". As I noted in Chapter 3, not being mountaineers, in some capacity or another, is something the majority of my interviewees could not envisage.

Ultimately, the possibility of death and the loss of friends was something the mountaineers just had to "work through". As Thomas said, "life is not going on forever ... you have to face up to these things". Indeed, in many ways the awareness of mortality provides impetus to continue climbing because the larger death looms in our lives, the greater the need to make life 'a purpose and a task' (Bauman, 1992b). If we were immortal, Bauman (1992a) points out, there would not be the same incentive to imbue our lives - that episode between birth and death - with meaning at all. I argued in Chapter 5 that to continue climbing after the death of friends in the mountains reinforces the meaning of the lost lives, as well as sustaining life-meaning for the living: that climbing mountains is what they love and what makes them who they are. This process plays a large part in their ability to cope with mountaineering deaths and the dangers of climbing. So too does the need, that we all have, to give one nod to death and then carry on as if it does not lurk around the very next corner and, even if it does, that we have the ability and good judgment to give it the slip. Or, as Simmel (1959:257) puts it, we are able to 'entrust our own strength with what it still cannot achieve by itself but only by its enigmatic co-operation with the powers of fate'.

If we cannot 'experience life in the sense of spontaneous activity', Fromm (1994:254) concludes, we take instead 'any kind of excitement and thrill: the thrill of drinking, of sports, of vicariously living the excitements of fictitious persons on the screen'. The mountaineers in my study were not seeking 'thrill' in the way Fromm describes here, as a means to 'escape from freedom'. Rather, they differ in significant ways from the 'sensation-seekers' otherwise found in the literature and theories surrounding adventurous leisure (referred to in Chapter 1). Adventure, Bob argued, is not "an activity which takes 
[you] safely to the edge of something, and gives you a fright”. On the contrary, the mountaineers took care to differentiate themselves from people who wanted "quick thrills" and those they considered not to be "real" adventurers: people who were just interested in "a challenge", rather than having a love for "the environment"; those who were "testosterone-charged" and "people who like talking about themselves"; people who gave up because they could not "keep up", or because the fashions changed and they were more interested in the "the appearance thing and the instant aspect".

Also questionable were those who climbed mountains, but who were not "having fun". As Bill said, "it's what happens on the way that, it's really all about ... Otherwise I don't think it's real mountaineering". As soon as competition and self-seeking creeps into it the spontaneity is gone, and this highlights the importance of the mountaineering virtues discussed in Chapter 4. Also in that chapter I examined the way in which the "moral framework' of the mountaineering tradition, and the nature of their experiences in the mountains, engenders in the mountaineers a sense that they are able to keep things in "perspective", and thereby differentiate between what is "real" and what is not: between what is 'liquid' and what is "solid".

I have moved among the various themes of my findings, in order to position them in relation to the theories of Fromm, Frankl and Antonovsky which were identified in Chapter 1 as being relevant to my enquiry into meaning and self. It is possible now to tie the threads together in order to address the suggestions made by theorists such as Bauman (2001) and Rojek (1993) that, under present social conditions, dedication and commitment are rare. In response to such suggestions one could ask (as I did in Chapter 1): how do committed mountaineers maintain a dedication to their chosen leisure activity characterised by an intensity and durability that eludes others? It is clear from my findings that the meaning with which the mountaineers infuse the mountains and the activity of climbing them, both in their individual biographies and through the socially constructed tradition of mountaineering, provides relatively 'fixed points of orientation' from which they can navigate towards a reasonably 'predictable destination'. This is achieved through commitment to an activity which can be experienced as spontaneous, that is, as expressing and exercising a "true" and durable self. It is also underpinned by the association of this activity with a tradition centred on a shared telos, which in this case is embodied by the ideal of the 'true' mountaineer, and a set of common values, which clarifies "what's important and what isn't". These elements make it possible for committed mountaineers 
to construct a coherent and constant narrative of self and purpose in their lives, given a certain flexibility in their boundaries.

Dubin (1979:405) argues that a 'relevant' sociology should do more than focus on the 'disarticulations between the individual and society'. What is needed, he maintains, are more theoretical models of how people do, nonetheless, succeed in living 'meaningful and worthwhile lives'. In elucidating the processes by which committed New Zealand mountaineers construct a meaningful life around the practice of climbing mountains, I have made a specific contribution to the larger sociological task described by Dubin, and by Bauman at the beginning of this chapter. My enquiry is a story about how certain people struggle with certain social and existential dilemmas, and how they find strategies, however 'home-made' and imperfect, by which to deal with these. This study, therefore, provides an empirical basis from which to reflect upon theories about how social and historical dynamics impact upon individual experience. I have been able to demonstrate the way in which a personal commitment to an adventurous leisure activity such as mountaineering is a means of sustaining self and life-meaning. In addition, by the criteria offered by Fromm, Frankl and Antonovsky, it can be characterised as a constructive solution to the problems of meaninglessness and fragmentation in contemporary life, at least for those in this study.

This is not to deny the 'darker side' and social costs of mountaineering. As I mentioned in Chapter 2, I met some resistance and eventually abandoned my attempts to interview people who had become disillusioned, or had experiences of mountaineering so traumatic that they stopped climbing. Others, with different credentials, have been more successful in this regard. Coffey (2003), whose own partner was killed in a climbing accident, has written a thought-provoking account of the personal costs of mountaineering, focusing particularly on the Himalayas where death rates are relatively high. Ortner (1999), drawing on years of anthropological fieldwork among the Sherpa communities of the Himalaya, gives a revealing account of the cultural dissonance between the Sherpas and the predominantly Western mountaineers who buy their services, and the high price they have paid for the economic benefits of these expeditions. Studies such as these provide a counter-balance to my more positive reading of mountaineering, and suggest that there may be other stories to be told about mountaineering in New Zealand as well. One possible approach for future research would be to follow Coffey's (2003) lead, and interview those who are not climbers themselves, but who have been affected by 
mountaineering tragedies. Wajnryb's (2001) enquiry into the 'silence' of Holocaust survivors may also provide a useful starting point for such research.

I argued, in Chapter 1, that there is a need to move beyond preoccupations with motivations and risk taking as the initial focus of enquiry into mountaineering and other forms of climbing and adventurous leisure. It was my contention that framing research in these terms had perhaps taken us as far as it could towards an understanding of the phenomenon of adventurous leisure. It is time, in my view, to take up on the hints and clues left by certain researchers, and place meaning and self or identity at the centre of the research agenda. In this way we can understand them not merely as an endpoint of participation, but as being integral to, indeed inseparable from, the processes by which we engage in and reflect upon our leisure, and how this in turn shapes our lives, and vice versa. Simmel's observation that adventure as a form of experiencing must connect back to life-meaning and identity, and theories from the likes of Taylor (1989), Bruner (1990; 2002) and MacIntyre (1981) about the need for a coherent biographical narrative and a stable moral framework, have pointed the way towards how leisure and life might be connected in the context of meaning and self.

There are some 'findings' in this research that overlap with elements of previous studies, in particular Stebbins (2005), Kiewa (2001; 2002) and Macaloon \& Csikszentmihalyi (1983). My contribution to this existing body of research has been to draw these elements towards an understanding of the dynamics by which participants construct a sense of who they are and a sense of what is important in their lives through mountaineering. I have also shed new light on the ways in which these are negotiated within an individual life narrative and a communal narrative of the 'true' (in this case, New Zealand) mountaineer. My findings concur with those of other commentators who maintain that 'risk' is not an attraction in and of itself; indeed, as I have argued, 'risk' is a problematic word to be using in the context of adventurous leisure. As an alternative conceptualisation of the issues, I have offered the interpretation that the dangers and uncertainty of mountaineering provide the opportunity to exercise judgement and responsibility for one's existence, to negotiate the elements of adventure (uncertainty, incalculability and our ultimate fate) and to find ways of engaging constructively with the world-as-player. This allows the mountaineers a sense of "clarity" and "perspective" which contributes to the comprehensibility, manageability and meaningfulness of their lives. 
Is mountain climbing in some sense 'caused' by rationalised society, by modernity's excesses, from which we feel compelled to escape? It is certainly not surprising that it has been interpreted as such in some of the literature, just as it is not surprising, given contemporary preoccupations, that 'risk' is what captures the attention of theorists. But, as with the question of 'risk', I would caution here that we should keep an open mind. The work of both Lyng (1990) and Mitchell (1983) demonstrate that, while it is possible to posit current forms of adventure as a direct response to alienation and disillusionment with modernisation, it is far harder to convincingly prove the connection. My response to these problems is a pragmatic one: that the question is perhaps not worth pursuing; that the search for such 'causes' of human behaviour is not ultimately the most fruitful or satisfying line of enquiry. There is more, I believe, to be said for the suggestion that an urge for adventure as a 'form of experiencing', or what the American scholar of comparative mythology Campbell (1991) called 'sacred space', is not peculiar to our age, although aspects of its expression and the meaning we give to it may be. Such a space, which is time 'out of time', will likely always be constructed, at least to some extent, by contrasting it with what is 'in time' in terms of lived experience.

My recommendations for further enquiry would be along the lines of those made by Bauman and Dubin. What is required to advance social theory is not so much the discovery of particular 'causes', as the illumination of the individual 'strategies' put together - sometimes with great thought and deliberation, and sometimes in a more haphazard manner - to help us reconcile ourselves to 'our tragic fate' as it presents itself under current social and historical conditions. Acknowledging this 'bias' of mine, I believe future research that might usefully build on the current study could consider how mountaineers in societies and cultures differing from New Zealand negotiate similar processes, and thus identify more keenly the impact of various socio-cultural factors. This study could also be usefully extended to other forms of adventurous leisure in order to draw conclusions regarding activity-specific influences.

It would also be of interest, in my view, to undertake a study using a similar methodology with a broader range of mountain climbers. This might include: those whose involvement is more sporadic than those in this research and those who have given it up (that is, those whose commitment faltered); those who consistently use a guide when climbing; and those who have turned it into a 'profession', either through competition, guiding, writing, or gaining sponsorship and raising a media 'profile' through a combination of these and other means. It would thereby be possible to represent more accurately those forms of mountain 
climbing which have been depicted as being 'different' to the approach taken by the mountaineers in this study, and thus to gauge how these strategies compare in terms the construction of meaning and self. I also acknowledge that a thorough consideration of the gender differences in biographical narratives, which was not attempted here, is warranted.

I end my 'tale' by bringing both the subject and object back into 'view' (Van Maanen, 1988). If the idea that 'the shortest route from self to self is through other' lies at the heart of hermeneutics (Kearney, 2004:8; italics in original), then the research presented here has also been about situating myself in relation to the other, both those I spoke to, and those 'imagined' others I have written for, in a dialogical relationship which is ultimately a path of understanding that leads back to myself. Thus, the transformative potential of research impacts, not least of all, on the researcher. So it is that the narratives reflect back to us the way in which we see, and do not see, ourselves.

On this final note, I pay tribute to the mountaineers who told me their stories, and thereby allowed me to tell the story that is this thesis. The mountaineering selves that people this study have reinforced for me what an impressive feat it is to negotiate the 'sea of meaning' that is our social world, and to find therein a self that is durable; that is, a sea-worthy vessel; and a meaning and purpose that give shape to their lives; that is, a sense of where they are going, or perhaps have to go, despite lurking fears that the world might indeed be flat. As Bruner (2002:14) says, our 'self' is 'probably the most impressive work of art we ever produce, surely the most intricate'.

While the mountaineers' lives and their narratives were not without tensions and complexities, in a world where we are urged to simply 'work, shop and die', as Beilharz (2000:161) so brutally puts it, it is no small accomplishment to stay afloat, much less to sail about with a good deal of enthusiasm and passion for, and commitment to, the undertaking. And while there are certainly times of tentativeness and contradiction in their lives, it is not necessarily ridding themselves of these that would make their passage ultimately any smoother, as modernity's demise has made apparent. It is rather, as Bauman (2001:138) argues, the cultivation of an 'ability to live daily and at peace with uncertainty and ambivalence', that will see them through. This is Campbell's (1991) 'joyful participation in the sorrows of the world'. Some appear to have achieved this with more ease than others. Sometimes, for example, I felt as if I were expecting tension and contradiction where there was none, and at other times the difficulties and sorrows of their lives were shared with a rawness that humbled me. It is a reminder then, that as long as we 
can maintain a sense of ourselves as 'active and creative' individuals, then we can maintain the sense that 'there is only one meaning of life: the act of living itself' (Fromm, 1994:261; italics in original).

The life stories, of course, are not finished, so there can be no last word, no 'answer to the question, What is the meaning of [a] life?', except that which can 'be given out of one's whole being - one's life is itself the answer to the question of its meaning' (Frankl, 2000:119). As Terry said, mountaineering has "got to be your soul ... you've got to live it”. It is perhaps not so much a meaning, then, as a feeling: a "little piece of joy that you carry around with you". In this case, it is a mountain feeling. 



\section{Bibliography}

Accidents. (1953). New Zealand Alpine Journal, 15(40), 321.

Accidents. (1955a). NZAC Bulletin(26).

Accidents. (1955b). NZAC Bulletin(25).

Adams, J. (1995). Risk. London: UCL Press.

After Caroline, what? (1970). NZAC Bulletin(56), 2-3.

Albert, E. (1999). Dealing with danger: The normalization of risk in cycling. International Review for the Sociology of Sport, 34(2), 157-171.

Allen, S. D. (1987). Risk recreation: A literature review and conceptual model. In J. F.

Meier, T. W. Morash \& G. E. Welton (Eds.), High-Adventure Outdoor Pursuits:

Organization and Leadership (Second ed., pp. 95-130). Columbus, Ohio:

Publishing Horizons, Inc.

The Alpine Club. (1958). New Zealand Alpine Journal, 17(45), 242-243.

Anderson, A. (1953). The pioneers. New Zealand Alpine Journal, 15(40), 277-278.

Annual meeting. (1954). New Zealand Alpine Journal, 15(41), 572-573.

Annual meeting. (1965). New Zealand Alpine Journal, 21(1), 180-181.

Annual meeting. (1966). New Zealand Alpine Journal, 21(2), 358-361.

Annual meeting. (1970). New Zealand Alpine Journal, 23(2), 542-543.

Antonovsky, A. (1987). Unraveling the Mystery of Health: How People Manage Stress and Stay Well. San Francisco; London: Jossey-Bass Publishers.

Atkinson, B. (1981). Mt Cook summer. New Zealand Alpine Journal, 34, 6-24.

Atkinson, P., \& Silverman, D. (1997). Kundera's Immortality: The interview society and the invention of the self. Qualitative Inquiry, 3(3), 304-325.

Barcott, B. (1996, August). Cliffhangers: The fatal descent of the mountain climbing memoir. Harper's Magazine, 64-68.

Bateson, M. C. (1990). Composing a Life. New York: Penguin.

Bauman, Z. (1978). Hermeneutics and Social Science: Approaches to Understanding. London: Hutchinson.

Bauman, Z. (1988). Freedom. Milton Keynes, England; Philadelphia: Open University Press.

Bauman, Z. (1992a). Mortality, Immortality and Other Life Strategies. Stanford, California: Stanford University Press.

Bauman, Z. (1992b). Survival as a social construct. Theory, Culture \& Society, 9, 1-36.

Bauman, Z. (1993). Postmodern Ethics. Oxford, UK \& Cambridge, USA: Blackwell. 
Bauman, Z. (1995). Life in Fragments: Essays in Postmodern Morality. Oxford, UK \&

Cambridge, USA: Blackwell.

Bauman, Z. (1998). Postmodern adventures of life and death. In G. Scambler \& P. Higgs

(Eds.), Modernity, Medicine and Health (pp. 216-231). London: Routledge.

Bauman, Z. (2000). Liquid Modernity. Cambridge: Polity Press.

Bauman, Z. (2001). The Individualized Society. Cambridge: Polity Press.

Beck, U. (1992). Risk Society: Towards a New Modernity (M. Ritter, Trans.). London:

Sage.

Beedie, P. (2003). Mountain guiding and adventure tourism: Reflections on the choreography of experience. Leisure Studies, 22, 147-167.

Beedie, P., \& Bourne, G. (2005). Media constructions of risk: A case study of the Stainforth Beck incident. Journal of Risk Research, 8(4), 331-339.

Beedie, P., \& Hudson, S. (2003). Emergence of mountain-based adventure tourism. Annals of Tourism Research, 30(3), 625-643.

Beilharz, P. (2000). Zygmunt Bauman: Dialectic of Modernity. London: Sage.

Belpoliti, M. (2001). I am a centaur (R. Gordon, Trans.). In M. Belpoliti \& R. Gordon (Eds.), The Voice of Memory: Interviews 1961-1987 / Primo Levi (pp. xvii-xxvi). New York: The New Press.

Berg, D. N., \& Smith, K. K. (Eds.). (1988). The Self in Social Inquiry: Researching Methods. Newbury Park, Calif.: Sage Publications.

Bergmann, F. (1977). On Being Free. Notre Dame, Indiana: University of Notre Dame Press.

Blackshaw, T. (2003). Leisure Life: Myth, Masculinity and Modernity. London and New York: Routledge.

Blame for accidents. (1954). NZAC Bulletin(24).

Bondi, L. (2003). Empathy and Identification: Conceptual Resources for Feminist

Fieldwork. Unpublished manuscript, University of Edinburgh.

Boone, C., \& Gerits, P. (1996). Locus of control, sensation seeking, and stress.

Psychological Reports, 79, 1307-1312.

Boyne, R. (2003). Risk. Buckingham; Philadelphia: Open University Press.

Bratton, R. D., Kinnear, G., \& Koroluk, G. (1979). Why man climbs mountains. International Review for the Sociology of Sport, 2, 23-36.

Breakspear, C., \& Hamilton, C. (2004). Getting a Life: Understanding the Downshifting Phenomenon in Australia. Canberra: The Australia Institute.

Breashears, D. F. (1997). The siren song of Everest. National Geographic, 192(3), 124135. 
Breivik, G. (Ed.). (1999a). Sensation Seeking in Sport. Oslo: Norges idrettshøgskole; Institutt for sammfunnsfag.

Breivik, G. (Ed.). (1999b). Empirical Studies of Risk Sports. Oslo: Norges idrettshøgskole; Institutt for sammfunnsfag.

Brown, J. R. (1996). The I in Science: Training to Utilize Subjectivity in Research. Oslo: Scandinavian University Press.

Bruner, J. (1990). Acts of Meaning. Cambridge, Mass.; London: Harvard University Press. Bruner, J. (1995). Meaning and self in cultural perspective. In D. Bakhurst \& C.

Sypnowich (Eds.), The Social Self (pp. 18-29). London: Sage.

Bruner, J. (1996). Frames for thinking: Ways of making meaning. In D. R. Olson \& N.

Torrance (Eds.), Modes of Thought: Explorations in Culture and Cognition (pp. 93105). Cambridge: Cambridge University Press.

Bruner, J. (1999). Narratives of aging. Journal of Aging Studies 13(1), 7.

Bruner, J. (2002). Making Stories: Law, Literature, Life. New York: Farrar, Straus and Giroux.

Bruner, J. (2004). Life as narrative. Social Research, 71(3), 691-710.

Buchanan, R. (1998). Dying to climb. Women's Sport and Fitness, 1(9), 118-123.

Buhl, H. (1956). Nanga Parbat Pilgrimage (H. Merrick, Trans.). London: Hodder and Stoughton.

Bulletin interviews Murray Jones. (1973). NZAC Bulletin(60/3), 21-24.

Campbell, J. (1991). Reflections on the Art of Living: A Joseph Campbell Companion. New York: HarperCollins.

Cary, L. J. (1999). Unexpected stories: Life history and the limits of representation. Qualitative Inquiry, 5(3), 411-427.

Ceglowski, D. (1997). That's a good story, but is it really research? Qualitative Inquiry, 3(2), 188-201.

Celsi, R. L., Rose, R. L., \& Leigh, T. W. (1993). An exploration of high-risk leisure consumption through skydiving. Journal of Consumer Research, 20(1).

Cherry-Garrard, A. (1937). The Worst Journey in the World: Antarctic 1910-1913. London: Chatto \& Windus.

Clandinin, D. J., \& Connelly, F. M. (1998). Personal experience methods. In N. K. Denzin \& Y. S. Lincoln (Eds.), Collecting and Interpreting Qualitative Materials (Second ed., pp. 150-178). Thousand Oaks, Calif.: Sage Publications.

Clandinin, D. J., \& Connelly, F. M. (2000). Narrative Inquiry: Experience and Story in Qualitative Research. San Francisco: Jossey-Bass Publishers.

Climbing. (1971). New Zealand Alpine Journal, 24(1), 214. 
The climbing season. (1964). New Zealand Alpine Journal, 20(51), 390.

Coffey, M. (2003). Where the Mountain Casts Its Shadow: The Personal Costs of

Climbing. London: Hutchinson.

Competitiveness in climbing. (1972). NZAC Bulletin(59/5), 2-3.

Cottle, T. J. (2002). On narratives and the sense of self. Qualitative Inquiry, 8(5), 535-549.

Creese, C. (1982). Frigid boogie. New Zealand Alpine Journal, 35, 16-18.

Creyer, E. H., Ross, W. T., \& Evers, D. (2003). Risky recreation: An exploration of factors influencing the likelihood of participation and the effects of experience. Leisure Studies, 22(July), 239-253.

Crumley, J. (1996, 5 July). A dignity shattered like ice. New Statesman, 32.

Csikszentmihalyi, M. (1975). Beyond Boredom and Anxiety. San Francisco: Jossey-Bass.

Csikszentmihalyi, M. (1990). Flow: The Psychology of Optimal Experience. San Francisco: Jossey-Bass.

Damasio, A. (1999). The Feeling of What Happens: Body and Emotion in the Making of Consciousness. London: Heinemann.

Davidson, L. (2002). The 'Spirit of the Hills': Mountaineering in Northwest Otago, New Zealand 1882-1940. Tourism Geographies, 4(1), 44-61.

Davidson, L. (2004). Tragedy in the adventure playground: Narratives of risk and responsibility in the newspaper reporting of mountaineering accidents in New Zealand. In W. Frost, G. Croy \& S. Beeton (Eds.), International Tourism and Media Conference Proceedings (pp. 39-50). Narre Warren, Vic. : Tourism Research Unit, Monash University.

Davidson, L. (2005). Losing that wilderness feeling: Mountain recreation and aircraft access in New Zealand's national parks, International Symposium on Society and Resource Management. Ostersund, Sweden: Mid Sweden University.

Davies, D. J. (2005). A Brief History of Death. Malden, MA: Blackwell Publishing.

Davis, C. G., \& Nolen-Hoeksema, S. (2001). Loss and meaning: How do people make sense of loss? American Behavioral Scientist, 44(5), 726-741.

de Léséleuc, E., Gleyse, J., \& Marcellini, A. (2002). The practice of sport as political expression? Rock climbing at Claret, France. International Sociology, 17(1), 73-90.

Denison, J. (1996). Sport narratives. Qualitative Inquiry, 2(3), 351-362.

Denison, J., \& Rinehart, R. (2000). Introduction: Imagining sociological narratives. Sociology of Sport Journal, 17, 1-4.

Denz, B. (1981). Headwall. New Zealand Alpine Journal, 34, 87-92.

Denzin, N. K. (1970). The Research Act in Sociology. Chicago: Aldine.

Denzin, N. K. (1989). Interpretive Biography. Newbury Park: Sage. 
Denzin, N. K. (2000). The practices and politics of interpretation. In N. K. Denzin \& Y. S. Lincoln (Eds.), The Handbook of Qualitative Research (Second ed., pp. 897-922). Thousand Oaks, Calif.: Sage Publications.

Denzin, N. K. (2001a). Interpretive Interactionism (Second ed.). Thousand Oaks: Sage.

Denzin, N. K. (2001b). The reflexive interview and a performative social science.

Qualitative Research, 1(1), 23-46.

Diamond, C. (2001). Who are we? The Climber(38), 18.

Donnelly, P. (1981a). Climbing is character building: The second of four fallacies.

Mountain(82), 20-23.

Donnelly, P. (1981b). Four fallacies. Mountain(80), 38-40.

Douglas, M. (1992). Risk and Blame: Essays in Cultural Theory. London: Routledge.

Dube, S. C. (1984). Development Perspectives for the 1980s. Kuala Lumpur: Pelanduk Publications.

Dubin, R. (1979). Central life interests: Self-integrity in a complex world. Pacific Sociological Review, 22(4), 405-426.

Editorial. (1972). NZAC Bulletin(59/4), 2.

Elliott, J. (2005). Using Narrative in Social Research: Qualitative and Quantitative Approaches. London; Thousand Oaks; New Delhi: Sage.

Ellis, C., \& Bochner, A. P. (2000). Autoethnography, personal narrative, reflexivity: Researcher as subject. In N. K. Denzin \& Y. S. Lincoln (Eds.), The Handbook of Qualitative Research (Second ed., pp. 733-768). Thousand Oaks, Calif.: Sage Publications.

Elmes, M., \& Barry, D. (1999). Deliverance, denial, and the death zone: A study of narcissism and regression in the May 1996 Everest climbing disaster. The Journal of Applied Behavioral Science, 35(2), 163-187.

Elsrud, T. (2001). Risk creation in travelling: Backpacker adventure narration. Annals of Tourism Research, 28(3), 597-617.

Erikson, E. H. (1959). Identity and the Life Cycle; Selected Papers, with a Historical Introduction by David Rapaport. New York: International Universities Press.

Erikson, E. H. (1965). Childhood and Society. Harmondsworth: Penguin.

The ethics of criticism. (1953). NZAC Bulletin(21).

Ewert, A. (1987a). Emerging trends in outdoor adventure recreation. In J. F. Meier, T. W. Morash \& G. E. Welton (Eds.), High-Adventure Outdoor Pursuits: Organization and Leadership (Second ed.). Columbus, Ohio: Publishing Horizons, Inc.

Ewert, A. (1987b). Research in outdoor adventure: Overview and analysis. The Bradford Papers Annual, 2, 15-28. 
Ewert, A. (1989). Outdoor Adventure Pursuits: Foundations, Models, and Theories.

Scottsdale, Arizona: Publishing Horizons, Inc.

Ewert, A. (1993). Differences in the level of motive importance based on trip outcome, experience level and group type. Journal of Leisure Research, 25(4), 335-349.

Ewert, A. (1994). Playing the edge: Motivation and risk taking in a high-altitude wildernesslike environment. Environment and Behavior, 26(1), 3-24.

F.M.C. Matters. (1950). NZAC Bulletin(12), 9.

Farley, F. (1986). The big T in personality; thrill-seeking often produces the best achievers but it can also create the worst criminals. Psychology Today, 20, 44-51.

Feher, P., Meyers, M. C., \& Skelly, W. A. (1998). Psychological profile of rock climbers: State and trait attributes. Journal of Sport Behavior, 21(2), 167-180.

Fluker, M. R., \& Turner, L. W. (2000). Needs, motivations, and expectations of a commercial whitewater rafting experience. Journal of Travel Research, 38(4), 380389.

Frank, A. W. (2002). Why study people's stories? A dialogical ethics of narrative analysis. International Journal of Qualitative Methods, 1(1), Article 6. Retrieved 21.03.06 from http://www.ualberta.ca/ ijqm/.

Frank Smythe. (1950). New Zealand Alpine Journal, 13(37), 289-292.

Franken, R. E., Gibson, K. J., \& Rowland, G. I. (1992). Sensation seeking and the tendency to view the world as threatening. Personality and Individual Differences, 13, 31-38.

Frankl, V. E. (1992). Man's Search for Meaning: An Introduction to Logotherapy (I. Lasch, Trans. fourth ed.). Boston: Beacon Press.

Frankl, V. E. (2000). Man's Search for Ultimate Meaning. Cambridge, MA: Perseus.

Frohlick, S. E. (2003). Negotiating the "global" within the global playscapes of Mount Everest. Canadian Review of Sociology and Anthropology 40(5), 525-542.

Fromm, E. (1956a). Man for Himself: An Enquiry into the Psychology of Ethics. London: Routledge \& Kegan Paul.

Fromm, E. (1956b). The Sane Society. London: Routledge \& Kegan Paul.

Fromm, E. (1973). The Anatomy of Human Destructiveness. New York: Holt, Rinehart and Winston.

Fromm, E. (1994). Escape from Freedom. New York: Henry Holt and Company.

Fromm, E. (1999). On Being Human. New York: Continuum.

Funkenstein, A. (1993). The incomprehensible catastrophe: Memory and narrative. In R. Josselson \& A. Lieblich (Eds.), The Narrative Study of Lives (Vol. 1, pp. 21-29). Newbury Park: Sage Publications. 
Furedi, F. (2005). Culture of Fear: Risk-taking and the Morality of Low Expectation (Revised ed.). London: Continuum.

Gallas, F. E. (1968). Letter to the Editor. NZAC Bulletin(51), 42.

Galloway, D. (1972). Alpine creativity - Understanding or renaissance? New Zealand Alpine Journal, 25, 127-128.

Gergen, K. J. (1991). The Saturated Self: Dilemmas of Identity in Contemporary Life. New York: Basic Books.

Gergen, K. J., \& Gergen, M. M. (1993). Narratives of the gendered body in popular autobiography. In R. Josselson \& A. Lieblich (Eds.), The Narrative Study of Lives (Vol. 1, pp. 191-218). Newbury Park: Sage Publications.

Gergen, K. J., \& Gergen, M. M. (2000). Qualitative inquiry: Tensions and transformation. In N. K. Denzin \& Y. S. Lincoln (Eds.), The Handbook of Qualitative Research (Second ed., pp. 1025-1046). Thousand Oaks, Calif.: Sage Publications.

Gervasutti, G. (1979). Gervasutti's Climbs (Second ed.). Seattle: The Mountaineers. Giddens, A. (1991). Modernity and Self-Identity: Self and Society in the Late Modern Age. Cambridge, U.K.: Polity Press.

Gilkison, J. (1965). An unfinished partnership. New Zealand Alpine Journal, 21(1), 73-77. Gillman, P. (1997). Folly's peak. World Press Review, 44(11), 44-45.

Glaser, B. G., \& Strauss, A. (1968). The Discovery of Grounded Theory. London: Weidenfeld and Nicholson.

Goddard, P. (2002). A green boat and big dreams. New Zealand Alpine Journal, 54, 56-60. Goffman, E. (1959). The Presentation of Self in Everyday Life. Garden City, NY: Doubleday.

Gonzales, L. (2003). Deep Survival: Who Lives, Who Dies, and Why. New York; London: W. W. Norton \& Company.

Gordon, R. S. C. (2001). Primo Levi's Ordinary Virtues: From Testimony to Ethics. Oxford: Oxford University Press.

The gradual approach. (1955). New Zealand Alpine Journal, 16(42), 1-4.

Green, W. S. (1883). The High Alps of New Zealand. London: Macmillan.

Gubrium, J. F., \& Holstein, J. A. (1998). Narrative practice and the coherence of personal stories. The Sociological Quarterly, 39(1), 163-187.

Hansen, P. H. (1995). Albert Smith, the Alpine Club, and the invention of mountaineering in mid-Victorian Britain. Journal of British Studies, 34, 300-324.

Hasell, G. E. (1962). 92 per cent avoidable: Analysis of fatalities since 1945. NZAC Bulletin(39), 11-13. 
Heath, R. P. (1997). You can buy a thrill: Chasing the ultimate rush. American Demographics, 19(6), 47-51.

Heller, A. (1993). A theory of needs revisited. Thesis Eleven(35), 18-35.

Heywood, I. (1994). Urgent dreams: Climbing, rationalization and ambivalence. Leisure Studies, 13(3), 179-194.

Hollway, W., \& Jefferson, T. (1997). Eliciting narrative through the in-depth interview. Qualitative Inquiry, 3(1), 53-70.

Holstein, J. A., \& Gubrium, J. F. (2000). The Self We Live By: Narrative Identity in a Postmodern World. New York; Oxford: Oxford University Press.

Holyfield, L. (1999). Manufacturing adventure: The buying and selling of emotions. Journal of Contemporary Ethnography, 28(1), 3-32.

Honderich, T. (Ed.). (1995). The Oxford Companion to Philosophy. Oxford; New York: Oxford University Press.

Hones, D. F. (1998). Known in part: The transformational power of narrative inquiry. Qualitative Inquiry, 4(2), 225-249.

How conservative are we? (1971). New Zealand Alpine Journal, 14(1), 1-2.

Huizinga, J. (1950). Homo Ludens. Boston: Beacon Press.

An interview with Bill Denz. (1977). NZAC Bulletin(64/1), 12-20.

Into the mainstream? (1970). New Zealand Alpine Journal, 13(2), 323-324.

Jarvinen, M. (2000). The biographical illusion: Constructing meaning in qualitative interviews. Qualitative Inquiry, 6(3), 370-391.

Jenkins, M. (1994). Ad-'ven-ture: Webster's defines it simply, but have we lost the meaning of the word? Backpacker, 22(1), 88-89.

Jenkinson, B. (1970). Professionalism. NZAC Bulletin (55), 18-23.

Jennings, G. (2005). Caught in the irons: One of the lived experiences of long-term ocean cruising women. Tourism Review International, 9(2), 195-211.

Jill Tremain. (1974). New Zealand Alpine Journal, 27, 122-123.

Johnston, B. R., \& Edwards, T. (1994). The commodification of mountaineering. Annals of Tourism Research, 21(3), 459-478.

Jones, M. (1980). Untitled. New Zealand Alpine Journal, 33, 62.

Kearney, R. (2004). On Paul Ricoeur: The Owl of Minerva. Boston College, USA: Ashgate.

Kiewa, J. (2001). Control over self and space in rockclimbing. Journal of Leisure Research, 33(4), 363-382.

Kiewa, J. (2002). Traditional climbing: Metaphor of resistance or metanarrative of oppression? Leisure Studies, 21, 145-161. 
King, M. (2003). The Penguin History of New Zealand. Auckland: Penguin Books.

Klein, G. (2001). Sources of Power: How People Make Decisions. Cambridge, MA; London: MIT Press.

Kohut, H. (1982). Advances in Self Psychology. (A. Goldberg, Ed.). New York: International Universities Press.

Le Breton, D. (2000). Playing symbolically with death in extreme sports. Body \& Society, 6(1), 1-11.

Le Breton, D. (2004). The anthropology of adolescent risk-taking behaviours. Body \& Society, 10(1), 1-15.

Lester, J. (1987). A psychologist on Mt. Everest. In J. F. Meier, T. W. Morash \& G. E. Welton (Eds.), High Adventure Outdoor Pursuits: Organization and Leadership (pp. 160-179). Columbus, Ohio: Publishing Horizons, Inc.

Lester, J. (2004). Spirit, identity, and self in mountaineering. Journal of Humanistic Psychology, 44(1), 86-100.

A letter from Charlie. (1981). New Zealand Alpine Journal, 34, 129.

Levenson, M. R. (1990). Risk taking and personality. Journal of Personality and Social Psychology, 58, 1073-1080.

Levi, P. (1987). If This is a Man. London: Abacus.

Levi, P. (2002). Moments of Reprieve (R. Feldman, Trans.). London: Penguin.

Levin, J. D. (1992). Theories of the Self. Washington, DC: Taylor \& Francis.

Levine, D. N. (1971). Introduction. In D. N. Levine (Ed.), George Simmel: On Individuality and Social Forms. Chicago: University of Chicago Press.

Lewis, N. (2000). The climbing body, nature and the experience of modernity. Body \& Society, 6(3-4), 58-80.

Lightfoot, C. (1997). The Culture of Adolescent Risk-taking. New York; London: Guilford Press.

Lincoln, Y. S., \& Denzin, N. K. (2000). The seventh moment: Out of the past. In N. K. Denzin \& Y. S. Lincoln (Eds.), The Handbook of Qualitative Research (Second ed., pp. 1047-1065). Thousand Oaks, Calif.: Sage Publications.

Lincoln, Y. S., \& Guba, E. G. (1985). Naturalistic Inquiry. Beverly Hills, Calif.: Sage Publications.

Linde, C. (1993). Life Stories: The Creation of Coherence. New York; Oxford: Oxford University Press.

Lipscombe, N. (1999). The relevance of the peak experience to continued skydiving participation: A qualitative approach to assessing motivations. Leisure Studies, 18, 267-288. 
Loewenstein, G. (1999). Because it is there: The challenge of mountaineering ... for Utility Theory. Kyklos, 52, 315-344.

Logan, H. (1980). The seventies: A decade of New Zealand climbing. New Zealand Alpine Journal, 33, 50-54.

Lunn, A. (1957). A Century of Mountaineering 1857-1957. London: Allen \& Unwin.

Lyng, S. (1990). Edgework: A social psychological analysis of voluntary risk taking. American Journal of Sociology, 95(4), 851-886.

Macaloon, J., \& Csikszentmihalyi, M. (1983). Deep play and the flow experience in rock climbing. In J. C. Harris \& R. J. Park (Eds.), Play, Games and Sport in Cultural Contexts (pp. 361-384). Champaign, Illinois: Human Kinetics Publishers.

Maccoby, M. (1995). Why Work? Motivating the New Workforce (Second ed.). Alexandria, Virginia: Miles River Press.

MacFarlane, R. (2004). Mountains of the Mind: Adventures in Reaching the Summit. New York: Vintage Books.

MacIntyre, A. (1981). After Virtue: A Study in Moral Theory. London: Duckworth.

Manning, P. K. (1999). High risk narratives: Textual adventures. Qualitative Sociology, 22(4), 285-299.

Matous, R. (1992). Quest for the summit. Parabola, 17(4), 10-15.

Maykut, P., \& Morehouse, R. (1994). Beginning Qualitative Research: A Philosophical and Practical Guide. London: The Falmer Group.

McCarthy, J. (2002). A theory of place in North American mountaineering. Philosophy and Geography, 5(2), 179-194.

McIntyre, N. (1992). Involvement in risk recreation: A comparison of objective and subjective measures of engagement. Journal of Leisure Research, 24(1), 64-71.

Meier, K. V. (1976). The kinship of the rope and the loving struggle: A philosophical analysis of communication in mountain climbing. Journal of the Philosophy of Sport, III, 52-64.

Messner, R. (1979). Everest. London: Kaye \& Ward.

Miké, V. (2000). Seeking the truth in a world of chance. Technology in Society, 22, $353-$ 360.

Miller, J., \& Glassner, B. (1997). The 'Inside' and the 'Outside': Finding realities in interviews. In D. Silverman (Ed.), Qualitative Research: Theory, Method and Practice (pp. 99-112). London: Sage.

Mills, C. W. (1940). Situated actions and vocabularies of motive. American Sociological Review, 5, 904-913. 
Mishler, E. G. (1986). The analysis of interview-narratives. In T. R. Sarbin (Ed.), Narrative Psychology: The Storied Nature of Human Conduct (pp. 233-255). New York: Praeger.

Mitchell, R. G. (1983). Mountain Experience: The Psychology and Sociology of Adventure. Chicago and London: University of Chicago Press.

Monasterio, E. (2005). Dying to climb. New Zealand Alpine Journal, 57, 135-137.

Morin, K. M., Longhurst, R., \& Johnston, L. (2001). (Troubling) spaces of mountains and men: New Zealand's Mount Cook and Hermitage Lodge. Social \& Cultural Geography, 2(2), 117-139.

Mount Cook fatality, February 1955. (1956). New Zealand Alpine Journal, 16(43), 540.

Mountain dangers. (1953). NZAC Bulletin(20).

Mountains of money. (1995, August 26). The Economist, 34.

Nationhood and identity. (2006). In J. Phillips (Ed.), Te Ara: The Encyclopedia of New Zealand. Wellington, N.Z.: Ministry of Culture and Heritage. Retrieved 17.05.06 from http://www.teara.govt.nz/NewZealandInBrief/GovernmentAndNation/9/en.

No room at the top; Climbing Everest; Too many climbers on Mount Everest. (2001, June 2). The Economist (US), 4.

Nolan, T. (1953). Reflections of an exiled hillman. New Zealand Alpine Journal, 15(40), 268-270.

Nordland, R. (1997, May 26). The gods must be angry. Newsweek, 44-45.

Noy, C. (2004). This trip really changed me: Backpackers' narratives of self-change. Annals of Tourism Research, 31(1), 78-102.

Noyce, W. (1958). The Springs of Adventure. London: John Murray.

Olivier, S. (2006). Moral dilemmas of participation in dangerous leisure activities. Leisure Studies, 25(1), 95-109.

Olssen, E. (1981). Towards a new society. In W. H. Oliver (Ed.), The Oxford History of New Zealand. Wellington; New York: Oxford University Press.

Ortner, S. B. (1999). Life and Death on Mount Everest: Sherpas and Himalayan Mountaineering. Princeton, N.J.: Princeton University Press.

Palmer, C. (2002). 'Shit happens': The selling of risk in extreme sport. The Australian Journal of Anthropology, 13(3), 323-336.

Palmer, C. (2004). Death, danger and the selling of risk in adventure sports. In B. Wheaton (Ed.), Understanding Lifestyle Sports: Consumption, Identity and Difference (pp. 55-69). Oxon, UK: Routledge.

Pamphilon, B. (1999). The zoom model: A dynamic framework for the analysis of life histories. Qualitative Inquiry, 5(3), 393-410. 
Patton, M. Q. (1990). Qualitative Evaluation and Research Methods. Newbury Park, Calif:: Sage Publications.

Pause and reflect. (1969). NZAC Bulletin(54), 2.

Pereira, A. L. (2005). The experience of risk in high-altitude climbing. World Leisure(2), $38-49$.

Phipps, M. (1985). Adventure - an inner journey to the self: The psychology of adventure expressed in Jungian terms. Adventure Education Journal, 2(4/5), 11-17.

Pomfret, G. (2006). Mountaineering adventure tourists: A conceptual framework for research. Tourism Management, 27, 113-123.

Prebble, M. (1980). A decade of hirsuto alpinism. New Zealand Alpine Journal, 33, 55.

President of F.M.C. sums up. (1952). NZAC Bulletin(18).

Rabinow, P., \& Sullivan, W. M. (Eds.). (1987). Interpretive Social Science: A Second Look (Second ed.). Berkeley: University of California Press.

Reid, M. D. (2005). Memory as initial experiencing of the past. Philosophical Psychology, 18(6), 671-698.

Richard, C. (1992). On the heights. In R. da Silva (Ed.), Leading Out: Women Climbers Reaching for the Top (pp. 53-67). Seattle: Seal Press.

Ricoeur, P. (1992). Oneself as Another (K. Blamey, Trans.). Chicago: University of Chicago Press.

Ritzer, G. (1988). Sociological Theory (Second ed.). New York: Alfred A. Knopf.

Robbins, D. (1987). Sport, hegemony and the middle class: The Victorian mountaineers. Theory, Culture \& Society, 4, 579-601.

Roberts, B. (2002). Biographical Research. Buckingham: Open University Press.

Roberts, P. (1994). Risk. Psychology Today, 27(6), 50-55.

Robinson, D. W. (1992). A descriptive model of enduring risk recreation involvement. Journal of Leisure Research, 24(1), 52-63.

Rojek, C. (1993). Ways of Escape: Modern Transformations in Leisure and Travel. Basingstoke: Macmillan.

Rosenthal, G. (1993). Reconstruction of life stories: Principles of selection in generating stories for narrative biographical interviews. In R. Josselson \& A. Lieblich (Eds.), The Narrative Study of Lives (Vol. 1, pp. 59-91). Newbury Park: Sage Publications.

Rosenwald, G. C., \& Ochberg, R. L. (1992). Life stories, cultural politics, and selfunderstanding. In G. C. Rosenwald \& R. L. Ochberg (Eds.), Storied Lives: The Cultural Politics of Self-Understanding (pp. 1-18). New Haven and London: Yale University Press.

Ross, M. (1914). A Climber in New Zealand. London: E. Arnold. 
Rossi, B., \& Cereatti, L. (1993). The sensation seeking in mountain athletes as assessed by Zuckerman's Sensation Seeking Scale. International Journal of Sport Psychology, 24, 417-431.

Rouse, K. A. G. (2004). Beyond Maslow's hierarchy of needs: What do people strive for? Performance Improvement, 43(10), 27-31.

Rubin, H. J., \& Rubin, I. S. (1995). Qualitative Interviewing: The Art of Hearing Data. Thousand Oaks: Sage.

Safe-climbing ideology. (1961). NZAC Bulletin(38), 6-8.

Samivel, M. (1949). The place of mountaineering in modern society. New Zealand Alpine Journal, 13(36), 2-6.

Schrader, M. P., \& Wann, D. L. (1999). High-risk recreation: The relationship between participant characteristics and degree of involvement. Journal of Sport Behavior, 22(3), 426-440.

Schueller, G. H. (2000, 29 April). Thrill or chill. New Scientist, 20-24.

Schwandt, T. A. (1999). On understanding understanding. Qualitative Inquiry, 5(4), 451464.

Shoham, A., Rose, G. M., \& Kahle, L. R. (1998). Marketing of risk sports: From intention to action. Journal of the Academy of Marketing Science, 26(4), 307-321.

Silverman, D. (2000). Analyzing talk and text. In N. K. Denzin \& Y. S. Lincoln (Eds.), The Handbook of Qualitative Research (pp. 821-834). Thousand Oaks, Calif.: Sage Publications.

Simmel, G. (1959). The adventurer. In K. H. Wolff (Ed.), Essays on Sociology, Philosophy and Aesthetics (pp. 243-258). New York: Harper \& Row.

Simpson, J. (1988). Touching the Void. London: Vintage.

Slanger, E., \& Rudestam, K. E. (1997). Motivation and disinhibition in high risk sports: Sensation seeking and self-efficacy. Journal of Research in Personality, 31, 355374.

Slemon, S. (1998). Climbing Mount Everest: Postcolonialism in the culture of ascent. Canadian Literature, 158, 15-35.

Slugoski, B. R., \& Ginsburg, G. P. (1989). Ego identity and explanatory speech. In J. Shotter \& K. J. Gergen (Eds.), Texts of Identity (pp. 36-55). London; Newbury Park, Calif.: Sage Publications.

Smith, D. (1999). Zygmunt Bauman: Prophet of Postmodernity. Cambridge: Polity Press.

Stebbins, R. A. (1992). Amateurs, Professionals and Serious Leisure. Montreal: McGillQueen's University Press. 
Stebbins, R. A. (2001). New Directions in the Theory and Research of Serious Leisure.

Lewiston: Edwin Mellen Press.

Stebbins, R. A. (2005). Challenging Mountain Nature: Risk, Motive and Lifestyle in Three Hobbyist Sports. Calgary: Detselig Enterprises Ltd.

Stewart, G. T. (1995). Tenzing's two wrist-watches: The conquest of Everest and late imperial culture in Britain, 1921-1953. Past \& Present(149), 170-197.

Storry, T. (2003). Ours to reason why. Journal of Adventure Education and Outdoor Learning, 3(2), 133-143.

Strang, J. (1980). Increasing awareness. New Zealand Alpine Journal, 33, 63.

Strauss, A., \& Corbin, J. (1998). Basics of Qualitative Research: Techniques and Procedures for Developing Grounded Theory. Thousand Oaks: Sage.

Taveira, M. (1991). Georg Simmel. In P. Beilharz (Ed.), Social Theory: A Guide to Central Thinkers. North Sydney: Allen \& Unwin.

Taylor, C. (1987). Interpretation and the sciences of man. In P. Rabinow \& W. M. Sullivan (Eds.), Interpretive Social Science: A Second Look (pp. 33-81). Berkeley:

University of California Press.

Taylor, C. (1989). Sources of the Self: The Making of Modern Identity. Cambridge, Mass.: Harvard University Press.

Temple, P. (1969). The World at their Feet. Christchurch: Whitcombe \& Tombs.

Tierney, W. G. (2000). Undaunted courage: Life history and the postmodern challenge. In

N. K. Denzin \& Y. S. Lincoln (Eds.), The Handbook of Qualitative Research (pp.

537-553). Thousand Oaks, Calif.: Sage Publications.

A time to ponder. (1964). New Zealand Alpine Journal, 20(51), 217-218.

Unruh, D. R. (1980). The nature of social worlds. Pacific Sociological Review, 23(3), 271296.

Unruh, D. R. (1983). Invisible Lives: Social Worlds of the Aged. Beverly Hills, Calif.: Sage.

Van Maanen, J. (1988). Tales of the Field: On Writing Ethnography. Chicago; London: University of Chicago Press.

Vanreusel, B., \& Renson, R. (1981). The social stigma of high-risk sport subcultures. In A. O. Dunleavy, A. W. Miracle \& C. R. Rees (Eds.), The 2nd Annual Conference of the North American Society for the Sociology of Sport (pp. 183-202). Fort Worth, Texas: Texas Christian University Press.

Vause, M. (2000). Mountaineering: The heroic expression of our age. In A. E. Watson, G. H. Aplet \& J. C. Hendee (Eds.), Personal, Societal, and Ecological Values of Wilderness: Sixth World Wilderness Congress (Vol. II, pp. 83-86). Bangalore, 
India: U.S. Department of Agriculture, Forest Service, Rocky Mountain Research Station.

Vervoorn, A. (1967). Mountaineering accidents. NZAC Bulletin(48), 28-30.

Vervoorn, A. (1969). Letter to the Editor. NZAC Bulletin(53), 26-28.

Vervoorn, A. (1981). Beyond the Snowline. Wellington/Dunedin: A.H. \& A.W. Reed/John McIndoe.

Vervoorn, A. (1990-91). Cultural strata of Hua Shan, the Holy Peak of the West. Monumenta Serica, 39, 1-30.

Vervoorn, A. (2000). Mountain Solitudes: Solo Journeys in the Southern Alps of New Zealand. Nelson, N.Z.: Craig Potton Publishing.

Vester, H.-G. (1987). Adventure as a form of leisure. Leisure Studies, 6, 237-249.

Wajnryb, R. (2001). The Silence: How Tragedy Shapes Talk. Crows Nest, NSW: Allen \& Unwin.

Walter, J. A. (1984). Death as recreation: Armchair mountaineering. Leisure Studies, 3, 6776.

The way ahead. (1971). NZAC Bulletin(57), 2-3.

Wedde, I. (2004, December 11-17). Action Man. Listener, 396, 34-37.

Wendy Butler. (1967). New Zealand Alpine Journal, 22(1), 227-229.

Wengraf, T. (2001). Qualitative Research Interviewing: Biographical Narrative and Semistructured Methods. London: Sage.

Wheaton, B. (Ed.). (2004). Understanding Lifestyle Sports: Consumption, Identity and Difference. Oxon, UK: Routledge.

Whitehouse, I. (1982). Overseas summary. New Zealand Alpine Journal, 35, 79-80.

Who the heck is Charlie Creese? (1982). New Zealand Alpine Journal, 35, 99-104.

Widdershoven, G. A. M. (1993). The story of life: Hermeneutic perspectives on the relationship between narrative and life history. In R. Josselson \& A. Lieblich (Eds.), The Narrative Study of Lives (Vol. 1, pp. 1-20). Newbury Park: Sage Publications.

Wiener, W. W., \& Rosenwald, G. C. (1993). A moment's monument: The psychology of keeping a diary. In R. Josselson \& A. Lieblich (Eds.), The Narrative Study of Lives (Vol. 1, pp. 30-58). Newbury Park: Sage Publications.

Wilson, J. (1968). The religion of a mountaineer. New Zealand Alpine Journal, 22(2), 423 427.

Wolfe, A. (2001). Moral Freedom: The Impossible Idea That Defines the Way We Live Now. New York; London: W. W. Norton \& Company.

Woodbury, R. (1999). Peak season. Time, 154(2), 50. 
Young, G. W. (1951). New Zealand destined to revive the glories that were Greece. NZAC Bulletin(15).

Zuckerman, M. (1979). Sensation Seeking: Beyond the Optimal Level of Arousal.

Hillsdale, N.J.: Lawrence Erlbaum Associates.

Zuckerman, M. (1983). Sensation seeking and sports. Personality and Individual Differences, 4(3), 285-293.

Zuckerman, M., \& Kuhlman, D. M. (2000). Personality and risk-taking: Common biosocial factors. Journal of Personality, 68(6), 999-1029. 
Appendix A

New Zealand Alpine Club membership data

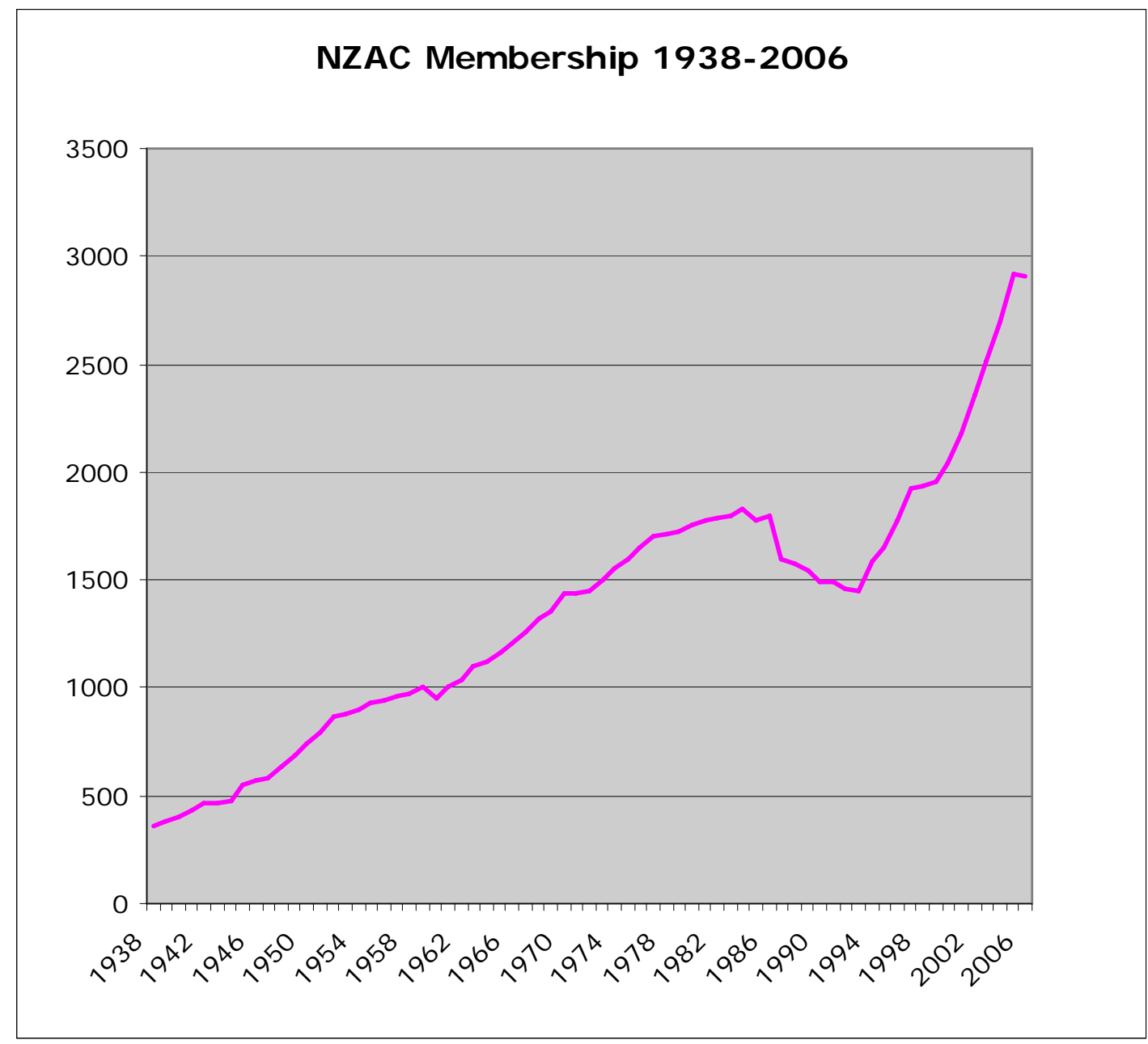

Figure 2: New Zealand Alpine Club Membership 1938-2006 



\section{Appendix B \\ Interview guide}

I Personal narrative

I'd like you please to tell me the story of your experience of climbing, including all those events and experiences which have been important for you, and how your climbing has developed up until now.

You could start with the period in your life when you first became interested in climbing, or wherever you think is relevant.

Please take all the time you need.

I'll listen first, I won't interrupt.

I'll just take some notes for after you've finished telling me about the experiences which have been important for you.

I'll tell you if I think that we are running seriously out of time.

II Elaboration of narrative

Possible question formats:

Can you give me any example of an occasion when ?

Can you give me any more examples of similar events / incidents at that time / of that type?

Was there a particular crucial incident or situation or time that you can recall?

Questions can be asked only of topics which were raised in the initial narrative.

Topics must be addressed in the exact sequence they arose in the narrative.

III Further questions ${ }^{94}$

Tell me about some of your most memorable experiences in the mountains?

${ }^{94}$ Some of these questions have been adapted from Stebbins' (2005) 'Interview guide for study of kayakers'. 
What have been your major achievements in climbing?

What major disappointments have you had in climbing?

Do you experience any tensions or stress in relation to climbing? If yes, how do you deal with it?

Do you ever think about giving up?

Aside from mountaineering, what else is important in your life? What other major achievements have you had? What gives you satisfaction?

How do you see yourself in the future? Still climbing? What are your main goals in life?

How do you think climbing is perceived by society in general? How do you feel about the way that climbing is portrayed in the media?

Do you think climbing is changing/has changed as an activity? If so, how? Why?

Have your attitudes to climbing changed over the years? If so, how? Why? 


\section{Appendix C \\ Interactional issues by interviewee}

\section{Chris}

I interviewed Chris in his small, open-plan home. It was a very friendly and relaxed setting, although I found it difficult initially to get Chris to tell a narrative as he raced over things reasonably quickly, without going into much detail. However I discovered, as the interview went on, that if I waited long enough he would often start talking again after a silence.

Dave

Dave was much more of a storyteller than Chris. He talked for approximately forty-five minutes, without additional prompting, in response to the initial narrative question. He began from his first memories of the mountains, and continued to tell a well-structured narrative, containing many detailed and entertaining stories, as well as comment and selfreflection. In the second and third phases of the interview he spoke at length on the topics raised, and the entire interview lasted almost two hours. Dave came across as someone who was very self-reflective, particularly in comparison to Chris who although he appeared thoughtful and gave his opinions on a number of things, did not speak much about himself.

\section{Bob}

I interviewed Bob in his home in a beautiful natural setting on the West Coast of the South Island. While I tried to focus Bob on telling stories about his life, he tended to talk in quite a 'stream of consciousness' way, sometimes about his own life and sometimes speculating about the nature of adventure and its importance in people's lives. Bob's story was very focused on the 'morals' of adventure.

Jess

Jess's interview took place in the office where she worked. She spoke very confidently, comfortably and quickly, directly answering all my questions with straightforward, matterof-fact answers - yet in a thoughtful way. She came across as being very sensible and her narrative didn't contain any of the on-going questioning and reflection that there had been, for example, in Dave's. 
Pip

I interviewed Pip at the kitchen table in her home that she shares with her partner who is also a climber, and her son. Pip was very happy to talk, and told me as I left that she'd had a lot of time to sit at home while her partner was away on trips and think about why she climbs and whether or not she wants to continue. Pip gave the impression of being very experienced and competent, and yet she didn't talk a lot about the names of particular climbs she had done or their difficulty.

\section{Sue}

Sue spoke easily and in great detail about her climbing trips. She saw the process of participating in the interview as a 'self-indulgence' - an opportunity to produce a full record of her climbing that could become a piece of 'family history' for her children to enjoy later if they became interested. After reading her transcript she wrote several extra pages of reflections, and filled in the gaps with trips that she had later remembered. She was the only participant who approached the interview in this way. Sue's husband was also a climber, but had died recently from an illness, leaving her to raise their three children on her own. I was initially concerned that Sue may find it difficult to talk about her climbing because of the death of her husband. However this did not appear to be the case at all.

\section{Mike}

I interviewed Mike in his living room, and he seemed relaxed and thoughtful, although a little quiet - the classic kiwi 'man of few words'. There were some things, however, that Mike was quite direct about: he said he had expected that I was going to ask him why he climbed, and had been thinking about this beforehand.

\section{Simon}

I interviewed Simon during his lunch break, as he was hoping to leave that evening on a climbing trip. Due to the time constraints his interview was barely an hour long, but he told some interesting stories. Simon reminded me somewhat of Dave. Although he was less talkative, he seemed very thoughtful, and he had a similar slightly 'off-beat' but selfassured manner.

Dan

Dan came to the place where I was staying to be interviewed. He seemed very thoughtful, and throughout the interview he often stared quite intensely out of the window. At the end 
of the interview he was surprised to find that he had been talking for an hour and a half, and said he had felt quite 'spaced out' while he was talking.

\section{Adam}

While Adam hadn't done a lot of alpine climbing, he had a background of 'trad' rock climbing in Australia, and he had just made the decision to give up his $\mathrm{PhD}$ studies and come to New Zealand so that he could focus on his mountaineering. Although still only a 'fledgling' New Zealand-based mountaineer, after meeting him informally first, I decided Adam would be an interesting participant to interview for the perspective of someone just starting out, who had nonetheless made a significant decision to commit himself to climbing.

Tim

Tim was very keen to do the interview and came around the same day that I phoned him. He'd just come out from a trip and it sounded as if he'd had a great time. He was limping around with a big bandage on his foot, having stood on a soldering iron. He'd done it before his last trip but hadn't noticed until the end of a week of climbing, when he took his boot off in the car park and it really started to hurt. Before I'd even finished my initial narrative question, he started talking. He spoke quickly, in short sentences, briefly summarising things, then stopping to wait for the next question. It was hard to get him to describe specific trips in detail. He seemed to have quite a practical, straightforward approach, and not to question himself as much, or find things as ambiguous as some of the others.

Jane

Jane was an enthusiastic story-teller. Although only in her mid twenties, she has been climbing quite consistently for seven years, and described her many trips in great detail, though she kept checking to see if I was interested in hearing more.

Kath

While Kath was very keen to help with my research, I found it a little difficult to get her to talk about her climbing in detail. She answered my questions directly and without much elaboration. In retrospect I felt that the very straightforwardness of the interview was interesting. Unlike many of the others, she didn't talk about anything in particular that she loved about climbing, and I didn't get the sense that she enjoyed talking about it. Climbing was what she did, and she said that she didn't really feel a need to rationalise it. She may 
have also felt that she didn't have anything particularly interesting to say, or that she couldn't articulate it very well. She said she had been interviewed once before and when she read back over the transcript she thought 'what a load of rubbish' and thought that it wouldn't be very useful. She often asked me to explain in more detail what I meant by certain questions, and asked me whether what she had said made sense.

Pete

Pete was very friendly and really seemed to enjoy talking, although early on in the interview he became a bit emotional when telling a story about a friend who had died. This was the first experience I'd had of someone becoming upset during an interview, and I felt a little upset myself that I had prompted him to remember this event. I waited quietly as Pete composed himself. Later he came back to the subject of friends dying and was more composed. The remainder of the interview was very comfortable, lasting more than two hours.

\section{Terry}

Terry was full of fun. He had a similar sense of irreverence as Bob, and the most memorable things for him seemed to be the "daft" and the "funny". On one wall of the room where we sat in his home was a painting of Mount Pollux, and on the other a pair of old climbing boots and a rope. Terry was another wonderful story-teller, speaking about and reflecting on his climbing effortlessly. The only time he faltered in the narrative was when talking about how his passion for mountaineering placed a strain on and ultimately ended his marriage of thirty years. At the end of the interview he read me a long extract from a book he loved. As he read the closing lines tears welled in his eyes. I felt moved that he had shared this with me in his effort to demonstrate how much it meant to him to be a mountaineer.

\section{Thomas}

Thomas was someone I had met previously on a climbing trip. When I went to his house to interview him he greeted me like an old friend. It was pleasant and relaxing talking to him. He spoke easily about things, stopping to check a few times to see if he was 'on the right track'. He expressed some strong views about attitudes towards climbing, but at the same time he was very modest, saying he didn't know if it would be any use to me and that he wouldn't be offended if I didn't use any of it. 
Steph

I interviewed Steph in a Department of Conservation staff house at Mount Cook where she was staying with friends between climbing trips. It wasn't an ideal setting, but it seemed to be the only way that I was going to get a chance to talk to her. In some respects it gave me an interesting insight into her life. It was cluttered and we had to sit on the floor. We were frequently interrupted by people coming in and out, though none of this seemed to faze her in telling her narrative. From what I had heard about Steph's mountaineering before I met her, I expected someone very confident and perhaps quite extroverted. On the contrary, she spoke quietly, reflectively and in a very measured, almost understated way. She seemed to be a very calm person, who also had a gentle sense of humour which I was able to see through her interaction with her friends (otherwise I would have thought she was quite serious).

Bill

I sat with Bill in the garden of his home, overlooking the sea. At first he seemed somewhat unsure of what I expected of him, as if he was uncomfortable with the idea of being interviewed. Perhaps he thought that I might be judgmental, or that I expected him to give me a well-formed, articulate philosophy of climbing. After a bit of a chat he seemed to relax and he started telling a wonderful narrative. After about ten minutes however, he asked me to switch off the tape recorder, so I continued just taking notes. Later he offered to lend me a manuscript written by a friend of his who is a climber. He'd also made me a copy of a life history project a student had once done on him, and some stories he'd written about trips that he had done.

Lyn

Lyn came to the motel where I was staying for her interview. She had been climbing for the day and seemed to be someone with a lot of energy. She spoke very directly, often stopping to ask whether or not she had answered my question. She also often gave an explanation or rationalisation for her climbing, with statements like: "that's why I climb". She had obviously assumed that this was what I was interested in. She also often asked me whether what she had said made sense.

\section{Mark}

I spoke with Mark on the deck of his home. He told wonderfully detailed stories and almost seemed to get lost in the telling, pausing, closing his eyes, remembering things vividly. I'd met him for the first time the evening before the interview and he'd joked that 
he was making up stories to tell me, but once he started talking he was serious and sincere, and generous with his thoughts and feelings. He told his narrative up until the point immediately prior to an accident in which he had sustained injuries that ended his climbing career. I respected his desire not to talk about the accident and didn't question him about it. At the end of the interview he said, half-joking, that he'd probably sit around feeling sorry for himself for the rest of the day. The evening after the interview I was invited for dinner at Mark's with a group of friends. That evening, he brought out his photo album to show me, and spoke about the accident.

Jan

Jan's was the longest interview, and the most detailed and inclusive narrative, lasting almost three hours. She carefully went through her life in (mostly) chronological order right up to present day, including climbing, family and work. She included, in generous detail, a number of traumatic events that had impacted on her life. In fact, she was tearful several times during the interview. I was touched by her openness about certain painful parts of her life. Jan also referred me to a number of articles that she had written for NZAC publications.

Phil

Phil's interview took place a year later than the others. My interest in interviewing him arose from the number of references I was finding, in the earlier interviews as well as NZAC publications, to the generation of climbers in the 1970s who were using new techniques and equipment from overseas to climb in a new style and at a new level in New Zealand. This group had inspired many climbers that came after them. I decided it would be important that at least one of interviews was with someone who had been active within this generation of climbers. At the first opportunity I made a trip back to the South Island to interview Phil. On meeting him, I was impressed and somewhat surprised by the friendly and unassuming demeanour of someone with a reputation for climbing difficult and demanding routes. He was quite softly spoken, very good humoured and accommodating. I arrived at his house in the evening so that I could interview him after work. I met his wife and one of his daughters, and we broke the interview part way through to have dinner together. 


\section{Appendix D \\ Example of a 'condensed' narrative}

Dan

Dan's original transcript was 11,600 words. This 'condensed' version reduces it to 4,000 words.

\section{$\underline{\text { Interactional }}$}

Dan had quite a thoughtful, pondering slant on things and it was actually quite difficult to get him to give much specific details. He often asked for assurance that he was on the track in terms of answering my questions. Throughout the interview he stared quite intensely out the window. At the end he said he felt quite 'spaced out' while he was talking, and he was surprised to find that he had talked for an hour and a half. He seemed quite seriously involved in the process of meaning making. He was a very obliging chap.

\section{Narrative themes}

Learning - being open

Discovering that what seemed impossible at first is actually do-able

Having faith and confidence in yourself

Discovering that climbing is what he wants to do - and feeling alright about that - that it's not being selfish

Importance of making a contribution

\section{Problematic issues}

Doing what he wants to do as opposed to what he feels he should do, or is expected to do.

\section{The told story}

Beginnings:

seven or eight years ago when, I was about nineteen. I was in Dunedin, I was a student there and went along on a university tramping club snow craft course for three days. ... I kind of slowly, slowly pieced together climbing gear and just kind of got out climbing whenever you could. ... it was always something I was really passionate about but, you know you're always busy studying and, I had quite a busy work schedule with university and so on, so it was kind of always something you fitted in around it and then when I finished my studies I kind of, realised more and more and I still realise more and more today that, it's not really something that you kind of, want to fit in around everything else, it's more like you want to fit everything else around your climbing really and, yeah so I guess I finished 
university and, just spent a lot more time climbing than I had been, at university and, yeah climbed, climbed overseas (1-2)

it's something that I've become more and more passionate about really, as opposed to, like I never feel like I've really kind of, had my fill. It's like the more I do the, more it becomes all engrossing and the more I want to do. [pause] Yeah I guess, I mean after, after my friends and family, climbing's probably, well climbing is the next most important thing in my life really. It's something you're always thinking about and, and working on and, you have missions and projects you want to do and you'll be working towards them and, and I guess, I guess I've learnt a lot from climbing a lot of things you, can bring back into every day life really and, and my adventures climbing have been some of the ... the more memorable and, definitely happy occasions that I kind of think of in my life, just really good trips away in beautiful places with really good friends and, just doing something that you love in an amazing environment ... I guess the, simplicity and the focus and the presentmindedness of climbing are all, are all really important things that you can kind of, that you can learn from and try to incorporate more into your, day to day existence and, yeah your life really. (2-3)

Mental attitude:

when you're, starting to, climb you kind of, you might hear about lots of climbers that have been doing all these, you know, amazing climbs and things and, you kind of think wow that's really amazing, and, I guess more and more I discover that, that they're all, all these kind of things that you once thought were, just completely impossible and amazing are actually very doable and that's kind of, it's more is getting your head around it ... getting a good bit of mileage and experience in your climbing and, you know, slowly becoming a better climber and starting to realise that, a lot of the things you once dreamed about you can, you know, are quite realistic goals ... to focus on something and climb regularly for an extended period and, feel yourself getting stronger and better and more confident ... that's really encouraging ... and motivating (4)

you heard of people climbing Mt Cook I thought wow that was always pretty amazing. ... then we went and climbed Mt Cook ... just a bit of common sense and, you know, bit of patience and practice and bit of effort you know, the things that you hear about and once thought were completely out there, are very doable. ... Mt Cook was one of those turning points for, kind of getting your head around things and realising that, you know, you can do a lot of the, a lot of those things that you kind of dreamed about doing. (5-6)

climbing is very much, in a lot of ways a mind game, and, a lot of it is getting your head around it and just, having, having confidence and faith in yourself ... it kind of expands the horizons ... you might get scared and you might come up to the, you know difficult section ... just back yourself and just be confident to move through it and climb it smoothly. Or else if you let your head start playing games with you and start worrying about what will happen if you fall and all that kind of thing then, you're just making life really difficult for yourself. Yeah so I guess that kind of, that confidence kind of, thing, kind of happens on all sorts of level, yeah. (7-8)

\footnotetext{
${ }^{95}$ Numbers in brackets refer to the relevant pages in the original transcript. I frequently referred back to the original when deciding on the relevance of a specific story, in particular to check what came immediately before and after the quote, and whether or not this might be significant for my interpretation of it. 
I remember, I remember we kind of, we were all doing really well, and then I remember getting onto this slab pitch, you know, yep it was really run out and some quite hard moves just at the most run out bit, I kind of backed off it a couple of times, and thought bugger it and went for it, and that was fine, that was great. And kind of from there it just kind of flowed ... it's times like that you've just got to keep the ball rolling, yeah. (9)

the North Buttress on Sabre. I went down with a friend and he hadn't done much rock climbing, he'd never done any multi-pitch rock climbing, and I wasn't an especially good climber at the time but, decided we'll be right, away we go. ... we were just fully both going for it and, fully knew that we could do it. And even though some of it was quite challenging for me, you just kind of get in the mode of, you know you can do it and you're going for it and that's it. And it was sweet. It just flowed. ... it's times like that when you just get into the right, mindset and, and you know climbing with the right person when you understand each other (10)

Learning from experience:

Pakistan ... for weeks and weeks we were just hungry and grumpy and starving and, the climb we tried to do was really hard and scary and, we had epics on that. [laughing] So kind of, for the whole trip really it didn't flow and, you know, so that's, I guess that's quite an extreme example, an extended period where nothing really went right, but, you know, I guess, that you always learn from that and, I guess it's like climbing in New Zealand, when you're starting to climb, you know, often you'll have epics. And it takes you a while just to get the formula right and to learn, you know, how to move quickly and safely and efficiently and, what you have to, what you need and what you don't need, and, you know, kind of get the recipe for success right really. (11-12)

Fun/memory:

But you're always learning from it, and I guess at the end of the day it's always good fun. Yeah, sometimes it's more fun in retrospect [laughs]. But, you always remember the good bits. (12)

you'll have a much more enjoyable trip if you go away with someone that you have more of a connection with ... if you go climbing for two or three days and you're just completely involved in what you're doing and you really are in your own little world and it's so removed from anything else in normal life and, you know, if you really, if you're both on the same wavelength with, you know with each other and with what you're trying to do, then it really can be quite an amazing little world that you put yourselves in for that time (14)

those moments in climbing when you're just really aware and present of who you're with and what's going on around you and, you know not distracted by a hundred and one other things, that aren't worth getting distracted about. Yeah and I think, if you can bring some of that back from your climbing to the way you live then, it can only be, be a good thing. (14) 
Finding someone to climb with:

I find it frustrating and I know a lot of other climbers do too if you have time off or you want to go away climbing, and trying to, trying to coordinate your schedule with somebody else. It can be hard sometimes to find the right people to go away with (15)

most climbers are fairly, generally on more or less the same wavelength ... often you find you have more in common with, climbers than, I don't know, other people you might bump into. (15)

there's quite a climbing community. There's a bunch of people you know, and yeah, everyone helps each other and looks after each other and, you know, that's quite neat. So I'm pretty confident that even if I, even if I rock down to the Darrans by myself that I'll bump into people to go climbing with. (16)

Feeling okay about climbing:

maybe it's the way I grew up or just, you kind of feel like it was expected of you or something but I always kind of thought that, you know, I guess I'd have a job doing something, maybe I could fit in climbing around that. ... But I think it's okay to say, okay, this is something that I'm really passionate about. This is something that I love. ... it's not something that I'm going to be happy doing on weekends. You know it's something that, it's much more a part of my life than that. I guess it's something I've kind of always known but I've always, I guess I've just been admitting it to myself really. ... More of a confirmation within yourself of what you really want to do, and that's really neat actually. ... . Just to say that it's alright to feel like this. It's okay to just want to go climbing, that's fine.... it's that, the old thing, oh yeah, the kind of thing in life of do what you really want to do and, versus what you feel like you should do or, you know, make decisions based out of love instead of out of fear. (16-18)

having said that it's easy enough to say that, on one level and then have to join that with the realities of, um, earning an income and, you know, doing what you have to do to be a responsible and a, giving member of society, but I think there's definitely $a$, definitely a way to synthesise the two. Where there's a will there's a way. (18)

Cumulative epiphany:

you read a few good books here and there about, doing what you feel like you should do and following your heart and that kind of thing. But I guess just being, having a, good bunch of close friends that, you know, you can have these discussions with and, talk about what's important to you and, you know, what it is you want to do, and I guess too just seeing, you know, having friends that are passionate about, passionate about climbing and, the hills and, have gone on to become guides and things like that and, yeah just - I don't think there's been, I can't point to any particular thing that's kind of, brought about this turning point it's more just kind of been a process over a couple of years of, experimentation really, you know, trying different things, ways of living, different jobs and travelling (18-19) 
I guess I kind of struggled for a long time thinking that it was really, climbing was quite a selfish activity. You know really you could be, giving more to people and, and others if you put the same amount of energy into something that's more, yeah I don't know, that was something more for the benefit of others but I've kind of, been realising that, that just by doing what you want to do and what you love to do that, you're going to be a lot happier and, more inspired in yourself all the time and, that just by living like that, you know, you are giving and helping people around you (19-20)

Doubts:

often you might go into the hills and, be away for a while or you might have a particular experience where you get a bit scared or, think, wow that was a bit close or something, and you'll really be questioning, you'll really be thinking well, you know, I could be, there's a lot of things I could be doing with my life that, you know I could be, setting out in this career and that would be quite a personally rewarding way to, give to, give to people and kind of reduce the, you know, without having to go out and feel like you're risking your life at times. But you might, you might have, get scared and have those thoughts, for five minutes or ten minutes and then, often a few hours later or definitely the next morning you're, you're rearing to go again. (21)

Climbing as good reflective time - appreciating what's important in life:

there's a middle ground in there somewhere and, definitely climbing is, you know, gives you a heightened appreciation of, you know, what is important in life and, yeah. Helps you to appreciate, life, and people and living and, I kind of think you need that, I need that, need to go away and have those reminders. And to have to, I think it's always good to question what you're doing, where you're going and, climbing's a good time for that. It's a good time to, remember, remember, you know, life and the way you want to live it and question what you're doing ... But you definitely, I mean, you often have those times when you're like, oh what the hell am I doing? (21)

Perception of risk:

as your experience and your climbing ability develops and, I guess your perception of risk changes and, things that you initially felt, might have been scared, you're quite comfortable with now. (21)

[it's] pretty easy to kind of get lost in, trivialities really (22)

[it's great] it was great, you know, just to leave all, push all that to the side, and just to go away and enjoy what you're doing and who you're with and, you know, and then to, to get to a bit more of a perspective on it. And I mean, lots of things can help you do that you know. Like it could be yoga or meditation or running or swimming or whatever. All of these things help, you know, they're all real great. Yeah I guess it's just, for me there's just something magical about climbing. Yeah. (23) 
Satisfaction:

Saying right, I know I can climb better than what I am now, I just need to climb regularly and focus for a while and, yep I want to climb nearer what I feel like my potential is. So doing that and having that work, that's really rewarding. ... just loving what you're doing and feeling really confident ... feeling fit ... It's good to go away and, you want to do something and you put your mind to it and you do it. (24)

[when things don't go well] I kind of look on those just more as learning experiences and, you know, that's just the way it is really, not actual disappointments. (26)

Stress:

if you're in an alpine environment, you know, you need to be pretty realistic about the dangers you're putting yourself under ... I think naturally you do put yourself under a bit of pressure just to, just to get on with it really, to be efficient and to look after each other. Yeah. But, on the whole I don't, I look on climbing as enjoyable and as a step aside from stress rather than, being put under stress.

Changes in attitude/learning:

when you first start climbing or doing a sport, and you're kind of, you're on a steep learning curve, and maybe it's good for your ego. You feel like you're doing really well, doing great ... and feel pretty proud of yourself ... even though I'm a much better climber now than I was years ago, kind of, I'm always trying to, be completely open to, just to learning different ways of doing everything. ... In some ways I feel like I'd like to go back a step and, just look at everything from a completely new perspective. ... I try to just, constantly be open to relearning everything that I thought I knew. (29-30)

when I was young and I was starting to climb and you hear about legendary climbers who have done this that and the other thing, and I thought wow, wish I could do that some day and, maybe some of that kind of ego thing involved that I mentioned before. Whereas now I just feel like everyone's just doing their thing and, that's at a different level for every person, and whatever it is that people need to do to inspire them or excite them or whatever then that's great for them.... So yeah, I guess that's a slight change, slight change in attitude there, eh. Yeah less kind of young male ego and, more awareness and, just, yeah appreciating that, everyone's doing their thing, and that's great. ... you see your friends go away on a trip to the hills and, they probably just went for a, you know, walk in a valley for a few days, and had a great time and that's fantastic. And you've seen one of your friends, they've gone and soloed some really, scary, route in winter and that's fantastic too you know. It's just doing, doing the things they want to do and enjoying it, yeah probably getting similar things out of it and everything in-between is good too, so, yeah. (32)

Inspiration:

I guess the thing that I've, always found really inspiring is, meeting, you know, these people that are, really good climbers and, just finding that they're really neat people too. Just humble and doing their things and they're just good people, you 
know, that want to climb ... Sam Bosshard ... Dave Vass ... people actually that I meet, that are talented, they're just really humble with what they're doing, and kind of got a really good attitude towards it all. (32-33)

Non-climber attitudes:

you just don't encounter people as much that, have a completely different outlook on life ... their concept and understanding of climbing and things, would just be completely, you know, just be like why the hell do you want to do that? - kind of thing. Yeah I mean I, I guess, I guess most people have got their thing though. ... if people can't understand climbing, if you can just kind of relate it to, to, relate it more to something that they're passionate about and, look at it just in terms of a hobby then I think that's, yeah, that's a helpful starting point ... there's a, kind of general perception that climbing is an incredibly dangerous ... sport that most people can't do or something, and that's why people can't understand it, they feel like they can't relate to it, whereas, at least, you know, introductory level it should just be a really safe and enjoyable thing to do and, I think if more people discover that (34-35)

the things that bombard you in the media of people climbing outrageously technical wild stuff. If people look at that and go 'well, that's climbing', then no wonder they go 'why the hell would you want to do that?' You know, but if the image is, more of the images in the media were of, people enjoying themselves in a, safe, controlled, environment people would be, 'hey wow, that looks fun, I'd like to give that a go'. So, yeah, I think advertising's got something to do with it really. Like my family are kind of outdoorsy but, none of them are climbers but, sometimes they, you know, I don't think they always fully understand why we choose to put ourselves into what they perceive as dangerous situations but, yeah I mean everyone can understand enjoying going for a walk in the bush and, it's just got another, to me it's just another step from there really. (36)

Climbing scene:

I really like the attitude of climbers here ... the Kiwi attitude of 'give it a go' and, you know, do it yourself kind of thing, whereas, overseas I guess, especially climbing in America, the gear aspect of climbing gets a bit much. ... people out with all this really expensive flash new gear and, they just, you know, they've hardly used it ... I just prefer the Kiwi mentality of make the most of what you've got and, it's kind of, the old perspective of, you know, with that fifty bucks you've got to buy a new piece of gear, you could actually go away and just make do with the gear you've got and learn a lot more, and have more fun. (36-37)

I lived in Oregon for a few months, a few years ago and we used to go climbing out at Smith Rock a bit and, and it was quite a, quite a thing. The way to climb there was, you'd need to be a couple, a guy and a girl, and you had to drive a big pick-up truck, it had to be at least V6 and um, you had to have black down jackets each and tights and you'd get there and you'd have your black down jacket and your closefitting pants and, um, you'd have a tent, preferably a North Face tent and if you had a dog on a red leash, then you had it made. (37-38) 
Contributing:

I'm also pretty aware of the need to balance it with some kind of career path really. ... and I'm thinking about, some synthesis of maybe outdoor instruction, ski patrolling, mountain guiding and outdoor education and maybe kind of, work in the health area as well. ... I think they're all quite compatible areas and there's a lot, a lot to be learned from some of them and taken into others ... and they also complement the climbing as well. ... good things to be doing for, for people and society too really. ... quite giving, giving things you can be doing, really contributing. (39-40)

I look a lot at, society and, the way the modern world is going and I look at, climbing and outdoor education, as a way to ... hold onto, some of the values and principles that are really important to people and life, and society. Also I can see people find it, feel like they're stepping away from those values and, principles and, with the way that society's going (45-46)

you can laugh about a lot of climbers as, you know, climbing bums, bumming around and drinking coffee and, running around in the hills and, I know there's kind of that funny, look on life that, I think a lot of climbers share, which is, quite off the wall really ... just being, you know, in the present and, aware of what you're doing and who you're with and, and thankful and appreciative for that and you just appreciate the little things in life. Just good companionship and good view of, you know, compared with most things that you, kind of take for granted in the fast track of modern life. ... to enjoy the environment and be aware of the world around them ... To look after the world and, looking after each other, you know, just, just respect for other people and looking after yourself. (47)

I know it will always be important to me and, I'll always enjoy reading and hearing of, other people's adventures and what they're up to and I like to think that I'll still be getting out there and doing it when I'm 40, 50, 60. (44) 


\section{Appendix E}

1. Sue's story of her mother's wish for her to stop climbing (page 83):

My mother didn't like it at all when I started getting into climbing at university and she tried hard to persuade me not to do it ... the nearest climbing area to where I was working was a great crack climbing place so my hands would always be covered with scars from the jamming and mother said 'ah, you can't go to work with hands like that. You'll have to, you'll have to stop it' you know. So I always joked afterwards that I did stop it but it was the work I stopped and not the climbing. ... I think she came to a point where she just accepted that that was me and I was going to do it and she just let me get on with it.

2. Mark's first experience in the mountains (page 83):

[We] headed up to the alpine club hut at 2,000 metres. And arrived at the hut. Everyone was wet and cold and miserable. And we lit the fire ... and warmed up and had a feed and told stories all night, and a storm came through and everything was, um, moving in the wind, howling and carrying on and the next morning to get back down we had to be roped up. Ice axes and helmets and, we just wandered out into the whiteout and this guy Tony [the instructor] just headed down the hill like he knew everywhere, he knew where we were going and, eventually we got down. It was one of those experiences that everyone hated at the time, but as soon as it was over everyone thought 'oh you know that was so cool we did this and we did that and it was so cold, everyone was freezing to bits and we were going to get lost but we didn't'. And yeah, and I thrived on it, I thought it was just the most amazing experience I'd ever had. Yeah. It was kind of unreal really. And so that got me into the outdoors, that made me want to go tramping and, camping and, doing stuff.

3. Dan's story about deciding to commit himself to climbing (page 89):

maybe it's the way I grew up or just, you kind of feel like it was expected of you or something but I always kind of thought that, you know, I guess I'd have a job doing something, maybe I could fit in climbing around that. ... But I think it's okay to say, okay, this is something that I'm really passionate about. This is something that I love ... it's not something that I'm going to be happy doing on weekends. You know it's something that, it's much more a part of my life than that. I guess it's something I've kind of always known but I've always, I guess I've just been admitting it to myself really. ... More of a confirmation within yourself of what you really want to do... Just to say that it's alright to feel like this. It's okay to just want to go climbing, that's fine ... I can't point to any particular thing that's kind of, brought about this turning point it's more just kind of been a process over a couple of years of, experimentation really, you know, trying different things, ways of living, different jobs and travelling.

4. Kath's story about her decision to commit herself to climbing (page 90):

I decided I didn't want a career I just wanted to be a climber. And so that meant living in places like Mt Cook and Fox Glacier and which in those days were quite dead end places, probably still are. ... working for $\mathrm{DOC}^{96}$ and cutting tracks and stuff, rather than go to university like all my friends. Yep. Yeah I definitely made a

${ }^{96}$ The Department of Conservation. 
conscious decision, like I dropped out of university basically because I didn't want to live in Christchurch I wanted to be a bit closer to the mountains, yeah. So I definitely made that kind of decision, that I'd put everything else aside at the time.

I found it easy to make but it wasn't necessarily an easy decision 'cause, 'cause I was like 18 and living in Fox Glacier and I didn't have the social life that my friends at university were having or anything like that. So I felt like I was missing out on that kind of thing, which I was you know. I wasn't sort of going to parties and things like that, like they were and meeting lots of boys. Not that I was really interested in boys but yeah I definitely felt there was, that all my friends were going that way and I was going that way. Because of the school I went to, it was that kind of school that sort of was an academic school and everyone was pushed to go to university and you know do well.

5. Mark's story about being alone in the mountains (page 100):

the self-reliance thing, ... I just think it's so good for your soul. And you also get in touch with who you are and, you know, all the, the thoughts and the feelings you know, the thoughts of why, why you actually do this. ... Why would you struggle up a hill for like four hours or five hours, uphill, quite steep country sweating away and getting cold and miserable 'cause it's actually snowing or it's sleeting or whatever, or getting so hot and sweaty and exhausted and dehydrated. ... And then you arrive and, you're cold and tired and thirsty and, I used to drink a lot of sachets of fruit drink and hot water. And you brew that and get a bit of sweetness in there and ... you sit there with that warming your hands and ... then you start thinking about, how self-sufficient you are and, and how nice it is to be just on your own, alone with your thoughts, all this beautiful landscape. Whether it's soft beautiful snow or whether it's wicked wind howling and you know the nature at its best. At its finest. At its most powerful. And how fragile this frail little human body is in this environment and, and you start to reap the rewards of, you know, spending those hours and hours of sweat and tears.

6. Kath's story about deciding to turn around (page 108):

When's the last time I turned around? Yeah in Alaska when I was there last year we did two fantastic climbs which went really well and the first one was sort of a warm up climb but it was still a great, you know I did it with another woman, we were the first women to ever do this route. And everything went really well, it went great and the next, the next - then we chose another route on the same mountain and again we're you know and this is a route that's very rarely climbed and again we were going to be the first female pair to do this. And we did it, but we were right, we were at our limit and the weather turned bad but we made this decision to go on because we wanted to do it basically [laughs]. And things were just in control but only just you know and then we, but we got to the top and we came down. And then we sort of went off to - had a couple of days rest then went off to climb this other thing and we got sort of two thirds of the way up it and the conditions started to deteriorate and they weren't as bad as they were on the climb that we'd done previously that we'd finished. But things started to deteriorate, the clouds started to come over, it started to snow but, and even though things weren't terrible we decided to come down. So I think we thought that we'd, that if we did this twice in a row that maybe this time we wouldn't be so lucky and ... we were quite satisfied with our two previous attempts that to come down on this one wasn't quite such a bad thing. And we just sort of thought 'okay we really pushed it out on that last climb. Perhaps we shouldn't, the gods won't be with us on this one. 
Perhaps we should just turn round', so we did. And we're both quite happy about that. So it was just, and I mainly thought 'oh you know this time we're a bit more tired because we had done a lot of climbing. Probably a bit more dehydrated and we're not thinking quite as straight and perhaps it just won't go with us this time' so ... it was an easy decision to come down. Does that make sense?

7. Sue's story of being stretched to her limits (page 109):

we were feeling good and confident and so we decided to go back the next day and climb the Central Couloir, which we did and it just happened to be that it was my lead when we got to the crux. We sort of soloed most of the bottom bit and then I think we must have done one pitch and then we got to the steep pitch and it didn't look too bad and I thought 'oh yeah I'll be okay'. So I led off up and towards the top, it was vertical and I'd never climbed really vertical ice before, never mind lead it and my arms were just giving out and ... my fingers were uncurling from, from the handles of my tools and I just thought 'I can't do this'. ... I had like about three or four feet to go before the angle eased off but I didn't know if I could actually swing my axe enough to do it. But yeah I managed to, my feet came off at one stage I remember, but I managed to get up there and it was just so nice to get up ... I really was sure I was going to take a whopper and it took me a long time, I was so relieved when I got my axe into a really good nice piece of névé snow up over the top and that's probably the hardest, oh it was definitely the hardest ice climbing I've ever done and I've never done anything as hard since.... And that was probably the highlight of, that and climbing the South Face of Cook would have been the two highlights.

8. Jane's story of 'fighting herself' on Timebinder (page 110):

Most of the climbs I've really enjoyed have been fights. Yeah. I love a good fight. Like, if there's a hard climb and I've been anticipating it, and it goes a bit easy I feel real disappointed. But I like, when I'm really pumped and, it's really hard or something ... it's like that love hate thing. I'm loving it, but really wanting to get it over with at the same time. ... There's one, Timebinder, which is in Montana that I did with Lisa, who's one of my dearest friends, and ah, it was due to storm that day so we did this climb, it was five pitches that you could get off quite easy. And, it was graded 5.11, ${ }^{97}$ it had four pitches of 5.10, then this hard 5.11 pitch, and it just went real smoothly and we just had a wicked time and, it was just up this valley that didn't have any paths, no one was around, just these beautiful sort of wooded hills, but Montana feels real big. Real vast, in a way. We could just see the storm clouds rolling in, this chilly breeze and things, and we got to the base of this 5.11 pitch and it, just looked, like nails-hard. And we'd both been thinking during the day, 'oh well we'll see how we go. We can always back off'. And it was just this flarey, kind of finger crack, ${ }^{98}$ and ah, just on it, and just those moves where you, you can't define whether you're sort of coming off or staying on. You're, you're somehow staying on, but you're not quite sure how, and just sort of keep going another move, and there's nothing to say, you know, whether you're coming off or not, apart from, I don't know, you I guess. And Lisa's sort of yelling, I'm grunting, got this massive pump going, yeah just kept on going to this rest, and, on this rest and you could see the climb still kept going above like through a little overhang, you can kind of tell it's going to be a bit easy, easier than what you've come up, so you're torn ...I

\footnotetext{
${ }^{97}$ Established climbs are usually given a grade to indicate their level of difficulty. The grades Jane has used here are from the US system for rock climbs.

${ }^{98}$ A finger-sized crack which is flaring outwards, making a firm grip difficult.
} 
want to have finished it, so that you've done it, but then another part of me never, wants to finish. Wants it to kind of keep going. And ah, I managed to get through that, it's just the most amazing feeling of, just, I don't know, you're battling, it's not, not like you're battling the rock or, any sort of thing like that but, you're battling yourself I guess, just to stay on. Yeah, I love that [laughs]. So that was just one of the best climbs I've done, mainly because it was with Lisa, and then we kind of rapped ${ }^{99}$ down and the wind was blowing our ropes out and, getting all tangled and, as we were driving back it started snowing and things. It was just a magical day. Yeah. That was one of the best. It's not like the hardest route I've ever done, or it's not the most famous, it was just fantastic. And every time you do something it just makes you feel like a bit better, and just empowers you a bit more I guess. Yeah.

9. Chris's story about people doing "the same old things" (page 115):

ninety percent of climbers go and climb the same old things - at the crag, and in the mountains. You see it all over the world. Pakistan, at Trango base camp, there were two expeditions there ... but in that time I think fourteen expeditions went past us up the Baltoro [glacier]. There were thirteen expeditions at Gasherbrum base camp, to climb Gasherbrum - whatever they are - II and III. They're just big snow lumps - they're 8,000 metre snow lumps. You know, and they've been climbed dozens of times before. The routes are really boring, quite dangerous, um, fixed ropes - they're absolutely uninspiring ... and ninety percent of people who go up there go to climb them [laughs]. And they walk past some of the most spectacular mountain scenery in the world and most - ninety-five percent of that is unclimbed. Unclimbed granite spires and needles, all shapes and sizes, that half of them you don't need a permit for ... And it blows me away. And it's the same here really. Everybody goes and does the same thing. I find it basically uninspiring.

\footnotetext{
${ }^{99}$ Rapping or abseiling is the technique used to descend a climb using the rope. A friction device or knot is used to attach oneself to the rope and to control the speed of descent. 


\section{Appendix F}

1. Jan's story of developing bonds with other climbers (page 125):

that's how Kay and I got on so well together in the mountains. She was in many ways a strange woman, people thought she was very strange, she wasn't very communicative at all, verbally communicative but, when you knew her well, you communicated in lots of ways in which you said very little.... But that's the bonds you develop. And so the bond with your rope mates is the real bond that really stays there forever and then there's the bonds with the others in your climbing group, and then the wider circle of those in the same climbing hut with you time and again and you meet up with them in different places. Yeah it's a fellowship.

2. Jan's story about the alpine club being hijacked by rock climbers (page 129):

But there came a point, and I can't just remember where this was, where even in the Alpine Club it became hijacked by rock climbers, who started being very derogatory about mountaineers. ... And actually that was when the drug scene came into the rock climbing scene. There was a period when, all the so-called 'in' rock climbers were all doped up ... early eighties I think perhaps ... you weren't 'in' unless you were a rock climber ... and that sort of sneering attitude towards alpinists was quite prevalent for a while, yes. They got a lot of really good rock climbs done, alpine rock climbs too, but a lot of them fell off and killed themselves, in the process. Yes, that period's past now. But it was a period where, there was that divisive feeling, quite strange.

3. Dave's story of getting his "mountain feeling" back (page 135):

when I went to [the Himalaya] I was going up the glacier and stuff and, ... I wasn't really enjoying going up the glacier it was sort of, so what this is a big, big mountains with big glacier and, blah you know it's not, I didn't really get it [laughs], didn't feel anything for the place you know, but umm, then on, I think was it the last day? No, no we were going up and down a few times and I came back down, and I remember stopping and watching the light, there was this brown hillside on the other side of a glacier and the light, the clouds were going across it and the light was changing and, and the mountains were really cool and I just sat there for ages and I felt that, that feeling and felt really good about the place and, got my mountain feeling back, and, so now I can, I mean that's one of the lasting memories I've had of that trip, is of the light changing and me sitting there in the middle of the glacier with all these big mountains around, and feeling really nice. Feeling really sort of, well at home I suppose and grounded with, with the place. ... I don't sort of recognise it when it happens as much, so, I sort of, but I mean it's that whole thing. If you can't go into the mountains and feel, get something from them, like that, amazing feeling then, it'd be a fairly weird experience going mountaineering. Because that's something, that's kind of what, allows you to suffer a little bit and put yourself through quite a lot of, ah, angst and suffering, pain and, all the rest of it.

4. Pip's story about being "sensible" and not getting "carried away" (Page 141): we were climbing up on a ridge and I was quite new to climbing and I hadn't done that much and the day was coming to an end. It was obvious that we should descend, but this person just wanted to keep on going, and she even went as far as 
leaving me there, and going up to a high point which you know was not the summit and I mean it's so stupid because - I mean nothing happened, we all got back fine but we got back really, really late and that caused other people to be concerned and, it was like, well but why you know if we'd turned back maybe half an hour beforehand. And why did she have to do that? It's just stupid. But anyway, I guess she had a need to fulfil but, and ... that demonstrated to me that, you're, you can get carried away, in the mountains and I think it's really, really important not to. It's really important to say what's sensible and what's not, otherwise you'll end up staying up there. You know I mean it does, it can lead people to, I mean it's just stupid.

5. Dave's story about a level of commitment where "magic happens" (page 146):

Paul and ... I think I was on the dole and he was on the dole, and we were just living the climbing bum life, and ... neither of us had girlfriends and we were just sort of careering along, it was really really good - it was an amazing time ... I'm not very good with dates. I can't remember ... I'm married and I can't remember Trish's birthday and stuff, but [that year I did a major climb ] in the middle of winter, and ... [it] was a huge winter with lots and lots of snow, it was also the winter that there were some army boys on Mount Ruapehu, I think, got killed. And, ah, the storm that Paul and I's trip finished on was the storm that killed those guys and so it was a really big winter and really cold ... we hadn't done anything like it before, nobody had, and we didn't know what we were in for and we did a few things wrong and stuff. But we ... because we were totally committed to what we were doing ... three or four days into the trip we lost our tent in a big snow storm. It got buried, ah, by three metres of snow and we were lucky to sort of get out of the storm alive, it was one of those storms where you couldn't have survived it in the open, it was horizontal snow, strong winds and in the middle of winter ... quite cold temperatures but we dug a snow hole and we cowered in that for two days but we'd lost most of our gear. It was buried ... by the snow, but then it cleared up and we dug most of our gear out, and then the next day it cleared up again and so we, I don't remember discussing whether or not we would bail - like we were so committed and so into it that, umm, we carried on, but with minus the tent so we had to bivvy. And bivvying in the middle of winter, back then, when we didn't have any bivvy bags, we just had our sleeping bags and stuff was full on, I mean, we, sort of, were starting to push the boat out. But ... it didn't really matter because we were ... committed, you know, it's like when you get to a level, that level of commitment in mountaineering it sort of is, it ... becomes magic and sort of magic happens, you know, you sort of don't really care whether you live or die kind of thing and it's really really cool.

6. Dave's story of disappointment at lack of commitment (page 146):

I think, 'cause that, ah, trip that Paul and I did ... We reached those levels of commitment where magic happens and where you, and I s'pose I've done that with my soloing as well, but umm, I think maybe I was quite keen to get that [on this trip]. And, that didn't happen. Well, it did actually for one pitch [laughs]. But not the whole trip. The whole trip was sort of like, this struggle of trying to, I don't know, come to terms with the place and, what I was doing there ... and yeah, there were funny group dynamics with, two of us I think Tom and I were really committed. Oh no Tom, very, very committed. Me, still looking for it, and I found it on my last pitch on the last day, I knew I would have carried on if the weather had come right. But then the other two were kind of easy-osy 'oh, this is a good holiday' kind of thing, you know, 'we're having a good time but, we've gotta get home for 
our jobs' and the rest of it. And you can't, you can't approach a peak like that. You've gotta have lots of time and you've gotta, release yourself from society. You can't have any ties, otherwise you'll, yeah, you tend to, you know, you'll rap off quite quickly. So that was a, that was a pretty big disappointment.

7. Dave's story about tempering his commitment to mountaineering (page 147):

there's a bit more, umm, give and take, especially 'cause I'm, I'm married and stuff too so we've got, sort of, joint debts and things, so I have to consciously think of Trish a bit but, umm ... She understands that as part of my, being you know, I have to go every now and then. I mean I couldn't, I couldn't, well I mean I could, like I could have kids and I could survive on three weeks holiday a year, but I choose not to. I don't actually want kids and I definitely don't want three weeks off holiday a year. You know, it just would blow me mind, you know, I need to go climbing. Still I mean it's, it's tempered, definitely, I mean, when I was with Paul and doing that we'd take off all the time, you know, be away all the time, but, umm, I certainly don't, it's not as pressing as it used to be 'cause I've done so much I s'pose. But every now and then it's a sort of like Aborigines going walkabout, you just get this, 'oh yeah, here it comes, I've got to go'. [laughs] ... There's a definite intensity to, umm, mountaineers that tend to push the limits, you know, and that can be quite sort of, quite weird to be around. It's amazing that we actually have steady relationships really, sometimes [laughs]. But then again that might be just me trying to be, standout [laughs].

8. Tim's story about finding other things to do (page 148):

when I was in America and stuff I was focused on one thing and now it's sort of you know, I'm basically, I don't think I could be a climbing bum any more ... it's nice to go and do some climbing and then switch off from climbing and do something else. Fully recover and then you go back into it again. ... go hard, have a rest, go hard ... you just need more things to put in the gaps between climbing, yeah. So I think that's become a big thing, eh is to not, not think of yourself as just a climber ... I'm into all these other sports as well and you've got to get into them.... And sometimes, you know, have a big break from climbing, I do a whole bunch of paddling and stuff like you kind of, it seems like breaks are actually quite beneficial.

9. Pip's story about enjoying climbing obscure mountains (page 149):

A lot of climbers look on major achievements as you know the most hardest technical, highest climb. But, um, I don't really think of climbing in that way.... you might say oh you climbed Mt Awful. They'll go 'is that a mountain?' You know 'and I did it by myself'.... I find it's a very male perspective way of looking at things. But it's quite a truthful way of looking at things, I mean you can either technically climb to that level or you can't.... But some of the climbs that, I guess, feel the most significance for me are, [pause] ... I get a lot more out of climbing some of the lesser peaks that, can be more tricky and maybe the rock's not so good or the climb's not so straightforward or it hasn't been done very often, or at all. Um. Or the access to those climbs are, a bit funky, yeah.

10. Dave's story about wanting to leave "a lasting legacy" (page 149):

I'd like to - secretly-you're probably the, interviews are funny because you tend to tell things to a sort of complete stranger. But umm, the ultimate would be to 
leave, when, yeah, I'm 65, they'll write somewhere that [I'd] climbed something either very classic or very, ah, very amazing. You know, that, that it was, well probably in New Zealand, that it was, it will stand apart from other routes it'll, you know, that, yeah, that's a funny goal because it's kind of ego-centred a little bit, you know, you want that sort of, I don't know, a lasting legacy or something, you know. I kind of look at it like painting an amazing picture, or writing something that people will just go 'wow', you know, and if I can maybe climb something like that in the New Zealand mountains then, that would my, that would be a really good goal. And it's quite a, it's, it's sort of attainable but it's not, you kind of, 'cause you're not sure, umm, if there is anything quite like that left, kind of thing, so. I s'pose that's my, you kinda gotta have a reason to motivate yourself and stuff, and I think that's probably, one of the reasons. But yeah, that would be quite neat. I'd feel, measurably proud, if ah, yeah, sitting in my wheelchair. That somebody comes up and says 'Ah, man, I climbed that route and yours and, it was a) really good fun, b) a beautiful line, and c) really, really hard'. You know, 'and we were stretched on it', you know, blah blah blah. But, you know, that's, all that is kind of, is kind of hard to talk about, publicly as well ...

11. Dave's story about the problems of climbing to boost your ego (page 150):

the thing that you ultimately, if you're trying to get too much from mountaineering to boost your ego is, is a dangerous one. That can turn you into a bit of a twisted person, yeah. Ego, if you're always striving to belittle somebody through your major achievements or you're trying to boost yourself up by doing something amazing, then ultimately you'll come a gutzer. Definitely, don't have much fun doing that, that's a really tricky one. That's a very fine line between getting self gratification or whatever from it and, getting, ego is, has to be, I find it has to be, addressed, like one of the reasons I do climb is for my ego. I mean I definitely, I like, like I said, that, climbing the ultimate route. I like the idea of being held in, in sort of higher esteem than the average Joe Blow, and I've kind of struggled with it a little bit and probably will continue, whether or not it's a healthy thing. You know, whether or not it does diminish my, umm, enjoyment of life but I can't really help it [laughs]. So, I'll just try and understand it but it's a funny one, it's quite a technical, tricky one to try and deal with is, is ego and there's, there's one mountaineer, Bill McLeod who, he doesn't, he hasn't published anything, he doesn't write stories, he doesn't tell anybody pretty much about what he does, he just goes off and solos things and he climbs some amazing out-there stuff. But he's very eccentric as well so I don't know how, you know, he doesn't have a, I don't think he has too many friends, he lives by himself, and he's very recluse and, so you know I don't know how much, although his enjoyment must be coming from just being totally, 'I don't really give a toss' and gets it from totally within. But I haven't reached that state of Zen [laughs]. I still need people to sort of go well 'well done Dave' you know 'that's great. Yeah, that's cool'. But I mean I'm not saying, that's not my driving force. If it was my driving force then it'd be really weird. And you definitely tend, because to get that, if you find you're not getting it, you'll tend to wank on about your, what you did. Maybe you'll boost it up a little bit or tell lots of like say tell lots of people or shout it from the rooftops or whatever you know if you're trying to get, if that's what you're trying to get, then you tend to be, you know, you tend to, like I say, put people down kind of thing, and that's not a good, good sign. 
12. Pip's story about not letting fear take over (page 158):

there's nothing wrong with having a little bit of fear. And I think that's something that climbing does teach people, is how to deal with that. ... walking on a steep snow slope, it's not steep enough to tie [into a rope] and, and the grip is good enough that you should be able walk across that, but if you slip it would not be very good. The outcomes would probably be particularly bad. And there's lots of that in climbing. There's lot of that for long periods of time. We have to concentrate really hard, to and deal with the fact that it's quite scary, terrain to be on, but if you concentrate on what you're doing and do it right, you'll be fine. It's a really good skill to have [laughs], because there's lots of situations in life that are really scary, and if you do concentrate, and do things correctly, you know use the correct technique or, stick to the way that you are, you are doing things carefully, if you're careful about things, then you will get through it.... if you can, you know get rid of the fear side of things and not let fear take you over, um, then I think that you'll, you'll finish it.

13. Jan's story about being able to cope (page 158):

I just love that feeling of total aloneness, just us, and that complete, emptiness all around you. But I loved the storms and things as well because we knew how to cope with bad weather and we had some terrible storms. But we knew how to cope with all this and it never felt, endangered. Never felt out of our depth experiencewise or any of that sort of thing.... we were as happy as sand boys if we could camp, bivouac in a high place somewhere and know that we had with us what we needed to cope, and go and explore to try to climb some particular route or something. And if it succeeded that was great but sometimes it didn't and we had some amazing experiences that didn't come off the way they were meant to come off, but that didn't actually matter, as long as we got ourselves out of our predicament. [laughs]

14. Jan's story about being held responsible for the incompetence of others (page 159):

it ended in tragedy before we got to the summit. An avalanche buried four members of the expedition, and we never found them.... I was co-leader with an Indian co-leader you see and we were supposed to be, well she was an incompetent right from the start. ... And we had these six Sherpas, ... they were not competent climbers ... the Indian Mountaineering Foundation had given us a bum lot of Sherpas and two of the young Indian women were quite keen to learn our techniques and climb with us, but the others refused to climb unless a Sherpa was leading the rope, you see, and they had old fashioned equipment and those ones wouldn't use our equipment ... Yeah. So anyway that was all terrible, and, the trauma of trying to cope with that was really quite great. I did the initial searching for [the buried climbers] on my own because the other Indian women by then had decided that they wanted to pull out, and had moved down the valley and the two Indians who wanted to continue were with us and they were the two that got killed. And I radioed down to the others to say we needed help for them to come up. But they were so lazy that only one came up to help, some of the so-called Sherpas came up to help but they were dead scared, spooked by the fact that the, the girls had disappeared under multiple little avalanches that had been set off by an earthquake we think. ... So a lot of it resolved on me ... they sent up a team to search for the girls who were incompetent, who couldn't even put on their crampons properly. ... then a helicopter was sent ... and they didn't do a competent search. ... And anyway we'd already been over it. We'd physically walked over all 
those avalanche sites, Kay and me and Anne, and couldn't find any evidence of the girls at all. And we'd been into every crevasse where the avalanche rubble had gone into the crevasse. Searched in them and we couldn't find anything. And then we were frog marched out of the area, more or less, back to Delhi for a court of enquiry and, had to go through this whole court enquiry business which was really traumatic because the Indian Mountaineering Foundation were very peaked because this was the first major accident with women on an expedition which they had sponsored, on their side.... And they were wanting to lay the blame on me, fairly and squarely. That it was all my fault. And sue me. And they'd insured the Indian women's lives for $x$ amount and, they were wanting to actually sue me, for all of this. And the New Zealand High Commission were really, really good to me and they got me their lawyer, and all the rest of it, and we managed to prevent them suing me for the deaths or for the insurance or any of that sort of thing. ... oh there was a lot of games played.

\section{Lyn's story of frustration at failure in Nepal (page 161):}

And at that stage, you know, yeah so that moment, when I realised that it was all over, that my body had not acclimatised as fast it could be, so that was very, I remember sort of crying, with the instructor guide. We were sitting close to camp one, with all the mountains around us and I was bawling my eyes out because I knew, you know that's, 'cause I had gone, it was at a stage when, you know, I was telling you about when I felt quite restless and I thought by doing a big mountain it would settle me down, you know, like it did in 1990. So, you know, I thought I'll get to the top, 'cause when I saw that peak, it's a beautiful peak, I thought I want to be standing there on top, and that moment of realisation that I was never going to, be standing on top of that, this beautiful peak. That was, that was memorable I can tell you. ... I think that's, that was the most frustrating, um, climbing experience in my, in my entire life. Yeah it was devastating, it was frustrating, 'cause I put so much, so much was at stake. Well in terms of, that it was going to, ah, make me feel better about my life. I would come back, having done this amazing peak and I'll, like in a way when I came back from the Mira peak. I felt much, you know, I was much more settled, so hoping you'll do the same trick, I think. [laughs] ... I was, um, I was devastated, for a while, but then I made the decision to come down to Christchurch and live here, so I left my job, and everything else, sold my house, and came down here. ... Yeah so, so it settled me for the first two years, but I'm beginning to feel itchy feet again. So I'm beginning to think what else, what big expedition can I, do next. [laughs] 


\section{Appendix G}

1. Phil's story about being out of his depth (page 175):

the first attempt we got up six or seven pitches and at nightfall we were under the big overhangs and just [had] to hang in our harnesses all night and it snowed that night and we hung there on the harnesses and ropes and snuggled together ... and in the morning we aided on through and came up onto the slabs, ah, which were covered in snow. We just scraped the snow off the slabs and made it up the slabs, still there was two thirds of the face above that so, [we weren't going to get up there], so we traversed off the right side which was a whole series of narrow rock ledges covered in snow, very slippery. Most of the time we couldn't get any anchors, [it was a] life and death sort of situation getting off. Had a few avalanches sliding down the slippery rock and we were struggling ... we were slipping and sliding trying to get up the [snow-covered] slabs. So that was a, desperate escape from the face.

2. Jess's story about overcoming her fear (page 198):

[climbing's] more a rational kind of fear. If I'm high in a paraglider I feel scared because I'm high and it's not because I'm unsafe, it's just because of height. Whereas rock climbing it's more immediate, I'm scared because I'm 20 metres above my last hold, you know, it's much more defined. ... Even though sports, a lot of sports I do have adrenaline involved, adrenaline is not the major reason why I do things. Like I can remember my kayaking trip which was doing the Tongariro River. ... We'd just done the first couple of rapids which are the more difficult rapids on it. I got to the bottom of it. Sitting there and thinking 'this is good, no problem, you're in control'. A friend of mine came up to me and he was paddling beside me and he says 'man I'm just so scared, this is great'. I go 'you've got a very strange attitude'. To me being scared is overcoming it and not being scared if that makes sense. It's like you need to be a little bit scared and then ... you can work out why you're scared and you can control it and you can do things ... in spite of being scared. Whereas he kind of seemed to be getting this buzz out of being scared and I was just going no. ... [it's about] getting into situations where I'm testing myself and fear is part of that test in some situations. But not getting beaten by it you know sort of saying okay fear is just one of those things and I can be afraid but it doesn't mean that I can't do it. ... I don't like being afraid unreasonably ... you're actually less safe close to the ground than you are really high. But I generally feel more scared up higher than I do close to the ground and so it's not rational and that's something I'd like to change because it doesn't make sense. So therefore being scared is not, not a buzz it's yeah it's more overcoming it and being scared for the right reasons and not scared when you don't need to be scared because the times that I've enjoyed most with climbing, flying, kayaking, are when I'm not scared. And when I've done something and gone 'yeah that was really good, felt totally in control' you know.... I wouldn't go bungy jumping personally. ... bungy jumps seem to me to be an utterly ridiculous concept. It's just totally adrenaline buzz for no reason and it's like well, so what's the point of that. To prove that you can be stupid enough to jump off a bridge, okay. ... I mean normally fear is what makes you not jump of bridges because you know you're going to die. So it's a mind over matter thing I suppose is what's so buzzy about it, but yeah. Fear stops you falling off things. And when it's like that it's quite useful, but ... [if] it actually stops you doing things at all, then it's not useful so it's getting the right balance. 
3. Chris's story about how he prefers climbing that is 'safe' (page 177):

[Mount Cook is] quite a dangerous place, it's as dangerous as anywhere I've been in the world, objectively, the weather's changeable and bad, there's lots of stuff falls down all over the place, the valleys are narrow ... [almost all] the climbing I've done around Cook in the last few years has been from the western side. It's much safer and much better rock and there's lots of unclimbed stuff. It's just better all round. I can't believe that people climb on the eastern side of the Divide ... it's just rubble, it's dirty and dangerous, shitty long walks. ... I don't go out there to put myself at risk, at all, or go into dangerous places. And I actively avoid dangerous places. There are plenty routes I'll never do ... the standard route on Cook is a pretty dangerous route.

I don't find climbing harder technical routes, any more dangerous really than ... walking around in the mountains. ... people often think, oh, you know, the harder the grade or more technical routes are more dangerous, but that's not the case at all. The more technical it is, the more gear you've got. And you've got two ropes, you've got a lot more protection generally. Then you obviously get the places or bits where you, might not have good protection or, it might be hard or, but you've just got to make the best of that ... I mean, I'm pretty conservative ... That's why I like the Darrans especially. Because it's objectively so much safer. ... the Darrans more than anywhere is sort of, I felt comfortable there, I really liked it, it's just a bit, it's way safer than Mount Cook.

\section{Phil's story about the 1970s (page 186):}

it was a big jump from the group before in terms of what we took on and ah, but ... it wasn't just us, there were other people who were making some big advances and I mean it's a worldwide thing ... [those] big leaps forward. But yeah I think before that ... mountaineering ... wasn't sort of going anywhere very much. And some of it was the new equipment, you know, better ropes and bolts and things like that. [But also] a change in attitude. Because I think what happened in our situation was we were, we tried to do things that were probably beyond what we should have been doing, in terms of safety and technical abilities and things, but we just kept on going, got away with it. And that's obviously how you make progress, by pushing things.

5. Bruce Jenkinson's (1970) comments about luck and safety in the mountains (page 188):

[a good climber is] self reliant, efficient and purposeful; accepts a luck factor but can turn it to a minimum. He is confident and recognises his confidence on a realistic judgment of his ability, fitness, experience and sense of standard.

... the best course of action for getting up a large mountain is seldom compatible with the safest course of action, which is usually staying in bed, or getting back there as soon as possible. Actually this is not as facetious as some of the fantasies seriously offered these days to reassure ourselves that others were fools to have accidents or get killed. Accidents are not mistakes. Like avalanches they are events, sometimes involving hundreds of variables. There are no clearcut rules on how they happen but one can spend a lifetime learning about the variables. And so 
nobody goes in the high mountains to be deliberately safe - if they do they deceive themselves....

Climbing ... is a continual calculated risk and sometimes the calculation involves pure chance not judgement. ... so a "code of good behaviour" which seeks to ensure survival but stifles performance and inspiration, seems rather a contradiction to what, for a lot of people, climbing's all about.... never should [beginning climbers] be encouraged to think they can do safely what can never be safe.

6. Mark's story about the difficulty of assessing avalanche danger (page 192):

we headed down [a snow field] and, the snow was dodgy ... there'd been an avalanche warning but there'd been a lot of kind of wet weather and, and you kind of expect things to consolidate, but, you know there's probably a bit of fresh snow around as well. 'Shall we wait until it's dark? Shall we wait until it freezes? Shall we go?' you know and just, I remember there was this really nice rounded slope which was just, just fantastic avalanche material. And, oh I stomped around and scuffed the surface and, and then we decided that we'd skirt round. Anyway we picked our way very gingerly and very carefully down the slope trying to minimise any risk of triggering anything as we went down. And, [my climbing partner] still to this day thinks it's a bloody stupid thing to do. But, I don't know. You don't know. Can't tell. Who knows? They say there's two people that will get caught in an avalanche, the novice that doesn't know a thing about them and the expert that thinks they know all about them. The people in between generally are too scared to, to venture anywhere. So I like to think I'm one of those people in the middle. Who knows?

7. Jan's story about recovering from her accidents and continuing to climb (page 197):

Had quite a traumatic accident. Got hit on the head ... ended up with a fractured skull ... So that was somewhat traumatic. [laughs] ... I was only in the hospital for a month, they let me out but I was still a mess ... And I was also fearful of climbing in case I fell. ... a good friend ... said 'you need to get back into the climbing'. She said 'I think it's more in your mind now that you can't climb rather than physically'. So she said '... sign up for a rock climbing course there where you're going to be safe and, you'll be led by someone else'. So that's what I did ... And that got me over my psychological hang-up of feeling I might fall ... So, I worked at that and, got over that, so that was fine. ... It took about a year for it to completely get over.

[After my second accident I was] quite debilitated for a long time. And I was fearful of falling after that. [laughs] I was fearful of, I wouldn't climb a ladder even I was so afraid, because it was a really big fall. It was only a miracle that we weren't killed.... So it took quite a lot of rehabilitation from that lot, as you can imagine. It took a long while to come right from that. Yeah. There was a lot of pain. ... Kate and I went off climbing. She rehabilitated me, oh and a lot of the climbing club ... so the second time, got over the psychological fear of falling. Fear of heights, yeah. So I mastered that again. The second time, no problems. Continued climbing. 
8. Dave's story about realising that he is scared of dying (page 209):

I used to be quite naïve about how, I thought I really had a finger on it, it was about four years ago I s'pose and I thought naively that, ah, you know 'I've got this whole death thing sorted' you know, and 'I can deal with this' and whatever 'I'm not afraid of my own death', you know, quite happy dying, but then I spent ... four and a half days in a crevasse with a broken hip and, waiting to be rescued ... lying on my back thinking about things and I discovered that I was actually pretty gripped about dying [laughs]. I was quite scared about the whole thing and that was, that was quite a bummer because, I mean when you think you've got something sorted and then all of a sudden you get this, lesson or whatever, this spank once more 'oh, damn I have to go back to the study', you know [laughs]. 'I'll have to go and maybe work that out a bit more'. So ... there's definite gaps in my understanding ... I don't, dwell on it too much but whenever death is around me I'll talk about it ... I think that's a major drawback of modern society, or modern New Zealand society, is that we're shielded way too much from death. 


\section{Appendix $\mathrm{H}$}

\section{A brief history of a culture of safety in the New Zealand Alpine Club, 1950-1970}

During the 1950s there was much interest in the 'cause' of accidents and a strong feeling among influential members of the NZAC that, if these causes were known, then appropriate lessons would be learnt, and such accidents avoided in the future, thereby ultimately reducing the occurrence of accidents. Accident reports were being compiled at the time by the Federated Mountain Clubs (FMC), and in 1950 it was suggested that these reports be read at alpine club evenings so that they could be discussed and "the lessons to be learned appreciated" ("F.M.C. Matters," 1950). It was reported in the Bulletin that the answer to reducing mountain fatalities lay in a "policy of gradualism" - that is, judicious care and caution in selecting climbing goals the difficulties of which did not vastly surpass one's abilities ("President of F.M.C. sums up," 1952). Particular years in which there were fewer accidents than usual were attributed to the success of the FMC's "campaign for safety in the mountains", and instruction courses instigated by a number of mountain recreation clubs.

The prominence given to the call to reduce accident numbers within the club appears to have been at least partly a response to public pressure. A fatality in early 1953 led to public debate on the possibility of introducing some means of regulating and controlling climbers in the mountains, presumably to save them from themselves. This prompted the NZAC to go to some lengths to demonstrate that government regulation was unnecessary because: "No-one is more interested than the mountaineering and tramping clubs in fostering a higher standard of safety among all who go into the wild" ("Mountain dangers," 1953). A subsequent enquiry by the Minister of Internal Affairs into mountain fatalities around that time led to the inauguration of a 'safety in the mountains' campaign, sponsored by the government.

By late 1952, accident reports were being published in newspapers in the hope that "lessons are learnt from errors and deficiencies and in this way the system is gradually improved" ("Accidents," 1953:321). A criticism of this practice, as unnecessarily adding to the pain of bereaved families and alienating the clubs to which the accident victims belonged, appeared in the NZAC Bulletin in November 1953. A member of the FMC's accident sub-Committee responded, defending their actions as fulfilling their responsibility 
"to point out any lessons to be learnt", and arguing that it was not a case of laying blame ("The ethics of criticism," 1953). This exchange followed an accident on Mount Egmont on July 26,1953 , in which six people died, and the report found fault with the Taranaki Alpine Club. In this incident, in the opinion of one NZAC member, "the rules of safe climbing have been flagrantly broken" ("Blame for accidents," 1954). In 1954 the NZAC president instructed members in their journal that:

it behoved every club member to do his utmost to climb safely and avoid risks. ... No person was a good climber who suffered accidents ... the taking of calculated risks ... could not be made competently unless ... the climber had acquired the necessary judgment to estimate the risks involved.

("Annual meeting," 1954)

In 1955, after an "unfortunate crop" of accidents and following the FMC's lead, the NZAC decided on a policy to investigate fatal and non-fatal accidents involving members. It was felt that "no effort must be spared to learn lessons from these", thus the purpose would be to establish 'cause' and "not to apportion blame” ("Accidents," 1955b). Increases in fatal accidents were repeatedly blamed on "a tendency for some parties to climb beyond their abilities" ("Accidents," 1955a). It was argued that people may be fit and technically competent but "in matters of judgment, of awareness of danger, of leadership, and of respect for the forces of nature about them they may be found lacking” ("The gradual approach," 1955). Take, for example, an accident report on an Aoraki/Mount Cook fatality in 1955 in which it was concluded that: "This accident is the direct result of a grossly exaggerated opinion of the party's own mountaineering capabilities". The two Australians involved were berated for not heeding the advice offered them by "experienced mountaineers" and were considered insufficiently experienced to read the signs of approaching bad weather, which indirectly led to the death of one of them ("Mount Cook fatality, February 1955," 1956).

Despite some questioning of the need to publish accident reports apportioning blame, it was not until the early 1960s that a stronger resistance to the 'safe-climbing ideology' appeared in the NZAC publications, including this satirical consideration of its nature and influences:

A whole new sport has grown up over the past few years - safe-climbing; this is climbing according to a set of laws formulated and agreed upon by sets of people in various mountaineering and tramping clubs, and not deviated from without the prospect of death.

And these laws are not stated explicitly, but are discernible within each of the multitude of rules about techniques and procedures and equipment that are forced upon every newcomer to the mountains. They are: 
Everything is possibly-fatally-dangerous;

Not all things are equally possibly-fatally-dangerous;

The least possibly-fatally-dangerous is the best.

... This ideology is born of ignoble fears, fears of Death and twisted personal fears; and it is all mixed up with the cult of Efficiency and twentieth-century theories of Successful Living, and moral imperatives, and with countless other nameless creeds with which the modern mind is constantly being injected - all of which are fallacies most of the time and are specially so when acted against a mountain background. ... there is a fallacy involved in the doctrine of 'the safest way is the best way', which is the touchstone and the cornerstone of that vast edifice of percept and rule that the safe-climber constructs and worships. For, reductio ad absurdum, hutwallowing is fully justifiable and, in fact, the most honourable occupation for a safe-climber.

("Safe-climbing ideology," 1961:6-8)

The anonymous writer of the article concluded by saying that "In truth, safety does not enter into the picture with any special prominence, much less is it the end-all of our activity". Nonetheless, the NZAC publications continued to be dominated by an "official line' which considered accidents to be avoidable and "safe climbing" to be ultimately achievable as long as all the rules were followed. In the 1962 Bulletin, an 'analysis' of climbing fatalities since 1945 concluded that $92 \%$ of fatalities were avoidable (how this was determined is unclear), that an increase in participants post-WWII had led to an increase in the accident rate, and that "approximately as many accidents occurred with experienced as inexperienced people" (though this does not appear to have been seen as a challenge to the firmly held belief that accidents happened to the inexperienced and foolhardy). The 'analysis' sought to determine "any particular cause" in the hope that tackling this may reduce the number of accidents. In terms of assigning causes, it was found that falls on rock bluffs or snow grass constituted the largest category, followed by "ice or frozen snow" as the cause (presumably also resulting in a fall), closely followed by "unroped and/or separated" which was considered a cause, and for the victims of which were reserved the most scathing comments. They "deserved little if any sympathy. They have broken a fundamental rule of safe climbing” (Hasell, 1962:11-13).

The 1963/64 climbing season saw a "large number" of accidents, and while it was reported to have been the "worst season of weather for 30 or 40 years", most accidents were attributed to "failure of complete novices to appreciate the dangerous conditions" ("The climbing season," 1964:390). It was conceded, however, that "one accident at least involved competent climbers and appears to have been in the nature of bad luck combined with unusual conditions" ("The climbing season," 1964:390). Again there seems to have 
been a degree of concern about how the spate of accidents was perceived in public and bureaucratic spheres, and that the "tide of public concern should be dealt with by the climbing fraternity before we find we have our freedom in pursuing our sporting interests severely limited by public pressure on the powers of government”. It was emphasised that improved access to the mountains had been made possible by better roading, light aeroplanes and jet boats, and hence "High altitude huts can now be utilised by the inexperienced or poorly qualified and inadequately-equipped". To deal with such threats the best course of action as the Club saw it was to "take definite steps to improve the standards of climbing ... [and] impress on the public the efforts we are making towards safe mountaineering ... [otherwise] there is the distinct possibility that our access to the mountains might be restricted" ("A time to ponder," 1964:217-218).

In 1965 another mountain safety campaign was inaugurated, and the national Mountain Safety Council was established. Once again in the NZAJ, the fatalities of the 1964/65 season were blamed on "sheer ignorance or lack of understanding”, and a "lack of responsibility displayed" ("Annual meeting," 1965:181). With accidents and rescues receiving coverage in the media in 1966, along with calls for greater restrictions and controls of climbers, the NZAC President again recommended a "vigorous campaign to encourage safe climbing ... [we] cannot afford to let public opinion grow in this respect" ("Annual meeting," 1966:359-360).

In 1967, a stronger rejection of the 'safe climbing ideology' appeared through letters and articles written in the Bulletin, including the following from a younger climber, Aat Vervoorn:

The idea of 'cause' in relation to accidents is a gross oversimplification ... how can we ever know with even reasonable certainty which factors were involved? ... blame cannot be placed anywhere in mountaineering accidents: nobody can produce a list of the conditions which need to be fulfilled if accidents are to be avoided and nobody can say that even if all the conditions were fulfilled accidents would be eliminated ... [there is a] misapprehension that it is impossible for experienced climbers using sound techniques to have accidents ... there are $\underline{\text { no }}$ 'given situations' in climbing. Mountaineers it seems, are human; which means they are not infallible, just as their technique is not foolproof.... Whether we like it or not, climbing is a dangerous sport in which we take our life in our hands.... it is impossible to judge when we can rightly accuse somebody of wilful ignorance - the factors involved are too numerous and varied, and we can only ever know a fraction of them. Yet people persist in their accusations, achieving little more than a nasty atmosphere of self-righteous indignation. ... Nietzsche's aphorism, that 'He who survives is right', has been applied to climbing before. I would like to stress that the opposite, 'He who has died was wrong', does not follow. 
A letter in response to Vervoorn's article from the Chairman of the FMC Accident Committee repeated a familiar line: that it was "not the purpose or intention of the reports to apportion blame but they are written to draw, where possible, conclusions from mistakes which may have contributed to accidents" (Gallas, 1968:42). In the same issue of the Bulletin an article appeared, written by an older climber, Jack Ede, who berated solo and unroped climbing which was becoming a more common practice among the younger generation of climbers. In the next edition of the Bulletin the Club was accused of being out of touch with younger climbers (as discussed in Chapter 4). Vervoorn responded to Ede's criticism, making the following points:

Mountaineering is rife with illusions and unrealities ... I'll give a few realistic pointers on mountain safety:

Acknowledge the reality of what is involved in mountaineering i.e. Danger and the possibility of death. ... Death is for real - it is not something that only happens to others.

Having this healthy fear within us, we now become determined that it will not happen to us.

So we learn to rely on nothing, except our own climbing ability ... it is a matter of individual ability and the willingness to accept responsibility for oneself. ... in most cases it is safer to climb solo.

His final point was that: "The only rule in mountaineering is one that in this 'advanced' age is scoffed at: Don't fall” (Vervoorn, 1969:27). Another prominent young climber, Bruce Jenkinson, responded to Ede and the “alarmist propaganda on 'Safe Climbing'," and an anonymous satirical piece also appeared. Ede wrote back, accusing his detractors of being “Angry Young Men”, but by 1970 accident reports were no longer being printed by the NZAC.

The 1970s saw a great number of "new and unusual routes” being climbed ("Climbing," 1971), with new equipment, techniques and inspiration from overseas. ${ }^{100}$ Phil explains: it was a big jump from the group before in terms of what we took on and ah, but... it wasn't just us, there were other people who were making some big advances and I mean it's a worldwide thing ... [those] big leaps forward. But yeah I think before that ... mountaineering ... wasn't sort of going anywhere very much. And some of it was the new equipment, you know, better ropes and bolts and things like that. [But also] a change in attitude. Because I think what happened in our situation was we were, we tried to do things that were probably beyond what we should have been doing, in terms of safety and technical abilities and things, but we just kept on going, got away with it. And that's obviously how you make progress, by pushing things.

\footnotetext{
${ }^{100}$ There are some who disagree about the extent and significance of the advances in the 1970s (Aat Vervoorn: personal communication, 30 November 2005), however such a debate is beyond the scope of the current discussion. What is relevant here is that it is widely held that a kind of 'breakthrough' occurred at this time.
} 
As Bruce Jenkinson wrote in the NZAC Bulletin at the beginning of the decade, "people are seeking out more dangerous climbs and deliberately paring down their margins of safety" (Jenkinson, 1970:21). Inevitably, this led to high annual accident rates during the 1970s, for example in 1974 when there were nine deaths (including Bruce Jenkinson) and seventeen rescue operations in Aoraki/Mount Cook alone. But it was not just the technical difficulties being undertaken that led to deaths, as variable conditions also played a role. Iin 1975, two large avalanches claimed seven lives, including the exceptionally unlucky Paul Gazley who had miraculously survived a previous avalanche after being buried for twelve hours. Throughout this period there was the occasional mention in the NZAC publications of people taking "unjustifiable risks" ("Competitiveness in climbing," 1972:2), and of "inexperienced climbers ... pushing routes that they are unready for" (Strang, 1980:63). However, what Bruce Jenkinson (1970) had described as the "bogged down in safety complex", which had been predominant in the publications throughout the previous two decades, seems to have faded away during the 1970s, despite the number of deaths. 